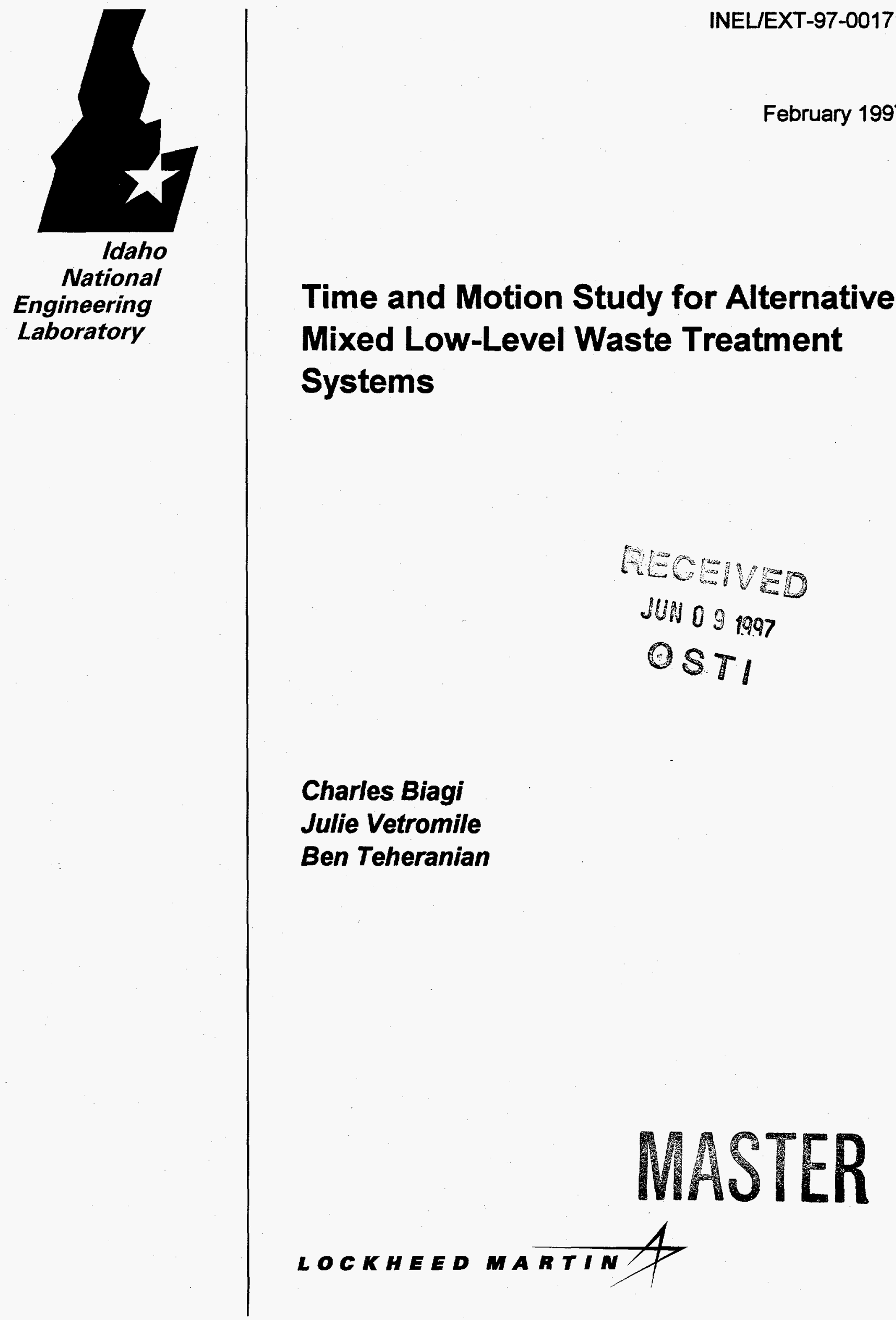




\title{
Time and Motion Study for Alternative Mixed Low-Level Waste Treatment Systems
}

\author{
Charles Biagi \\ Julie Vetromile \\ Ben Teheranian
}

Published February 1997

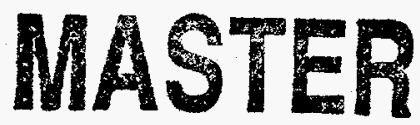

Idaho National Engineering Laboratory

Lockheed Martin Idaho Technologies Company

Idaho Falls, Idaho 83415

DISTRIBUTION OF THIS DOCUMENT IS UNLIMITED

Prepared for the

U.S. Department of Energy

Assistant Secretary for Environment, Safety, and Health

Under DOE Idaho Operations Office

Contract DE-AC07-94ID13223 


\section{DISCLAIMER}

This report was prepared as an account of work sponsored by an agency of the United States Government. Neither the United States Government nor any agency thereof, nor any of their employees, make any warranty, express or implied, or assumes any legal liability or responsibility for the accuracy, completeness, or usefulness of any information, apparatus, product, or process disclosed, or represents that its use would not infringe privately owned rights. Reference herein to any specific commercial product, process, or service by trade name, trademark, manufacturer, or otherwise does not necessarily constitute or imply its endorsement, recommendation, or favoring by the United States Government or any agency thereof. The views and opinions of authors expressed herein do not necessarily state or reflect those of the United States Government or any agency thereof. 


\section{DISCLAIMER}

Portions of this document may be illegible in electronic image products. Images are produced from the best available original document. 


\section{ACRONYMS AND ABBREVIATIONS}

$\begin{array}{ll}\text { APC } & \text { air pollution control } \\ \text { CaSO }_{4} & \text { calcium sulfate } \\ \text { CWO } & \text { catalytic wet oxidation } \\ \text { DOE } & \text { U.S. Department of Energy } \\ \text { FTE } & \text { full-time equivalent } \\ \text { GAC } & \text { granular activated carbon } \\ \text { GPCR } & \text { gas phase corona reactor } \\ \text { HEPA } & \text { high efficiency particulate air filter } \\ \text { gpm } & \text { gallons per minute } \\ \text { INEL } & \text { Idaho National Engineering Laboratory } \\ \text { INTS } & \text { integrated nonthermal treatment system } \\ \text { ITTS } & \text { integrated thermal treatment system } \\ \text { LMTCO } & \text { Lockheed Martin Idaho Technologies Company } \\ \text { MEO } & \text { mediated electrochemical oxidation } \\ \text { MLLW } & \text { mixed low-level (radioactive) waste } \\ \text { OSORT } & \text { open, dump and sort activities } \\ \text { psi } & \text { pounds per inch } \\ \text { PAN } & \text { passive/active neutron scanning } \\ \text { R\&D } & \text { research and development } \\ \text { RCPRP } & \text { receiving and preparation activities } \\ \text { RTR } & \text { real-time radiography } \\ \text { SCC } & \text { secondary combustion chamber } \\ \text { SCM } & \text { system cost model } \\ \text { SGS } & \text { segmented gamma scanning } \\ \text { TDS } & \text { total dissolved solids } \\ \text { TOC } & \text { total organic carbon } \\ \text { TRU } & \text { transuranic } \\ \text { UV } & \text { ultraviolet light } \\ \text { WBS } & \text { work breakdown structure } \\ \text { WRAP } & \text { Waste Receiving and Processing } \\ & \end{array}$




\section{CONTENTS}

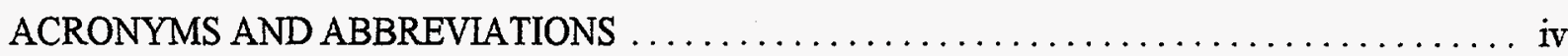

EXECUTIVE SUMMARY $\ldots \ldots \ldots \ldots \ldots \ldots \ldots \ldots \ldots \ldots \ldots \ldots \ldots \ldots \ldots \ldots$

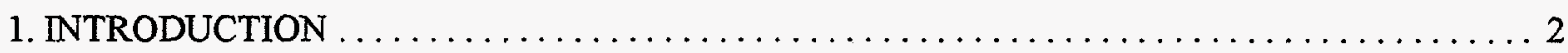

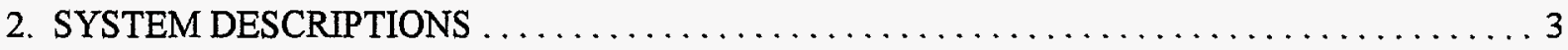

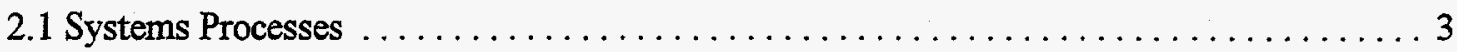

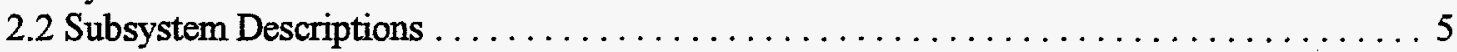

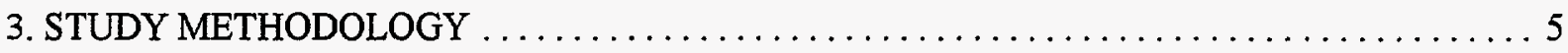

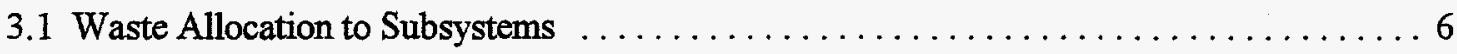

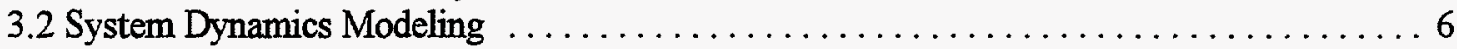

4. TASKS EVALUATED FOR EACH SUBSYSTEM $\ldots \ldots \ldots \ldots \ldots \ldots \ldots \ldots \ldots \ldots \ldots$

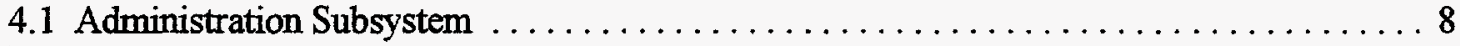

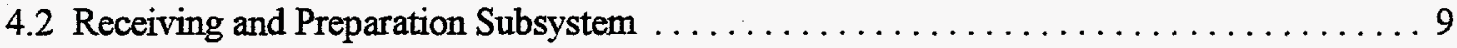

4.3 Aqueous Waste Treatment Subsystem $\ldots \ldots \ldots \ldots \ldots \ldots \ldots \ldots \ldots \ldots \ldots \ldots \ldots \ldots \ldots \ldots \ldots$

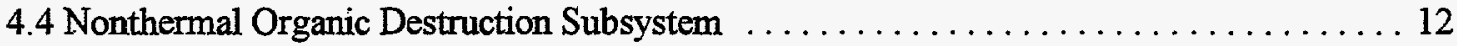

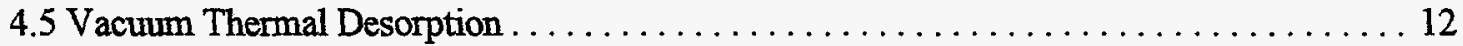

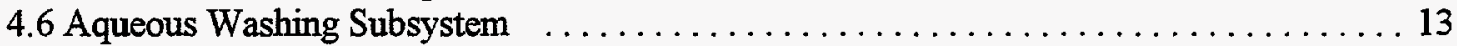

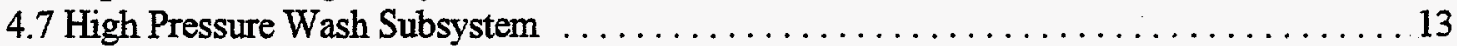

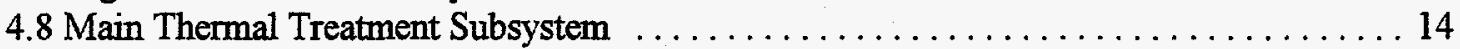

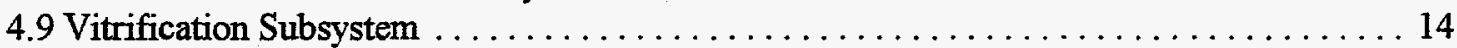

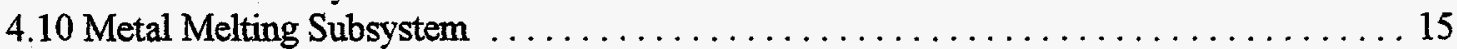

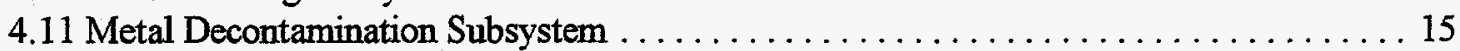

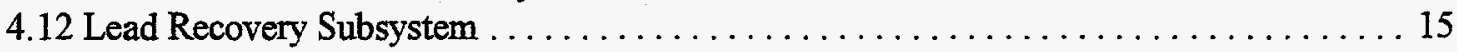

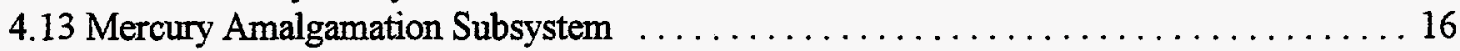

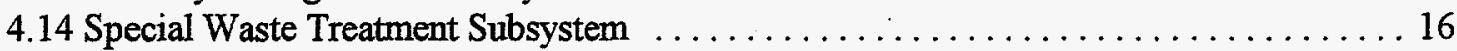

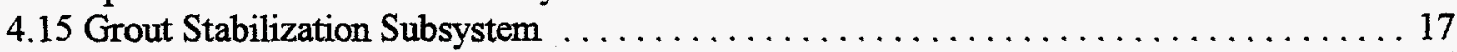

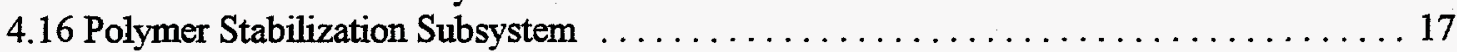

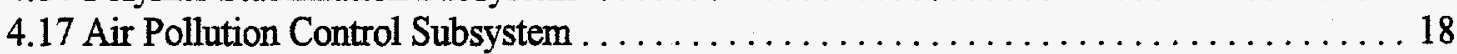

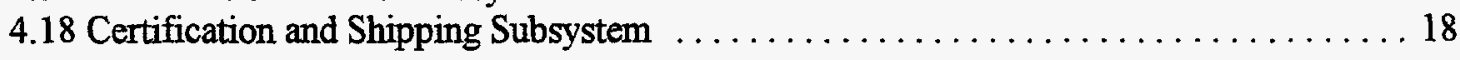

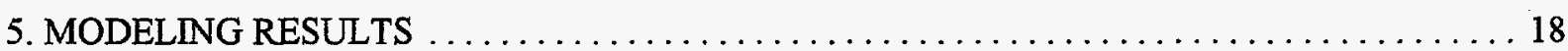

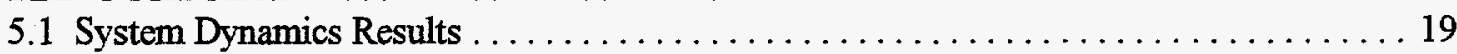

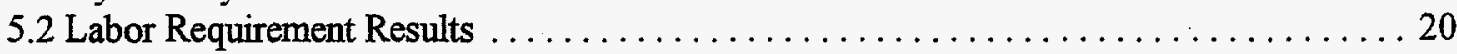

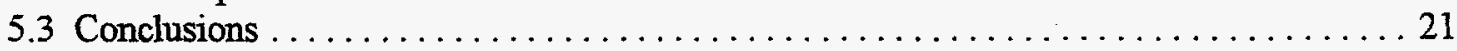

6. RECOMMENDATIONS FOR FUTURE WORK $\ldots \ldots \ldots \ldots \ldots \ldots \ldots \ldots \ldots \ldots \ldots \ldots \ldots \ldots$

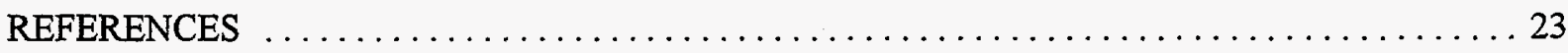




\section{CONTENTS (Continued)}

\section{APPENDICES}

Appendix A Time and Motion Study Calculations

Appendix B SureTrak Modeling Assumptions

TABLES

1. Time and Motion Study FTE Estimate and Comparison with ITTS and INTS FTE Estimates

\section{FIGURES}

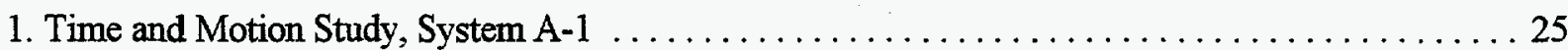

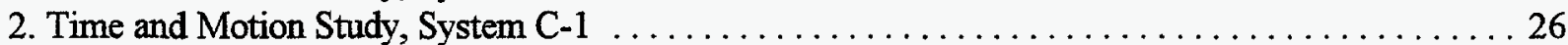

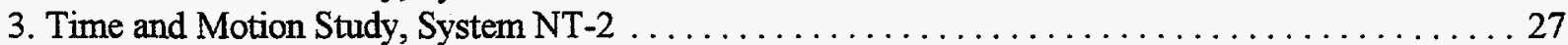

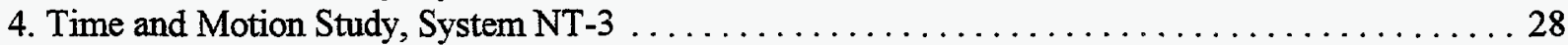

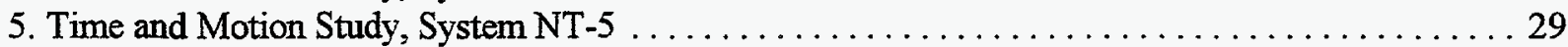




\section{EXECUTIVE SUMMARY}

The time and motion study was developed to look at time-related aspects of the technologies and systems studied in the Integrated Thermal Treatment Systems (ITTS) and Integrated Nonthermal Treatment Systems (INTS) studies. The INTS and ITTS studies combined technologies into systems and subsystems for evaluation. The system approach provides DOE a method of measuring advantages and disadvantages of the many technologies currently being researched.For example, technologies which are more likely to create secondary waste or require extensive pretreatment handling may be less desirable than technologies which require less support from other processes.

The time and motion study was designed to address the time element in the INTS and ITTS systems studies. Previous studies have focused on material balance, cost, technical effectiveness, regulatory issues, community acceptance, and operability. This study looks at system dynamics by estimating the treatment time required for a unit of waste, from receipt to certification for shipping. Labor estimates are also developed, based on the time required to do each task for each process. This focus on time highlights critical path processes and potential bottlenecks in the INTS and ITTS systems.

Gant charts were selected to model fumctions in this study. Although Gant charts do show a critical path, this type of analysis is not sufficiently accurate to pinpoint the exact bottlenecks in a continuously operating facility. Other commercially available scheduling software might be used to provide a more accurate work schedule and a critical path analysis model.

The purpose of this time and motion study is to provide data for research prioritization and allocation of research resources. The study is based on a review of the technologies involved, discussions with vendors, and the authors' industrial chemical processing and material handling experience.

The time focus also allows quantification of task requirements, such as sorting and characterization. One of the more interesting results of this study is that radioactive characterization labor requirements are greater than those for shredding or sorting. 
The key results of the study are the following:

- Characterization is a critical path process and very labor intensive

- The differences in receiving and preparation between thermal and nonthermal systems are less dramatic than estimated in the INTS and ITTS studies

- Material handling is more significant than processing in terms of labor and time

- One-step thermal treatment processes require significantly less labor than incineration combined with vitrification of ash

- Special waste treatment is on the critical path for thermal systems

- Treatment of special wastes will require significant allocation of resources

- Storage requirements for special waste will be extensive if processes are not available for treatment

- Debris treatment is on the critical path for nonthermal systems

- Labor FTEs may be about $20 \%$ higher than estimated in the INTS and ITTS reports

\section{INTRODUCTION}

The purpose of this time and motion study is to provide data for further research prioritization. The time and motion study was performed on five systems developed in the Integrated Thermal and Nonthermal Treatment System studies. Systems were selected to study the impacts of various treatment technologies on the flow of materials through an integrated mixed low level waste treatment facility. The time and motion study estimated the labor to operate each system, and the time required for treatment of a drum of waste for each system. The time to process a unit of waste highlights critical path issues and potential bottlenecks in each system. Research efforts to reduce such bottlenecks may provide significant dividends to the DOE in the form of reduced labor and cost. Time-efficient operation should reduce chemical and radioactivity exposure to workers. Also, systems and technologies with fewer bottlenecks are more attractive for development demonstrations and future implementation. 


\section{SYSTEM DESCRIPTIONS}

Three systems from the Integrated Nonthermal Treatment Study (INTS) and two systems from the Integrated Thermal Treatment Study (ITTS) were studied. These systems were chosen as representative of the INTS and ITTS systems. The five systems are included in the report Comparison oj Alternative Treatment Systems jor DOE Mixed Low-Level Waste (Schwinkendorf, 1996).

\subsection{Systems Processes}

This section provides only a brief introduction to these systems. They are already thoroughly described in the INTS (Biagi, 1997) and ITTS reports (Feizollahi, 1995). This brief description references the key processes.

\section{THERMAL SYSTEMS}

\section{System A-1}

This system includes the following major subsystems:

- rotary kiln with air for combustion for organic destruction

- vitrification of ash

- polymer stabilization of secondary wastes

- decontamination of surface contaminated metals

- melting of metals with entrained contamination

- retorting of mercury contaminated waste, with amalgamation of mercury

\section{System C-1}

Major subsystems include:

- plasma furnace with air for combustion for organic destruction

- polymer stabilization of secondary wastes

- decontamination of surface contaminated metals

- melting of metals with entrained contamination

- retorting of mercury contaminated waste, with amalgamation of mercury 


\section{NONTHERMAL SYSTEMS:}

\section{System NT-2}

This system includes the following major subsystems:

- catalytic wet oxidation for organic destruction

- thermal desorption of soil, process residue and debris

- decontamination of surface contaminated metals

- primary stabilization of treated sludge and secondary waste in polymer

- primary stabilization of treated soil and treated debris in grout

- amalgamation of mercury waste

\section{System NT-3}

Major subsystems include:

- mediated electrochemical oxidation for organic destruction

- washing of soil, process residue and debris

- decontamination of surface contaminated metals

- primary stabilization of treated sludge and secondary waste in polymer

- primary stabilization of treated soil and treated debris in grout

- amalgamation of mercury waste

\section{System NT-5}

This system includes the following major subsystems:

- catalytic wet oxidation for organic destruction of liquids and soft (combustible) debris

- thermal desorption of process residue

- washing of soil and debris

- decontamination of surface contaminated metals

- primary stabilization of treated sludge and secondary wastes in polymer

- primary stabilization of treated soil and treated debris in grout

- amalgamation of mercury waste 


\subsection{Subsystem Descriptions}

Each system consists of several subsystems. Most of the subsystems are identical or only slightly modified for the different systems. The subsystems which are consistent for all systems in this time and motion study are the following:

- administration

- receiving and preparation

- aqueous waste treatment

- metal decontamination

- special waste treatment

- air pollution control

- polymer stabilization

- certification and shipping

The following subsystems are used in the ITTS and INTS systems as indicated:

- vitrification (ITTS: A-1)

- metal melting (ITTS: A-1)

- mercury amalgamation, with retorting of debris (ITTS: A-1, C-1)

- mercury amalgamation (INTS: NT-2, NT-3, NT-5)

- lead recovery (ITTS: A-1, C-1)

- lead decontamination and stabilization (INTS: NT-2, NT-3, NT-5)

- incineration (ITTS: A-1)

- plasma furnace thermal treatment (ITTS: C-1)

- mediated electrochemical oxidation (INTS: NT-1, NT-3)

- catalytic wet oxidation (INTS: NT-2, NT-5)

- vacuum thermal desorption (INTS: NT-2, NT-5)

- grout stabilization (INTS: NT-2, NT-3, NT-5)

- aqueous wash (INTS: NT-3, NT-5)

- high pressure wash (INTS: NT-3, NT-5)

These subsystems are described in detail in the ITTS and INTS reports (Feizollahi, 1995; Biagi, 1997).

\section{STUDY METHODOLOGY}

The overall approach of the time and motion study was to follow the waste received in a single shift of operation, through handling and treatment steps. This approach did not attempt to optimize the subsystems, but only to present the subsystems as currently developed. A series of interlinked spreadsheets was developed to estimate the processing time for each handling and treatment step. A 
series of Gant charts presents the time required for the waste to pass from receiving through primary and secondary treatment, stabilization and finally certification and shipping. The Gant charts are provided as Figures 1 through 5 to illustrate the time elapsed for treatment of waste in each subsystem and to identify critical path functions.

The labor requirements were estimated for each step, and the total labor for each subsystem was calculated. The labor estimate is provided in Table 1. This table provides the results of the time and motion study, and compares it with the full time equivalents (FTEs) presented in the ITTS and INTS studies. These results of the time and motion study were not incorporated in the ITTS and INTS reports.

The tables from the interlinked spreadsheets are provided in Appendix $\mathrm{A}$. The tables are numbered by system (e.g., Table NT5-a through NT5-r). The first table for each subsystem (Table A1-a, Table C1-a, Table NT2-a, Table NT3-a and Table NT5-a) shows waste allocation (mass flow rate). The last table in each section of Appendix A provides a summary of the full time equivalent employees (FTEs) and the time required for processing.

\subsection{Waste Allocation to Subsystems}

Waste was allocated to the various treatment systems based on the INTS mass balance (Biagi, 1997) and the ITTS mass balance of April 23, 1996 (Brown, 1996). Secondary as well as primary flows are accounted for by using the INTS and ITTS mass balances developed by Blaine Brown of LMITCO (Brown, 1996). Because of secondary flows, more waste is treated than is received.

Waste densities are assumed for all waste entering a given subsystem. Where available, densities from the mass balance were used. Density data developed for the Systems Cost Model were used for waste streams without assigned densities (Shropshire, 1995). For each waste type, a drum density was developed (pounds /55 gallon drum). This allowed the expression of incoming waste in terms of drums of waste per shift. The drum densities are listed on Tables A1-a, C1-a, NT2-a, NT3-a and NT5-a.

\subsection{System Dynamics Modeling}

The time and motion study estimated the time required for various processing steps at the design throughputs of the equipment specified in the INTS and ITTS studies. Where multiple steps or steps with low throughput were necessary, the processing time required increased. For example, special waste processing through receiving and preparation includes time required for truck receiving and unloading, waste assay, container staging, container opening, dumping and sorting, size reduction, sampling, and container decontamination for each unit of waste. For convenience, a drum of waste 
was selected as the unit of waste used for estimating processing time. The development of system dynamics provided insights into critical path processes and potential bottlenecks in the facility.

The time and motion study was performed by breaking down each subsystem into multiple discrete tasks. The time to perform each task was evaluated. Treatment time was estimated based on the design capacity of the equipment and estimated throughput. The total of all tasks performed in a subsystem defines the treatment time for a drum of waste. The number of drums which require treatment during a shift, multiplied by the treatment time per drum, provides a total treatment time.

For batch processes utilizing more than one drum, or for continuous processes, the total treatment time must be calculated for all the drums of waste processed in an 8 hour shift. The lag time between drums was estimated, multiplied by the number of drums, and added to the time for a single drum to traverse the subsystem. Sampling and equipment monitoring times were also estimated. The total time to process the waste sent to each subsystem was then calculated. This information was used in preparation of the Gant charts (Figures 1 through 5).

The processing time was used to determine the number of FTEs. For some processes, the FTEs were based on monitoring time, rather than flow through a process. Monitoring time was estimated by considering the number of times a piece of equipment would be monitored (typically every 20 minutes or 24 times/shift) and the amount of time required for each monitoring task (usually 2-5 minutes). Monitoring tasks are assumed to include periods of perfunctory monitoring as well as analysis during mechanical or process problems. This approach accounts for parallel operations, because it assumes an operator can monitor multiple equipment items. The assessment of total monitoring time for all operations in a subsystem provides an estimate of the number of FTEs required for monitoring. Start-up time is included for batch processes.

The FTEs are based on the total personnel required per day to run a subsystem. Supervisory personnel are included at a ratio of one supervisor to ten workers. Also, an FTE absentee value of 6 weeks per year was assigned to account for employee vacations, holiday, sick leave, jury duty, etc. Finally, an efficiency of 70 percent was assigned to all FTEs. This 70 percent factor includes time off for lunch, breaks and meetings as well as process downtime occurring during their shift.

Tables A1-b through A1-o, C1-b through C1-1, NT2-b through NT2-n, NT3-b through NT3-o, and NT5-b through NT5-q present the time and motion analysis for the subsystems associated with each system. In most subsystems, all the waste entering requires the same treatment, but in some cases waste is divided by subtypes for distinct treatment trains. For example, the receiving and preparation subsystem discussed in Section 4.2 allocates waste by waste type to certain separation processes. Another example is the aqueous waste treatment subsystem, where aqueous waste is divided into high and low total dissolved solids and organics. 
Sampling frequency is generally estimated at one sample per ten drums. In-process sampling is assumed for most processes, although the type of analysis is not specified.

Table 1 and Tables A1-p, C1-m, NT2-o, NT3-p and NT5-r provide a summary of the results of the analysis. The total FTEs shown in the time and motion analysis are about $20 \%$ higher than the FTEs estimated in the ITTS and INTS study reports. The reasons for this difference are discussed in Section 5.2.

The Gant charts (Figures 1 through 5), developed with SureTrak software, are based on the summary tables A1-p, C1-m, NT2-o, NT3-p and NT5-r. The assumptions used in the modeling are presented in Appendix B.

\section{TASKS EVALUATED FOR EACH SUBSYSTEM}

This section discusses the tasks evaluated and the results for each subsystem. Results are discussed for the five systems in this study. Some subsystems, such as administration, will be the same for all systems. Others, such as incineration, are only appropriate for a single system. Subsystems such as certification and shipping have the same tasks for all systems, but the FTEs will be different depending on the volume of waste shipped.

\subsection{Administration Subsystem}

The administration subsystem analysis estimates the FTEs required to operate the facility. Tables A1-b, C1-b, NT2-b, NT3-b and NT5-b show the estimated FTEs for the Administration subsystem. The facility staff was estimated, assuming an operation similar to an industrial facility with a total of 300 FTEs. Additional supervisory staff is included for each subsystem. Laboratory staff is estimated based on:

- The estimated number of samples received per shift (totaled from other subsystems)

- Four FTEs are needed to fill all shifts in a 5 day week for a given shift assignment; this accounts for vacation, sick and holiday relief

- Analysis time for in-process samples (10 minutes)

- Analysis for characterization (30 minutes)

- Analysis for raw materials (20 minutes) 
The non-laboratory staff is estimated to be the same for all thermal and nonthermal systems. A staff of 35 is estimated for the following functions:

- Facility management

- Operations Management

- Personnel/ Security

- Environmental

- Shipping/Receiving

- Purchasing

- Accounting

- Health Physics

The laboratory technician staff required is based on the expected sampling required for waste characterization, in-process testing, raw materials testing, and final waste form analysis. The laboratory staff ranges from 12 for System C-1 to 23 for System NT-3.

The total administration subsystem FTEs for each of the systems are presented below and in Table 1:

- 48 for System A-1

- 47 for System C-1

- 52 for System NT-2

- 57 for System NT-3

- 58 for System NT-5

\subsection{Receiving and Preparation Subsystem}

The operations in the receiving and preparation subsystem was divided into specific detailed tasks. In addition to the ITTS and INTS reports, the design document for Hanford Site's WRAP 2A (Shaw, 1995) was used as a basis for developing these tasks. Tables A1-c, C1-c, NT2-c, NT3-c and NT5-c present the Receiving and Preparation Subsystem time and motion study. Eighteen tasks are identified, but not all tasks are required for all waste types. Several assumptions are made regarding how much waste will be treated by various unit operations, such as sorting, shredding, size reduction, glove box sorting, etc. These assumptions are presented in Tables A1-c, C1-c, NT2-c, NT3-c and NT5-c. 
The tasks are listed below:

- Receiving trucks containing waste

- Receiving trucks with empty containers

- Receiving trucks containing supplies

- Transfer of waste from truck to interim storage or staging areas

- Assay waste by real time radiography, gamma spectroscopy, passive/active neutron (PAN) assay

- Transfer and staging of waste for sorting

- Opening drums

- Dumping drums

- Sorting waste robotically at tables

- Glove box sorting

- Assessing debris for compliance with debris rule

- Gross size reduction (cutting)

- Shredding

- Characterization sampling

- Transferring waste to bins

- Transfer of waste between subsystem

- Box breakdown

- Container decontamination.

For each system, the mix of tasks varies. All waste must be received, staged, and assayed. For thermal systems, 50 percent of the waste is assumed to require sorting; for nonthermal systems 75 percent of the waste is assumed to require sorting. In this study, the type of waste determines the number of tasks required. For example, special waste is sorted within glove boxes. Lead waste is sent to gross size reduction, but not shredding. Many planning level assumptions were made to establish how much of each waste type would require processing through the various steps. Tables in Appendix $\mathrm{A}$ list the assumptions used.

The number of employees required was estimated as follows (Table 1):

- 170 for System A-1

- 168 for System C-1

- 198 for System NT-2

- 195 for System NT-3

- 192 for System NT-5

As expected, the additional sorting requirements translate into a greater number of FTEs for the nonthermal systems. However, the difference is less marked than expected. 
Much of the FTE requirements are due to the initial assaying requirements. Vendor estimates show that more that two hours is typically needed to perform the three analyses (PAN, SGS and RTR) which translates to a requirement of over 60 FTEs to assay the waste (Mettler, 1996). With over nine drums of waste assayed per hour, nine of each type of instrument would be needed to avoid a bottleneck. Thus, significant savings in capital and labor could be made if assaying time was reliably reduced. Further savings would be experienced if the instrumentation did not require the constant attention of an operator.

\subsection{Aqueous Waste Treatment Subsystem}

This subsystem is very similar for thermal and nonthermal systems. Both require sampling and monitoring and both use UV oxidation for organic destruction. In the nonthermal systems, all aqueous waste is sent to UV oxidation, whereas in thermal systems scrubber liquor does not require further treatment for organics. Thermal systems process more aqueous waste (primarily scrubber liquor), but through fewer operations. Tables A1-e, C1-e, NT2-f, NT3-e and NT5-g present the time and motion analysis for the aqueous waste treatment subsystem. The tasks in this subsystem are divided as follows:

- Waste receiving

- Preliminary treatment (sampling, filtration, oil/water separation, precipitation)

- UV oxidation.

The number of employees required for each system was estimated to be (Table 1):

- 6 for System A-1

- 5 for System C-1

- 14 for System NT-2

- 5 for System NT-3

- 23 for System NT-5

The differences in nonthermal systems relate to the mass of waste transferred to this subsystem. System NT -5 has the highest labor requirement because of aqueous waste generated from soft debris treatment. Also, much of the wash water in System NT-3 is treated and recycled within the washing process and is not sent to the aqueous waste treatment subsystem. 


\subsection{Nonthermal Organic Destruction Subsystem}

Two types of nonthermal organic destruction were analyzed: Mediated Electrochemical Oxidation (MEO) and Catalytic Wet Oxidation (CWO). For both subsystems, the following tasks are appropriate:

- Receiving waste through an air lock; transferring liquids into a tank, and sampling

- Feeding waste to the reactor

- Operating the reactor

For MEO, several additional tasks are specified:

- Silver recovery

- Acid recovery

- Offgas treatment.

For CWO, additional tasks include:

- Waste transfer/recycle of acids

- Treatment of inorganics.

Tables NT2-d, NT3-d and NT5-d present the time and motion analysis for the organic destruction subsystem. For MEO, 26 FTEs are needed; for CWO 11 FTEs are estimated. MEO requires more FTEs because of the complex recycling processes. For the treatment of soft debris by CWO, 21 FTEs are needed (Table NT-5e).

\subsection{Vacuum Thermal Desorption}

The tasks involved in this subsystem are as follows:

- Waste receiving

- Transfer of the waste into the batch vacuum thermal desorber

- Vacuum thermal desorber operation

- Monitoring offgas

- Unloading of desorbed waste and transfer of waste to mercury treatment or stabilization

- Mercury contaminated solids leaching

- Leachate /filtrate treatment. 
To estimate FTEs, it was assumed that 30 percent of the desorbed solids would require leaching to remove the mercury contamination. Tables NT2-e and NT5-f present the time and motion analysis for the vacuum thermal desorption subsystem. System NT-2 was estimated to require 23 FTEs due to the large volume of waste treated in this subsystem. System NT-5, in which only sludges and process residue is desorbed, required 10 FTEs.

\subsection{Aqueous Washing Subsystem}

This subsystem was used to treat process residue and sludge in System NT-3, and soil in both NT-3 and NT-5. Tables NT3-f and NT5-h present the time and motion analysis for the aqueous washing subsystem. The steps required are:

- Waste receiving

- Wash water preparation

- Washing process

- Pre-rinse and rinse

- Recycle processes (solubility reduction, ultrafiltration, dissolved air flotation, surfactant separation, steam stripping).

Employee requirements were estimated at 7 FTEs for System NT-3 and 4 FTEs for System NT-5. Many operations require monitoring, but the simple nature of the equipment and operations requires less overall attention than more sophisticated and complex processes such as vacuum thermal desorption combined with mercury leaching. The monitoring requirements were more labor intensive than estimated in the INTS report, as shown on Table 5-1.

\subsection{High Pressure Wash Subsystem}

This subsystem uses a batch washing and rinsing process. The process was estimated to be 3000 $\mathrm{lbs} / \mathrm{batch}$, and 90 minutes for each of three stages of washing/rinsing. The tasks identified were:

- Debris waste receiving

- Waste transfer to wash/rinse vessel

- Wash water solution preparation

- Washing/rinsing process

Tables NT3-g and NT5-i present the time and motion analysis for the high pressure wash subsystem. System NT-3 processes much more waste by pressure washing than System NT-5. System NT-5 is estimated to require 5 FTEs, and NT-3 needs 37 FTEs. 


\subsection{Main Thermal Treatment Subsystem}

Five tasks define the incineration subsystem:

- Waste receiving

- Shredding

- Characterization sampling

- Incineration (feed, incinerate, discharge)

- Monitoring instrumentation

In addition to the first three tasks listed for incineration, the plasma subsystem tasks are:

- Plasma treatment operation (feeding, reactor operation, discharge)

- Plasma treatment monitoring instrumentation

- Cooling

- Final waste container decontamination

Table A1- $d$ presents the time and motion analysis for the incineration subsystem and Table $\mathrm{Cl}-\mathrm{d}$ presents the plasma treatment subsystem. Employee requirements were estimated at 20 FTEs for incineration and 23 FTEs for plasma treatment. These values are similar to those in the ITTS report. Notably, for the plasma system (C-1), the estimates are less than those reported in ITTS (Table 5-1).

\subsection{Vitrification Subsystem}

This subsystem provides capability to vitrify ash following thermal treatment. The tasks required are:

- Ash receiving through airlock

- Waste transfer to feed bin

- Vitrification

- Monitoring vitrification instrumentation and equipment

- Cooling

- Monitoring the APC

- Decontamination of the final waste container

This subsystem requires 14 FTEs. Only System A-1 requires this subsystem (Table A1-g). The additional labor needs showcase the advantage of the one-step thermal processes which do not require vitrification. 


\subsection{Metal Melting Subsystem}

System A-1 uses metal melting to process metal with entrained contamination (Table Al-f). The identified tasks are:

- Metal receiving (from receiving and preparation)

- Metal melting

- Metal cooling

- Instrumentation and monitoring of the APC.

This subsystem labor requirement is estimated at 6 FTEs.

\subsection{Metal Decontamination Subsystem}

This relatively simple subsystem requires two tasks:

- Metals receiving/feed preparation

- Waste decontamination

Tables A1-h, C1-f, NT2-g, NT3-h and NT5-j present the time and motion analysis for the metal decontamination subsystem. The number of FTEs for each system is similar for all systems because the volumes are similar. Sixteen FTEs are estimated for both nonthermal and thermal systems. This estimate is significantly higher than the ITTS and INTS estimates (Table 5-1). Assay and decontamination time estimates increased the labor needed.

\subsection{Lead Recovery Subsystem}

Lead recovery for nonthermal systems includes the following tasks:

- Lead receiving and feed preparation

- Decontamination

For thermal treatment, lead melting and metal cooling tasks are added. Because waste is treated by either decontamination or metal melting, both thermal and nonthermal systems have the same number of FTEs. The time and motion study analysis is based on volume of waste (Tables A1-i. C1-g, NT2-h, NT3-i and NT5-k). Lead has a high density and, therefore, the studied volume of waste is low. Only 2 FTEs are needed to treat this waste by decontamination or melting. 


\subsection{Mercury Amalgamation Subsystem}

Like lead, the mercury waste has a high density and a low volume of waste requiring treatment. This subsystem has the following tasks for both thermal and nonthermal systems (Tables A1-j. C1-h, NT2-i, NT3-j and NT5-1):

- Waste receiving and feed preparation

- Mercury amalgamation.

Thermal systems also treat mercury contaminated debris, using the following tasks:

- Shredding debris

- Retorting debris for mercury removal.

The mercury recovered is amalgamated as in the nonthermal systems. The thermal systems require 2 FTEs, while the nonthermal systems, which process much less waste, need less than 1 FTE.

\subsection{Special Waste Treatment Subsystem}

The ITTS and INTS concept for special waste treatment was that certain wastes could not be treated in the other subsystems in the facility. Therefore, a space was allotted for treatment processes that were either mobile or under development to treat the variety of waste that could not be treated by other subsystems. To estimate FTEs, it was assumed that the waste required preparation, such as size reduction, for an average of one hour per drum of waste. The waste would be treated in an unspecified batch process for two hours, sampled, and repackaged. As shown in Tables A1-k. Cl-i, NT2-j, NT3-k and NT5-m, the tasks defined are defined as follows:

- Waste receiving and feed preparation

- Waste treatment.

Because the amount of special waste is significant ( 5 percent of the total), 11 FTEs are needed. The labor estimates for this subsystem were significantly different from the ITTS and INTS estimates.

This analysis shows that the treatment of special waste will require significant allocation of resources. Storage of waste to be treated by mobile or temporary processes in campaigns will require extensive space because special waste volume is estimated at 5 drums per shift. Therefore, treatment processes must be available before the waste can be received at the facility. This finding shows the importance of developing treatment processes to treat the less common waste streams. 


\subsection{Grout Stabilization Subsystem}

This subsystem provides encapsulation of waste in grout. As shown in Tables NT2-k, NT3-l and NT5-n, the tasks are:

- Waste receiving and preparation

- Waste micro- or macroencapsulation

- Curing

- Decontamination of containers

Curing is estimated only in terms of the time required to move the waste in and out of a curing area, and to monitor the curing process. The actual time required for curing is not estimated. The analysis indicates that storage requirements for curing will be needed for 60 to 80 drums per shift for each shift of curing required.

The labor requirements for this subsystem are highly dependent on the waste volume which varies by system. The number of employees required was estimated as follows (Table 1):

- 21 for System NT-2

- 16 for System NT-3

- 11 for System NT-5

\subsection{Polymer Stabilization Subsystem}

Polymer stabilization has the same basic tasks as grout, although the specific processing steps are different. As in the grout subsystem, the actual time required for curing is not estimated. As shown in Tables A1-m, C1-j, NT2-1, NT3-m and NT5-o, the tasks are:

- Waste receiving and preparation, including drying waste

- Waste microencapsulation

- Curing

- Decontamination of containers 
Labor needs reflect volume throughput. The number of employees required was estimated as follows:

- 13 for System A-1

- 13 for System C-1

- 36 for System NT-2

- 41 for System NT-3

- 36 for System NT-5

\subsection{Air Pollution Control Subsystem}

Equipment monitoring is the only task identified for the air pollution control subsystem. The details are shown on Tables A1-n, C1-k, NT2-m, NT3-n and NT5-p. This subsystem is much less volume dependent than other subsystems because of the absence of waste handling. Labor is based on time required to monitor equipment. The nonthermal systems require 4 FTEs. The more complex APC subsystems for thermal systems require 10 FTEs.

\subsection{Certification and Shipping Subsystem}

As shown in Tables A1-o, C1-1, NT2-n, NT3-o and NT5-q, the certification and shipping subsystems include the following tasks:

- Waste receiving from processing subsystems

- Waste assay

- Staging of certified waste

- Shipping (loading trucks)

The differences in labor requirements are due to the volume of waste shipped. The number of employees required was estimated as follows (Table 1):

- 24 for System A-1

- 24 for System C-1

- 101 for System NT-2

- 110 for System NT-3

- 89 for System NT-5

\section{MODELING RESULTS}

The simple Gant charts developed for this study provide early indication of time consumed by major functions of the facilities, and identify activities which fall on the critical path. Figures 1 
though 5 present Gant charts for the systems analyzed. Table 1 summarizes the labor resource needs for all major activities for each system. For comparison, the ITTS and INTS FTEs are also listed.

Key results of this modeling are:

- Characterization is a critical path process and very labor intensive

- The differences in receiving and preparation between thermal and nonthermal systems are less dramatic than estimated in the INTS and ITTS studies

- Material handling is more significant than processing in terms of labor and time

- One-step thermal treatment processes require significantly less labor than incineration combined with vitrification of ash

- Special waste treatment is on the critical path for thermal systems

- Treatment of special wastes will require significant allocation of resources

- Storage requirements for special waste will be extensive if processes are not available for treatment

- Debris treatment is on the critical path for nonthermal systems

- Labor FTEs may be about 20 percent higher than estimated in the INTS and ITTS reports

\subsection{System Dynamics Results}

The time and motion study estimates the time required for various processing steps at the throughputs provided for the equipment specified. This development of system dynamics provides insights into potential bottlenecks in the facility. The results are summarized below.

- The assay function stands out as the most limiting process in the facility. Following a discussion with the assay equipment vendor, the time assigned for assay by passive/active neutron and gamma scanning was determined to be one hour per container for each scanning process.

- Other time consuming processes include material handling, shredding, and sampling. The receiving and preparation subsystem, the polymer stabilization subsystem and the certification and shipping subsystem require the longest processing time.

- Soft debris, process residue and special waste treatment require the most preparation and processing time.

- Polymer stabilization requires more treatment time than grout stabilization. Curing time is not included in the analysis, although time for moving waste into and out of the curing area is included. 


\subsection{Labor Requirement Results}

For most subsystems, the time and motion study indicates more full time equivalent employees will be needed than were estimated in the INTS and ITTS studies. Factors that are responsible for the differences include the following:

- The time and motion study included supervisory personnel, time lost due to vacation and sick leave, and a worker efficiency of 70 percent.

- Previous analysis focused on processing requirements. In this area, the ITTS and INTS numbers were closest to the time and motion study.

- The assay function requires nearly three hours per drum with constant supervision by an operator. This function requires 63 FTEs per shift for all systems. Time for individually supervised assays was not included in earlier analyses.

- Material handling was not the focus of the INTS and ITTS studies. In a typical chemical plant, feed to a process and equipment designed to handle that specific material will be consistent. For a radioactive waste processing facility, movement of a variety of waste streams contributes to considerable time per drum. This analysis assumes each INTS drum and most ITTS drums must be opened and emptied. For several processes, the rate limiting step is getting the waste from drums to the process.

- Previous analyses characterized sorting as time consuming. The time and motion study quantifies sorting requirements. For example, glove box sorting requires five employees per shift to sort slightly less than one drum per hour. 


\subsection{Conclusions}

The following conclusions can be derived from the time and motion study analysis:

- Front-end and back-end handling are the areas requiring the most FTEs and processing time. These functions are most closely related to the volume of waste handled.

- After front and back-end handling and administration, stabilization processes for nonthermal systems, especially polymer, require the most time and FTEs.

- Metal decontamination and special waste treatment are labor-intensive and time consuming.

- Treatment of major waste streams, such as incinerable waste in ITTS systems and process residue in INTS systems, require significant labor and processing time. Although the processing time per unit is small, the volume of waste treated increases labor and processing time.

- Higher capacity equipment can lead to more efficient processing and reduced labor time. However, this efficiency would not be significant unless material handling and material transfer time can be reduced.

- Feed operations and transfer of material between cells require extensive effort; improvements in material transfer would have significant pay-back.

- Labor FTEs may be about 20 percent higher than estimated in the INTS and ITTS reports

\section{RECOMMENDATIONS FOR FUTURE WORK}

Real-time assay and characterization needs, sorting needs, size reduction needs, and material handling issues are among the major sources of design and cost uncertainties in the ITTS and INTS studies. These uncertainties indicate a need for increased R\&D in this area. 
The following areas are recommended for research:

- Gamma and PAN Assay:

Develop methods with reduced assay time and reduced direct observation by an operator.

- Material handling bins:

Develop bins or hoppers which are easily transported, filled from drums and emptied into feed systems. These bins should be dust and liquid tight.

- Sorting and segregation:

Evaluate sorting and segregation material handling devices on the market for applicability to DOE mixed waste.

- Shredding:

Support development of efficient, reliable shredders which need little operator support yet meet process requirements.

- Special waste:

Develop treatment methods for special waste. Determine the effect of potential treatment processes on the size of the facility (including storage requirements) prior to facility design.

- Material handling of drums:

Evaluate improved methods of drum transfer, drum opening, removal of drum contents, drum cleaning and drum sealing.

- Material transfer:

Develop airlock system which allows for quick transfer of material, possibly by a closed conveyor.

- Drum decontamination:

Develop methods that require little labor. Develop quick assay method.

- Polymer stabilization:

Develop and optimize process to minimize labor. Automate material transfer to reduce handling. 


\section{REFERENCES}

Biagi, Charles, William J. Quapp, Tom Bechtold, Daryoush Bahar, Blaine Brown, William Schwinkendorf, Ginger Swartz, Ben Teheranian, and Julia Vetromile, Integrated Nonthermal Treatment System Study, Final Draft, (INEL-96-0273) prepared for Idaho National Engineering Laboratory, Idaho Falls, ID, January, 1997.

Brown, Blaine, Process Modeling for the Integrated Nonthermal Treatment System Study, unpublished draft, prepared for Idaho National Engineering Laboratory, Idaho Falls, ID, January 1997.

Brown, Blaine, Aspen Mass Balance for the ITTS study, unpublished draft, prepared for Idaho National Engineering Laboratory, Idaho Falls, ID, April 23, 1996.

Feizollahi, Fred and William J. Quapp, Integrated Thermal Treatment System Study - Phase 2 Results, EGG-MS-11211, prepared for Idaho National Engineering Laboratory, Idaho Falls, ID, August, 1995.

Mettler, Steven, Canberra Corporation, personal communication to Julia Vetromile of Morrison Knudsen Corporation, May 6, 1996, San Francisco, CA.

Shaw, Richard, Wrap 2A Process Control and Data Acquisition Design Basis, Waste Receiving and Processing Facility, by Raytheon Engineers for the U.S. Department of Energy, Richland, WA, January 1995

Schwinkendorf, William E. Comparison of Alternative Treatment Systems for DOE Mixed Lowleve/ Waste. (INEL-96-0247) prepared for Idaho National Engineering Laboratory, Idaho Falls, ID, 1996

Shropshire, David System Cost Model, Version 1.3, (INEL-95/0273, Rev 1 prepared for Idaho National Engineering Laboratory, Idaho Falls, ID, February 1996.

SureTrak Software, Project Manager for Windows, Primavera Systems, 1994

U. S. Department of Energy, Interim Mixed Waste Inventory Report, (DOE/NBM-1100), March 1993 


\begin{tabular}{|c|c|c|c|c|c|c|c|c|c|c|c|c|c|c|c|c|}
\hline Subsystems & $\begin{array}{l}\text { System } \\
\text { A-1 } \\
\text { Time/ } \\
\text { motion } \\
\text { FTEs }\end{array}$ & $\begin{array}{l}\text { System } \\
\text { A-1 } \\
\\
\text { INTS } \\
\text { FTES } \\
\end{array}$ & $\begin{array}{c}\text { System A-1 } \\
\% \text { diff. }\end{array}$ & $\begin{array}{c}\text { System } \\
\text { C-1 } \\
\text { Time/ } \\
\text { motion } \\
\text { FTEs } \\
\end{array}$ & $\begin{array}{c}\text { System } \\
\text { C-1 } \\
\\
\text { INTS } \\
\text { FTEs } \\
\end{array}$ & $\begin{array}{c}\text { System } \\
\text { C-1 } \\
\text { \% diff. } \\
\end{array}$ & $\begin{array}{l}\text { System } \\
\text { NT-2 } \\
\text { Time/ } \\
\text { motion } \\
\text { FTEs } \\
\end{array}$ & $\begin{array}{l}\text { System } \\
\text { NT-2 } \\
\\
\text { INTS } \\
\text { FTEs } \\
\end{array}$ & $\begin{array}{c}\text { System } \\
\text { NT-2 }\end{array}$ & $\begin{array}{l}\text { System } \\
\text { NT-3 } \\
\text { Timel } \\
\text { motlon } \\
\text { FTEs } \\
\end{array}$ & $\begin{array}{l}\text { System } \\
\text { NT-3 } \\
\\
\text { INTS } \\
\text { FTEs } \\
\end{array}$ & $\begin{array}{c}\text { System } \\
\text { NT-3 } \\
\text { \% diff. } \\
\end{array}$ & $\begin{array}{l}\text { System } \\
\text { NT-5 } \\
\text { Time/ } \\
\text { motion } \\
\text { FTEs } \\
\end{array}$ & $\begin{array}{l}\text { System } \\
\text { NT-5 } \\
\\
\text { INTS } \\
\text { FTES } \\
\end{array}$ & $\begin{array}{l}\text { System } \\
\text { NT-5 } \\
\text { \% diff. }\end{array}$ & \begin{tabular}{|c} 
Average \% \\
change \\
between \\
Time/ Motion \\
and INTSI \\
ITTS \\
\end{tabular} \\
\hline Administraton Subsystem & 48 & 27 & $44.2 \%$ & 47 & 27 & $42.1 \%$ & 52 & 32 & $38.6 \%$ & 57 & 32 & $44.2 \%$ & 58 & 32 & $44.7 \%$ & $42.8 \%$ \\
\hline Receiving and Preparation Subsystem & 170 & 112 & $34.2 \%$ & 168 & 112 & $33.1 \%$ & 198 & 170 & $14.0 \%$ & 195 & 170 & $13.0 \%$ & 192 & 170 & $11.4 \%$ & $21.2 \%$ \\
\hline Aqueous Waste Treatment Subsystem & 6 & 16 & $-172.5 \%$ & 5 & 16 & $-202.1 \%$ & 14 & 5 & $65.3 \%$ & 5 & 5 & $3.5 \%$ & 23 & 5 & $78.6 \%$ & $-45.4 \%$ \\
\hline Organic Destruction Subsystem & & & ! & 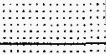 & & & 11 & 12 & $-12.5 \%$ & 26 & 12 & $53.0 \%$ & 11 & 12 & $-13.4 \%$ & $9.0 \%$ \\
\hline Vacuum Thermal Desorption Subsystem & & & & 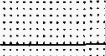 & & & 23 & 16 & $30.5 \%$ & & a & & 10 & 8 & $22.5 \%$ & $26.5 \%$ \\
\hline Aqueous Wash Subsystem & & & & 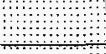 & & & 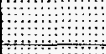 & $\cdots$ & & 7 & 3 & $53.9 \%$ & 4 & 2 & $53.7 \%$ & $53.8 \%$ \\
\hline Soft Debris-CWO Subsystem & & 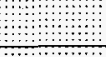 & 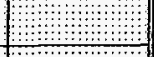 & 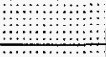 & & 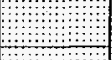 & 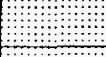 & I & & 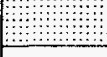 & s & ma & 21 & 14 & $31.9 \%$ & $31.9 \%$ \\
\hline $\begin{array}{l}\text { Open Debris-High Pressure Wash } \\
\text { Subsystem }\end{array}$ & & m & sons & & is & ! & (1) & & & 37 & 16 & $56.6 \%$ & 5 & 8 & $-67.5 \%$ & $-5.4 \%$ \\
\hline Main Thermal Treatment Subsystem & 20 & 16 & $19.4 \%$ & 23 & 32 & $-37.3 \%$ & 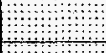 & $\because$ & & 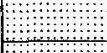 & : & & & & & $-9.0 \%$ \\
\hline Vitrificalion Subsystem & 14 & 16 & $-16.9 \%$ & 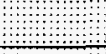 & 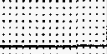 & \& & se & 8 & : & $\lcm{\square ! s}$ & 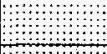 & me & 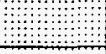 & : & Os: & $-16.9 \%$ \\
\hline Metal Melting Subsystem & 6 & 5 & $14.1 \%$ & & & & 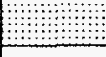 & : & 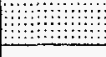 & : & 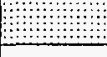 & mon & : & ! & mon & $14.1 \%$ \\
\hline Metal Decontamination Subsystem & 16 & 5 & $69.7 \%$ & 16 & 5 & $69.7 \%$ & 16 & 4 & $75.5 \%$ & 16 & 4 & $75.5 \%$ & 16 & 4 & $75.5 \%$ & $73.2 \%$ \\
\hline Lead Treatment Subsystem & 2 & 8 & $-273.4 \%$ & 2 & 8 & $-273.4 \%$ & 2 & 3 & $-25.4 \%$ & 2 & 3 & $-51.1 \%$ & 2 & 3 & $-51.1 \%$ & $-134.9 \%$ \\
\hline Mercury Amalgamation Subsystem & 2 & 4 & $-134.3 \%$ & 2 & 4 & $-134.3 \%$ & 0.31 & 1 & $-221.9 \%$ & 0.09 & 1 & $-1072.6 \%$ & 0.09 & 1 & $-986.2 \%$ & $-509.9 \%$ \\
\hline Special Waste Treatment Subsystem & 11 & 2 & $81.3 \%$ & 11 & 2 & $81.3 \%$ & 11 & 3 & $72.3 \%$ & 11 & 3 & $72.3 \%$ & 11 & 3 & $72.3 \%$ & $75.9 \%$ \\
\hline Grout Stabilization Subsystem & & & & 21 & & & 21 & 8 & $61.3 \%$ & 16 & 8 & $50.4 \%$ & 11 & 8 & $27.4 \%$ & $46.4 \%$ \\
\hline Polymer Subsystem & 13 & 8 & $39.5 \%$ & 13 & 8 & $39.5 \%$ & 36 & 38 & $-4.0 \%$ & 41 & 40 & $4.6 \%$ & 36 & 38 & $-2.8 \%$ & $15.4 \%$ \\
\hline Air Pollution Control Subsystem & 10 & 4 & $59.6 \%$ & 10 & 4 & $59.6 \%$ & 4 & 4 & $1.8 \%$ & 4 & 4 & $1.8 \%$ & 4 & 4 & $1.8 \%$ & $24.9 \%$ \\
\hline Certification and Shipping Subsystem & 24 & 32 & $-33.6 \%$ & 24 & 32 & $-33.6 \%$ & 101 & 105 & $-4.3 \%$ & 100 & 110 & $-9.6 \%$ & 89 & 88 & $1.0 \%$ & $-16.0 \%$ \\
\hline แ্র & BOE & & ! & : & & 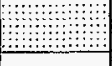 & 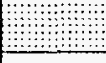 & mo & m! & $+\ldots$ & 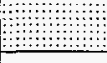 & @ & !n & 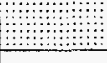 & & \\
\hline Total & 342 & 255 & $25.4 \%$ & 321 & 250 & $22.1 \%$ & 489 & 401 & $18.2 \%$ & 518 & 411 & $20.8 \%$ & 494 & 400 & $19.0 \%$ & $20.7 \%$ \\
\hline
\end{tabular}

Note: Minor discrepancies can be noticed between the certification and shipping numbers shown here compared to those in the INTS report.

The numbers in the INTS report and ITTSNNTS comparison report reflect an earlier draft of the time and motion study, calculated with a slightly different mass balance. 
Time and Motion Study, System A-1

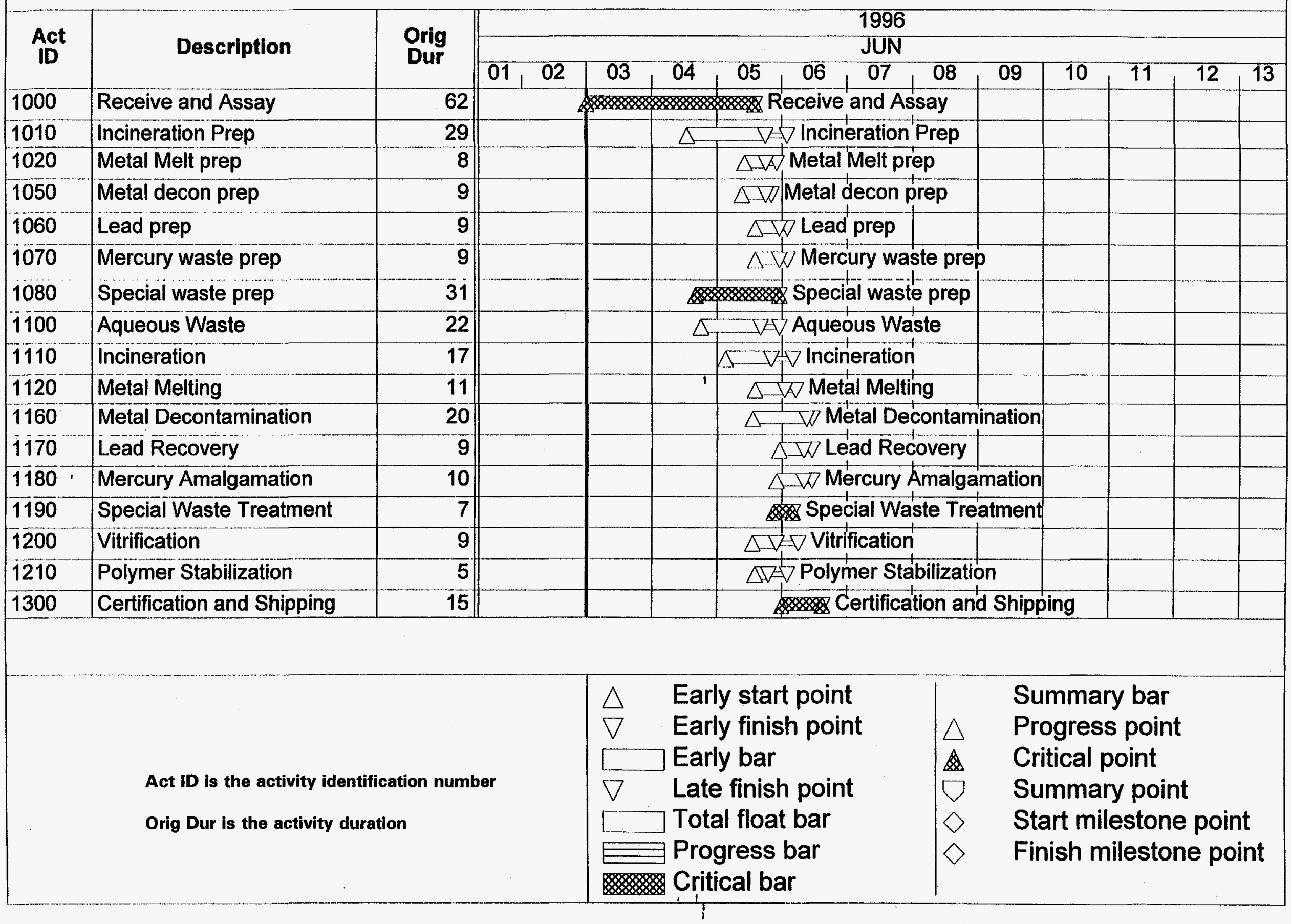




\section{Figure 2}

\section{Time and Motion Study, System C-1}

\begin{tabular}{|c|c|c|c|c|c|c|c|c|c|c|c|}
\hline \multirow{3}{*}{$\begin{array}{c}\text { Act } \\
\text { ID }\end{array}$} & \multirow{3}{*}{ Description } & \multirow{3}{*}{$\begin{array}{l}\text { Orig } \\
\text { Dur }\end{array}$} & \multicolumn{9}{|c|}{1996} \\
\hline & & & & & & JUN & & & & & \\
\hline & & & 01,02 & 03 & 04 & $05,06,07,08$ & 09 & 10 & 11 & 12 & 13 \\
\hline 1000 & Receive and Assay & 62 & & 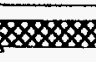 & 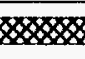 & Receive and Assay & & & & & \\
\hline 1010 & Plasma Prep & 30 & & & $\triangle$ & $\nabla \frac{1}{7} \nabla$ Plasma Prep & & & & & \\
\hline 1050 & Metal decon prep & 9 & & & & Metal decon prep & & & & & \\
\hline 1060 & Lead prep & 9 & & & & $\triangle \backslash$ Lead prep & & & & & \\
\hline 1070 & Mercury waste prep & 9 & & & & $\triangle \triangle$ Mercury waste pre & & & & & \\
\hline 1080 & Special waste prep & 31 & & & & Special waste prep & & & & & \\
\hline 1100 & Aqueous Waste & 12 & & & & $\triangle \triangle A$ Aqueous Waste & & & & & \\
\hline 1110 & Plasma Treatment & 19 & & & & $\Delta \nabla \nabla$ Plasma Treatmer & & & & & \\
\hline 1160 & Metal Decontamination & 20 & & & & Metal Decontan & nation & & & & \\
\hline 1170 & Lead Recovery & 9 & & & & $\triangle \nabla$ Lead Recovery & & & & & \\
\hline 1180 & Mercury Amalgamation & 10 & & & & A Mercury Amalg & mation & & & & \\
\hline 1190 & Special Waste Treatment & 7 & & & & Special Waste Trea & ment & & & & \\
\hline 1210 & Polymer Stabilization & 5 & & & & $\triangle A$ Polymer Stabilizatio & & & & & \\
\hline 1300 & Certification and Shipping & 15 & & & & Certification ar & Shipp & ing & & & \\
\hline
\end{tabular}

$\begin{array}{ll}\triangle \quad & \text { Early start point } \\ \nabla \quad \text { Early finish point } \\ \square \quad \text { Early bar } \\ \nabla \quad \text { Late finish point } \\ \square \quad \text { Total float bar } \\ \quad \text { Progress bar } \\ \quad \text { Critical bar }\end{array}$

Summary bar

$\triangle \quad$ Progress point

Critical point

Act ID is the activity identification number

Orig Dur is the activity duration.
Summary point

Start milestone point

Finish milestone point 


\section{Figure 3}

\section{Time and Motion Study, System NT-2}

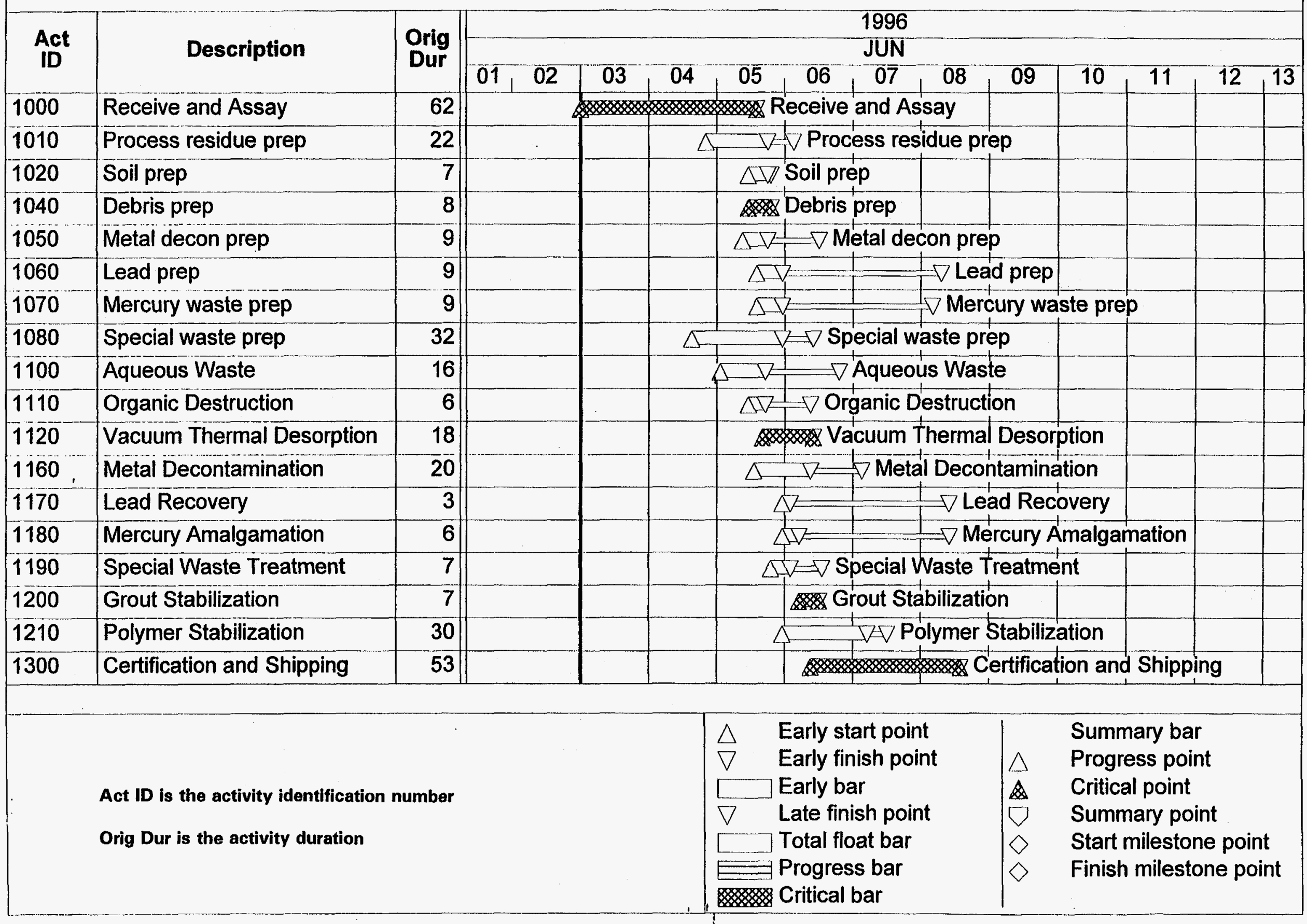




\section{Figure 4}

Time and Motion Study, System NT-3

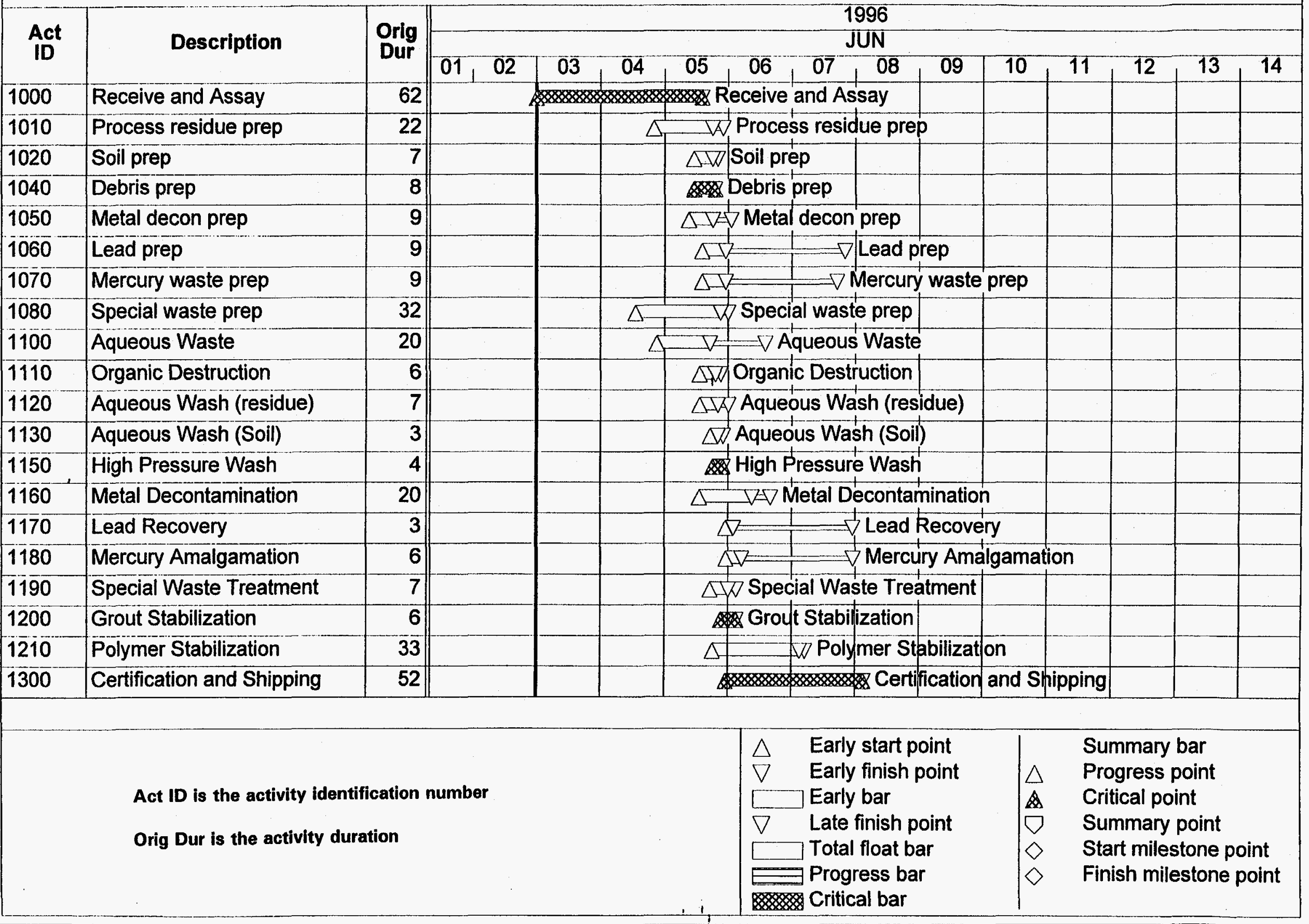




\section{Figure $5 \quad$ Time and Motion Study, System NT-5}

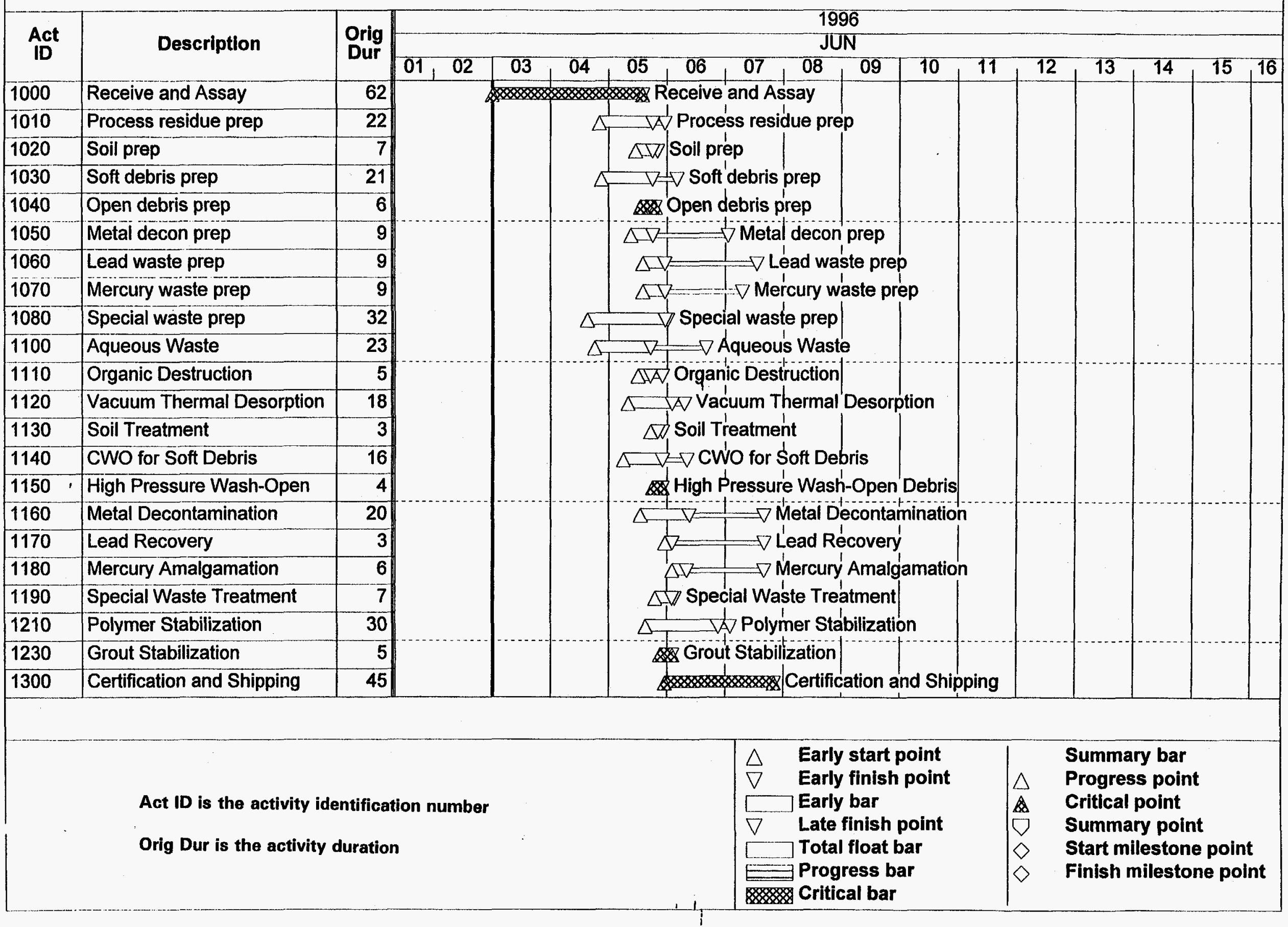




\section{APPENDIX A}

Time and Motion Study Calculations 


\section{Table of Contents}

Introduction

System A-1 Time and Motion Study Tables

System C-1 Time and Motion Study Tables

System NT-2 Time and Motion Study Tables

System NT-3 Time and Motion Study Tables

System NT-5 Time and Motion Study Tables 


\section{Introduction}

The tables in this appendix are produced from five interlinked spreadsheets.

The first table in each series (Table A1-a, C1-a, NT2-a, NT3-a and NT5-a) presents the waste feed to each subsystem, as developed in the ASPEN mass balance. For each subsystem the dominant waste types were selected, based on the MWIR waste descriptions (DOE, 1993). As shown in the third column, Waste Type, the MWIR code is shown. The fifth column shows the estimated density of the unprocessed waste in $\mathrm{kg} / \mathrm{cu} \mathrm{m}$, as developed in the Systems Cost Model (Shropshire, 1996). The density is converted to pounds per cubic foot and to pounds/drum in the sixth and seventh columns respectively. The fourth column is the result of the second column (mass flow, lb/hr) divided by the seventh column (drum density, lb/drum).

The remaining tables estimate full time equivalent employees (FTEs) and the time required for waste treatment. The columns of these tables are described below:

- Columns one and two: Tasks and subtasks are identified.

- Column three, administration subsystem: The administration subsystem table lists FTEs without calculation in this column, because they are an estimate based on a 300 person facility.

- Column three, other subsystems (as shown in Table Al-c and others): Shows the occurrence per shift, such as drums, trucks or pallets.

- Column four: The unit for occurrence per shift is expressed, usually drums.

- Column five: "Time required" is estimated for each subtask.

- Column six: "Total Time per Shift" is the product of column three and column five. Totals for each task are provided.

- Column seven: "FTEs needed" is the total time per shift divided by the minutes in a shift.

- Column eight: "Additional Time for Next Drum" shows the estimate of the lag time between drums.

- Column nine: "Average Minutes per Shift per Drum" only appears in the receiving and preparation subsystem, is the product of the required time (column five) times the frequency of occurrence. This accounts for waste types which require different tasks; e.g. special waste requires glovebox sorting but not shredding. Column nine shows the estimated average time 
a drum of waste requires for processing. If only $10 \%$ of the waste is treated in a given task, then this column reflects $10 \%$ of the time required, shown in column five.

The last table in each series (Table A1-p, C1-m, NT2-o, NT3-p and NT5-r) shows the summary of the FTEs and time required for waste processing. 


\section{System A-1 Time and Motion Study Tables}

A1-a System A-1: Time and Motion Analysis

A1-b Administration Subsystem

A1-c Receiving and Preparation Subsystem

Al-d Incineration Subsystem

A1-e Aqueous Waste Treatment Subsystem

Al-f Metal Melting

A1-g Vitrification of Ash

A1-h Metal Decontamination Subsystem

Al-i Lead Recovery

Al-j Mercury Amalgamation

A1-k Special Waste

A1-1 Grout Stabilization Subsystem

A1-m Polymer Stabilization Subsystem

Al-n Air Pollution Control Subsystem

Al-o Certification and Shipping

A1-p Summary of FTEs and time for a single drum to work through a system 


\begin{tabular}{|c|c|c|c|c|c|c|}
\hline Subsystem & $\begin{array}{c}\text { Mass Flow } \\
(\mathrm{lb} / \mathrm{hr})\end{array}$ & Waste Type & $\begin{array}{l}\text { No. of } \\
\text { Drums }\end{array}$ & $\begin{array}{c}\text { SCM } \\
\text { Unprocessed } \\
\text { Density } \\
\mathrm{kg} / \mathrm{m} 3\end{array}$ & $\begin{array}{c}\text { Density } \\
\mathrm{lb} / \mathrm{ft} 3\end{array}$ & $\begin{array}{l}\text { Density } \\
\mathrm{lb} / \text { drum }\end{array}$ \\
\hline Administration & 2,927 & & & & & \\
\hline Receiving and preparation & 2,927 & all & 6 & & 64 & 471 \\
\hline Aqueous waste treatment & 13,474 & $\mathrm{~L} 1100$ & 30 & & 62 & 456 \\
\hline Incineration & 2,000 & 55300,5110 & 4 & & 64 & 471 \\
\hline Vitrification & 1,495 & $\mathbf{S 3 1 1 0}$ & 3 & 650 & 64 & 471 \\
\hline Metal Melting & 149 & S5110 & 1 & 509 & 32 & 234 \\
\hline Metal decontamination & 468 & $\mathbf{S 5 1 1 0}$ & 2 & 509 & 32 & 234 \\
\hline Mercury amalgamation & 50 & $\times 7100$ & 0 & 2000 & 125 & 918 \\
\hline Lead recovery & 26 & $\times 7200$ & 0 & 2000 & 125 & 918 \\
\hline Polymer stabilization & 113 & S3120 & 0 & 700 & 44 & 321 \\
\hline Air pollution control & 21,420 & & N/A & & & \\
\hline Grout stabilization & 0 & soil/debris & 0 & 750 & 47 & 344 \\
\hline Special treatment & 153 & $\times 6000, \times 7500$ & 1 & 500 & 31 & 229 \\
\hline Certification and shipping & 1,958 & 2000 & 1 & 2500 & 179 & 1320 \\
\hline Vol reduction (out/in) & 1.49 & & 0.24 & & & \\
\hline
\end{tabular}

Notes:

This table provides the basis for the time and motion analysis.

Quantities of waste to a subsystem (lbs/hr) are based on LMITCO mass balance.

Densities are the same as the LMITCO mass balance except where values are shown in the SCM column.

Where values are shown in the SCM column, densities are taken from SCM and converted to $\mathrm{lb} / \mathrm{ft} 3 .$.

Waste types are based on MWIR

The waste quantities are converted from $\mathrm{lbs} / \mathrm{hr}$ to $\mathrm{drums} / \mathrm{hr}$.

Subsequent analysis is based on drums/shift of waste to a subsystem. 


\begin{tabular}{|c|c|c|c|c|c|}
\hline Task & Subtask & $\begin{array}{l}\text { FTEs } \\
\text { needed }\end{array}$ & $\begin{array}{l}\text { Samples/ } \\
\text { Shift }\end{array}$ & $\begin{array}{l}\text { Time } \\
\text { Required } \\
\text { (min) }\end{array}$ & $\begin{array}{c}\text { Total Time } \\
\text { Shift }\end{array}$ \\
\hline Facility Management & $\begin{array}{l}\text { Facility Manager } \\
\text { Secretary } \\
\text { Receptionist/word processor }\end{array}$ & $\begin{array}{l}1 \\
1 \\
1\end{array}$ & & & \\
\hline Operations Management & $\begin{array}{l}\text { Department managers } \\
\text { Communications } \\
\text { Engineering Manager } \\
\text { Engineering staff } \\
\text { Maintenance Supervisor }\end{array}$ & $\begin{array}{l}2 \\
1 \\
1 \\
2 \\
1\end{array}$ & & & \\
\hline Personnel & $\begin{array}{l}\text { Personnel Manager } \\
\text { Nurse/medical/industrial safety } \\
\text { Security guards at facility } \\
\text { Security at guard bldg }\end{array}$ & $\begin{array}{l}1 \\
1 \\
4 \\
4\end{array}$ & & & \\
\hline Environmental & $\begin{array}{l}\text { Environmental manager } \\
\text { Environmental clerk }\end{array}$ & $\begin{array}{l}1 \\
1\end{array}$ & & & \\
\hline Shipping/Receiving/Traffic & $\begin{array}{l}\text { Manager } \\
\text { Clerk }\end{array}$ & $\begin{array}{l}1 \\
1\end{array}$ & & & \\
\hline Purchasing & Buyer & 1 & & & \\
\hline Accounting & $\begin{array}{l}\text { Cost Accounting } \\
\text { Accounting Clerk } \\
\text { Payroll Clerks }\end{array}$ & $\begin{array}{l}2 \\
1 \\
2\end{array}$ & & & \\
\hline Laboratory & $\begin{array}{l}\text { Laboratory Manager } \\
\text { Lab Shift manager } \\
\text { Lab technicians for OSORT } \\
\text { Lab technicians for internal processes } \\
\text { Lab technicians for final waste form } \\
\text { Lab technicians for incoming supplies }\end{array}$ & $\begin{array}{c}1 \\
4 \\
1 \\
4 \\
3 \\
0.2\end{array}$ & $\begin{array}{c}4.1 \\
36.2 \\
8.4 \\
1.0\end{array}$ & $\begin{array}{l}30.0 \\
10.0 \\
30.0 \\
20.0\end{array}$ & $\begin{array}{l}123.2 \\
362.1 \\
250.9 \\
20.0\end{array}$ \\
\hline \multirow[t]{2}{*}{ Health Physics } & $\begin{array}{l}\text { Shift health physics staff } \\
\text { Health physics manager }\end{array}$ & $\begin{array}{l}4 \\
1 \\
\end{array}$ & & & \\
\hline & $\begin{array}{l}\text { Total except Lab } \\
\text { Total Lab } \\
\text { Total Admin }\end{array}$ & $\begin{array}{l}35 \\
13 \\
48 \\
\end{array}$ & & & \\
\hline
\end{tabular}


Table A1-c. Receiving and Preparation Subsystem

\begin{tabular}{|c|c|c|c|c|c|c|c|c|}
\hline Task & Subtask & $\begin{array}{c}\text { Occurrencel } \\
\text { Shift }\end{array}$ & Units & $\begin{array}{c}\text { Time } \\
\text { Required } \\
\text { (min) }\end{array}$ & $\mid \begin{array}{c}\text { Total Time/ } \\
\text { Shift }\end{array}$ & $\begin{array}{l}\text { FTEs } \\
\text { Needed }\end{array}$ & $\begin{array}{c}\text { Add'I/Time } \\
\text { for Next } \\
\text { Drum }\end{array}$ & $\begin{array}{c}\text { Ave } \\
\text { Minutes/Shift/ } \\
\text { Drum }\end{array}$ \\
\hline Receive Waste & & & & & & \multirow[b]{7}{*}{0.3} & \multirow{7}{*}{ Son } & \multirow[b]{7}{*}{153} \\
\hline \multirow[t]{5}{*}{$\begin{array}{l}\text { Truck } \\
\text { Trus }\end{array}$} & Truck docking & 0.6 & truck & 30 & 17 & & & \\
\hline & Settle Paperwork & 0.6 & truck & 120 & 68 & & & \\
\hline & Unload truck & 0.6 & truck & 60 & 34 & & & \\
\hline & Stage pallets & 0.6 & truck & 60 & 34 & & & \\
\hline & No of pallets/shift & & & & & & & \\
\hline Total Task 1 & & & & 270 & 153 & & & \\
\hline Receive Empty & Truck docking & 0.3 & truck & 30 & 8 & \multirow[b]{5}{*}{0.1} & \multirow[b]{5}{*}{0} & \multirow[b]{5}{*}{40} \\
\hline & Settle Paperwork & 0.3 & truck & 30 & 8 & & & \\
\hline & Unload truck & 0.3 & truck & 60 & 17 & & & \\
\hline & Stage pallets & 0.3 & truck & 20 & 6 & & & \\
\hline Total Task 2 & & & & 140 & 40 & & & \\
\hline \multirow[t]{4}{*}{ Receive Supplies } & Truck docking & 0.2 & truck & 30 & $\overline{\overline{6}}$ & \multirow[b]{5}{*}{0.1} & \multirow[b]{5}{*}{0} & \multirow[b]{5}{*}{28} \\
\hline & Settle Paperwork & 0.2 & truck & 30 & 6 & & & \\
\hline & Unload truck & 0.2 & truck & 60 & 12 & & & \\
\hline & Stage pallets & 0.2 & truck & 20 & 4 & & & \\
\hline Total Task 3 & & & & 140 & 28 & & & \\
\hline \multirow[t]{3}{*}{$\begin{array}{l}\text { Transfer to } \\
\text { Interim Storage }\end{array}$} & $\begin{array}{l}\text { Move pallets to } \\
\text { storage area }\end{array}$ & 6.2 & Pallet & 5 & 31 & & & \\
\hline & $\begin{array}{l}\text { Stack pallets/ } \\
\text { organize storage }\end{array}$ & 6.2 & Pallet & 10 & 62 & & & \\
\hline & Transfer to assay & 6.2 & Pallet & 5 & $\overline{31}$ & & & \\
\hline Total Task 4 & & & & 20 & 124 & 0.3 & 10 & 10 \\
\hline \multirow[t]{9}{*}{ Assay Drums } & Stage pallets & $\overline{12.4}$ & Pallet & 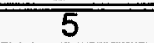 & $\overline{62}$ & \multirow[b]{9}{*}{14.8} & \multirow[b]{9}{*}{60} & \multirow[b]{9}{*}{150} \\
\hline & Load on conveyor & 49.8 & drum & 1 & 50 & & & \\
\hline & Assay RTR & 49.8 & drum & 15 & 746 & & & \\
\hline & Assay gamma & 49.8 & drum & 60 & 2986 & & & \\
\hline & Assay PAN & 49.8 & drum & 60 & 2986 & & & \\
\hline & $\begin{array}{l}\text { Remove from } \\
\text { convevor }\end{array}$ & 498 & drum & 3 & 149 & & & \\
\hline & Repalletize & 49.8 & drum & $\frac{3}{1}$ & 50 & & & \\
\hline & $\begin{array}{l}\text { Stage pallets after } \\
\text { assaying }\end{array}$ & 12.4 & Pallet & 5 & 62 & & & \\
\hline & & & & 150 & 7091 & & & \\
\hline \multirow[t]{3}{*}{$\begin{array}{l}\text { Stage and move } \\
\text { to OSORT }\end{array}$} & $\begin{array}{l}\text { Store solid waste } \\
\text { by category }\end{array}$ & 12.4 & Pallet & 10 & 124 & \multirow[b]{4}{*}{0.4} & \multirow[b]{4}{*}{5} & \multirow[b]{4}{*}{20} \\
\hline & $\begin{array}{l}\text { Move to } 50 \% \text { to } \\
\text { OSORT }\end{array}$ & 62 & Pallet & 5 & 31 & & & \\
\hline & Stage at OSORT & 6.2 & Pallet & 5 & $\frac{51}{31}$ & & & \\
\hline Total Task 6 & & & Pallet & 20 & 187 & & & \\
\hline \multirow{8}{*}{ Open Drums } & Stage at drum & & & & & \multirow[b]{8}{*}{08} & \multirow[b]{8}{*}{5} & \\
\hline & opener & 6.2 & Pallet & 5 & 31 & & & \\
\hline & Load on conveyor & 24.9 & Drums & 5 & 124 & & & \\
\hline & Drum lid clamp & 24.9 & drum & 2 & 50 & & & \\
\hline & Drum lid opener & 24.9 & drum & 5 & 124 & & & \\
\hline & Lid staging & 24.9 & drum & 1 & 25 & & & \\
\hline & $\begin{array}{l}\text { Remove from } \\
\text { conveyor }\end{array}$ & 24.9 & drum & 1 & 25 & & & \\
\hline & & & & 19 & 398 & & & 19 \\
\hline
\end{tabular}


Table A1-c. Receiving and Preparation Subsystem

\begin{tabular}{|c|c|c|c|c|c|c|c|c|}
\hline Task & Subtask & $\begin{array}{c}\text { Occurrencel } \\
\text { Shift }\end{array} \mid$ & Units & $\begin{array}{l}\text { Time } \\
\text { Required } \\
\text { (min) }\end{array}$ & $\begin{array}{c}\text { Total Times } \\
\text { Shift }\end{array} \mid$ & $\begin{array}{l}\text { FTEs } \\
\text { Needed }\end{array}$ & $\begin{array}{l}\text { Add'l/Time } \\
\text { for Next } \\
\text { Drum }\end{array}$ & $\begin{array}{c}\text { Ave } \\
\text { Minutes/Shift } \\
\text { Drum }\end{array}$ \\
\hline Dump Drums & $\begin{array}{l}\text { Assign drums to } \\
\text { dump stations }\end{array}$ & 24.9 & drum & 3 & 75 & \multirow[b]{4}{*}{0.7} & \multirow[b]{4}{*}{5} & \multirow[b]{4}{*}{13} \\
\hline & $\begin{array}{l}\text { Move drums to sort } \\
\text { table /bins }\end{array}$ & 24.9 & drum & 5 & 124 & & & \\
\hline \multirow[b]{2}{*}{ Total Task 8} & Dump drums & 24.9 & drum & 5 & 124 & & & \\
\hline & & & & 13 & 323 & & & \\
\hline \multirow[t]{4}{*}{ Sort Drums } & $\begin{array}{l}\text { Sort waste } \\
\text { robotically }\end{array}$ & 24.9 & drum & 30 & 746 & \multirow[b]{5}{*}{2.6} & \multirow[b]{5}{*}{45} & \multirow[b]{5}{*}{38} \\
\hline & $\begin{array}{l}\text { Transfer waste to } \\
\text { container }\end{array}$ & 24.9 & drum & 15 & 373 & & & \\
\hline & $\begin{array}{l}\text { Select destination } \\
\text { for sorted waste }\end{array}$ & 24.9 & drum & 3 & 75 & & & \\
\hline & $\begin{array}{l}\text { Move container to } \\
\text { subsystem bin or } \\
\text { shredder }\end{array}$ & 24.9 & drum & 3 & 75 & & & \\
\hline Total Task 9 & & & & 51 & 1269 & & & \\
\hline \multirow[t]{6}{*}{ Glove Box Sort } & $\begin{array}{l}\text { Transfer to glove } \\
\text { box (several trips) }\end{array}$ & 6.0 & drum & 30 & 180 & \multirow[b]{6}{*}{4.7} & \multirow[b]{6}{*}{315} & \multirow[b]{6}{*}{5} \\
\hline & $\begin{array}{l}\text { Sort waste by hand } \\
\text { in glove box } \\
\text { Sampling (1/drum) }\end{array}$ & $\frac{6.0}{6.0}$ & $\frac{\text { drum }}{\text { drum }}$ & $\frac{240}{15}$ & $\frac{1440}{90}$ & & & \\
\hline & $\begin{array}{l}\text { Transfer waste to } \\
\text { containers }\end{array}$ & 6.0 & drum & 60 & 360 & & & \\
\hline & $\begin{array}{l}\text { Select destination } \\
\text { for sorted waste }\end{array}$ & 6.0 & drum & 15 & 90 & & & \\
\hline & $\begin{array}{l}\text { Move containers to } \\
\text { subsystem bin or } \\
\text { shredder }\end{array}$ & 6.0 & drum & 15 & 90 & & & \\
\hline & & & & 375 & 2250 & & & \\
\hline \multirow[t]{4}{*}{$\begin{array}{l}\text { Gross Size } \\
\text { Reduction }\end{array}$} & $\begin{array}{l}\text { Transfer to cutting } \\
\text { table }\end{array}$ & 5.4 & drum & 3 & 16 & \multirow[b]{5}{*}{0.5} & \multirow[b]{5}{*}{35} & \multirow[b]{5}{*}{6} \\
\hline & Cut waste & 5.4 & drum & 30 & 161 & & & \\
\hline & Return to container & 5.4 & drum & 5 & 27 & & & \\
\hline & $\begin{array}{l}\text { Transfer to next } \\
\text { process }\end{array}$ & 5.4 & drum & 3 & 16 & & & \\
\hline Total Task 11 & & & & 41 & 220 & & & \\
\hline \multirow[t]{10}{*}{ Shredding } & $\begin{array}{l}\text { Transfer drums to } \\
\text { shredder }\end{array}$ & 3.1 & drum & 2 & 6 & \multirow[b]{11}{*}{0.3} & \multirow[b]{11}{*}{2} & \multirow[b]{11}{*}{30} \\
\hline & Stage drums & 3.1 & drum & 2 & 6 & & & \\
\hline & $\begin{array}{l}\text { Feed waste to } \\
\text { shredder }\end{array}$ & 3.1 & drum & 2 & 6.22 & & & \\
\hline & $\begin{array}{l}\text { Feed bad drums to } \\
\text { shredder }\end{array}$ & 12.4 & drum & 2 & 25 & & & \\
\hline & Shred stage 1 & 12.4 & drum & 2 & 25 & & & \\
\hline & Shred stage 2 & 12.4 & drum & 2 & 25 & & & \\
\hline & $\begin{array}{l}\text { Sample size of } \\
\text { waste }\end{array}$ & 1.2 & drum & 5 & 6 & & & \\
\hline & Rework $10 \%$ & 0.1 & drum & 15 & 2 & & & \\
\hline & Return to container & 12.4 & drum & 3 & 37 & & & \\
\hline & $\begin{array}{l}\text { Transfer to next } \\
\text { process }\end{array}$ & 12.4 & drum & 2 & 25 & & & \\
\hline Total Task 12 & & & & 37 & 164 & & & \\
\hline
\end{tabular}


Table A1-c. Receiving and Preparation Subsystem

\begin{tabular}{|c|c|c|c|c|c|c|c|c|}
\hline Task & Subtask & $\begin{array}{c}\text { Occurrencel } \\
\text { Shift }\end{array}$ & Units & $\begin{array}{c}\text { Time } \\
\text { Required } \\
\text { (min) }\end{array}$ & $\begin{array}{c}\text { Total Time/ } \\
\text { Shift }\end{array}$ & $\begin{array}{c}\text { FTEs } \\
\text { Needed }\end{array}$ & $\begin{array}{l}\text { Add'I/Time } \\
\text { for Next } \\
\text { Drum }\end{array}$ & $\begin{array}{c}\text { Ave } \\
\text { Minutes/Shift } \\
\text { Drum }\end{array}$ \\
\hline \multirow[t]{5}{*}{ Sampling } & & & & & 0 & \multirow[b]{6}{*}{0.2} & \multirow[b]{6}{*}{10} & \multirow[b]{6}{*}{30} \\
\hline & $\begin{array}{l}\begin{array}{l}\text { Sample opened } \\
\text { drums }\end{array} \\
\end{array}$ & 2.5 & drum & 5 & 12 & & & \\
\hline & $\begin{array}{l}\text { Sample sorted } \\
\text { waste } \\
\end{array}$ & 1.2 & drum & 5 & 6 & & & \\
\hline & Resample (10\%) & 0.4 & drum & 5 & 2 & & & \\
\hline & Reportleval. results & 4.1 & drum & 10 & 41 & & & \\
\hline Total Task 13 & & & & 25 & 62 & & & \\
\hline \multirow[t]{5}{*}{$\begin{array}{l}\text { Subsystem Bin } \\
\text { operation }\end{array}$} & Monitor bin height & 24.9 & drum & 3 & 75 & \multirow[b]{6}{*}{1.8} & \multirow[b]{6}{*}{0} & \multirow[b]{6}{*}{26} \\
\hline & Fill containers & 24.9 & drum & 3 & 75 & & & \\
\hline & Move containers & 24.9 & drum & 2 & 50 & & & \\
\hline & Stage containers & 24.9 & drum & 3 & 75 & & & \\
\hline & $\begin{array}{l}\text { Organize } \\
\text { campaigns }\end{array}$ & 24.9 & drum & 15 & 373 & & & \\
\hline Total Task 14 & & & & 26 & 647 & & & \\
\hline \multirow[t]{8}{*}{ Internal Transfer } & $\begin{array}{l}\text { Move waste from } \\
\text { OSORT to other } \\
\text { subsystems }\end{array}$ & 24.9 & drum & 10 & 249 & \multirow[b]{9}{*}{4.9} & \multirow[b]{9}{*}{10} & \multirow[b]{9}{*}{57} \\
\hline & $\begin{array}{l}\text { Move waste from } \\
\text { subsystems to } \\
\text { CSHIP }\end{array}$ & 11.8 & drum & 10 & 118 & & & \\
\hline & $\begin{array}{l}\text { Move treated } \\
\text { waste to } \\
\text { stabilization }\end{array}$ & 80.0 & drum & 10 & 800 & & & \\
\hline & $\begin{array}{l}\text { Move unsorted } \\
\text { waste to incin }\end{array}$ & 6.2 & drum & 10 & 62 & & & \\
\hline & $\begin{array}{l}\text { Move waste to } \\
\text { secondary } \\
\text { treatment } \\
\end{array}$ & 20.0 & drum & 10 & 200 & & & \\
\hline & $\begin{array}{l}\text { Move supplies } \\
\text { around }\end{array}$ & 20.0 & drum & 3 & 60 & & & \\
\hline & Move new drums & 24.9 & drum & 3. & 75 & & & \\
\hline & $\begin{array}{l}\text { Schedule } \\
\text { movement }\end{array}$ & 187.8 & drum & 1 & 188 & & & \\
\hline Total Task 15 & & & & 57 & 1752 & & & \\
\hline \multirow[t]{4}{*}{ Box Breakdown } & Stage boxes & 10.0 & box & 2 & 20 & \multirow[b]{5}{*}{0.5} & \multirow[b]{5}{*}{10} & \\
\hline & $\begin{array}{l}\text { Move to opening } \\
\text { area }\end{array}$ & 10.0 & box & 3 & 30 & & & \\
\hline & Open boxes & 10.0 & box & 10 & 100 & & & \\
\hline & Transfer to dump & 10.0 & box & 3 & 30 & & & \\
\hline Total Task 16 & & & & 18 & 180 & & & 2 \\
\hline \multirow[t]{6}{*}{ Container Decon } & Stage containers & $\overline{499.8}$ & drum & 5 & 249 & \multirow[b]{7}{*}{6.2} & \multirow[b]{7}{*}{15} & \multirow[b]{7}{*}{45} \\
\hline & Load conveyors & 49.8 & drum & 5 & 249 & & & \\
\hline & Decon drums & 49.8 & drum & 10 & 498 & & & \\
\hline & \begin{tabular}{|l} 
Assay drums \\
\end{tabular} & 49.8 & drum & 15 & 746 & & & \\
\hline & Unload conveyers & 49.8 & drum & 5 & 249 & & & \\
\hline & Stage drums & 49.8 & drum & 5 & 249 & & & \\
\hline Total Task 17 & & & & 45 & 2239 & & & \\
\hline
\end{tabular}


Table A1-c.

Receiving and Preparation Subsystem

\begin{tabular}{|c|c|c|c|c|c|c|c|c|}
\hline Task & Subtask & $\begin{array}{c}\text { Occurrencel } \\
\text { Shift }\end{array}$ & Units & $\begin{array}{c}\text { Time } \\
\text { Required } \\
\text { (min) }\end{array}$ & $\begin{array}{c}\text { Total Time/ } \\
\text { Shift }\end{array}$ & $\begin{array}{c}\text { FTEs } \\
\text { Needed }\end{array}$ & $\begin{array}{c}\text { Add'I/Time } \\
\text { for Next } \\
\text { Drum }\end{array}$ & $\begin{array}{c}\text { Ave } \\
\text { Minutes/Shift } \\
\text { Drum }\end{array}$ \\
\hline FTEs/shift & & & & & 0 & 32.3 & & \\
\hline Supervision & Ratio of $1: 10$ & & & & & 3.2 & & \\
\hline $\begin{array}{l}\text { Vac/sick/holiday } \\
\text { relief }\end{array}$ & $\begin{array}{l}\text { Assume } 6 \text { wks of } \\
\text { absence }\end{array}$ & & & & & 4.1 & & \\
\hline $\begin{array}{l}\text { Break relief } \\
\text { (included in } 6 \mathrm{hr} \\
\text { day) }\end{array}$ & $\begin{array}{l}\text { One person can } \\
\text { relieve } 3 \\
\text { (accounted for in } \\
\text { efficiency) }\end{array}$ & & & & & & & \\
\hline Total/shift & & & & & & 39.7 & & \\
\hline $\begin{array}{l}\text { Adj for } 70 \% \\
\text { Efficiency }\end{array}$ & & & & & & 6.7 & & \\
\hline Total/C & & & & & & & & \\
\hline
\end{tabular}

Notes:

Assume FTEs are available for $8 \mathrm{hrs} / \mathrm{day}$; because overall $70 \%$ efficiency is taken at the end.

Trucks have 22 pallets. Waste density is $64 \mathrm{lb} / \mathrm{ft} 3$.

Pallets are assumed to hold four 55 gallon drums

As in inventory, assume $50 \%$ of drums are contaminated and can't be deconned.

Assume $50 \%$ of waste received requires interim storage; this will be dependent on assay system

Assume $10 \%$ of incoming waste is sampled

Assume opened and sorted waste is $50 \%$ of total

Assume $10 \%$ of sorted waste is sampled

Assume gross size reduction is necessary for wastes to metal decon \& lead

Assume gross size reduction is $1 \mathrm{hr}$ per drum.

Assume shredding is necessary for drums only

Assume $10 \%$ of shredded waste is sampled.

Box breakdown includes time beyond that required if waste was packaged in drums

Assume glove box sorting required for special, mercury and lead

Assume glove box waste requires 1 sample/drum

Assume transfer control for liquids takes the same time as for solids

Assume paperwork is accomplished within times shown

Ave. time per drum includes times for activities multiplied by the probability that the activity will occur.

Least time/drum/subsystem includes only the minimum requirements, no extra staging, sorting, or shredding

Max time/drum/subsystem includes all staging, shredding, glove box, etc 


\begin{tabular}{|c|c|c|c|c|c|c|c|c|}
\hline Task & Subtask & $\begin{array}{c}\text { Occurrencel } \\
\text { Shift }\end{array}$ & Units & $\begin{array}{l}\text { Time } \\
\text { Required } \\
\text { (min) }\end{array}$ & $\begin{array}{c}\text { Total Timel } \\
\text { Shift }\end{array} \mid$ & $\begin{array}{l}\text { FTEs } \\
\text { Needed }\end{array}$ & $\begin{array}{l}\text { Minutes/ } \\
\text { Drum }\end{array}$ & $\begin{array}{l}\text { Timel } \\
\text { Add'l } \\
\text { Drum }\end{array}$ \\
\hline \multirow[t]{3}{*}{ Receive Waste } & Transfer through air lock & 8.5 & pallet & 5 & 43 & & & \\
\hline & Stage drums for campaigns & 8.5 & pallet & 15 & 128 & & & \\
\hline & & & & 20 & 170 & 0.35 & 20 & 15 \\
\hline \multirow[t]{6}{*}{ Shredding } & $\begin{array}{l}\text { Transfer waste/drums to } \\
\text { shredder } \\
\text { Stage drums and waste } \\
\text { Shred stage } 1 \\
\end{array}$ & $\begin{array}{l}34.0 \\
34.0 \\
34.0 \\
\end{array}$ & \begin{tabular}{|l|} 
drum \\
drum \\
drum \\
\end{tabular} & $\frac{2}{2}$ & $\begin{array}{l}68 \\
68 \\
68 \\
\end{array}$ & \multirow[b]{6}{*}{0.96} & \multirow[b]{6}{*}{29} & \multirow[b]{6}{*}{15} \\
\hline & $\begin{array}{l}\text { Shred stage } 2 \\
\text { Sample size of waste }\end{array}$ & $\frac{34.0}{3.4}$ & \begin{tabular}{|l|} 
drum \\
drum
\end{tabular} & $\frac{2}{5}$ & $\frac{68}{17}$ & & & \\
\hline & Rework $10 \%$ & 0.3 & drum & 11 & 4 & & & \\
\hline & Return to container & 34.0 & drum & 3 & 102 & & & \\
\hline & Transfer to next process & 34.0 & \begin{tabular}{|l|} 
drum \\
\end{tabular} & 2 & 68 & & & \\
\hline & & & & 29 & 463 & & & \\
\hline \multirow[t]{5}{*}{ Sampling } & & & & & 0 & \multirow[b]{5}{*}{0.16} & \multirow[b]{5}{*}{20} & \multirow[b]{5}{*}{10} \\
\hline & $\begin{array}{l}\text { Sample shredded waste to } \\
\text { characterize }\end{array}$ & 3.4 & drum & 5 & 17 & & & \\
\hline & Resample (10\%) & 0.3 & drum & 5 & 2 & & & \\
\hline & Report/eval. results & 3.7 & drum & 10 & 37 & & & \\
\hline & & & & 20 & 56 & & & \\
\hline \multirow{7}{*}{ Incineration } & Select waste for feeding & 34.0 & drums & 5 & 170 & & & \\
\hline & Stage waste for feeding & 34.0 & drums & 5 & 170 & & & \\
\hline & $\begin{array}{l}\text { Feed incinerator }(50 \mathrm{ft} 3 / \mathrm{hr} \text { or } \\
6.8 \text { drums } / \mathrm{hr} \text { ) }\end{array}$ & 34.0 & drums & 0 & 4 & & & \\
\hline & Incinerate waste ( $1 \mathrm{hr})$ & 34.0 & & 60 & 2040 & & & \\
\hline & Discharge waste $(50 \mathrm{ft} 3 / \mathrm{hr})$ & 20.4 & & 0 & 2 & & & \\
\hline & Sample waste in and out & 16.0 & times & 10 & 160 & & & \\
\hline & & & & 80 & 504 & 1.05 & 80 & 9 \\
\hline \multirow[t]{7}{*}{ Monitor incinerator } & Monitor feeding & & & & & & & \\
\hline & Monitor gas/air ratio & 24.0 & times & 5 & 120 & & & \\
\hline & Monitor burner & 24.0 & times & 5 & 120 & & & \\
\hline & Monitor feeding & 24.0 & times & 5 & 120 & & & \\
\hline & $\begin{array}{l}\text { Montor secondary } \\
\text { combustion }\end{array}$ & 24.0 & times & 5 & 120 & & & \\
\hline & Monitor discharge & 24.0 & times & 5 & 120 & & & \\
\hline & & & & 25 & 600 & 1.25 & 0 & 0 \\
\hline FTEs/shift & & & & & 0 & 3.77 & 149.23 & 15 \\
\hline Supervision & Ratio of 1:10 & & & & & 0.38 & & \\
\hline $\begin{array}{l}\text { Vac/sick/holiday } \\
\text { relief }\end{array}$ & Assume 6 wks of absence & & & & & 0.48 & & \\
\hline Total/shift & & & & & & 4.63 & 149 & 15 \\
\hline $\begin{array}{l}\text { Adjustment for } \\
70 \% \text { Efficiency }\end{array}$ & & & & & & 6.61 & & \\
\hline Total/day & & & & & & 19.84 & & \\
\hline
\end{tabular}

Notes:

Feed to incinerator requires shredding; whole drums can be shredded.

Assume $15 \mathrm{~min} / \mathrm{drum}$ per stage of shredding

Assume 1 hour kiln residence time

Assume rate of feeding and discharge @ $50 \mathrm{ft} 3 / \mathrm{hr}$

Waste discharge based on bottom ash @ 80\% of waste to vit (mass balance shows 1196 bottom ash and 299 fly ash)

No. of samples $=20$ 


\begin{tabular}{|c|c|c|c|c|c|c|c|c|}
\hline Task & Subtask & $\begin{array}{c}\text { Occurrence } \\
\text { / Shift }\end{array}$ & Units & $\begin{array}{l}\text { Time } \\
\text { Required } \\
\text { (min) }\end{array}$ & $\begin{array}{c}\text { Total Timel } \\
\text { Shitt }\end{array}$ & $\begin{array}{l}\text { FTEs } \\
\text { Needed }\end{array}$ & $\left|\begin{array}{c}\text { Minutes } \\
\text { Drum }\end{array}\right|$ & $\begin{array}{l}\text { Timel } \\
\text { Add"l } \\
\text { Drum }\end{array}$ \\
\hline \multirow[t]{10}{*}{ Receive Waste } & Transfer through air lock & 1.4 & drum & 5 & 7 & & & \\
\hline & Feed waste from drum & 1.4 & drum & 3 & 4 & & & \\
\hline & Hook to transfer device & 1.4 & drum & 3 & 4 & & & \\
\hline & Transfer to tank $(10 \mathrm{gpm})$ & 1.4 & drum & 6 & 8 & & & \\
\hline & Empty drum bottoms & 1.4 & drum & 2 & 3 & & & \\
\hline & Sample feed vessel & 2.0 & drum & 10 & 20 & & & \\
\hline & Detach \& remove drum & 1.4 & drum & 3 & 4 & & & \\
\hline & $\begin{array}{l}\text { Sample waste from processes: } \\
\text { incin, vitrification, APC }\end{array}$ & 4.0 & N/A & & & & & \\
\hline & Arrange for transfer & 12863.0 & gal & 0 & 77 & & & \\
\hline & & & & 32 & 127 & 0.27 & 32 & 5 \\
\hline \multirow[t]{12}{*}{$\begin{array}{l}\text { Preliminary } \\
\text { Treatment }\end{array}$} & Sample high TDS tank & 0.0 & drums & 15 & 0 & & & \\
\hline & Sample low TDS tank & 9.4 & drums & 15 & 14 & & & \\
\hline & Sample TOC waste & 1.1 & drums & 15 & 2 & & & \\
\hline & $\begin{array}{l}\text { Select treatment methods (10 } \\
\text { drum batch) }\end{array}$ & 1.1 & drums & 20 & 2 & & & \\
\hline & $\begin{array}{l}\text { Transfer organic waste to oil } \\
\text { water separator }\end{array}$ & 1.1 & drums & 3 & 3 & & & \\
\hline & $\begin{array}{l}\text { Filter high, low TDS and organic } \\
\text { waste (say } 50 \mathrm{gal} / \mathrm{min} \text { ) }\end{array}$ & 10.5 & drums & 1 & 12 & & & \\
\hline & Neutralize/ppt high TDS waste & 0.0 & drums & 11 & 0 & & & \\
\hline & $\begin{array}{l}\text { Detue preciprateo aqueous } \\
\text { waste }\end{array}$ & 0.0 & drums & 6 & 0 & & & \\
\hline & Evaporate solids $(50 \mathrm{gpm})$ & 10.5 & drums & 1 & 12 & & & \\
\hline & Monitor filter & 24.0 & times & 5 & 120 & & & \\
\hline & Monitor evaporator & 24.0 & times & 5 & 120 & & & \\
\hline & & & & 86 & 261 & 0.54 & 86 & 20 \\
\hline \multirow[t]{7}{*}{ UV Oxidation } & $\begin{array}{l}\text { Adjust UV oxidation ( } 30 \mathrm{~min} / 10 \\
\text { drums) }\end{array}$ & 1.1 & drums & 3 & 3 & & & \\
\hline & $\begin{array}{l}\text { Process through UV oxidation } \\
\text { (50 gpm) }\end{array}$ & 1.1 & drums & 1 & 1 & & & \\
\hline & Carbon filtration $(50 \mathrm{gpm})$ & 10.5 & drums & 1 & 12 & & & \\
\hline & Ion exchange (50 gpm) & 10.5 & drums & 1 & 12 & & & \\
\hline & Monitor carbon \& ion exchange & 12.0 & times & 5 & 60 & & & \\
\hline & Sample waste before discharge & 2.0 & times & 30 & 60 & & & 1 \\
\hline & & & & 6 & 147 & 0.31 & 6 & \\
\hline Total per shift & & & & & o & 1.12 & 124 & 26 \\
\hline Supervision & Ratio of $1: 10$ & & & & & 0.11 & & \\
\hline Vac/sick/holiday relief & Assume 6 wks of absence & & & & & 0.14 & & \\
\hline $\begin{array}{l}\text { Adjustment for } 70 \% \\
\text { Efficiency }\end{array}$ & & & & & & 1.96 & & \\
\hline Total per day & & & & & & 5.87 & & \\
\hline
\end{tabular}

Notes:

Assume waste from APC is low TDS; assume other secondary waste = Assume waste from RCPRP is organic liq Total drums/hour $=236.4$

Assume sampling of low TDS waste is one/25 drums

Assume transfer of waste requires $15 \mathrm{~min} / 2500$ gallons

Assume tank batches are 550 gallons ( 10 drums)

Assume treatment selection time is required for waste from RCPRP only:scrubber liquor has the same treatment.

Assume residence time in oil water separator is 1 hour and tank is 1000 gallons (16 gpm)

Assume filtration, centrifuge and ppt rates are $10 \mathrm{gpm}$.

Assume evaporation rate is $50 \mathrm{gpm}$

Assume UV oxidation unit is $50 \mathrm{gpm}$

Process samples $=16.5$

$\begin{array}{cccc}13413.70 & \mathrm{lbs} / \mathrm{hr} & 235 & \text { drums/shift } \\ 60.30 & \mathrm{lbs} / \mathrm{hr} & 1 & \text { drums/shift }\end{array}$




\begin{tabular}{|c|c|c|c|c|c|c|c|c|}
\hline Task & Subtask & $\begin{array}{c}\text { Occurrencel } \\
\text { Shift }\end{array}$ & Units & $\begin{array}{c}\text { Time } \\
\text { Required } \\
\text { (min) }\end{array}$ & $\begin{array}{l}\text { Total } \\
\text { Timel } \\
\text { Shift }\end{array}$ & $\begin{array}{c}\text { FTEs } \\
\text { Needed }\end{array}$ & $\begin{array}{l}\text { Minutes/ } \\
\text { Drum }\end{array}$ & $\begin{array}{l}\text { Minutes/ } \\
\text { Add'I Drum }\end{array}$ \\
\hline Metal Receiving & Transfer through air lock & 5.1 & drums & 5 & 26 & & & \\
\hline Total Task & & & & 5 & 26 & 0.05 & 5 & 5 \\
\hline \multirow[t]{6}{*}{$\begin{array}{l}\text { Feed Waste from } \\
\text { drum }\end{array}$} & Stage at feed bin (drums) & 5.1 & drums & 3 & 15 & & & \\
\hline & Hook to transfer device & 5.1 & drums & 3 & 15 & & & \\
\hline & $\begin{array}{l}\text { Transfer into feed bin } \\
\text { (direct discharge) }\end{array}$ & 5.1 & drums & 2 & 10 & & & 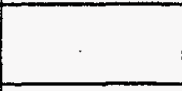 \\
\hline & Empty drum bottoms & 5.1 & drums & 2 & 10 & & & \\
\hline & $\begin{array}{l}\text { Sample feed vessel } \\
\text { (every } 10 \text { drums) }\end{array}$ & 0.5 & drums & 10 & 5 & & & \\
\hline & Detach \& remove drum & 5.1 & drums & 3 & 15 & & & \\
\hline Total Task & & & & 23 & 72 & 0.15 & 23 & 10 \\
\hline \multirow[t]{7}{*}{ Metal Melting } & Setup/check equipment & 0.5 & $\begin{array}{l}\text { timel } \\
\text { batch }\end{array}$ & 30 & 15 & & & \\
\hline & Stage waste for feeding & 0.5 & batch & 20 & 10 & & & \\
\hline & Adjust flux to melter & 0.5 & batch & 20 & 10 & & & \\
\hline & $\begin{array}{l}\text { Feed melter (10 } \\
\text { min/drum) }\end{array}$ & 0.5 & batch & 100 & 51 & & & \\
\hline & Melt waste & 0.5 & batch & 60 & 31 & & & \\
\hline & Discharge waste & 0.1 & batch & 60 & 6 & & & \\
\hline & & & & 260 & 124 & 0.26 & 260 & 260 \\
\hline \multirow[t]{7}{*}{ Metal Cooling } & $\begin{array}{l}\text { Metal discharge into } \\
\text { containers }\end{array}$ & 0.1 & drums & 15 & 2 & & & \\
\hline & Metal cooling & 0.1 & drums & N/A & $\underline{0}$ & & & \\
\hline & $\begin{array}{l}\text { Staging waste into } \\
\text { cooling }\end{array}$ & 0.1 & & 15 & 2 & & & \\
\hline & Slag cooling & 0.0 & drums & N/A & 0 & & & \\
\hline & $\begin{array}{l}\text { Staging waste out of } \\
\text { cooling }\end{array}$ & 0.1 & & 15 & 2 & & & \\
\hline & Collect samples & 0.1 & drums & 15 & 2 & & & \\
\hline & & & & 60 & 6 & 0.01 & 60 & 0 \\
\hline \multirow[t]{6}{*}{ Monitor APC } & Quench cooler & $4 . \overline{0}$ & times & 5 & 20 & & & \\
\hline & Baghouse/ceramic filter & 4.0 & times & 5 & 20 & & & \\
\hline & Mist eliminator & 4.0 & times & 2 & 8 & & & \\
\hline & GAC & 4.0 & times & 2 & 8 & & & \\
\hline & HEPA filter & 4.0 & times & 2 & 8 & & & \\
\hline & Offgas monitor & 24.0 & times & 10 & 240 & & & \\
\hline Total Task & & & & 26 & 304 & 0.63 & 26 & \\
\hline \multicolumn{2}{|c|}{ Total FTEs/day= FTEs per shift } & & & & & 1.11 & & \\
\hline Supervision & Ratio of $1: 10$ & & & & & 0.11 & 348 & \\
\hline $\begin{array}{l}\text { Vac/sick/holiday } \\
\text { relief }\end{array}$ & $\begin{array}{l}\text { Assume } 6 \text { wks of } \\
\text { absence }\end{array}$ & & & & & 0.14 & & \\
\hline Total/shift & & & & & & 1.36 & & \\
\hline $\begin{array}{l}\text { Adjustment for } 70 \% \\
\text { Efficiency }\end{array}$ & & & & & & 1.94 & & \\
\hline Total/day & & & & & & 5.82 & & \\
\hline
\end{tabular}

Notes:

Assume 3 hour batches at 10 drums/batch

Assume cooling time is long; staging of waste in and out is only time considered Assume $10 \%$ slag. 


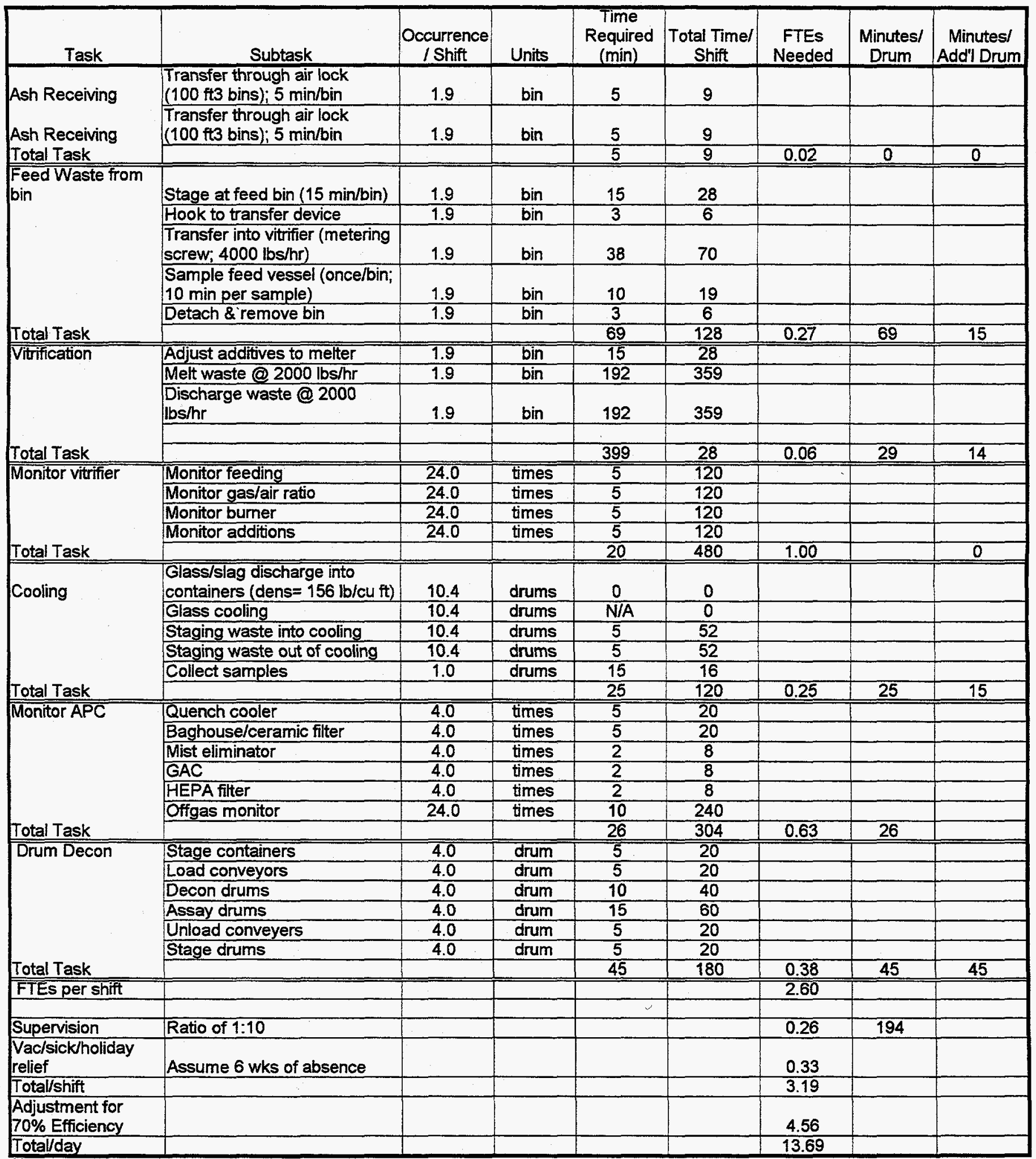

Notes:

Assume bins from incin are $100 \mathrm{ft} 3$ (this is our design assumption).

For time evaluation, $13.6 \quad$ drums

Assume screw empties at $4000 \mathrm{lbs} / \mathrm{hr}=\quad 63 \quad \mathrm{ft} 3 / \mathrm{hr}$

Assume retech vitrifier at $2000 \mathrm{lbs} / \mathrm{hr}$; continuous operation

Assume cooling time is long; staging of waste in and out is only time considered

No of samples $=4.8$ 
Table A1-h.

Metal Decontamination Subsystem

\begin{tabular}{|c|c|c|c|c|c|c|c|c|}
\hline Task & Subtask & $\begin{array}{c}\text { Occurrencer } \\
\text { Shift }\end{array}$ & Units & $\begin{array}{c}\text { Time } \\
\text { Required } \\
\text { (min) }\end{array}$ & $\begin{array}{c}\text { Total Time/ } \\
\text { Shift }\end{array}$ & $\begin{array}{c}\text { FTEs } \\
\text { Needed }\end{array}$ & $\begin{array}{c}\text { Minutes/ } \\
\text { Drum }\end{array}$ & $\begin{array}{c}\text { Minutes/ } \\
\text { Add'I Drum }\end{array}$ \\
\hline $\begin{array}{l}\text { Metals Receiving/ } \\
\text { Feed Prep }\end{array}$ & Transfer through air lock & 16.0 & drums & 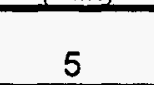 & 80 & & & \\
\hline Total Task & & & & 5 & 80 & 0.17 & 5 & 0 \\
\hline \multirow[t]{7}{*}{ Waste Decon } & Stage containers & 16.0 & drum & $\overline{5}$ & $\overline{80}$ & & & \\
\hline & Decon waste & 16.0 & drum & 10 & 160 & & & \\
\hline & Assay for recycle & 16.0 & drum & 30 & 480 & & & \\
\hline & Repack in drums & 16.0 & drum & 15 & 240 & & & \\
\hline & Close drum lid & 16.0 & drum & 15 & 240 & & & \\
\hline & Stage drums & 16.0 & drum & 5 & 80 & & & \\
\hline & $\begin{array}{l}\text { Monitor recirc filtration } \\
\text { and fugitive dust system }\end{array}$ & 24.0 & times & 6 & 144 & & & \\
\hline Total Task & & & & 86 & 1424 & 2.97 & 86 & \\
\hline Total FTEs/shift & & & & & & 3.13 & $\overline{\overline{91}}$ & \\
\hline Supervision & Ratio of $1: 10$ & & & & & 0.31 & & \\
\hline $\begin{array}{l}\text { Vac/sick/holiday } \\
\text { relief }\end{array}$ & $\begin{array}{l}\text { Assume } 6 \text { wks of } \\
\text { absence }\end{array}$ & & & & & 0.40 & & \\
\hline Total/shift & & & & & & 3.84 & & \\
\hline $\begin{array}{l}\text { Adjustment for } \\
70 \% \text { Efficiency }\end{array}$ & & & & & & 5.49 & & \\
\hline Total/day & & & & & & 16.48 & & \\
\hline
\end{tabular}

Notes:

Assume $50 \%$ of waste must be size reduced.

Assume $60 \mathrm{~min} / \mathrm{drum}$ for cutting 


\begin{tabular}{|c|c|c|c|c|c|c|c|c|}
\hline Task & Subtask & $\begin{array}{c}\text { Occurrence } \\
\text { I Shift }\end{array}$ & Units & $\begin{array}{c}\text { Time } \\
\text { Required } \\
\text { (min) }\end{array}$ & $\begin{array}{c}\text { Total Timel } \\
\text { Shift }\end{array}$ & $\begin{array}{l}\text { FTEs } \\
\text { Needed }\end{array}$ & $\begin{array}{c}\text { Minutes/ } \\
\text { Drum }\end{array}$ & $\begin{array}{c}\text { Minutes/ } \\
\text { Add'I Drum }\end{array}$ \\
\hline \multirow[t]{5}{*}{$\begin{array}{l}\text { Lead } \\
\text { Receiving/Feed } \\
\text { Prep }\end{array}$} & Transfer through air lock & 0.2 & drums & 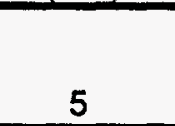 & 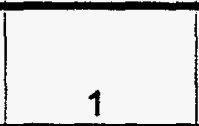 & & & \\
\hline & $\begin{array}{l}\text { Glove box separation of } \\
\text { sheet lead and gloves }\end{array}$ & 0.2 & drums & 60 & 14 & & & \\
\hline & Stage at decon $(80 \%)$ & 0.2 & drums & 10 & 2 & & & \\
\hline & Stage at melter $(20 \%)$ & 0.05 & drums & 10 & 0 & & & \\
\hline & & & & 85 & 18 & 0.04 & 85 & \\
\hline \multirow[t]{8}{*}{ Waste Decon } & Stage containers & 0.2 & drum & 5 & 1 & & & \\
\hline & Decon waste & 0.2 & drum & 10 & 2 & & & \\
\hline & Assay for recycle & 0.2 & drum & 30 & 6 & & & \\
\hline & Repack in drums & 0.2 & drum & 15 & 3 & & & \\
\hline & Close drum lid & 0.2 & drum & 15 & 3 & & & \\
\hline & Stage drums & 0.2 & drum & 5 & 1 & & & \\
\hline & $\begin{array}{l}\text { Monitor recirc filtration } \\
\text { and fugitive dust system }\end{array}$ & 24.0 & times & 6 & 144 & & & \\
\hline & & & & 86 & 159 & 0.33 & 86 & 30 \\
\hline \multirow[t]{7}{*}{ Lead Melting } & Setup/check equipment & 0.05 & $\begin{array}{l}\text { timel } \\
\text { batch }\end{array}$ & 30 & 1 & & & \\
\hline & Stage waste for feeding & 0.05 & batch & 20 & 1 & & & \\
\hline & Adjust flux to melter & 0.05 & batch & 20 & 1 & & & \\
\hline & $\begin{array}{l}\text { Feed melter (10 } \\
\text { min/drum) }\end{array}$ & 0.05 & batch & 100 & 5 & & & \\
\hline & Melt waste & 0.05 & batch & 180 & 9 & & & \\
\hline & $\begin{array}{l}\text { Monitor APC during } \\
\text { batch }\end{array}$ & 0.05 & batch & 350 & 17 & & & \\
\hline & & & & 670 & 15 & 0.03 & 320 & 180 \\
\hline \multirow[t]{7}{*}{ Metal Cooling } & $\begin{array}{l}\text { Metal discharge into } \\
\text { containers }\end{array}$ & 0.05 & drums & 15 & 1 & & & \\
\hline & Metal cooling (90\%) & 0.04 & drums & N/A & 0 & & & \\
\hline & $\begin{array}{l}\text { Staging waste into } \\
\text { cooling }\end{array}$ & 0.05 & drums & 15 & 1 & & & \\
\hline & Slag cooling (10\%) & 0.00 & drums & N/A & 0 & & & \\
\hline & $\begin{array}{l}\text { Staging waste out of } \\
\text { cooling }\end{array}$ & 0.05 & drums & 15 & 1 & & & \\
\hline & Collect samples & 0.05 & drums & 15 & 1 & & & \\
\hline & & & & 60 & 3 & 0.01 & 60 & 0 \\
\hline Total FTEs/shift & & & & & & $\overline{0.41}$ & 551 & \\
\hline Supervision & Ratio of $1: 10$ & & & & & 0.04 & & \\
\hline $\begin{array}{l}\text { Vac/sick/holiday } \\
\text { relief }\end{array}$ & $\begin{array}{l}\text { Assume } 6 \text { wks of } \\
\text { absence }\end{array}$ & & & & & 0.05 & & \\
\hline Total/shift & & & & & & 0.50 & & \\
\hline $70 \%$ efficiency & & & & & & 0.71 & & \\
\hline Total/day & & & & & & 2.14 & & \\
\hline
\end{tabular}

Notes:

Assume assay for all drums @ $30 \mathrm{~min} / \mathrm{drum}$

$20 \%$ of input is melted and $80 \%$ is deconned (ITTS ph2 assumption, fig A1-4)

Assume melter batch time is 3 hours

Assume 10 drum ( $9170 \mathrm{lb}$ or $550 \mathrm{gal}$ ) batches 


\begin{tabular}{|c|c|c|c|c|c|c|c|c|}
\hline Task & Subtask & $\begin{array}{c}\text { Occurrencel } \\
\text { Shift }\end{array}$ & Units & $\begin{array}{c}\text { Time } \\
\text { Required } \\
\text { (min) }\end{array}$ & $\begin{array}{c}\text { Total } \\
\text { Timel Shift }\end{array}$ & $\begin{array}{c}\text { FTEs } \\
\text { Needed }\end{array}$ & $\begin{array}{l}\text { Minutes/ } \\
\text { Drum }\end{array}$ & $\begin{array}{c}\text { Minutes/ } \\
\text { Add'I Drum }\end{array}$ \\
\hline \multirow[t]{4}{*}{$\begin{array}{l}\text { Mecury Receiving/ } \\
\text { Feed Prep }\end{array}$} & Transfer through air lock & 0.4 & drums & 5 & 2 & & & \\
\hline & $\begin{array}{l}\text { transfer liq mercury to tank } \\
\text { (5\% of } \mathrm{Hg} \text { waste) }\end{array}$ & 0.0 & drums & 60 & 1 & & & \\
\hline & $\begin{array}{l}\text { transfer } \mathrm{Hg} \text { contaminated } \\
\text { waste to feed bin } \\
\end{array}$ & 0.4 & drums & 15 & & & & \\
\hline & & & & 65 & 3 & 0.01 & 65 & 15 \\
\hline Shredding & $\begin{array}{l}\text { Transfer waste/drums to } \\
\text { shredder } \\
\text { Stage drums and waste } \\
\text { Shred stage } 1 \\
\text { Shred stage } 2 \\
\text { Sample size of waste } \\
\text { Rework } 10 \% \\
\text { Return to container } \\
\text { Transfer to retort staging } \\
\end{array}$ & $\begin{array}{l}0.4 \\
0.4 \\
0.4 \\
0.4 \\
0.4 \\
0.0 \\
0.4 \\
0.4 \\
\end{array}$ & $\begin{array}{l}\text { drum } \\
\text { drum } \\
\text { drum } \\
\text { drum } \\
\text { drum } \\
\text { drum } \\
\text { drum } \\
\text { drum } \\
\end{array}$ & $\begin{array}{c}\frac{2}{2} \\
2 \\
2 \\
5 \\
11 \\
3 \\
5 \\
32\end{array}$ & $\begin{array}{l}\frac{1}{1} \\
\frac{1}{1} \\
\frac{1}{2} \\
\frac{1}{1} \\
\frac{2}{8}\end{array}$ & 0.02 & 32 & 11 \\
\hline \multirow[t]{9}{*}{ Mercury Retorting } & Setup/check equipment & 0.4 & $\begin{array}{l}\text { timel } \\
\text { batch }\end{array}$ & 30 & 11 & & & \\
\hline & $\begin{array}{l}\text { Stage shredded waste for } \\
\text { feeding (batch=1 drum) } \\
\end{array}$ & 0.4 & drum & 20 & 8 & & & \\
\hline & Feed retort ( $20 \mathrm{~min} / \mathrm{drum}$ ) & 0.4 & drum & 20 & 8 & & & \\
\hline & Heat waste & 0.4 & drum & 60 & 23 & & & \\
\hline & Condense mercury & 0.0 & drum & 10 & $\overline{0}$ & & & \\
\hline & Separate offgas and $\mathrm{Hg}$ & 0.0 & drum & 10 & 0 & & & \\
\hline & Discharge waste & 0.4 & drum & 60 & 22 & & & \\
\hline & Monitor APC during batch & 0.4 & drum & 160 & 61 & & & \\
\hline & & & & 210 & 132 & 0.28 & 210 & 60 \\
\hline \multirow[t]{10}{*}{$\begin{array}{l}\text { Mercury } \\
\text { Amalgamation }\end{array}$} & Inspect equipment & 0.0 & drum & 30 & 1 & & & \\
\hline & $\begin{array}{l}\text { Transfer liq mercury to } \\
\text { amalgamater (1 gpm) }\end{array}$ & 0.0 & drum & 55 & 2 & & & \\
\hline & Measure additives & 0.0 & drum & 30 & 1 & & & \\
\hline & Batch amalgamation & 0.0 & drum & 120 & 5 & & & 120 \\
\hline & Transfer out of amalgamater & 0.0 & drum & 55 & 2 & & & \\
\hline & Sample waste & 0.0 & drum & 15 & 1 & & & \\
\hline & Stage & 0.0 & drum & 5 & 0 & & & \\
\hline & Place at assay & 0.0 & drum & 5 & 0 & & & \\
\hline & Assay & 0.0 & drum & 20 & 1 & & & \\
\hline & Remove from assay & 0.0 & drum & 2 & 0 & & & \\
\hline Total Task & & & & 307 & 12 & 0.02 & 307 & 120 \\
\hline Total FTEs/shift & & & & & & 0.32 & 614 & \\
\hline Supervision & Ratio of $1: 10$ & & & & & 0.03 & & \\
\hline $\begin{array}{l}\text { Vac/sick/holiday } \\
\text { relief }\end{array}$ & Assume 6 wks of absence & & & & & 0.04 & & \\
\hline Total/shift & & & & & & 0.40 & & \\
\hline $\begin{array}{l}\text { Adjustment for } \\
70 \% \text { Efficiency }\end{array}$ & & & & & & 0.57 & & \\
\hline Total/day & & & & & & 1.71 & & \\
\hline
\end{tabular}

Notes:

Assume $5 \%$ of mercury waste is elemental, rest is debris

Assume $5 \%$ of debris is mercury.

Assume all debris requires 2 stage shredding

Assume retort is 1 drum batch.

Batch size for amalgamater: Assume 1 drum/batch, 2 hrs /batch 
Table A1-k.

Special Waste

\begin{tabular}{|c|c|c|c|c|c|c|c|c|}
\hline Task & Subtask & $\begin{array}{c}\text { Occurrencel } \\
\text { Shift }\end{array}$ & Units & $\begin{array}{c}\text { Time } \\
\text { Required } \\
\text { (min) }\end{array}$ & $\begin{array}{c}\text { Total } \\
\text { Time/ Shift } \\
\end{array}$ & $\begin{array}{l}\text { FTEs } \\
\text { Needed }\end{array}$ & $\begin{array}{c}\text { Minutes/ } \\
\text { Drum }\end{array}$ & $\begin{array}{l}\text { Minutes/ } \\
\text { Add'l Drum }\end{array}$ \\
\hline $\begin{array}{l}\text { Special } \\
\text { Receiving/Feed Prep }\end{array}$ & Transfer through air lock & 5.4 & drums & 5 & 27 & & & \\
\hline & $\begin{array}{l}\text { Glove box preparation of } \\
\text { wastes }\end{array}$ & 5.4 & drums & 60 & 322 & & & \\
\hline & Stage waste & 5.4 & drums & 3 & 16 & & & \\
\hline Total Task & & & & 68 & 364 & 0.76 & 68 & 60 \\
\hline \multirow[t]{7}{*}{ Waste Treatment } & Stage containers & $\overline{\overline{5.4}}$ & drum & 3 & 16 & & & \\
\hline & $\begin{array}{l}\text { Treat waste as special } \\
\text { processes TBD }\end{array}$ & 5.4 & drum & 60 & 322 & & & \\
\hline & Sample treated waste & 5.4 & drum & 15 & 80 & & & \\
\hline & Repack in drums & 5.4 & drum & 30 & 161 & & & \\
\hline & Close drum lid & 5.4 & drum & 3 & $\overline{16}$ & & & \\
\hline & Stage drums & 5.4 & drum & 3 & 16 & & & \\
\hline & & & & 114 & 611 & 1.27 & 114 & 60 \\
\hline Total FTEs/shift & & & & & & 2.03 & 182 & \\
\hline Supervision & Ratio of $1: 10$ & & & & & 0.20 & & \\
\hline $\begin{array}{l}\text { Vac/sick/holiday } \\
\text { relief }\end{array}$ & $\begin{array}{l}\text { Assume } 6 \text { wks of } \\
\text { absence }\end{array}$ & & & & & 0.26 & & \\
\hline Total/shift & & & & & & 2.49 & & \\
\hline $\begin{array}{l}\text { Adjustment for } 70 \% \\
\text { Efficiency }\end{array}$ & & & & & & 3.56 & & \\
\hline Total/day & & & & & & 10.69 & & \\
\hline
\end{tabular}

Notes:

Assume all waste is prepared in glove box

Assume waste is treated in various batch processes that average 2 hours/drum

TBD $=$ To be determined 
Table A1-1. Grout Stabilization Subsystem

\begin{tabular}{|c|c|c|c|c|c|c|c|c|}
\hline Task & Subtask & $\begin{array}{c}\text { Occurrence/ } \\
\text { Shift }\end{array}$ & Units & $\begin{array}{c}\text { Time } \\
\text { Required } \\
\text { (min) }\end{array}$ & \begin{tabular}{|c|}
$\begin{array}{c}\text { Total Time/ } \\
\text { Shift }\end{array}$ \\
\end{tabular} & $\begin{array}{l}\text { FTEs } \\
\text { Needed } \\
\end{array}$ & $\begin{array}{c}\text { Minutes/ } \\
\text { Drum }\end{array}$ & $\begin{array}{c}\text { Minutes/ } \\
\text { Add'I Drum }\end{array}$ \\
\hline \multirow[t]{7}{*}{$\begin{array}{l}\text { Waste } \\
\text { Receiving/ } \\
\text { Feed Prep }\end{array}$} & Transfer through air lock & 0 & drums & 5 & 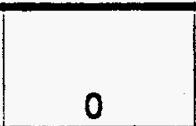 & & & \\
\hline & Sample waste & 0 & drums & 15 & 0 & & & \\
\hline & Select process for waste & 0 & drums & 5 & 0 & & & \\
\hline & $\begin{array}{l}\text { Transfer to } \\
\text { macroencapsulation }\end{array}$ & & drums & 2 & 0 & & & \\
\hline & $\begin{array}{l}\text { Transfer to } \\
\text { microencapsulation }\end{array}$ & 0 & drums & 2 & 0 & & & \\
\hline & Stage at process & 0 & drums & 2 & 0 & & & \\
\hline & & & & 31 & 0 & 0 & 31 & 5 \\
\hline \multirow[t]{8}{*}{$\begin{array}{l}\text { Waste } \\
\text { Encapsulation }\end{array}$} & Measure binder & 0 & drum & 15 & 0 & & & \\
\hline & Mix binder & 0 & drum & 15 & 0 & & & \\
\hline & Combine with waste & 0 & drum & 30 & 0 & & & \\
\hline & Repack in drums & 0 & drum & 15 & 0 & & & \\
\hline & Close drum lid & 0 & drum & 15 & $\overline{0}$ & & & \\
\hline & Stage pallets & 0 & drum & 2 & $\overline{0}$ & & & \\
\hline & $\begin{array}{l}\text { Monitor activated carbon } \\
\text { and fugitive dust system }\end{array}$ & 2 & times & 6 & 12 & & & \\
\hline & & & & 98 & 12 & & 98 & 30 \\
\hline \multirow[t]{4}{*}{$\begin{array}{l}\text { Binder setup } \\
\text { time }\end{array}$} & $\begin{array}{l}\text { Move pallets to curing } \\
\text { area }\end{array}$ & 0 & drum & 5 & 0 & & & \\
\hline & Curing time & 0 & drum & & 0 & & & \\
\hline & Monitor curing process & 0 & drum & 10 & 0 & & & \\
\hline & $\begin{array}{l}\text { Move pallets from curing } \\
\text { area }\end{array}$ & 0 & times & 5 & 0 & & & \\
\hline Total Task & & & & 20 & 0 & 0 & 20 & 5 \\
\hline \multirow{7}{*}{ Drum Decon } & Stage containers & $\overline{0}$ & drum & 5 & $\overline{0}$ & & & \\
\hline & Load conveyors & 0 & drum & 5 & $\overline{0}$ & & & \\
\hline & Decon drums & 0 & drum & 10 & $\mathbf{0}$ & & & \\
\hline & Assay drums & $\mathbf{0}$ & drum & 30 & 0 & & & \\
\hline & Unload conveyers & 0 & drum & 5 & 0 & & & \\
\hline & Palletize drums & $\mathbf{0}$ & drum & 2 & 0 & & & \\
\hline & Stage drums & 0 & drum & 5 & 0 & & & \\
\hline Total Task & & & & 62 & 0 & 0 & & 30 \\
\hline Total FTEs/shift & & & & & & $\overline{0}$ & & \\
\hline Supervision & Ratio of 1:10 & & & & & $\mathbf{0}$ & & \\
\hline $\begin{array}{l}\text { Vac/sick/holida } \\
\text { y relief }\end{array}$ & $\begin{array}{l}\text { Assume } 6 \text { wks of } \\
\text { absence }\end{array}$ & & & & & 0 & & \\
\hline Total/shift & & & & & & $\mathbf{0}$ & & \\
\hline $70 \%$ efficiency & & & & & & 0 & & \\
\hline Total/day & & & & & & 0 & & \\
\hline
\end{tabular}

Notes:

Assume all complex debris ( 8 drums) will be sent to macroencapsulation, rest to micro.

Assume $10 \%$ of drums are deconned.

Assume $10 \%$ of drums are assayed

Assume mixing requires $30 \mathrm{~min} / \mathrm{drum}$ 
Table A1-m.

Polymer Stabilization Subsystem

\begin{tabular}{|c|c|c|c|c|c|c|c|c|}
\hline Task & Subtask & $\begin{array}{c}\text { Occurrence/ } \\
\text { Shift }\end{array}$ & Units & $\begin{array}{c}\text { Time } \\
\text { Required } \\
\text { (min) }\end{array}$ & $\begin{array}{c}\text { Total Timer } \\
\text { Shift }\end{array}$ & $\begin{array}{l}\text { FTEs } \\
\text { Needed }\end{array}$ & $\begin{array}{c}\text { Minutes/ } \\
\text { Drum }\end{array}$ & $\begin{array}{c}\text { Minutes/ } \\
\text { Add'l } \\
\text { Drum }\end{array}$ \\
\hline \multirow[t]{7}{*}{$\begin{array}{l}\text { Waste } \\
\text { Receiving/Feed Prep }\end{array}$} & Transfer through air lock & 2.8 & drums & 5 & 14 & & & \\
\hline & Sample waste & 0.3 & drums & 15 & 4 & & & \\
\hline & Evaluate dryness & 0.3 & drums & 5 & 1 & & & \\
\hline & Dry waste & 2.8 & drums & 30 & N/A & & & \\
\hline & Monitor drying & 24.0 & times & 10 & 240 & & & \\
\hline & Stage at process & 2.8 & drums & 2 & 6 & & & \\
\hline & & & & 57 & 265 & 0.55 & 57 & 30 \\
\hline \multirow[t]{9}{*}{ Encapsulation } & Measure polymer & $2 . \overline{8}$ & drum & 5 & 14 & & & \\
\hline & Mix polymer & 2.8 & drum & 10 & 28 & & & \\
\hline & $\begin{array}{l}\text { Combine with waste in } \\
\text { extruder }\end{array}$ & 2.8 & drum & 10 & 28 & & & \\
\hline & Repack in drums & 24.0 & drum & 5 & 120 & & & \\
\hline & Close drum lid & 2.8 & drum & 3 & 8 & & & \\
\hline & Palletize drums & 2.8 & drum & 2 & 6 & & & \\
\hline & Stage drums & 24.0 & drum & 2 & 48 & & & \\
\hline & $\begin{array}{l}\text { Monitor activated carbon } \\
\text { and fugitive dust system }\end{array}$ & 8.0 & times & 6 & 48 & & & \\
\hline & & & & 43 & 300 & 0.63 & 43 & 60 \\
\hline \multirow[t]{6}{*}{ Binder setup time } & Move pallets to curing area & 24.0 & drum & 5 & 120 & & & \\
\hline & Curing time & 24.0 & drum & & 0 & & & \\
\hline & Sample every 10 drums & 2.4 & drum & 15 & 36 & & & \\
\hline & Monitor curing & 24.0 & drum & 10 & 240 & & & \\
\hline & $\begin{array}{l}\text { Move pallets from curing } \\
\text { area }\end{array}$ & 24.0 & times & 5 & 120 & & & \\
\hline & & & & 35 & 516 & 1.08 & 35 & 5 \\
\hline \multirow[t]{7}{*}{ Drum Decon } & Stage containers & 2.8 & drum & 5 & 14 & & & \\
\hline & Load conveyors & 2.8 & drum & 5 & 14 & & & \\
\hline & Decon drums & 2.8 & drum & 10 & 28 & & & \\
\hline & Assay drums & 2.8 & drum & 15 & 42 & & & \\
\hline & Unload conveyers & 2.8 & drum_ & 5 & 14 & & & \\
\hline & Stage drums & 2.8 & drum & 5 & 14 & & & \\
\hline & & & & 45 & 126 & 0.26 & 45 & 60 \\
\hline Total FTEs/shift & & & & & & 2.52 & 180 & \\
\hline Supervision & Ratio of $1: 10$ & & & & & 0.25 & & \\
\hline $\begin{array}{l}\text { Vac/sick/holiday } \\
\text { relief }\end{array}$ & Assume 6 wks of absence & & & & & 0.32 & & \\
\hline Total/shift & & & & & & 3.09 & & \\
\hline $\begin{array}{l}\text { Adjustment for } 70 \% \\
\text { Efficiency }\end{array}$ & & & & & & 4.41 & & \\
\hline Total/day & & & & & & 13.22 & & \\
\hline
\end{tabular}

Notes:

Assume $30 \%$ of process residue waste and $100 \%$ of other waste requires drying

Assume dryer can accept waste at the rate of 2 drums/hour

No. of samples $=2.4$ 
Table A1-n.

Air Pollution Control Subsystem

\begin{tabular}{|c|c|c|c|c|c|c|c|}
\hline Task & Subtask & $\begin{array}{c}\text { Occurrence/ } \\
\text { Shift }\end{array}$ & Units & $\begin{array}{l}\text { Time } \\
\text { Required } \\
\text { (min) }\end{array}$ & $\begin{array}{c}\text { Total Timel } \\
\text { Shift }\end{array}$ & $\begin{array}{c}\text { FTEs } \\
\text { Needed }\end{array}$ & Minutes/ lb \\
\hline \multirow[t]{13}{*}{ Monitor Equipment } & Dry filfration & 8.0 & times & 10 & 80 & & \\
\hline & Quencher & 24.0 & times & 5 & 120 & & \\
\hline & Prefilter/hepa filter & 4.0 & times & 5 & 20 & & \\
\hline & Acid gas scrubber & 24.0 & times & 5 & 120 & & \\
\hline & GAC & 4.0 & times & 2 & 8 & & \\
\hline & Mersorb & 4.0 & times & $\overline{2}$ & 8 & & \\
\hline & Evaporator System & 24.0 & times & 5 & 120 & & \\
\hline & Dioxin/ Denox Filter & 8.0 & times & 5 & 40 & & \\
\hline & Hydrosonic Scrubber & 24.0 & times & 5 & 120 & & \\
\hline & Liquid/ Solid Separator & 24.0 & times & 5 & 120 & & \\
\hline & Mist Eliminator & 4.0 & times & 2 & 8 & & \\
\hline & Heat Exchanger & 4.0 & times & 5 & 20 & & \\
\hline & Offgas monitor & 24.0 & times & 5 & 120 & & \\
\hline Total Task & & & & 61 & 904 & 1.88 & 0 \\
\hline Supervision & Ratio of 1:10 & & & & & 0.19 & \\
\hline $\begin{array}{l}\text { Vac/sick/holiday } \\
\text { relief }\end{array}$ & Assume 6 wks of absence & & & & & 0.24 & \\
\hline Total/shift & & & & & & 2.31 & \\
\hline $\begin{array}{l}\text { Adjustment for } 70 \% \\
\text { Efficiency }\end{array}$ & & & & & & 3.30 & \\
\hline Total/day & & & & & & 9.90 & \\
\hline
\end{tabular}


Table A1-0.

Certification and Shipping

\begin{tabular}{|c|c|c|c|c|c|c|c|c|}
\hline Task & Subtask & $\begin{array}{c}\text { Occurrencel } \\
\text { Shift }\end{array}$ & Units & $\begin{array}{c}\text { Time } \\
\text { Required } \\
\text { (min) }\end{array}$ & $\begin{array}{c}\text { Total Timel } \\
\text { Shift }\end{array}$ & $\begin{array}{l}\text { FTEs } \\
\text { Needed }\end{array}$ & $\begin{array}{c}\text { Minutes/ } \\
\text { Drum }\end{array}$ & $\begin{array}{l}\text { Minutes/ } \\
\text { Add"I Drum }\end{array}$ \\
\hline \multirow[t]{5}{*}{ Waste Receiving } & Transfer through air lock & 11.8 & drums & 5 & 59 & & & \\
\hline & Sample waste & 1.2 & drums & 15 & 18 & & & \\
\hline & Resample waste & 0.1 & drums & 15 & 2 & & & \\
\hline & Stage waste & 11.8 & drums & 5 & 59 & & & \\
\hline & & & & 40 & 138 & 0.29 & 40 & 15 \\
\hline \multirow[t]{8}{*}{ Waste Assay } & Stage pallets & 91.8 & drum & $=$ & 36 & & & \\
\hline & Load on conveyor & 11.8 & drum & 1 & 12 & & & \\
\hline & Assay RTR & 11.8 & drum & 15 & 178 & & & \\
\hline & Assay gamma & 11.8 & drum & 60 & 710 & & & \\
\hline & Assay PAN & 11.8 & drum & 60 & 710 & & & \\
\hline & Remove from conveyor & 11.8 & drum & 1 & 12 & & & \\
\hline & Repalletize & 11.8 & drum & 3 & 36 & & & \\
\hline & $\begin{array}{l}\text { Stage pallets after } \\
\text { assaying }\end{array}$ & 11.8 & drum & 15 & 178 & & & \\
\hline Total Task & & & & 158 & 1871 & 3.90 & 158 & 60 \\
\hline \multirow[t]{4}{*}{ Stage waste } & Stage uncertified waste & 11.8 & drum & $\overline{3}$ & 36 & & & \\
\hline & Transfer waste & 11.8 & drum & 3 & 36 & & & \\
\hline & Stage certified waste & 11.8 & drum & 3 & 36 & & & \\
\hline & Transfer waste & 11.8 & drum & 3 & 36 & & & \\
\hline Total Task & & & & 12 & 142 & 0.30 & 12 & \\
\hline \multirow[t]{4}{*}{ Ship Waste Truck } & Truck docking & 0.1 & truck & 30 & $\overline{4}$ & & & \\
\hline & Settle Paperwork & 0.1 & truck & 120 & 16 & & & \\
\hline & Load truck & 0.1 & truck & 60 & 8 & & & \\
\hline & Truck leaving & 0.1 & truck & 60 & 8 & & & \\
\hline Total Task & & & & 270 & 36 & 0.08 & 12 & \\
\hline Total FTEs/shift & & & & & & 4.56 & 222 & \\
\hline Supervision & Ratio of $1: 10$ & & & & & 0.46 & & \\
\hline $\begin{array}{l}\text { Vac/sick/holiday } \\
\text { relief }\end{array}$ & $\begin{array}{l}\text { Assume } 6 \text { wks of } \\
\text { absence }\end{array}$ & & & & & 0.58 & & \\
\hline Total/shift & & & & & & 5.59 & & \\
\hline $\begin{array}{l}\text { Adjustment for } 70 \% \\
\text { Efficiency }\end{array}$ & & & & & & 7.99 & & \\
\hline Total/day & & & & & & 23.96 & & \\
\hline
\end{tabular}

Notes:

Assume $10 \%$ of waste requires sampling

Samples collected $=1.2$ 


\begin{tabular}{|c|c|c|c|c|c|c|}
\hline & Daily FTEs & $\begin{array}{l}\text { Time (min)/ } \\
\text { Single Drum }\end{array}$ & Time (hrs) & $\begin{array}{l}\text { Add'l Time } \\
\text { for Next } \\
\text { Drum }\end{array}$ & $\begin{array}{l}\text { Time/Drums } \\
\text { Received in a } \\
\text { Shift (min) }\end{array}$ & Time (hrs) \\
\hline Administration & 48.4 & N/A & & & & \\
\hline $\begin{array}{l}\text { Receiving /nspection Tasks common } \\
\text { for all waste }\end{array}$ & & 802 & 13 & 60 & 3728 & 62 \\
\hline Receiving and Prep-incin & & $\frac{229}{257}$ & 4 & 45 & 1714 & $\frac{29}{9}$ \\
\hline Receiving and Prep-metal melt & & 267 & 4 & 45 & 452 & 8 \\
\hline Receiving and Prep-lead & & 557 & 9 & 315 & 557 & 9 \\
\hline Receiving and Prep-mercury & & 516 & 9 & 315 & 516 & 9 \\
\hline Receiving and Prep-special & & 516 & 9 & 315 & 1889 & 31 \\
\hline Receiving and Prep-metal decon & & 229 & 4 & 35 & 560 & 9 \\
\hline Receiving and Prep & 170.1 & 670.7 & 11 & & & 0 \\
\hline Aqueous Waste & 5.9 & 124 & 2 & 5 & 1301 & 22 \\
\hline Incineration & 19.8 & 149 & 2 & 26 & 1007 & 17 \\
\hline Vitrification & 13.7 & 194 & 3 & 15 & 561 & 9 \\
\hline$\frac{\text { Metal Decon }}{\text { Metal Melting }}$ & $\frac{16.5}{5.8}$ & $\frac{91}{348}$ & $\frac{2}{6}$ & $\frac{75}{75}$ & $\frac{1216}{657}$ & $\frac{20}{11}$ \\
\hline Lead & 2 & 551 & 9 & N/A & 551 & 9 \\
\hline Mercury & 1.7 & 614.0 & 10 & N/A & 614 & 10 \\
\hline Special & 10.7 & 182.0 & 3 & 60.0 & 444 & 7 \\
\hline Grout & 0.0 & 0 & 0 & & 0 & $\underline{0}$ \\
\hline Polymer & 13.2 & 180 & 3 & 60 & 288 & 5 \\
\hline APC & 9.9 & 904 & 15 & & 904 & 15 \\
\hline Certification and Shipping & 24.0 & 222 & 4 & 60 & 872 & 15 \\
\hline Total & 341.8 & & & & & \\
\hline
\end{tabular}

Notes:

Allocation of receiving and preparation time was done as follows:

Average time per drum was estimated, multiplied by the number

of drums per shift. The time for each waste type was allocated

according its percentage of total waste. 




\section{System C-1 Time and Motion Study Tables}

C1-a System C-1: Time and Motion Analysis

C1-b Administration Subsystem

C1-c Receiving and Preparation Subsystem

C1-d Plasma Reactor

C1-e Aqueous Waste Treatment Subsystem

C1-f Metal Decontamination Subsystem

C1-g Lead Recovery

Cl-h Mercury Amalgamation

C1-i Special Waste

Cl-j Polymer Stabilization Subsystem

C1-k Air. Pollution Control Subsystem

C1-1 Certification and Shipping

C1-m Summary of FTEs and time for a single drum to work through a system 


\begin{tabular}{|c|c|c|c|c|c|c|}
\hline Subsystem & $\begin{array}{c}\text { Mass Flow } \\
(\mathrm{lb} / \mathrm{hr})\end{array}$ & Waste Type & $\begin{array}{l}\text { No. of } \\
\text { Drums }\end{array}$ & $\begin{array}{c}\text { SCM } \\
\text { Unprocessed } \\
\text { Density } \\
\mathrm{kg} / \mathrm{m} 3\end{array}$ & $\begin{array}{c}\text { Density } \\
\text { lb/ft3 }\end{array}$ & $\begin{array}{l}\text { Density } \\
\text { Ib/drum }\end{array}$ \\
\hline Administration & 2,927 & & & & & \\
\hline Receiving and preparation & 2,927 & all & 6.2 & & 64 & 471 \\
\hline Aqueous waste treatment & 6,645 & L1100 & 14.6 & & $\overline{62}$ & 456 \\
\hline Plasma Treatment & 2,149 & $\mathbf{5 5 3 0 0 , 5 1 1 0}$ & 4.6 & & 64 & 471 \\
\hline Thermal treated waste & 1,451 & 53110 & 1.1 & & 187 & 1375 \\
\hline Metal Melting & 0 & 55110 & 0.0 & 509 & 32 & 234 \\
\hline Metal decontamination & 468 & $\mathbf{5 5 1 1 0}$ & 2.0 & 509 & 32 & 234 \\
\hline Mercury amalgamation & 50 & $\times 7100$ & 0.1 & 2000 & 125 & 918 \\
\hline Lead recovery & 26 & $\mathrm{X7200}$ & 0.0 & 2000 & 125 & 918 \\
\hline Polymer stabilization & 113 & 53120 & 0.4 & 700 & 44 & 321 \\
\hline Air pollution control & 6,762 & & N/A & & & \\
\hline Special treatment & 153 & $\times 6000, \times 7500$ & 0.7 & 500 & 31 & 229 \\
\hline Certification and shipping & 1,958 & 2000 & 1.5 & 2500 & 180 & 1326 \\
\hline vol reduction (out/in) & 1.49 & & 0.2 & & & \\
\hline
\end{tabular}

Notes:

This table provides the basis for the time and motion analysis.

Quantities of waste to a subsystem (lbs/hr) are based on LMITCO mass balance.

Densities are the same as the LMITCO mass balance except where values are shown in the SCM column. Where values are shown in the SCM column, densities are taken from SCM and converted to Ib/ft3.

Density for thermal treatment is based on $33 \%$ combustible (5300) and $67 \%$ noncombustible (5110).

The waste quantities are converted from $\mathrm{lbs} / \mathrm{hr}$ to drums $/ \mathrm{hr}$.

Subsequent analysis is based on drums/shift of waste to a subsystem.

Thermal treated waste refers to waste processed through the plasma reactor. 
Table c1-b.

Administration Subsystem

\begin{tabular}{|c|c|c|c|c|c|}
\hline Task & Subtask & $\begin{array}{l}\text { FTEs } \\
\text { Needed }\end{array}$ & $\begin{array}{l}\text { Samples/ } \\
\text { Shift }\end{array}$ & $\begin{array}{l}\text { Time } \\
\text { Required } \\
\text { (min) }\end{array}$ & $\begin{array}{l}\text { Total Time/ } \\
\text { Shift }\end{array}$ \\
\hline Facility Management & $\begin{array}{l}\text { Facility Manager } \\
\text { Secretary } \\
\text { Receptionist/word processor }\end{array}$ & $\begin{array}{l}1 \\
1 \\
1\end{array}$ & & & \\
\hline Operations Management & $\begin{array}{l}\text { Department managers } \\
\text { Communications } \\
\text { Engineering Manager } \\
\text { Engineering staff } \\
\text { Maintenance Supervisor }\end{array}$ & $\begin{array}{l}2 \\
1 \\
1 \\
2 \\
1\end{array}$ & & & \\
\hline Personnel & $\begin{array}{l}\text { Personnel Manager } \\
\text { Nurse/medical/industrial safety } \\
\text { Security guards at facility } \\
\text { Security at guard bldg }\end{array}$ & $\begin{array}{l}1 \\
1 \\
4 \\
4\end{array}$ & & & \\
\hline Environmental & $\begin{array}{l}\text { Environmental manager } \\
\text { Environmental clerk }\end{array}$ & $\begin{array}{l}1 \\
1\end{array}$ & & & \\
\hline Shipping/receiving/Traffic & $\begin{array}{l}\text { Manager } \\
\text { Clerk }\end{array}$ & $\begin{array}{l}1 \\
1\end{array}$ & & & \\
\hline Purchasing & Buyer & 1 & & & \\
\hline Accounting & $\begin{array}{l}\text { Cost Accounting } \\
\text { Accounting Clerk } \\
\text { Payroll Clerks }\end{array}$ & $\begin{array}{l}2 \\
1 \\
2\end{array}$ & & & \\
\hline Laboratory & $\begin{array}{l}\text { Laboratory Manager } \\
\text { Lab Shift manager } \\
\text { Lab technicians for OSORT } \\
\text { Lab technicians for internal processes } \\
\text { Lab technicians for final waste form } \\
\text { Lab technicians for incoming supplies }\end{array}$ & $\begin{array}{c}1 \\
4 \\
1 \\
4 \\
1 \\
0.2\end{array}$ & $\begin{array}{c}4.1 \\
32.0 \\
4.4 \\
1.0\end{array}$ & $\begin{array}{l}30.0 \\
10.0 \\
30.0 \\
20.0\end{array}$ & $\begin{array}{l}123.2 \\
320.3 \\
132.8 \\
20.0 \\
\end{array}$ \\
\hline Health Physics & $\begin{array}{l}\text { Shift health physics staff } \\
\text { Health physics manager }\end{array}$ & $\begin{array}{l}4 \\
1\end{array}$ & & & \\
\hline & $\begin{array}{l}\text { Total except Lab } \\
\text { Total Lab } \\
\text { Total Admin }\end{array}$ & $\begin{array}{l}35 \\
12 \\
47 \\
\end{array}$ & & & \\
\hline
\end{tabular}




\begin{tabular}{|c|c|c|c|c|c|c|c|c|}
\hline Task & Subtask & $\begin{array}{c}\text { Occurrence } \\
\text { IShift }\end{array} \mid$ & Units & $\begin{array}{c}\text { Time } \\
\text { Required } \\
\text { (min) }\end{array}$ & $\begin{array}{c}\text { Total Timel } \\
\text { Shift }\end{array}$ & $\begin{array}{l}\text { FTEs } \\
\text { Needed }\end{array}$ & \begin{tabular}{|c|} 
Add"T Time \\
for Next \\
Drum
\end{tabular} & $\begin{array}{c}\text { Ave } \\
\text { Minutes/Shitt } \\
\text { Drum }\end{array}$ \\
\hline \multirow[t]{5}{*}{ Receive Waste Truck } & Truck docking & 0.6 & truck & 30 & 17 & \multirow[b]{6}{*}{0.3} & \multirow{6}{*}{ Sinin } & \multirow[b]{6}{*}{153} \\
\hline & Settle Paperwork & 0.6 & truck & 120 & 68 & & & \\
\hline & Unload truck & 0.6 & truck & 60 & 34 & & & \\
\hline & Stage pallets & 0.6 & truck & 60 & 34 & & & \\
\hline & No of pallets/shift & & & & & & & \\
\hline Total Task 1 & & & & 270 & 153 & & & \\
\hline \multirow[t]{4}{*}{$\begin{array}{l}\text { Receive Empty } \\
\text { container Truck }\end{array}$} & Truck docking & 0.3 & truck & 30 & 8 & \multirow[b]{5}{*}{0.1} & \multirow[b]{5}{*}{0} & \multirow[b]{5}{*}{40} \\
\hline & Settle Paperwork & 0.3 & truck & 30 & $\frac{0}{8}$ & & & \\
\hline & Unload truck & 0.3 & truck & 60 & 17 & & & \\
\hline & Stage pallets & 0.3 & truck & 20 & 6 & & & \\
\hline Total Task 2 & & & & 140 & 40 & & & \\
\hline \multirow[t]{4}{*}{ Receive Supplies } & Truck docking & $\overline{0.2}$ & truck & 30 & 6 & \multirow[b]{5}{*}{0.1} & \multirow[b]{5}{*}{0} & \multirow[b]{5}{*}{28} \\
\hline & Settle Paperwork & 0.2 & truck & 30 & 6 & & & \\
\hline & Unload truck & 0.2 & truck & 60 & 12 & & & \\
\hline & Stage pallets & 0.2 & truck & 20 & 4 & & & \\
\hline Total Task 3 & & & & 140 & 28 & & & \\
\hline \multirow[t]{3}{*}{$\begin{array}{l}\text { Transfer to Interim } \\
\text { Storage }\end{array}$} & $\begin{array}{l}\text { Move pallets to } \\
\text { storage area }\end{array}$ & 6.2 & Pallet & 5 & 31 & \multirow[b]{4}{*}{0.3} & \multirow[b]{4}{*}{10} & \multirow[b]{4}{*}{10} \\
\hline & $\begin{array}{l}\text { Stack pallets/ } \\
\text { organize storage }\end{array}$ & 6.2 & Pallet & 10 & 62 & & & \\
\hline & Transfer to assay & 6.2 & Pallet & 5 & 31 & & & \\
\hline Total Task 4 & & & & 20 & 124 & & & \\
\hline \multirow{9}{*}{ Assay Drums } & Stage pallets & $\overline{12.4}$ & Pallet & 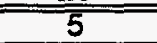 & 62 & \multirow[b]{10}{*}{14.8} & \multirow[b]{10}{*}{60} & \multirow[b]{10}{*}{150} \\
\hline & Load on conveyor & 49.8 & drum & 1 & 50 & & & \\
\hline & Assay RTR & 49.8 & drum & 15 & 746 & & & \\
\hline & Assay gamma & 49.8 & drum & 60 & 2986 & & & \\
\hline & Assay PAN & 49.8 & drum & 60 & 2986 & & & \\
\hline & Remove from & & & & & & & \\
\hline & conveyor & 49.8 & drum & 1 & 50 & & & \\
\hline & Repalletize & 49.8 & drum & 3 & 149 & & & \\
\hline & $\begin{array}{l}\text { Stage pallets after } \\
\text { assaying }\end{array}$ & 12.4 & Pallet & 5 & 62 & & & \\
\hline Total Task 5 & & & & 150 & 7091 & & & \\
\hline \multirow[t]{4}{*}{$\begin{array}{l}\text { Stage and move to } \\
\text { OSORT }\end{array}$} & $\begin{array}{l}\text { Store solid waste } \\
\text { by category }\end{array}$ & 12.4 & Pallet & 10 & 124 & \multirow[b]{4}{*}{0.4} & & \\
\hline & $\begin{array}{l}\text { Move to } 50 \% \text { to } \\
\text { OSORT }\end{array}$ & 6.2 & Pallet & 5 & 31 & & & \\
\hline & Stage at OSORT & 6.2 & Pallet & 5 & 31 & & & \\
\hline & & & Pallet & 20 & 187 & & 5 & 20 \\
\hline Open Drums & $\begin{array}{l}\text { Stage at drum } \\
\text { opener }\end{array}$ & 6.2 & Pallet & 5 & 31 & & & \\
\hline & Load on conveyor & 24.9 & Drums & 5 & 124 & & & \\
\hline & Drum lid clamp & 24.9 & drum & $\overline{2}$ & 50 & & & \\
\hline & Drum lid opener & 24.9 & drum & 5 & 124 & & & \\
\hline & Lid staging & 24.9 & drum & 1 & 25 & & & \\
\hline & $\begin{array}{l}\text { Remove from } \\
\text { conveyor }\end{array}$ & 24.9 & drum & 1 & 25 & & & \\
\hline Total Task 7 & & & & 19 & 398 & 0.8 & 5 & 19 \\
\hline Dump Drums & $\begin{array}{l}\text { Assign drums to } \\
\text { dump stations }\end{array}$ & 24.9 & drum & 3 & 75 & & & \\
\hline & $\begin{array}{l}\text { Move drums to sort } \\
\text { table /bins }\end{array}$ & 24.9 & drum & 5 & 124 & & & \\
\hline & Dump drums & 24.9 & drum & 5 & 124 & & & \\
\hline Total Task 8 & & & & 13 & 323 & 0.7 & 5 & 13 \\
\hline
\end{tabular}




\begin{tabular}{|c|c|c|c|c|c|c|c|c|}
\hline Task & Subtask & $\begin{array}{c}\text { Occurrence } \\
\text { / Shift }\end{array} \mid$ & Units & $\begin{array}{l}\text { Time } \\
\text { Required } \\
\text { (min) }\end{array}$ & $\begin{array}{c}\text { Total Time/ } \\
\text { Shift }\end{array}$ & $\begin{array}{l}\text { FTEs } \\
\text { Needed }\end{array}$ & $\begin{array}{c}\text { Add'l Time } \\
\text { for Next } \\
\text { Drum }\end{array}$ & $\begin{array}{c}\text { Ave } \\
\text { Minutes/Shift } \\
\text { Drum }\end{array}$ \\
\hline \multirow[t]{5}{*}{ Sort Drums } & $\begin{array}{l}\text { Sort waste } \\
\text { robotically }\end{array}$ & 24.9 & drum & 30 & 746 & \multirow[b]{5}{*}{2.6} & \multirow[b]{5}{*}{45} & \multirow[t]{5}{*}{-1} \\
\hline & $\begin{array}{l}\text { Transfer waste to } \\
\text { container }\end{array}$ & 24.9 & drum & 15 & 373 & & & \\
\hline & $\begin{array}{l}\text { Select destination } \\
\text { for sorted waste }\end{array}$ & 24.9 & drum & 3 & 75 & & & \\
\hline & $\begin{array}{l}\text { Move container to } \\
\text { subsystem bin or } \\
\text { shredder }\end{array}$ & 24.9 & drum & 3 & 75 & & & \\
\hline & & & & 51 & 1269 & & & \\
\hline \multirow[t]{7}{*}{ Glove Box Sort } & $\begin{array}{l}\text { Transfer to glove } \\
\text { box (several trips) }\end{array}$ & 6.0 & drum & 30 & 180 & \multirow[b]{7}{*}{4.7} & \multirow[b]{7}{*}{315} & \multirow[b]{7}{*}{5} \\
\hline & $\begin{array}{l}\text { Sort waste by hand } \\
\text { in glove box }\end{array}$ & 6.0 & drum & 240 & 1440 & & & \\
\hline & Sampling (1/drum) & 6.0 & drum & 15 & 90 & & & \\
\hline & $\begin{array}{l}\text { Transfer waste to } \\
\text { containers }\end{array}$ & 6.0 & drum & 60 & 360 & & & \\
\hline & $\begin{array}{l}\text { Select destination } \\
\text { for sorted waste }\end{array}$ & 6.0 & drum & 15 & 90 & & & \\
\hline & $\begin{array}{l}\text { Move containers to } \\
\text { subsystem bin or } \\
\text { shredder }\end{array}$ & 6.0 & drum & 15 & 90 & & & \\
\hline & & & & 375 & 2250 & & & \\
\hline \multirow[t]{5}{*}{ Gross Size Reduction } & $\begin{array}{l}\text { Transfer to cutting } \\
\text { table }\end{array}$ & 0.2 & drum & 3 & 1 & \multirow[b]{5}{*}{0.0} & \multirow[b]{5}{*}{35} & \multirow[b]{5}{*}{6} \\
\hline & Cut waste & 0.2 & drum & 30 & 7 & & & \\
\hline & Return to container & 0.2 & drum & 5 & 1 & & & \\
\hline & $\begin{array}{l}\text { Transfer to next } \\
\text { process }\end{array}$ & 0.2 & drum & 3 & 1 & & & \\
\hline & & & & 41 & 10 & & & \\
\hline \multirow[t]{11}{*}{ Shredding } & $\begin{array}{l}\text { Transfer drums to } \\
\text { shredder }\end{array}$ & 3.1 & drum & 2 & 6 & \multirow[b]{11}{*}{0.3} & \multirow[b]{11}{*}{2} & \multirow[b]{11}{*}{30} \\
\hline & Stage drums & 3.1 & drum & 2 & 6 & & & \\
\hline & $\begin{array}{l}\text { Feed waste to } \\
\text { shredder }\end{array}$ & 3.1 & drum & 2 & 6.22 & & & \\
\hline & $\begin{array}{l}\text { Feed bad drums to } \\
\text { shredder }\end{array}$ & 12.4 & drum & 2 & & & & \\
\hline & Shred stage 1 & 12.4 & drum & 2 & 25 & & & \\
\hline & Shred stage 2 & 12.4 & drum & 2 & 25 & & & \\
\hline & $\begin{array}{l}\text { Sample size of } \\
\text { waste }\end{array}$ & 1.2 & drum & 5 & 6 & & & \\
\hline & Rework $10 \%$ & 0.1 & drum & 15 & 2 & & & \\
\hline & Return to container & 12.4 & drum & 3 & 37 & & & \\
\hline & $\begin{array}{l}\text { Transfer to next } \\
\text { process }\end{array}$ & 12.4 & drum & 2 & 25 & & & \\
\hline & & & & 37 & 139 & & & \\
\hline \multirow[t]{6}{*}{ Sampling } & & & & & $\overline{0}$ & \multirow[b]{6}{*}{0.2} & \multirow[b]{6}{*}{10} & \multirow[b]{6}{*}{30} \\
\hline & $\begin{array}{l}\text { Sample opened } \\
\text { drums }\end{array}$ & 2.5 & drum & 5 & 12 & & & \\
\hline & $\begin{array}{l}\text { Sample sorted } \\
\text { waste }\end{array}$ & 1.2 & drum & 5 & 6 & & & \\
\hline & Resample (10\%) & 0.4 & drum & 5 & 2 & & & \\
\hline & Report/eval. results & 4.1 & drum & 10 & 41 & & & \\
\hline & & & & 25 & 62 & & & \\
\hline
\end{tabular}




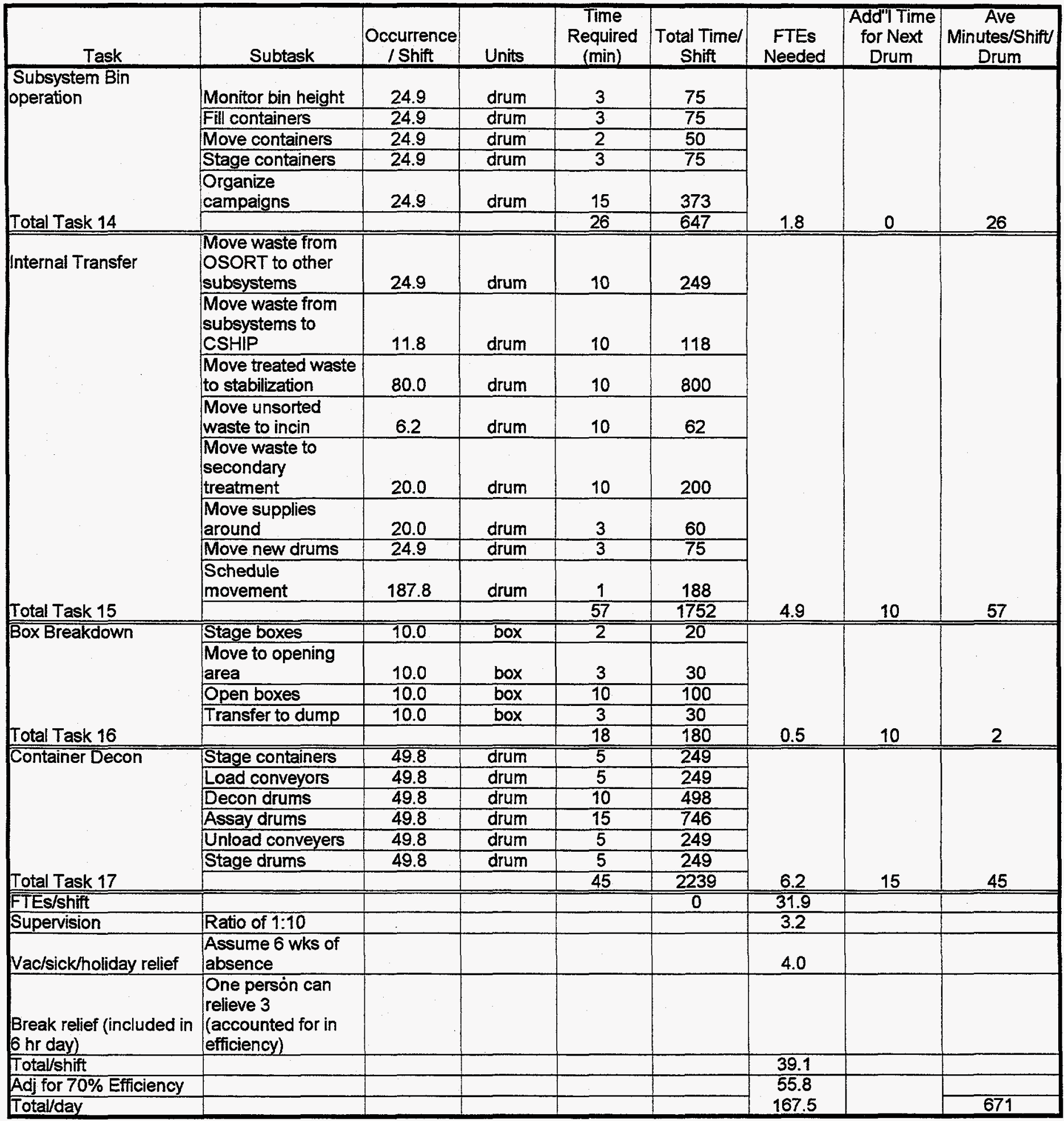

Notes:

Assume FTEs are available for $8 \mathrm{hrs} /$ day; because overall $70 \%$ efficiency is taken at the end.

Trucks have 22 pallets. Waste density is $64 \mathrm{lb} / \mathrm{cu} \mathrm{ft}$.

Pallets are assumed to hold 455 gallon drums

As in inventory, assume $50 \%$ of drums are contaminated and can't be deconned.

Assume $50 \%$ of waste received requires interim storage; this will be dependent on assay system

Assume $10 \%$ of incoming waste is sampled

Assume opened and sorted waste is $50 \%$ of total 


\begin{tabular}{|c|c|c|c|c|c|c|c|}
\hline Task & Subtask & $\begin{array}{c}\text { Occurrence } \\
\text { / Shift }\end{array}$ & Units & $\begin{array}{c}\text { Time } \\
\text { Required } \\
\text { (min) }\end{array}$ & $\begin{array}{c}\text { Total Time/ } \\
\text { Shift }\end{array}$ & $\begin{array}{c}\text { FTEs } \\
\text { Needed }\end{array}$ & $\begin{array}{c}\text { Add"/Time } \\
\text { for Next } \\
\text { Drum }\end{array}$ \\
$\begin{array}{c}\text { Minutes/Shift/ } \\
\text { Drum }\end{array}$ \\
\hline
\end{tabular}

Notes (cont.):

Assume $10 \%$ of sorted waste is sampled

Assume gross size reduction is necessary for wastes to metal decon \& lead

Assume gross size reduction is $1 \mathrm{hr}$ per drum.

Assume shredding is necessary for drums only

Assume $10 \%$ of shredded waste is sampled.

Box breakdown includes time beyond that required if waste was packaged in drums

Assume glove box sorting required for special, mercury and lead

Assume glove box waste requires 1 sample/drum

Assume transfer control for liquids takes the same time as for solids

Assume paperwork is accomplished within times shown

Average time per drum includes times for activities multiplied by the probability that the activity will occur.

Least time/drum/subsystem includes only the minimum requirements, no extra staging, sorting, or shredding

Max time/drum/subsystem includes all staging, shredding, glove box, etc 


\begin{tabular}{|c|c|c|c|c|c|c|c|c|}
\hline Task & Subtask & $\begin{array}{c}\text { Occurrencel } \\
\text { Shift }\end{array}$ & Units & $\begin{array}{l}\text { Time } \\
\text { Required } \\
\text { (min) }\end{array}$ & $\begin{array}{c}\text { Total Timel } \\
\text { Shift }\end{array}$ & $\begin{array}{l}\text { FTEs } \\
\text { Needed }\end{array}$ & $\begin{array}{l}\text { Minutes/ } \\
\text { Drum }\end{array}$ & $\begin{array}{l}\text { Minutes/ } \\
\text { Add'l drum }\end{array}$ \\
\hline \multirow[t]{3}{*}{ Receive Waste } & Transfer through air lock & 9.1 & pallet & 5 & 46 & \multirow[b]{3}{*}{0.38} & \multirow[b]{3}{*}{20} & \multirow[b]{3}{*}{15} \\
\hline & Stage drums for campaigns & 9.1 & pallet & 15 & 137 & & & \\
\hline & & & & 20 & 183 & & & \\
\hline \multirow[t]{8}{*}{ Shredding } & $\begin{array}{l}\text { Transfer waste/drums to } \\
\text { shredder }\end{array}$ & 36.6 & drum & 2 & 73 & \multirow[b]{9}{*}{1.04} & \multirow[b]{9}{*}{29} & \multirow[b]{9}{*}{15} \\
\hline & Stage drums and waste & 36.6 & drum & 2 & 73 & & & \\
\hline & Shred stage 1 & 36.6 & drum & 2 & 73 & & & \\
\hline & Shred stage 2 & 36.6 & drum & 2 & 73 & & & \\
\hline & Sample size of waste & 3.7 & drum & 5 & 18 & & & \\
\hline & Rework $10 \%$ & 0.4 & drum & 11 & 4 & & & \\
\hline & Return to container & 36.6 & drum & 3 & 110 & & & \\
\hline & Transfer to next process & 36.6 & drum & 2 & 73 & & & \\
\hline Total Task & & & & 29 & 498 & & & \\
\hline \multirow[t]{4}{*}{ Sampling } & $\begin{array}{l}\text { Sample shredded waste to } \\
\text { characterize }\end{array}$ & 3.7 & drum & 5 & 18 & \multirow[b]{4}{*}{0.17} & \multirow[b]{4}{*}{20} & \multirow[b]{4}{*}{10} \\
\hline & Resample (10\%) & 0.4 & drum & 5 & 2 & & & \\
\hline & Report/eval. results & 4.0 & drum & 10 & 40 & & & \\
\hline & & & & 20 & 60 & & & \\
\hline \multirow[t]{7}{*}{ Feeding } & Select waste for feeding & 36.6 & drums & 5 & 183 & \multirow[b]{7}{*}{1.10} & \multirow[b]{7}{*}{80} & \multirow[b]{7}{*}{9} \\
\hline & Stage waste for feeding & 36.6 & drums & 5 & 183 & & & \\
\hline & $\begin{array}{l}\text { Feed plasma reactor }(50 \mathrm{ft} 3 / \mathrm{hr} \\
\text { or } 6.8 \text { drums } / \mathrm{hr}) \\
\end{array}$ & $\begin{array}{l}36.6 \\
36.6\end{array}$ & drums & $\frac{0}{60}$ & $\frac{4}{2194}$ & & & \\
\hline & Incinerate waste (1 hr) & 36.6 & & 60 & 2194 & & & \\
\hline & Discharge waste ( $50 \mathrm{ft} 3 / \mathrm{hr})$ & 6.8 & & 0 & 1 & & & \\
\hline & Sample waste in and out & 16.0 & times & 10 & 160 & & & \\
\hline & & & & 80 & 530 & & & \\
\hline \multirow[t]{6}{*}{ Plasma treatment } & Monitor feeding & & & & & \multirow[b]{7}{*}{0.75} & \multirow[b]{7}{*}{25} & \\
\hline & Monitor gas/air ratio & 24.0 & times & 5 & 120 & & & \\
\hline & Monitor burner & 24.0 & times & 5 & 120 & & & \\
\hline & Monitor feeding & 24.0 & times & 5 & 120 & & & \\
\hline & Monitor secondary combustion & 24.0 & times & 5 & 120 & & & \\
\hline & Monitor discharge & 24.0 & times & 5 & 120 & & & \\
\hline Total Task & & & & 25 & 360 & & & 9 \\
\hline Cooling & $\begin{array}{l}\text { Glass/slag discharge into } \\
\text { containers (dens= } 156 \mathrm{lb} / \mathrm{ft} 3 \text { ) }\end{array}$ & 8.4 & drums & 0 & 0 & & & \\
\hline & Glass cooling & 8.4 & drums & N/A & 0 & & & \\
\hline & Staging waste into cooling & 8.4 & drums & 5 & 42 & & & \\
\hline & Staging waste out of cooling & 8.4 & drums & 5 & 42 & & & \\
\hline & Collect samples & 0.8 & drums & 15 & 13 & & & \\
\hline Total Task & & & & 25 & 97 & 0.20 & 15 & 0 \\
\hline Drum Decon & Stage containers & 8.4 & drum & 5 & 42 & & & \\
\hline & Load conveyors & 8.4 & drum & 5 & 42 & & & \\
\hline & Decon drums & 8.4 & drum & 10 & 84 & & & \\
\hline & Assay drums & 8.4 & drum & 15 & 127 & & & \\
\hline & Unioad conveyers & 8.4 & drum & 5 & 42 & & & \\
\hline & Stage drums & 8.4 & drum & 5 & 42 & & & \\
\hline Total Task & & & & 45 & 380 & 0.79 & 45 & \\
\hline FTEs/shift & & & & & & 4.43 & 234 & 15 \\
\hline Supervision & Ratio of 1:10 & & & & & 0.44 & & \\
\hline Vac/sick/holiday relief & Assume 6 wks of absence & & & & & 0.56 & & \\
\hline Total/shift & & & & & & 5.44 & 234 & 15 \\
\hline $\begin{array}{l}\text { Adjustment for } 70 \% \\
\text { Efficiency }\end{array}$ & & & & & & 7.77 & & \\
\hline Total/day & & & & & & 23.31 & & \\
\hline
\end{tabular}

Notes:

Feed to incinerator requires shredding; whole drums can be shredded.

Assume $15 \mathrm{~min} /$ drum per stage of shredding

Assume 1 hour reactor residence time

Assume rate of feeding and discharge @ $50 \mathrm{cu} \mathrm{ft/hr}$

Treated waste mass amount from LITCO mass balance of 4/23/96

Assume cooling time is long; staging of waste in and out is only time considered

No. of process samples $=20.0$ 


\begin{tabular}{|c|c|c|c|c|c|c|c|c|}
\hline Task & Subtask & $\begin{array}{c}\text { Occurrencel } \\
\text { Shift }\end{array}$ & Units & $\begin{array}{l}\text { Time } \\
\text { Required } \\
\text { (min) }\end{array}$ & $\begin{array}{c}\text { Total Time/ } \\
\text { Shift }\end{array}$ & $\begin{array}{l}\text { FTEs } \\
\text { Needed }\end{array}$ & $\begin{array}{l}\text { Minutes' } \\
\text { Drum }\end{array}$ & $\begin{array}{l}\text { Minutes/ } \\
\text { Add'l drum }\end{array}$ \\
\hline \multirow[t]{9}{*}{ Receive Waste } & Transfer through air lock & 1.4 & drum & 5 & 7 & & & \\
\hline & Feed waste from drum & 1.4 & drum & 3 & 4 & & & \\
\hline & Hook to transfer device & 1.4 & drum & 3 & 4 & & & \\
\hline & Transfer to tank (10 gpm) & 1.4 & drum & 6 & 8 & & & \\
\hline & Empty drum bottoms & 1.4 & & 2 & 3 & & & \\
\hline & Sample feed vessel & 2.0 & & 10 & 20 & & & \\
\hline & Detach \& remove drum & 1.4 & & 3 & 4 & & & \\
\hline & $\begin{array}{l}\text { Sample waste from processes: } \\
\text { incin, aqueous, Decon,APC }\end{array}$ & 4.0 & N/A & & & & & \\
\hline & Arrange for transfer & 6304.5 & gal & 0 & 38 & & & \\
\hline Total Task & & & & 32 & 88 & 0.18 & 32 & 5 \\
\hline \multirow[t]{11}{*}{ Preliminary Treatment } & Sample high ToS tank & 0.0 & drums & 15 & $\overline{0}$ & & & \\
\hline & Sample low TDS tank & 4.6 & drums & 15 & 7 & & & \\
\hline & Sample TOC waste & 1.4 & drums & 15 & 2 & & & \\
\hline & $\begin{array}{l}\text { Select treatment methods (10 } \\
\text { drum batch) }\end{array}$ & 1.4 & drums & 20 & 3 & & & \\
\hline & $\begin{array}{l}\text { Transfer organic waste to oil } \\
\text { water separator }\end{array}$ & 1.4 & drums & 3 & 5 & & & \\
\hline & $\begin{array}{l}\text { Filter high, low TDS and organic } \\
\text { waste (say } 50 \mathrm{gal} / \mathrm{min} \text { ) }\end{array}$ & 6.0 & drums & 1 & 7 & & & \\
\hline & Neutralize/ppt high TDS waste & 0.0 & drums & 11 & $\overline{0}$ & & & \\
\hline & $\begin{array}{l}\text { Settle precipitated aqueous } \\
\text { waste }\end{array}$ & 0.0 & drums & 6 & 0 & & & \\
\hline & Evaporate solids (50 gpm) & 6.0 & drums & 1 & 7 & & & \\
\hline & Monitor filter & 24.0 & times & 5 & 120 & & & \\
\hline & Monitor evaporator & 24.0 & times & 5 & 120 & & & \\
\hline Total Task & & & & 86 & 256 & 0.53 & 86 & 20 \\
\hline \multirow[t]{6}{*}{ UV Oxidation } & $\begin{array}{l}\text { Adjust UV oxidation ( } 30 \mathrm{~min} / 10 \\
\text { drums) }\end{array}$ & 1.4 & drums & 3 & 4 & & & \\
\hline & $\begin{array}{l}\text { Process through UV oxidation } \\
(50 \mathrm{gpm})\end{array}$ & 1.4 & drums & 1 & 2 & & & \\
\hline & Carbon filtration $(50 \mathrm{gpm})$ & 6.0 & drums & 1 & 7 & & & \\
\hline & Ion exchange $(50 \mathrm{gpm})$ & 6.0 & drums & 1 & 7 & & & \\
\hline & Monitor carbon \& ion exchange & 12.0 & times & 5 & 60 & & & \\
\hline & Sample waste before discharge & 2.0 & times & 30 & 60 & & & 1 \\
\hline Total Task 3 & & & & 6 & 139 & 0.29 & 6 & \\
\hline Total per shift & & & & & 0 & 1.01 & 124 & 26 \\
\hline Supervision & Ratio of 1:10 & & & & & 0.10 & & \\
\hline Vac/sick/holiday relief & Assume 6 wks of absence & & & & & 0.13 & & \\
\hline Efficiency & & & & & & 1.77 & & \\
\hline Total per day & & & & & & 5.30 & & \\
\hline
\end{tabular}

Notes:

Assume waste from APC and other secondary waste is low TDS

$6565.00 \quad \mathrm{lbs} / \mathrm{hr} \quad 115 \mathrm{drums} / \mathrm{sh}$ ift

Assume waste from RCPRP is organic liq

$80.00 \quad \mathrm{lbs} / \mathrm{hr} \quad 1 \quad$ drums/shift

Total drums per hour= 116.6

Assume sampling of low TDS waste is one/25 drums

Assume transfer of waste requires $15 \mathrm{~min} / 2500$ gallons

Assume tank batches are 550 gallons (10 drums)

Assume treatment selection time is required for waste from RCPRP only;scrubber liquor has the same treatement.

Assume residence time in oil water separator is 1 hour and tank is 1000 gallons (16 gpm)

Assume filtration, centrifuge and ppt rates are $10 \mathrm{gpm}$.

Assume evaporation rate is $50 \mathrm{gpm}$

Assume UV oxidation unit is $50 \mathrm{gpm}$

Number of process sampl 12.0 


\begin{tabular}{|c|c|c|c|c|c|c|c|c|}
\hline Task & Subtask & $\begin{array}{c}\text { Occurrence/ } \\
\text { Shift }\end{array}$ & Units & $\begin{array}{l}\text { Time } \\
\text { Required } \\
\text { (min) }\end{array}$ & $\begin{array}{c}\text { Total Time/ } \\
\text { Shift }\end{array}$ & $\begin{array}{l}\text { FTEs } \\
\text { Needed }\end{array}$ & $\begin{array}{l}\text { Minutes } \\
\text { / Drum }\end{array}$ & $\begin{array}{c}\text { Minutes } \\
\text { Add'l Drum }\end{array}$ \\
\hline \multirow{2}{*}{$\begin{array}{l}\text { Metals Receiving/ Feed } \\
\text { Prep } \\
\text { Total Task }\end{array}$} & Transfer through air lock & 16.0 & drums & 5 & 80 & & & \\
\hline & & & & 5 & 80 & 0.17 & 5 & 0 \\
\hline \multirow[t]{8}{*}{ Waste Decon } & Stage containers & 16.0 & drum & 5 & 80 & & & \\
\hline & Decon waste & 16.0 & drum & 10 & 160 & & & \\
\hline & Assay for recycle & 16.0 & drum & 30 & 480 & & & \\
\hline & Repack in drums & 16.0 & drum & 15 & 240 & & & \\
\hline & Close drum lid & 16.0 & drum & 15 & 240 & & & \\
\hline & Stage drums & 16.0 & drum & 5 & 80 & & & \\
\hline & $\begin{array}{l}\text { Monitor recirc filtration and } \\
\text { fugitive dust system }\end{array}$ & 24.0 & times & 6 & 144 & & & \\
\hline & & & & 86 & 1424 & 2.97 & 86 & \\
\hline Total FTEs/shift & & & & & & 3.13 & $\overline{91}$ & \\
\hline Supervision & Ratio of $1: 10$ & & & & & 0.31 & & \\
\hline Vac/sick/holiday relief & Assume 6 wks of absence & & & & & 0.40 & & \\
\hline Total/shift & & & & & & 3.84 & & \\
\hline $\begin{array}{l}\text { Adjustment for } 70 \% \\
\text { Efficiency }\end{array}$ & & & & & & 5.49 & & \\
\hline Total/day & & & & & & 16.48 & & \\
\hline
\end{tabular}

Notes:

Assume $50 \%$ of waste must be size reduced.

Assume $60 \mathrm{~min} / \mathrm{drum}$ for cutting 


\begin{tabular}{|c|c|c|c|c|c|c|c|c|}
\hline Task & Subtask & $\begin{array}{c}\text { Occurrence } \\
\text { / Shift }\end{array}$ & Units & $\begin{array}{c}\text { Time } \\
\text { Required } \\
\text { (min) }\end{array}$ & $\begin{array}{c}\text { Total Time/ } \\
\text { Shift }\end{array}$ & $\begin{array}{c}\text { FTEs } \\
\text { Needed }\end{array}$ & $\begin{array}{c}\text { Minutes/ } \\
\text { Drum } \\
\end{array}$ & $\begin{array}{c}\text { Minutes/ } \\
\text { Add'l Drum }\end{array}$ \\
\hline \multirow[t]{4}{*}{$\begin{array}{l}\text { Lead Receiving/Feed } \\
\text { Prep }\end{array}$} & Transfer through air lock & 0.2 & drums & 5 & 1 & & & \\
\hline & $\begin{array}{l}\text { Glove box separation of } \\
\text { sheet lead and gloves }\end{array}$ & 0.2 & drums & 60 & 14 & & & \\
\hline & Stage at decon $(80 \%)$ & 0.2 & drums & 10 & 2 & & & \\
\hline & Stage at melter $(20 \%)$ & 0.0 & drums & 10 & 0 & & & \\
\hline Total Task & & & & 85 & 18 & 0.04 & 85 & \\
\hline \multirow{8}{*}{ Waste Decon } & Stage containers & $\overline{0.2}$ & drum & 5 & 1 & & & \\
\hline & Decon waste & 0.2 & drum & 10 & 2 & & & \\
\hline & Assay for recycle & 0.2 & drum & 30 & 6 & & & \\
\hline & Repack in drums & 0.2 & drum & 15 & $\overline{3}$ & & & \\
\hline & Close drum lid & 0.2 & drum & 15 & 3 & & & \\
\hline & Stage drums & 0.2 & drum & 5 & 1 & & & \\
\hline & $\begin{array}{l}\text { Monitor recirc filtration } \\
\text { and fugitive dust system }\end{array}$ & 24.0 & times & 6 & 144 & & & \\
\hline & & & & 86 & 159 & 0.33 & 86 & 30 \\
\hline \multirow[t]{7}{*}{ Lead Melting } & Setup/check equipment & 0.05 & $\begin{array}{l}\text { time/ } \\
\text { batch }\end{array}$ & 30 & 1 & & & \\
\hline & Stage waste for feeding & 0.05 & batch & 20 & 1 & & & \\
\hline & Fdjust flux to melter & 0.05 & batch & 20 & 1 & & & \\
\hline & $\begin{array}{l}\text { Feed melter (10 } \\
\text { min/drum) }\end{array}$ & 0.05 & batch & 100 & 5 & & & \\
\hline & Melt waste & 0.05 & batch & 180 & 9 & & & \\
\hline & batch & 0.05 & batch & 350 & 17 & & & t. \\
\hline & & & & 670 & 15 & 0.03 & 320 & 180 \\
\hline \multirow[t]{7}{*}{ Metal Cooling. } & $\begin{array}{l}\text { Metal discharge into } \\
\text { containers }\end{array}$ & 0.05 & drums & 15 & 1 & & & \\
\hline & Metal cooling (90\%) & 0.04 & drums & N/A & 0 & & & \\
\hline & $\begin{array}{l}\text { Staging waste into } \\
\text { cooling }\end{array}$ & 0.05 & drums & 15 & 1 & & & \\
\hline & Slag cooling $(10 \%)$ & 0.00 & drums & N/A & 0 & & & \\
\hline & $\begin{array}{l}\text { Staging waste out of } \\
\text { cooling }\end{array}$ & 0.05 & drums & 15 & 1 & & & \\
\hline & Collect samples & 0.05 & drums & 15 & 1 & & & \\
\hline & & & & 60 & 3 & 0.01 & 60 & 0 \\
\hline Total FTEs/shift & & & & & & 0.41 & 551 & \\
\hline Supervision & Ratio of $1: 10$ & & & & & 0.04 & & \\
\hline Vac/sick/holiday relief & $\begin{array}{l}\text { Assume } 6 \text { wks of } \\
\text { absence }\end{array}$ & & & & & 0.05 & & \\
\hline Total/shift & & & & & & 0.50 & & \\
\hline $\begin{array}{l}\text { Adjustment for } 70 \% \\
\text { Efficiency }\end{array}$ & & & & & & 0.71 & & \\
\hline Total/day & & & & & & 2.14 & & \\
\hline
\end{tabular}

Notes:

Assume assay for all drums @ $30 \mathrm{~min} / \mathrm{drum}$

$20 \%$ of input is melted and $80 \%$ is deconned (ITTS ph2 assumption, fig A1-4)

Assume melter batch time is 3 hours

Assume 10 drum ( $9170 \mathrm{lb}$ or $550 \mathrm{gal}$ ) batches 
Table C1-h.

Mercury Amaigamation

\begin{tabular}{|c|c|c|c|c|c|c|c|c|}
\hline Task & Subtask & $\begin{array}{c}\text { Occurrence } \\
\text { / Shift }\end{array}$ & Units & $\begin{array}{c}\text { Time } \\
\text { Required } \\
\text { (min) }\end{array}$ & $\begin{array}{c}\text { Total } \\
\text { Time/ Shift }\end{array}$ & $\begin{array}{l}\text { FTEs } \\
\text { Needed }\end{array}$ & $\begin{array}{l}\text { Minutes/ } \\
\text { Drum }\end{array}$ & $\begin{array}{l}\text { Minutes/ } \\
\text { Add'l Drum }\end{array}$ \\
\hline \multirow[t]{4}{*}{$\begin{array}{l}\text { Mecury Receiving/ } \\
\text { Feed Prep }\end{array}$} & Transfer through air lock & 0.4 & drums & -1 & 2 & & & \\
\hline & $\begin{array}{l}\text { Transfer liq mercury to tank } \\
(5 \% \text { of } \mathrm{Hg} \text { waste })\end{array}$ & 0.0 & drums & 60 & 1 & & & \\
\hline & $\begin{array}{l}\text { Transfer Hg contaminated } \\
\text { waste to feed bin }\end{array}$ & 0.4 & drums & 15 & & & & \\
\hline & & & & 65 & 3 & 0.01 & 65 & 15 \\
\hline \multirow[t]{9}{*}{ Shredding } & $\begin{array}{l}\text { Transfer waste/drums to } \\
\text { shredder }\end{array}$ & 0.4 & drum & 2 & 1 & & & \\
\hline & Stage drums and waste & 0.4 & drum & 2 & 1 & & & \\
\hline & Shred stage 1 & 0.4 & drum & 2 & 1 & & & \\
\hline & Shred stage 2 & 0.4 & drum & 2 & 1 & & & \\
\hline & Sample size of waste & 0.4 & drum & 5 & 2 & & & \\
\hline & Rework $10 \%$ & 0.0 & drum & 11 & 0 & & & \\
\hline & Return to container & 0.4 & drum & 3 & 1 & & & \\
\hline & Transfer to retort staging & 0.4 & drum & 5 & 2 & & & \\
\hline & & & & 32 & 8 & 0.02 & 32 & 11 \\
\hline \multirow[t]{9}{*}{ Mercury Retorting } & Setup/check equipment & 0.4 & time/ batch & 30 & 11 & & & \\
\hline & $\begin{array}{l}\text { Stage shredded waste for } \\
\text { feeding (batch = } 1 \text { drum) }\end{array}$ & 0.4 & drum & 20 & 8 & & & \\
\hline & Feed retort ( $20 \mathrm{~min} / \mathrm{drum})$ & 0.4 & drum & 20 & 8 & & & \\
\hline & Heat waste & 0.4 & drum & 60 & 23 & & & \\
\hline & Condense mercury & 0.0 & drum & 10 & 0 & & & \\
\hline & Separate offgas and $\mathrm{Hg}$ & 0.0 & drum & 10 & 0 & & & \\
\hline & Discharge waste & 0.4 & drum & 60 & 22 & & & \\
\hline & Monitor APC during batch & 0.4 & drum & 160 & 61 & & & \\
\hline & & & & 210 & 132 & 0.28 & 210 & 60 \\
\hline \multirow[t]{11}{*}{ Mercury Amalgamation } & Inspect equipment & $\overline{0.0}$ & drum & 30 & 1 & & & \\
\hline & $\begin{array}{l}\text { Transfer liq mercury to } \\
\text { amaigamater (1 gpm) }\end{array}$ & 0.0 & drum & 55 & 2 & & & \\
\hline & Measure additives & 0.0 & drum & 30 & 1 & & & \\
\hline & Batch amalgamation & 0.0 & drum & 120 & 5 & & & 120 \\
\hline & Transfer out of amalgamater & 0.0 & drum & 55 & 2 & & & \\
\hline & Sample waste & 0.0 & drum & 15 & 1 & & & \\
\hline & Stage & 0.0 & drum & 5 & 0 & & & \\
\hline & Place at assay & 0.0 & drum & 5 & 0 & & & \\
\hline & Assay & 0.0 & drum & 20 & 1 & & & \\
\hline & Remove from assay & 0.0 & drum & 2 & 0 & & & \\
\hline & & & & 307 & 12 & 0.02 & 307 & 120 \\
\hline Total FTEs/shift & & & & & & $0 . \overline{32}$ & 614 & \\
\hline Supervision & Ratio of $1: 10$ & & & & & 0.03 & & \\
\hline Vac/sick/holiday rellef & Assume 6 wks of absence & & & & & 0.04 & & \\
\hline Total/shift & & & & & & 0.40 & & \\
\hline $\begin{array}{l}\text { Adjustment for } 70 \% \\
\text { Efficiency }\end{array}$ & & & & & & 0.57 & & \\
\hline Total/day & & & & & & 1.71 & & \\
\hline
\end{tabular}

Notes:

Assume $5 \%$ of mercury waste is elemental, rest is debris

Assume $5 \%$ of debris is mercury.

Assume all debris requires 2 stage shredding

Assume retort is 1 drum batch.

Batch size for amalgamater. Assume 1 drum/batch, 2 hrs /batch 
Table C1-i.

Special Waste

\begin{tabular}{|c|c|c|c|c|c|c|c|c|}
\hline Task & Subtask & $\begin{array}{c}\text { Occurrence } \\
\text { / Shift }\end{array}$ & Units & $\begin{array}{c}\text { Time } \\
\text { Required } \\
\text { (min) }\end{array}$ & $\begin{array}{l}\text { Total } \\
\text { Timel } \\
\text { Shift } \\
\end{array}$ & $\begin{array}{c}\text { FTEs } \\
\text { Needed } \\
\end{array}$ & $\begin{array}{c}\text { Minutes/ } \\
\text { Drum }\end{array}$ & $\begin{array}{l}\text { Minutes/ } \\
\text { Add'I Drum }\end{array}$ \\
\hline $\begin{array}{l}\text { Special } \\
\text { Receiving/Feed Prep }\end{array}$ & Transfer through air lock & 5.4 & drums & 5 & 27 & & & \\
\hline 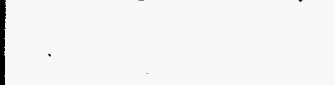 & $\begin{array}{l}\text { Glove box preparation of } \\
\text { wastes }\end{array}$ & 5.4 & drums & 60 & 322 & & & \\
\hline & Stage waste & 5.4 & drums & 3 & 16 & & & \\
\hline Total Task & & & & 68 & 364 & 0.76 & 68 & 60 \\
\hline Waste Treatment & Stage containers & $\overline{5.4}$ & drum & $\overline{3}$ & $\overline{16}$ & & & \\
\hline & $\begin{array}{l}\text { Treat waste as special } \\
\text { processes TBD }\end{array}$ & 5.4 & drum & 60 & 322 & & & \\
\hline & Sample treated waste & 5.4 & drum & 15 & 80 & & & \\
\hline & Repack in drums & 5.4 & drum & 30 & 161 & & & \\
\hline & Close drum lid & 5.4 & drum & 3 & 16 & & & \\
\hline & Stage drums & 5.4 & drum & 3 & 16 & & & \\
\hline Total Task & & & & 114 & 611 & 1.27 & 114 & 60 \\
\hline Total FTEs/shift & & & & & & 2.03 & 182 & \\
\hline Supervision & Ratio of $1: 10$ & & & & & 0.20 & & \\
\hline Vac/sick/holiday relief & $\begin{array}{l}\text { Assume } 6 \text { wks of } \\
\text { absence }\end{array}$ & & & & & 0.26 & & \\
\hline Total/shift & & & & & & 2.49 & & \\
\hline $\begin{array}{l}\text { Adjustment for } 70 \% \\
\text { Efficiency }\end{array}$ & & & & & & 3.56 & & \\
\hline Total/day & & & & & & 10.69 & & \\
\hline
\end{tabular}

Notes:

Assume all waste is prepared in glove box

Assume waste is treated in various batch processes that average 2 hours/drum

$\mathrm{TBD}=\mathrm{To}$ be dètermined 
Table C1j.

Polymer Stabilization Subsystem

\begin{tabular}{|c|c|c|c|c|c|c|c|c|}
\hline Task & Subtask & $\begin{array}{c}\text { Occurrence } \\
\text { IShift }\end{array}$ & Units & $\begin{array}{c}\text { Time } \\
\text { Required } \\
\text { (min) }\end{array}$ & $\begin{array}{c}\text { Total Timel } \\
\text { Shift }\end{array}$ & $\begin{array}{l}\text { FTEs } \\
\text { Needed }\end{array}$ & $\begin{array}{c}\text { Minutes/ } \\
\text { Drum }\end{array}$ & $\begin{array}{c}\text { Minutes/ } \\
\text { Add"I Drum }\end{array}$ \\
\hline \multirow[t]{6}{*}{$\begin{array}{l}\text { Waste Receiving/Feed } \\
\text { Prep }\end{array}$} & Transfer through air lock & 2.8 & drums & 5 & 14 & & & \\
\hline & Sample waste & 0.3 & drums & 15 & 4 & & & \\
\hline & Evaluate dryness & 0.3 & drums & 5 & 1 & & & \\
\hline & Dry waste & 2.8 & drums & 30 & N/A & & & \\
\hline & Monitor drying & 24.0 & times & 10 & 240 & & & \\
\hline & Stage at process & 2.8 & drums & 2 & 6 & & & \\
\hline \multirow{9}{*}{$\begin{array}{l}\text { Total Task } \\
\text { Encapsulation }\end{array}$} & & & & 57 & 265 & 0.55 & 57 & 30 \\
\hline & Measure polymer & 2.8 & drum & 5 & 14 & & & \\
\hline & Mix polymer & 2.8 & drum & 10 & 28 & & & \\
\hline & $\begin{array}{l}\text { Combine with waste in } \\
\text { extruder }\end{array}$ & 2.8 & drum & 10 & 28 & & & \\
\hline & Repack in drums & 24.0 & drum & 5 & 120 & & & \\
\hline & Close drum lid & 2.8 & drum & 3 & 8 & & & \\
\hline & Palletize drums & 2.8 & drum & 2 & 6 & & & \\
\hline & Stage drums & 24.0 & drum & 2 & 48 & & & \\
\hline & $\begin{array}{l}\text { Monitor activated carbon } \\
\text { and fugitive dust system }\end{array}$ & 8.0 & times & 6 & 48 & & & \\
\hline Total Task & & & & 43 & 300 & 0.63 & 43 & 60 \\
\hline \multirow[t]{6}{*}{ Binder setup time } & Move pallets to curing area & 24.0 & drum & 5 & 120 & & & \\
\hline & Curing time & 24.0 & drum & & 0 & & & \\
\hline & Sample every 10 drums & 2.4 & drum & 15 & 36 & & & \\
\hline & Monitor curing & 24.0 & drum & 10 & 240 & & & \\
\hline & $\begin{array}{l}\text { Move pallets from curing } \\
\text { area }\end{array}$ & 24.0 & times & 5 & 120 & & & \\
\hline & & & & 35 & 516 & 1.08 & 35 & 5 \\
\hline \multirow[t]{6}{*}{ Drum Decon } & Stage containers & 2.8 & drum & 5 & 14 & & & \\
\hline & Load conveyors & 2.8 & drum & 5 & 14 & & & \\
\hline & Decon drums & 2.8 & drum & 10 & 28 & & & \\
\hline & Assay drums & 2.8 & drum & 15 & 42 & & & \\
\hline & Unload conveyers & 2.8 & drum & 5 & 14 & & & \\
\hline & Stage drums & 2.8 & drum & 5 & 14 & & & \\
\hline Total Task & & & & 45 & 126 & 0.26 & 45 & 60 \\
\hline Total FTEs/shift & & & & & & 2.52 & 180 & \\
\hline Supervision & Ratio of $1: 10$ & & & & & 0.25 & & \\
\hline Vac/sick/holiday relief & Assume 6 wks of absence & & & & & 0.32 & & \\
\hline Total/shift & & & & & & 3.09 & & \\
\hline $\begin{array}{l}\text { Adjustment for } 70 \% \\
\text { Efficiency }\end{array}$ & & & & & & 4.41 & & \\
\hline Totalday & & & & & & 13.22 & & \\
\hline
\end{tabular}

Notes:

Assume $30 \%$ of process residue waste and $100 \%$ of other waste requires drying

Assume dryer can accept waste at the rate of 2 drums/hour

No. of samples $=2.4$ 
Table C1-k.

Air Pollution Control Subsystem

\begin{tabular}{|c|c|c|c|c|c|c|c|}
\hline Task & Subtask & $\begin{array}{c}\text { Occurrence/ } \\
\text { Shift }\end{array}$ & Units & $\begin{array}{c}\text { Time } \\
\text { Required } \\
\text { (min) }\end{array}$ & $\begin{array}{l}\text { Total Timef } \\
\text { Shift }\end{array}$ & $\begin{array}{l}\text { FTEs } \\
\text { Needed }\end{array}$ & Minutes/ lb \\
\hline \multirow[t]{13}{*}{ Monitor Equipment } & Dry filtration & 8.0 & times & 10 & 80 & & \\
\hline & Quencher & 24.0 & times & 5 & 120 & & \\
\hline & Prefilter/hepa filter & 4.0 & times & 5 & 20 & & \\
\hline & Acid gas scrubber & 24.0 & times & 5 & 120 & & \\
\hline & $\overline{G A C}$ & 4.0 & times & 2 & 8 & & \\
\hline & Mersorb & 4.0 & times & 2 & 8 & & \\
\hline & Evaporator System & 24.0 & times & 5 & 120 & & \\
\hline & Dioxin/ Denox Filter & 8.0 & times & 5 & 40 & & \\
\hline & Hydrosonic Scrubber & 24.0 & times & 5 & 120 & & \\
\hline & Liquid/ Solid Separator & 24.0 & times & 5 & 120 & & \\
\hline & Mist Eliminator & 4.0 & times & 2 & 8 & & \\
\hline & Heat Exchanger & 4.0 & times & 5 & 20 & & \\
\hline & Offgas monitor & 24.0 & times & 5 & 120 & & \\
\hline Total Task & & & & 61 & 904 & 1.88 & 0 \\
\hline Supervision & Ratio of $1: 10$ & & & & & 0.19 & \\
\hline Vac/sick/holiday relief & Assume 6 wks of absence & & & & & 0.24 & \\
\hline Total/shift & & & & & & 2.31 & \\
\hline $\begin{array}{l}\text { Adjustment for } 70 \% \\
\text { Efficiency }\end{array}$ & & & & & & 3.30 & \\
\hline Total/day & & & & & & 9.90 & \\
\hline
\end{tabular}




\begin{tabular}{|c|c|c|c|c|c|c|c|c|}
\hline Task & Subtask & $\begin{array}{c}\text { Occurrencel } \\
\text { Shift }\end{array} \mid$ & Units & $\begin{array}{l}\text { Time } \\
\text { Required } \\
\text { (min) }\end{array}$ & $\begin{array}{c}\text { Total Timel } \\
\text { Shift }\end{array}$ & $\mid \begin{array}{c}\text { FTEs } \\
\text { Needed }\end{array}$ & $\begin{array}{l}\text { Minutes/ } \\
\text { Drum }\end{array}$ & $\begin{array}{c}\text { Minutes/ } \\
\text { Add"l Drum }\end{array}$ \\
\hline \multirow[t]{5}{*}{ Waste Receiving } & Transfer through air lock & 11.8 & drums & 5 & 59 & & & \\
\hline & Sample waste & 1.2 & drums & 15 & 18 & & & \\
\hline & Resample waste & 0.1 & drums & 15 & 2 & & & \\
\hline & Stage waste & 11.8 & drums & 5 & 59 & & & \\
\hline & & & & 40 & 138 & 0.29 & 40 & 15 \\
\hline \multirow[t]{8}{*}{ Waste Assay } & Stage pallets & 11.8 & drum & $\overline{3}$ & 36 & & & \\
\hline & Load on conveyor & 11.8 & drum & 1 & 12 & & & \\
\hline & Assay RTR & 11.8 & drum & 15 & 178 & & & \\
\hline & Assay gamma & 11.8 & drum & 60 & 710 & & & \\
\hline & Assay PAN & 11.8 & drum & 60 & 710 & & & \\
\hline & Remove from conveyor & 11.8 & drum & 1 & 12 & & & \\
\hline & Repalletize & 11.8 & drum & 3 & 36 & & & \\
\hline & Stage pallets after assaying & 11.8 & drum & 15 & 178 & & & \\
\hline Total Task & & & & 158 & 1871 & 3.90 & 158 & 60 \\
\hline \multirow[t]{5}{*}{ Stage waste } & Stage uncertified waste & 11.8 & drum & $\overline{3}$ & 36 & & & \\
\hline & Transfer waste & 11.8 & drum & 3 & 36 & & & \\
\hline & Stage certified waste & 11.8 & drum & 3 & 36 & & & \\
\hline & Transfer waste & 11.8 & drum & 3 & 36 & & & \\
\hline & & & & 12 & 142 & 0.30 & 12 & \\
\hline \multirow[t]{4}{*}{ Ship Waste Truck } & Truck docking & 0.1 & truck & 30 & $\overline{4}$ & & & \\
\hline & Settle Papenwork & 0.1 & truck & 120 & 16 & & & \\
\hline & Load truck & 0.1 & truck & 60 & 8 & & & \\
\hline & Truck leaving & 0.1 & truck & 60 & 8 & & & \\
\hline Total Task & & & & 270 & 36 & 0.08 & 12 & \\
\hline Total FTEs/shift & & & & & & 4.56 & 222 & \\
\hline Supervision & Ratio of 1:10 & & & & & 0.46 & & \\
\hline Vac/sick/holiday relief & Assume 6 wks of absence & & & & & 0.58 & & \\
\hline Total/shift & & & & & & 5.59 & & \\
\hline $\begin{array}{l}\text { Adjustment for.70\% } \\
\text { Efficiency }\end{array}$ & & & & & & 7.99 & & \\
\hline Total/day & & & & & & 23.96 & & \\
\hline
\end{tabular}




\begin{tabular}{|l|c|c|c|c|c|c|}
\hline & $\begin{array}{c}\text { Daily } \\
\text { FTEs }\end{array}$ & $\begin{array}{c}\text { Time (min)/ } \\
\text { Single Drum }\end{array}$ & Time (hrs) & $\begin{array}{c}\text { Add'l Time } \\
\text { for Next } \\
\text { Drum }\end{array}$ & $\begin{array}{c}\text { Time/Drums } \\
\text { Received in a } \\
\text { Shift (minutes) }\end{array}$ & Time (hrs) \\
\hline Administration & 46.6 & N/A & & & & \\
\hline $\begin{array}{l}\text { Receiving /nspection Tasks } \\
\text { Common for all waste }\end{array}$ & & 802 & 13 & 60 & 3728 & 62 \\
\hline Receiving and Prep-plasma & & 229 & 4 & 45 & 1829 & 30 \\
\hline Receiving and Prep-lead & & 557 & 9 & 315 & 557 & 9 \\
\hline Receiving and Prep-mercury & & 516 & 9 & 315 & 516 & 9 \\
\hline Receiving and Prep-special & & 516 & 9 & 315 & 1889 & 31 \\
\hline Receiving and Prep-metal decon & & 229 & 4 & 35 & 560 & 9 \\
\hline Receiving and Prep & 167.5 & 670.7 & 11 & & & 0 \\
\hline Aqueous Waste & 5.3 & 124 & 2 & 5 & 702 & 12 \\
\hline Plasma Treatment & 23.3 & 234 & 4 & 26 & 1159 & 19 \\
\hline Metal Decon & 16.5 & 91 & 2 & 75 & 1216 & 20 \\
\hline Lead & 2 & 551 & 9 & N/A & 551 & 9 \\
\hline Mercury & 1.7 & 614.0 & 10 & N/A & 614 & 10 \\
\hline Special & 10.7 & 182.0 & 3 & 60.0 & 444 & 7 \\
\hline Polymer & 13.2 & 180 & 3 & 60 & 288 & 5 \\
\hline APC & 9.9 & 904 & 15 & & 904 & 15 \\
\hline Certification and Shipping & 24.0 & 222 & 4 & 60 & 872 & 15 \\
\hline & & & & & & \\
\hline Total & 320.8 & & & & & \\
\hline
\end{tabular}

\section{Notes:}

Allocation of receiving and preparation time was done as follows: Average time per drum was estimated, multiplied by the number of drums per shift. The time for each waste type was allocated according its percentage of total waste. 



\section{System NT-2 Time and Motion Study Tables}

NT2-a System NT-2: Time and Motion Analysis

NT2-b Administration Subsystem

NT2-c Receiving and Preparation Subsystem

NT2-d CWO Organic Destruction Subsystem

NT2-e Vacuum Thermal Desorption for Process Residue

NT2-f Aqueous Waste Treatment Subsystem

NT2-g Metal Decontamination Subsystem

NT2-h Lead Recovery

NT2-i Mercury Amalgamation

NT2-j Special Waste

NT2-k Grout Stabilization Subsystem

NT2-1 Polymer Stabilization Subsystem

NT2-m Air Pollution Control Subsystem

NT2-n Certification and Shipping

NT2-o Summary of FTEs and time for a single drum to work through a system 


\begin{tabular}{|c|c|c|c|c|c|c|}
\hline Subsystem & $\begin{array}{c}\text { Mass Flow } \\
(\mathrm{lb} / \mathrm{hr})\end{array}$ & Waste Type & $\begin{array}{l}\text { No. of } \\
\text { Drums }\end{array}$ & $\begin{array}{c}\text { SCM } \\
\text { Unprocessed } \\
\text { Density } \\
\text { kg/cu m }\end{array}$ & $\begin{array}{l}\text { Density } \\
\mathrm{lb} / \mathrm{cu} \mathrm{ft}\end{array}$ & $\begin{array}{l}\text { Density } \\
\text { lb/drum }\end{array}$ \\
\hline Administration & 2,927 & & & & & \\
\hline Receiving and preparation & 2,927 & all & 6.2 & & 64 & 471 \\
\hline Aqueous waste treatment (total) & 1,258 & $\mathrm{L1100}$ & 2.8 & & 62 & 456 \\
\hline High TDS aqueous waste & 641 & $\mathrm{~L} 1100$ & 1.4 & & 62 & 456 \\
\hline Low TDS Aqueous waste & 268 & $\mathrm{~L} 1100$ & 0.6 & & 62 & 456 \\
\hline Organic aqueous waste & 350 & L1200 & 0.8 & & 62 & 456 \\
\hline Organic destruction & 268 & $L 2110$ & 0.6 & & 62 & 456 \\
\hline $\begin{array}{l}\text { Process residue and inorganic } \\
\text { sludge treatment }\end{array}$ & 1,020 & $\$ 3120$ & 3.2 & 700 & 44 & 321 \\
\hline Bulk soil treatment & 329 & $\$ 4100$ & 0.7 & & 67 & 493 \\
\hline Soft Debris treatment & 435 & 55300 & 3.0 & 320 & 20 & 147 \\
\hline Open Debris treatment & 80 & 55110 & 0.4 & 400 & 25 & 184 \\
\hline Complex Debris treatment & 177 & $\$ 5110$ & 1.0 & 400 & 25 & 184 \\
\hline Metal decontamination & 462 & $\$ 5110$ & 2.0 & 509 & 32 & 234 \\
\hline Mercury amalgamation & 5 & $\times 7100$ & 0.0 & 2000 & 125 & 918 \\
\hline Lead recovery & 56 & $\times 7200$ & 0.1 & 2000 & 125 & 918 \\
\hline Polymer stabilization & 1,110 & $S 3120$ & 3.5 & 700 & 44 & 321 \\
\hline Pre-polymer drying & 438 & $\mathbf{S 3 1 2 0}$ & 1.4 & 700 & 44 & 321 \\
\hline Air pollution control & 823 & & N/A & & & \\
\hline Grout stabilization & 1,228 & soil/debris & 3.6 & 750 & 47 & 344 \\
\hline Special treatment & 155 & $\times 6000, \times 7500$ & 0.7 & 500 & 31 & 229 \\
\hline Certification and shipping & 5,067 & 20000 & 6.2 & N/A & 111 & 815 \\
\hline Vol reduction (out/in) & 0.58 & & 1.0 & & & \\
\hline
\end{tabular}

Notes:

This table provides the basis for the time and motion analysis.

Quantities of waste to a subsystem (lbs/hr) are based on LMITCO mass balance for system NT2

Densities are the same as the LMITCO mass balance except where values are shown in the SCM column.

Where values are shown in the SCM column, densities are taken from SCM and converted to $\mathrm{b} / \mathrm{ft} 3$. .

The waste quantities are converted from lbs/hr to drums/hr.

Subsequent analysis is based on drums/shift of waste to a subsystem.

Pre-polymer drying assumes desorbed wastes that do not go through the leaching process ( $70 \%$ of output) will not need drying. 


\begin{tabular}{|c|c|c|c|c|c|}
\hline Task & Subtask & $\begin{array}{c}\text { FTEs } \\
\text { needed }\end{array}$ & $\begin{array}{l}\text { Samples/ } \\
\text { Shift }\end{array}$ & $\begin{array}{l}\text { Time } \\
\text { Required } \\
\text { (min) }\end{array}$ & $\begin{array}{l}\text { Total Timel } \\
\text { Shiff }\end{array}$ \\
\hline Facility Management & $\begin{array}{l}\text { Facility Manager } \\
\text { Secretary } \\
\text { Receptionist/word processor }\end{array}$ & $\begin{array}{l}1 \\
1 \\
1\end{array}$ & & & \\
\hline Operations Management & $\begin{array}{l}\text { Department managers } \\
\text { Communications } \\
\text { Engineering Manager } \\
\text { Engineering staff } \\
\text { Maintenance Supervisor }\end{array}$ & $\begin{array}{l}2 \\
1 \\
1 \\
2 \\
1\end{array}$ & & & \\
\hline Personnel & $\begin{array}{l}\text { Personnel Manager } \\
\text { Nurse/medical/industrial safety } \\
\text { Security guards at facility } \\
\text { Security at guard bldg }\end{array}$ & $\begin{array}{l}1 \\
1 \\
4 \\
4\end{array}$ & & & \\
\hline Environmental & $\begin{array}{l}\text { Environmental manager } \\
\text { Environmental clerk }\end{array}$ & $\begin{array}{l}1 \\
1 \\
\end{array}$ & & & \\
\hline Shipping/Receiving/Traffic & $\begin{array}{l}\text { Manager } \\
\text { Clerk }\end{array}$ & $\begin{array}{l}1 \\
1\end{array}$ & & & \\
\hline Purchasing & Buyer & 1 & & & \\
\hline Accounting & $\begin{array}{l}\text { Cost Accounting } \\
\text { Accounting Clerk } \\
\text { Payroll Clerks }\end{array}$ & $\begin{array}{l}2 \\
1 \\
2\end{array}$ & & & \\
\hline Laboratory & $\begin{array}{l}\text { Laboratory Manager } \\
\text { Lab Shift manager } \\
\text { Lab technicians for OSORT } \\
\text { Lab technicians for internal processes } \\
\text { Lab technicians for final waste form } \\
\text { Lab technicians for incoming supplies }\end{array}$ & $\begin{array}{l}1 \\
4 \\
4 \\
5 \\
3 \\
0.2\end{array}$ & $\begin{array}{c}11.3 \\
42.7 \\
10.2 \\
1.0\end{array}$ & $\begin{array}{l}30.0 \\
10.0 \\
30.0 \\
20.0\end{array}$ & $\begin{array}{c}339.2 \\
426.7 \\
307.0 \\
20.0 \\
\end{array}$ \\
\hline Health Physics & $\begin{array}{l}\text { Shift health physics staff } \\
\text { Health physics manager }\end{array}$ & $\begin{array}{l}4 \\
1\end{array}$ & & & \\
\hline & $\begin{array}{l}\text { Total except Lab } \\
\text { Total Lab } \\
\text { Total Admin }\end{array}$ & $\begin{array}{l}35 \\
17 \\
52\end{array}$ & & & \\
\hline
\end{tabular}




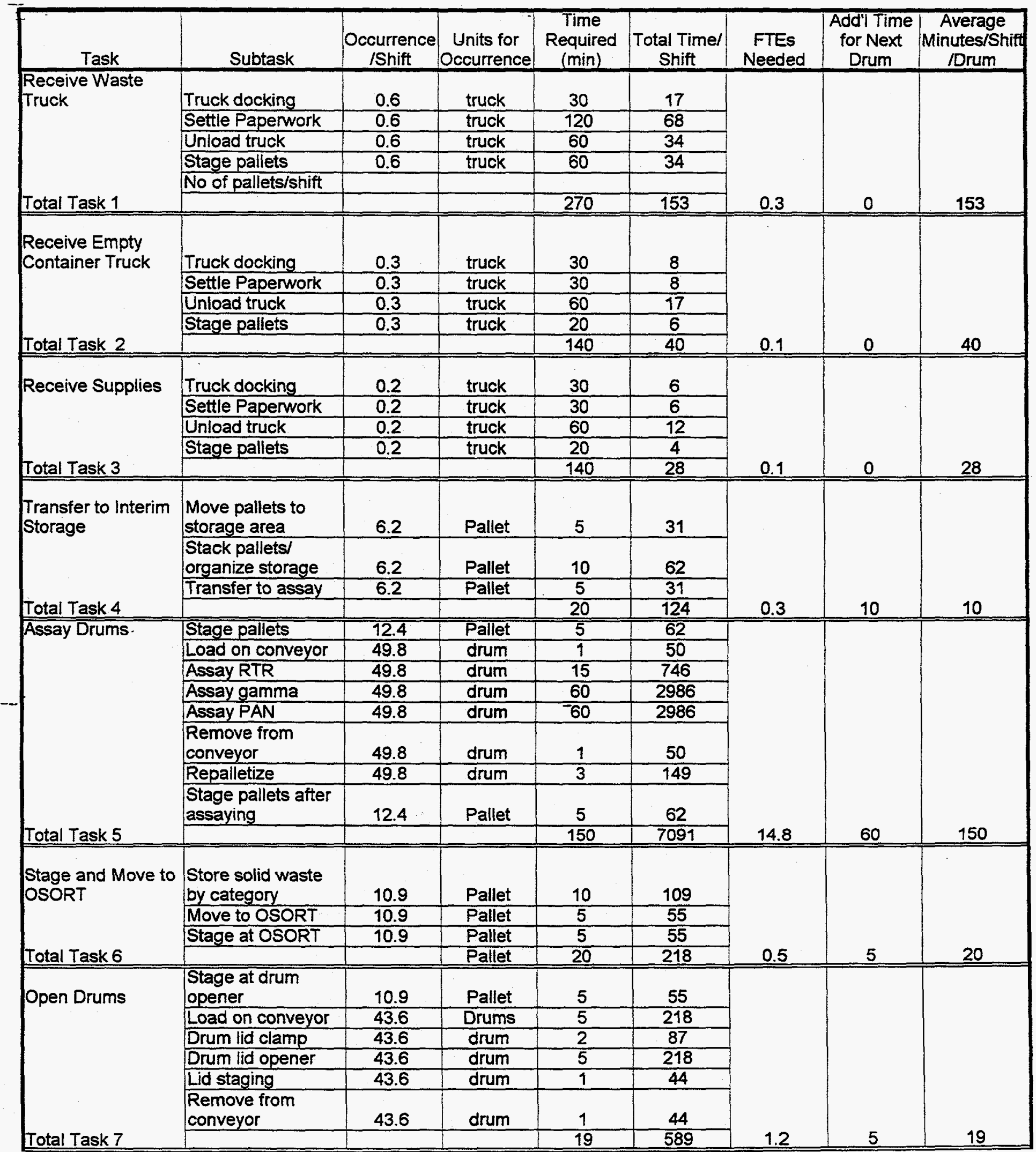


Table NT2-C.

Receiving and Preparation Subsystem

\begin{tabular}{|c|c|c|c|c|c|c|c|c|}
\hline Task & Subtask & $\begin{array}{c}\text { Occurrence } \\
\text { IShift }\end{array}$ & \begin{tabular}{|c|} 
Units for \\
Occurrence
\end{tabular} & $\begin{array}{c}\text { Time } \\
\text { Required } \\
\text { (min) }\end{array}$ & $\begin{array}{c}\text { Total Time/ } \\
\text { Shift }\end{array}$ & $\begin{array}{l}\text { FTEs } \\
\text { Needed }\end{array}$ & $\begin{array}{l}\text { Add" Time } \\
\text { for Next } \\
\text { Drum }\end{array}$ & $\begin{array}{c}\text { Average } \\
\text { Minutes/Shit } \\
\text { /Drum } \\
\end{array}$ \\
\hline Dump Drums & $\begin{array}{l}\text { Assign drums to } \\
\text { dump stations }\end{array}$ & 43.6 & drum & 3 & 131 & \multirow[b]{4}{*}{1.2} & \multirow[b]{4}{*}{5} & \multirow[b]{4}{*}{13} \\
\hline thes & $\begin{array}{l}\text { Move drums to sort } \\
\text { table /bins }\end{array}$ & 43.6 & drum & 5 & 218 & & & \\
\hline \multirow[b]{2}{*}{ Total Task 8} & Dump drums & 43.6 & drum & 5 & 218 & & & \\
\hline & & & & 13 & 567 & & & \\
\hline \multirow[t]{5}{*}{ Sort Drums } & $\begin{array}{l}\text { Sort waste } \\
\text { robotically }\end{array}$ & 32.7 & drum & 30 & 982 & \multirow[b]{5}{*}{3.5} & \multirow[b]{5}{*}{45} & \multirow[b]{5}{*}{38} \\
\hline & $\begin{array}{l}\text { Transfer waste to } \\
\text { container }\end{array}$ & 32.7 & drum & 15 & 491 & & & \\
\hline & $\begin{array}{l}\text { Select destination } \\
\text { for sorted waste }\end{array}$ & 32.7 & drum & 3 & 98 & & & \\
\hline & $\begin{array}{l}\text { Move container to } \\
\text { subsystem bin or } \\
\text { shredder }\end{array}$ & 32.7 & drum & 3 & 98 & & & \\
\hline & & & & 51 & 1669 & & & \\
\hline \multirow[t]{7}{*}{ Glove Box Sort } & $\begin{array}{l}\text { Transfer to glove } \\
\text { box (several trips) }\end{array}$ & 7.1 & drum & 30 & 214 & \multirow[b]{7}{*}{5.6} & \multirow[b]{7}{*}{315} & \multirow[b]{7}{*}{5} \\
\hline & $\begin{array}{l}\text { Sort waste by hand } \\
\text { in glove box }\end{array}$ & 7.1 & drum & 240 & 1711 & & & \\
\hline & sampling (1/drum) & 7.1 & drum & 15 & 107 & & & \\
\hline & $\begin{array}{l}\text { Transfer waste to } \\
\text { containers } \\
\end{array}$ & 7.1 & drum & 60 & 428 & & & \\
\hline & $\begin{array}{l}\text { Select destination } \\
\text { for sorted waste }\end{array}$ & 7.1 & drum & 15 & 107 & & & \\
\hline & $\begin{array}{l}\text { Move containers to } \\
\text { subsystem bin or } \\
\text { shredder }\end{array}$ & 7.1 & drum & 15 & 107 & & & \\
\hline & & & & 375 & 2673 & & & \\
\hline \multirow[t]{4}{*}{$\begin{array}{l}\text { Assess Debris for } \\
\text { Debris Rule } \\
\text { Compliance }\end{array}$} & $\begin{array}{l}\text { Transfer soft, open } \\
\text { and complex debris }\end{array}$ & 35.0 & drum & -3 & 105 & \multirow[b]{5}{*}{1.1} & \multirow[b]{5}{*}{5} & \multirow[b]{5}{*}{6} \\
\hline & Screen debris & 35.0 & drum & 4 & 140 & & & \\
\hline & \begin{tabular}{|l|} 
Additional \\
sampling (25\%) \\
\end{tabular} & 8.7 & drum & 10 & 87 & & & \\
\hline & Inspection & 35.0 & drum & 5 & 175 & & & \\
\hline Total Task 11 & & & & 22 & 507 & & & \\
\hline \multirow[t]{5}{*}{$\begin{array}{l}\text { Gross Size } \\
\text { Reduction }\end{array}$} & $\begin{array}{l}\text { Transfer to cutting } \\
\text { table }\end{array}$ & 14.3 & drum & 3 & 43 & \multirow[b]{5}{*}{1.2} & \multirow[b]{5}{*}{35} & \multirow[b]{5}{*}{6} \\
\hline & Cut waste & 14.3 & drum & 30 & 429 & & & \\
\hline & Return to container & 14.3 & drum & 5 & 72 & & & \\
\hline & $\begin{array}{l}\text { Transfer to next } \\
\text { process }\end{array}$ & 14.3 & drum & 3 & 43 & & & \\
\hline & & & & 41 & 587 & & & \\
\hline \multirow[t]{9}{*}{ Shredding } & $\begin{array}{l}\text { Transfer to } \\
\text { shredder }\end{array}$ & 37.3 & drum & 2 & 75 & & & \\
\hline & Stage waste & 37.3 & drum & 2 & 75 & & & \\
\hline & $\begin{array}{l}\text { Feed waste to } \\
\text { shredder }\end{array}$ & 37.3 & drum & 2 & 75 & & & \\
\hline & $\begin{array}{l}\text { Feed bad drums to } \\
\text { shredder }\end{array}$ & 21.8 & drum & 2 & 44 & & & \\
\hline & Shred stage 1 & 59.1 & drum & 2 & 118 & & & \\
\hline & Shred stage 2 & 59.1 & drum & $\overline{2}$ & 118 & & & \\
\hline & $\begin{array}{l}\text { Sample size of } \\
\text { waste }\end{array}$ & 5.9 & drum & 5 & 30 & & & \\
\hline & Rework $10 \%$ & 0.6 & drum & 15 & 9 & & & \\
\hline & Return to container & 59.1 & drum & 3 & 177 & & & \\
\hline
\end{tabular}




\begin{tabular}{|c|c|c|c|c|c|c|c|c|}
\hline Task & Subtask & $\begin{array}{c}\text { Occurrence } \\
\text { IShift }\end{array}$ & $\begin{array}{c}\text { Units for } \\
\text { Occurrence }\end{array}$ & $\begin{array}{l}\text { Time } \\
\text { Required } \\
\text { (min) }\end{array}$ & $\begin{array}{c}\text { Total Time/ } \\
\text { Shift }\end{array}$ & $\begin{array}{l}\text { FTEs } \\
\text { Needed }\end{array}$ & $\begin{array}{l}\text { Add' Time } \\
\text { for Next } \\
\text { Drum }\end{array}$ & \begin{tabular}{|c|}
$\begin{array}{c}\text { Average } \\
\text { Minutes/Shift } \\
\text { Drum }\end{array}$ \\
\end{tabular} \\
\hline & $\begin{array}{l}\text { Transfer to next } \\
\text { process }\end{array}$ & 59.1 & drum & 2 & 118 & \multirow[b]{2}{*}{1.7} & \multirow[b]{2}{*}{2} & \multirow[b]{2}{*}{30} \\
\hline Total Task 13 & & & & 37 & 838 & & & \\
\hline \multirow[b]{5}{*}{ Total Task 14} & $\begin{array}{l}\text { Sample opened } \\
\text { drums }\end{array}$ & 4.4 & drum & 5 & 22 & \multirow[b]{5}{*}{0.5} & \multirow[b]{5}{*}{10} & \multirow[b]{5}{*}{30} \\
\hline & $\begin{array}{l}\text { Sample sorted } \\
\text { waste }\end{array}$ & 5.9 & drum & 5 & 30 & & & \\
\hline & Resample (10\%) & 1.0 & drum & 5 & 5 & & & \\
\hline & Report/eval. results & 11.3 & drum & 10 & 113 & & & \\
\hline & & & & 25 & 170 & & & \\
\hline \multirow[t]{5}{*}{$\begin{array}{l}\text { Subsystem Bin } \\
\text { operation }\end{array}$} & Monitor bin height & 4.4 & drum & 3 & 13 & \multirow[b]{6}{*}{0.3} & \multirow[b]{6}{*}{0} & \multirow[b]{6}{*}{26} \\
\hline & Fill containers & 4.4 & drum & 3 & 13 & & & \\
\hline & Move containers & 4.4 & drum & 2 & 9 & & & \\
\hline & Stage containers & 4.4 & drum & 3 & 13 & & & \\
\hline & $\begin{array}{l}\text { Organize } \\
\text { campaigns }\end{array}$ & 4.4 & drum & 15 & 65 & & & \\
\hline Total Task 15 & & & & 26 & 113 & & & \\
\hline \multirow[t]{9}{*}{ Internal Transfer } & $\begin{array}{l}\text { Move waste from } \\
\text { OSORT to other } \\
\text { subsystems }\end{array}$ & 4.4 & drum & 10 & 44 & \multirow[b]{9}{*}{5.4} & \multirow[b]{9}{*}{10} & \multirow[b]{9}{*}{57} \\
\hline & $\begin{array}{l}\text { Move waste from } \\
\text { subsystems to } \\
\text { CSHIP }\end{array}$ & 49.8 & drum & 10 & 498 & & & \\
\hline & $\begin{array}{l}\text { Move treated } \\
\text { waste to } \\
\text { stabilization }\end{array}$ & 80.0 & drum & 10 & 800 & & & \\
\hline & $\begin{array}{l}\text { Move liquid waste } \\
\text { to AQWTR and } \\
\text { OrgDes }\end{array}$ & 6.1 & drum & 10 & 61 & & & \\
\hline & \begin{tabular}{|l} 
Move waste to \\
secondary \\
treatment
\end{tabular} & 20.0 & drum & 10 & 200 & & & \\
\hline & $\begin{array}{l}\text { Move supplies } \\
\text { around }\end{array}$ & 20.0 & drum & 3 & 60 & & & \\
\hline & Move new drums & 24.9 & drum & 3 & 75 & & & \\
\hline & $\begin{array}{l}\text { Schedule } \\
\text { movement }\end{array}$ & 205.1 & drum & 1 & 205 & & & \\
\hline & & & & 57 & 1942 & & & \\
\hline \multirow[t]{4}{*}{ Box Breakdown } & Stage boxes & 10.0 & box & 2 & 20 & \multirow[b]{5}{*}{0.5} & \multirow[b]{5}{*}{10} & \multirow[b]{5}{*}{2} \\
\hline & $\begin{array}{l}\text { Move to opening } \\
\text { area }\end{array}$ & 10.0 & box & 3 & 30 & & & \\
\hline & Open boxes & 10.0 & box & 10 & 100 & & & \\
\hline & Transfer to dump & 10.0 & box & 3 & 30 & & & \\
\hline Total Task 17 & & & & 18 & 180 & & & \\
\hline \multirow[t]{7}{*}{ Container Decon } & Stage containers & 49.8 & drum & 5 & 249 & \multirow[b]{7}{*}{6.2} & \multirow[b]{7}{*}{15} & \multirow[b]{7}{*}{45} \\
\hline & Load conveyors & 49.8 & drum & 5 & 249 & & & \\
\hline & Decon drums & 49.8 & drum & 10 & 498 & & & \\
\hline & Assay drums & 49.8 & drum & 15 & 746 & & & \\
\hline & Unload conveyers & 49.8 & drum & 5 & 249 & & & \\
\hline & Stage drums & 49.8 & drum & 5 & 249 & & & \\
\hline & & & & 45 & 2239 & & & \\
\hline
\end{tabular}


Table NT2-c.

Receiving and Preparation Subsystem

\begin{tabular}{|c|c|c|c|c|c|c|c|c|}
\hline Task & Subtask & $\begin{array}{c}\text { Occurrence } \\
\text { /Shift }\end{array}$ & $\begin{array}{c}\text { Units for } \\
\text { Occurrence }\end{array}$ & $\begin{array}{c}\text { Time } \\
\text { Required } \\
\text { (min) }\end{array}$ & \begin{tabular}{|c|} 
Total Timel \\
Shift
\end{tabular} & $\begin{array}{c}\text { FTEs } \\
\text { Needed }\end{array}$ & $\begin{array}{l}\text { Add'l Time } \\
\text { for Next } \\
\text { Drum } \\
\end{array}$ & $\begin{array}{c}\text { Average } \\
\text { Minutes/Shift } \\
\text { /Drum } \\
\end{array}$ \\
\hline FTEs/shift & & & & & $\overline{0}$ & 37.6 & & \\
\hline Supervision & Ratio of $1: 10$ & & & & & 3.8 & & \\
\hline $\begin{array}{l}\text { Vac/sick/holiday } \\
\text { relief }\end{array}$ & $\begin{array}{l}\text { Assume } 6 \text { wks of } \\
\text { absence }\end{array}$ & & & & & 4.8 & & \\
\hline Total/shift & & & & & & 46.1 & & \\
\hline $\begin{array}{l}\text { Adj for } 70 \% \\
\text { Efficiency }\end{array}$ & & & & & & .9 & & \\
\hline Total/day & & & & & & 197.7 & & 676 \\
\hline
\end{tabular}

Notes:

Assume FTEs are available for $8 \mathrm{hrs} /$ day; because overall $70 \%$ efficiency is taken at the end.

Trucks carry 22 pallets. Truckloads received based on total inventory to shipping at $300 \mathrm{lb} /$ drum (see separate truck calc sheet)

Pallets are assumed to hold 4-55 gallon drums

Assume $50 \%$ of drums are contaminated and can't be deconned.

Assume $50 \%$ of waste received requires interim storage (this will be dependent on assay system)

Assume $10 \%$ of incoming waste is sampled

Assume sorted waste is $75 \%$ of total; all of debris, no liq, no lead/merc/spec, $70 \%$ of residue and soil

Assume $10 \%$ of sorted waste is sampled

Assume gross size reduction is necessary for wastes to metal decon \& lead

Assume gross size reduction is $1 \mathrm{hr}$ per drum.

Assume shredding is necessary for waste to proc res, soil, soft debris(sorted or not)

0.75 =fraction of feed to RCPRP requiring shredding

Assume $10 \%$ of shredded waste is sampled.

Box breakdown includes time beyond that required if waste was packaged in trums

Assume glove box sorting required for $10 \%$ of open and complex debris, + all of special, mercury and lead

0.14 =fraction of feed to RCPRP requiring sorting

Assume glove box waste requires 1 sample/drum

Assume all debris must be assessed as none will be destroyed.

Assume liquids will arrive in drums and be transferred from receiving, and not go to the sorting cell

Assume transfer control for liquids takes the same time as for drums

Assume paperwork is accomplished within times shown

Average time per drum includes times for activities multiplied by the probability that the activity will occur.

Least time/drum/subsystem includes only the minimum requirements, no extra staging, sorting, or shredding

Max time/drum/subsystem includes all staging, shredding, glove box, etc 


\begin{tabular}{|c|c|c|c|c|c|c|c|c|}
\hline Task & Subtask & $\begin{array}{c}\text { Occurrencel } \\
\text { shitt }\end{array}$ & Units & $\begin{array}{l}\text { Time } \\
\text { Required } \\
\text { (min) }\end{array}$ & $\left|\begin{array}{c}\text { Total Time } / \\
\text { Shift }\end{array}\right|$ & $\begin{array}{l}\text { FTEs } \\
\text { Needed }\end{array}$ & $\begin{array}{l}\text { Minutes/ } \\
\text { First Drum }\end{array}$ & $\begin{array}{l}\text { Minutes/ } \\
\text { Add'I Drum }\end{array}$ \\
\hline \multirow[t]{8}{*}{ Receive Waste } & Transfer through air lock & 3.3 & drum & 5 & 16 & & & \\
\hline & Feed waste from drum & 3.3 & drum & 3 & 10 & & & \\
\hline & Hook to transfer device & 3.3 & drum & 3 & 10 & & & \\
\hline & Transfer to tank $(10 \mathrm{gpm})$ & 3.3 & drum & 6 & 18 & & & \\
\hline & Empty drum bottoms & 3.3 & drum & 2 & 7 & & & \\
\hline & Detach \& remove drum & 3.3 & drum & 3 & 10 & & & \\
\hline & Sample feed vessel & 3.3 & drum & 5 & 16 & & & \\
\hline & $\begin{array}{l}\text { Arrange for transfer of } \\
\text { secondary waste from other } \\
\text { subsystems }\end{array}$ & 1.5 & drum & 2 & 2 & & & \\
\hline Total Task & & & & 28 & 88 & 0.2 & 28 & 17 \\
\hline \multirow[t]{3}{*}{$\begin{array}{l}\text { Feed waste to } \\
\text { reactor }\end{array}$} & $\begin{array}{l}\text { Startup Instrumentation and } \\
\text { valve check }\end{array}$ & 1.0 & & 30 & 30 & & & \\
\hline & $\begin{array}{l}\text { Meter waste to reactor } \\
\text { (monitoring time) }\end{array}$ & 24.0 & & 10 & 240 & & & \\
\hline & $\begin{array}{l}\text { Meter waste to reactor ( } 300 \\
\text { lbs/hr) }\end{array}$ & 4.7 & drums & 6 & 26 & & & \\
\hline Total Task & & & & 36 & 270 & 0.6 & 36 & 6 \\
\hline \multirow[t]{4}{*}{ Operate Reactor } & Instrumentationd Equip check & 1.0 & time & 30 & 30 & & & \\
\hline & $\begin{array}{l}\text { Time to react organics } \\
\text { (min/drum) reaction rate: } 797 \\
\text { lbs/hr }\end{array}$ & 4.7 & drums & 34 & 162 & & & \\
\hline & $\begin{array}{l}\text { Flow velocity (gpm) }= \\
\text { drums/shift*55gal/drum } /(480 \\
\text { min/shift) }\end{array}$ & 0.5 & & & & & & \\
\hline & $\begin{array}{l}\text { Residence time (min)=Reactor } \\
\text { volume/flow velocity: Reactor } \\
\text { volume is } 5 \% \text { of } 500 \mathrm{gal}\end{array}$ & 46.2 & minutes & & & & & \\
\hline Total Task & & & & 64 & 192 & 0.4 & 64 & 34 \\
\hline \multirow[t]{9}{*}{$\begin{array}{l}\text { Waste Transfer! } \\
\text { Recycle }\end{array}$} & $\begin{array}{l}\text { Waste removed from tank } \\
\text { (pump } 500 \text { gal @10 gpm) }\end{array}$ & 9.1 & drum & 6 & 50 & & & \\
\hline & Filter solution & 24.0 & times & 2 & 48 & & & \\
\hline & Sample filtrate & 2.0 & times & 15 & 30 & & & \\
\hline & Recycle acids & 24.0 & times & 2 & 48 & & & \\
\hline & Operate condenser & 1.0 & times & 16 & 16 & & & \\
\hline & Wash solution & 24.0 & times & 2 & 48 & & & \\
\hline & Sample & 2.0 & times & 15 & 30 & & & \\
\hline & Transfer@10 gpm to filter & 47.2 & drums & 6 & 260 & & & \\
\hline & Transfer @ $10 \mathrm{gpm}$ from filter & 47.2 & drums & 6 & 260 & & & \\
\hline Total Task & & & & 63 & 270 & 0.6 & 63 & 6 \\
\hline \multirow[t]{6}{*}{ Treat inorganics } & Transfer to neutralizer & 24.0 & & 2 & $4 \overline{88}$ & & & \\
\hline & Precipitate filtered solids & 24.0 & & 2 & 48 & & & \\
\hline & Filter precipitate & 24.0 & & 2 & 48 & & & \\
\hline & Transfer filtrate to Aq. Waste & 24.0 & & 2 & 48 & & & \\
\hline & $\begin{array}{l}\text { Transfer precipitated solids to } \\
\text { polymer }\end{array}$ & 24.0 & & 2 & 48 & & & \\
\hline & Collect sample & 2.0 & & 5 & 10 & & & \\
\hline Total Task & & & & 15 & 250 & 0.5 & 15 & 34 \\
\hline
\end{tabular}




\begin{tabular}{|c|c|c|c|c|c|c|c|c|}
\hline Task & Subtask & $\begin{array}{c}\text { Occurrenced } \\
\text { shift }\end{array} \mid$ & Units & $\begin{array}{l}\text { Time } \\
\text { Required } \\
\text { (min) }\end{array}$ & {$\left[\begin{array}{c}\text { Total Time } ~ \\
\text { Shift }\end{array}\right.$} & $\begin{array}{c}\text { FTEs } \\
\text { Needed }\end{array}$ & $\begin{array}{l}\text { Minutes/ } \\
\text { First Drum }\end{array}$ & $\begin{array}{c}\text { Minutes' } \\
\text { Add'I Drum }\end{array}$ \\
\hline Receive Waste & Transfer through air lock & 3.3 & drum & 5 & 16 & & & \\
\hline FTEsishift & & & & & & 2.2 & 206 & \\
\hline Supervision & Ratio of $1: 10$ & & & & & 0.2 & & \\
\hline $\begin{array}{l}\text { Vac/sick/ holiday } \\
\text { relief }\end{array}$ & Assume 6 wks of absence & & & & & 0.3 & & \\
\hline $\begin{array}{l}\text { Adjustment for } 70 \% \\
\text { Efficiency }\end{array}$ & & & & & & 0.8 & & \\
\hline Total/shift & & & & & & 3.6 & & \\
\hline Total/day & & & & & & 10.7 & & \\
\hline
\end{tabular}

Notes:

Total samples/shift

4.3

Assume sampling frequency $=10 \%$ of drums

From Blaine's mass balance, the feed to subsystem $=\quad 241$

Total feed is (drums/hr) =

0.6 (See Overall Table)

Assume continuous CWO process

Assume solids removal once/day

Waste transfer/recycle processes are continuous. Time is expected labor monitoring time 


\begin{tabular}{|c|c|c|c|c|c|c|c|c|c|c|}
\hline Task & Subtask & $\begin{array}{c}\text { Occurrence } \\
\text { /shift }\end{array}$ & Units & $\begin{array}{c}\text { Time } \\
\text { Required } \\
\text { (min) }\end{array}$ & $\begin{array}{c}\text { Total Time I } \\
\text { Shift }\end{array}$ & $\begin{array}{c}\text { FTEs } \\
\text { Needed }\end{array}$ & $\begin{array}{c}\text { Min/ } \\
\text { Drum }\end{array}$ & $\begin{array}{c}\text { Time/Add'l } \\
\text { drum }\end{array}$ & $\begin{array}{c}\text { Minimum } \\
\text { (minutes/ } \\
\text { shift) }\end{array}$ & $\begin{array}{c}\text { Maximum } \\
\text { (minutesf } \\
\text { shift) }\end{array}$ \\
\hline Receive Waste & Transfer through air lock & 65.8 & & 5 & 329 & & & & & \\
\hline \multirow{3}{*}{ Receive Waste } & Transfer through air lock & 65.8 & & 5 & 329 & & & & & \\
\hline & Stage drums for campaigns & 65.8 & & 2 & 132 & & & & & \\
\hline & & & & 7 & 460 & 0.96 & 7 & 2 & 7 & 7 \\
\hline \multirow[t]{7}{*}{$\begin{array}{l}\text { Feed Waste } \\
\text { from drum }\end{array}$} & Stage at feed bin (drums) & 65.8 & & 3 & 197 & & & & & \\
\hline & Hook to transfer device & 65.8 & & 3 & 197 & & & & & \\
\hline & Transfer into feed bin & 65.8 & & 5 & 329 & & & & & \\
\hline & Empty drum bottoms & 65.8 & & 2 & 132 & & & & & \\
\hline & Sample feed vessel & 2.0 & & 5 & 10 & & & & & \\
\hline & Detach \& remove drum & 65.8 & & 3 & 197 & & & & & \\
\hline & & & & 16 & 733 & 1.53 & 16 & 5 & 16 & 16 \\
\hline \multirow[t]{8}{*}{$\begin{array}{l}\text { Vacuum Thermal } \\
\text { Desorption }\end{array}$} & $\begin{array}{l}\text { Unit is number of batchs } \\
\text { Batch is } 15,000 \mathrm{lbs} \text { or }\end{array}$ & 46.7 & & $\begin{array}{l}\text { drumsl } \\
\text { batch }\end{array}$ & & & & & & \\
\hline & $\begin{array}{l}\text { Check equipment, instruments } \\
\text { before startup }\end{array}$ & 1.1 & & 30 & 33 & & & & & \\
\hline & Charge desorber ( 15000 lbs/hr) & 1.1 & & 60 & 65 & & & & & \\
\hline & Heat desorber & 1.1 & & 60 & 65 & & & & & \\
\hline & Desorber batch & 1.1 & & 60 & 65 & & & & & \\
\hline & Cool desorber & 1.1 & & 30 & 33 & & & & & \\
\hline & Discharge desorbed waste & 1.1 & & 15 & 16 & & & & & \\
\hline & & & & 225 & 245 & 0.51 & 225 & 0 & 225 & 225 \\
\hline \multirow[t]{5}{*}{ Monitor Offgas } & Monitor cooler 1 & 24.0 & & 1 & 24 & & & & & \\
\hline & Monitor condenser 1 & 24.0 & & 1 & 24 & & & & & \\
\hline & Monitor condenser 2 & 24.0 & & 1 & 24 & & & & & \\
\hline & Monitor transfer lines to APC & 24.0 & & 1 & 24 & & & & & \\
\hline & & & & 4 & 96 & 0.20 & 0 & $\underline{0}$ & 0 & 0 \\
\hline \multirow[t]{4}{*}{$\begin{array}{l}\text { Condensate } \\
\text { handling }\end{array}$} & $\begin{array}{l}\text { Sample holding vessel from } \\
\text { cond. } 1\end{array}$ & 1.0 & time & 15 & 15 & & & & & \\
\hline & $\begin{array}{l}\text { Sample holding vessel from } \\
\text { condenser } 2 \\
\end{array}$ & 1.0 & time & 15 & 15 & & & & & \\
\hline & $\begin{array}{l}\text { Transfer to aqueous waste } \\
\text { treatment }\end{array}$ & 1.0 & time & 20 & 20 & & & & & \\
\hline & $\begin{array}{l}\text { Transfer to mercury } \\
\text { amalgamation }\end{array}$ & 1.0 & time & 20 & 20 & & & & & \\
\hline Total Task & & & & 70 & 70 & 0.15 & & & 0 & 70 \\
\hline \multirow[t]{5}{*}{$\begin{array}{l}\text { Separate } \\
\text { desorbed waste }\end{array}$} & Sample waste & 1.1 & batch & 5 & 5 & & & & & \\
\hline & Select destination & 41.8 & drums & 1 & 42 & & & & & \\
\hline & Transfer waste to $\mathrm{Hg}$ leaching $\mathrm{pr}$ & 12.5 & drums & 2 & 25 & & & & & \\
\hline & Transfer waste to polymer stabili & 29.2 & drums & 2 & 58 & & & & & \\
\hline & & & & 10 & 131 & 0.27 & 10 & 8 & 10 & 10 \\
\hline \multirow[t]{15}{*}{$\begin{array}{l}\text { Mercury cont. } \\
\text { solids leaching }\end{array}$} & \multicolumn{4}{|c|}{ Process is sized for $1000 \mathrm{lbs} / \mathrm{hr}$ of waste or $25 \mathrm{drums} / \mathrm{shift}$} & & & & & & \\
\hline & Measure leaching agent & 0.5 & drums & 20 & 9 & & & & & \\
\hline & Leach waste & 0.5 & & 90 & 41 & & & & & \\
\hline & Transfer to wash 1 & 0.5 & & 20 & 9 & & & & & \\
\hline & Wash & 0.5 & & 60 & 28 & & & & & \\
\hline & Sample & 0.5 & & 15 & 7 & & & & & \\
\hline & Transfer to wash 2 & 0.5 & & 20 & 9 & & & & & \\
\hline & Wash & 0.5 & & 60 & 28 & & & & & \\
\hline & Sample & 0.5 & & 15 & 7 & & & & & \\
\hline & Transfer to filter & 0.5 & & 20 & 9 & & & & & \\
\hline & Filter solids & 0.5 & & 30 & 14 & & & & & \\
\hline & Sample/evaluate & 0.5 & & 30 & 14 & & & & & \\
\hline & Transfer liquid to aqueous waste & 0.5 & & 10 & 5 & & & & & \\
\hline & Transfer solid to polymer & 0.5 & & 10 & 5 & & & & & \\
\hline & & & & 400 & 184 & 0.38 & 84 & 0 & & 400 \\
\hline
\end{tabular}




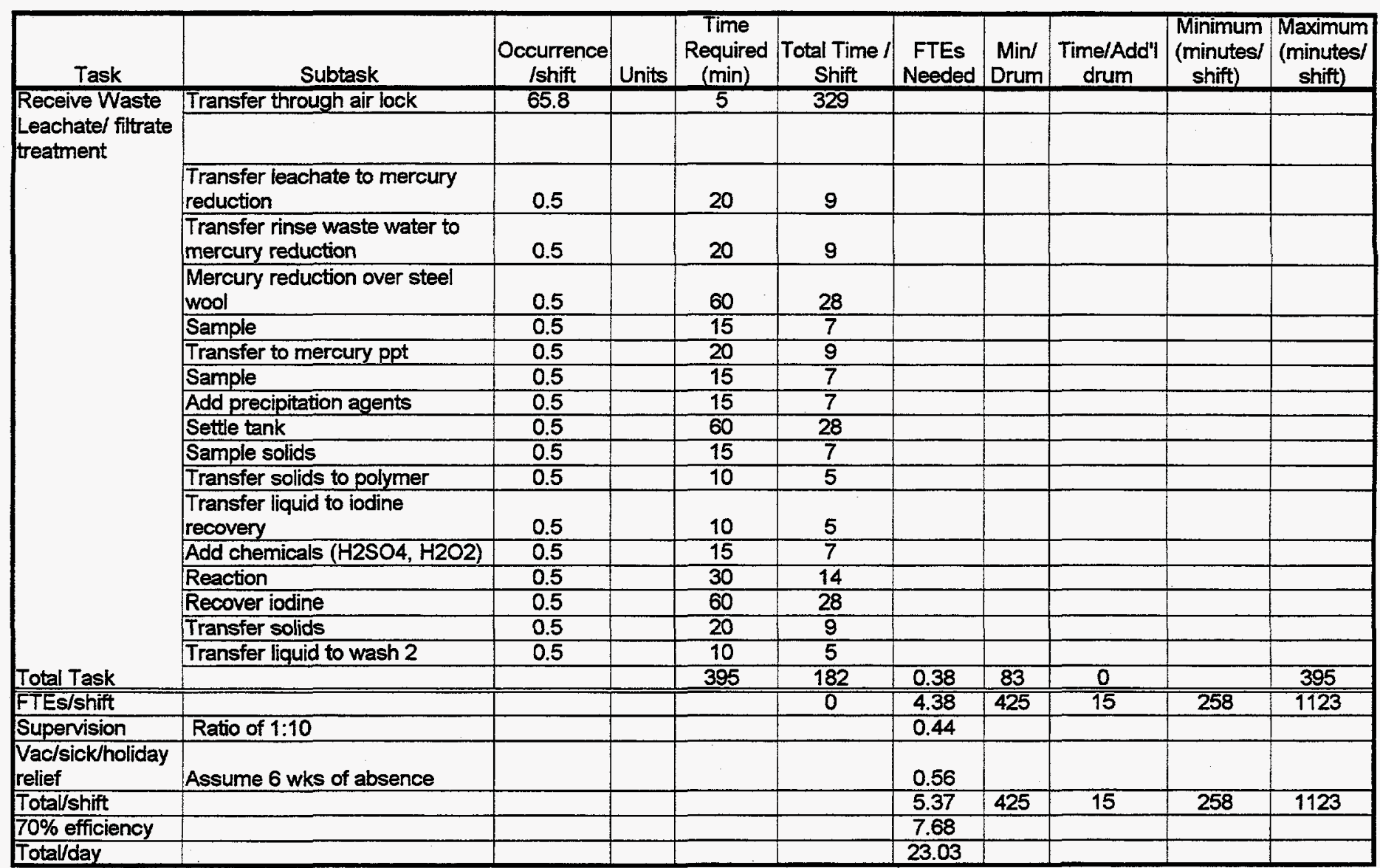

\section{Notes:}

Thermal Desorption Batch size of 15,000 lbs

Assume drum transfer of $15 \mathrm{~min}$ drum or $.5 \mathrm{cu} \mathrm{ft} / \mathrm{min}$

Only 1.14 batches are required per shift based on feed to subsystem

The condenser/aqueous transfer monitoring functions will occur when the desorber is running

Number of drums following treatment is based on the $5 / 30$ mass balance: $1020 \mathrm{lbs} / \mathrm{hr}$ in and $648 \mathrm{lbs} / \mathrm{hr}$ out

Assume $30 \%$ of the waste goes to mercury leaching process

Mercury leaching process was sized for $1000 \mathrm{lbs} / \mathrm{hr}$ of waste (@ $297 \mathrm{lbs} / \mathrm{drum}$ thisconverts to $25 \mathrm{drums} / \mathrm{shift}$ )

The weighted average of drum density was calculated to be $297 \mathrm{lbs} / \mathrm{drum}$ for this system. 


\begin{tabular}{|c|c|c|c|c|c|c|c|c|}
\hline Task & Subtask & $\begin{array}{c}\text { Occurrence } \\
\text { I Shift }\end{array}$ & & $\begin{array}{c}\text { Time } \\
\text { Required } \\
\text { (min) }\end{array}$ & $\begin{array}{c}\text { Total Time } \\
\text { Shift }\end{array}$ & $\begin{array}{l}\text { FTEs } \\
\text { Needed }\end{array}$ & $\mid \begin{array}{c}\text { Minutes/ } \\
\text { Drum }\end{array}$ & $\begin{array}{c}\text { Minutes/ } \\
\text { Add'l Drum }\end{array}$ \\
\hline \multirow[t]{9}{*}{ Receive Waste } & Transfer through air lock & 1.4 & drum & 5 & 7 & & & \\
\hline & Feed waste from drum & 1.4 & drum & 3 & 4 & & & \\
\hline & Hook to transfer device & 1.4 & drum & 3 & 4 & & & \\
\hline & Transfer to $\operatorname{tank}(10 \mathrm{gpm})$ & 1.4 & drum & 6 & 8 & & & \\
\hline & Empty drum bottoms & 1.4 & & 2 & 3 & & & \\
\hline & Sample feed vessel & 2.0 & & 10 & 20 & & & \\
\hline & Detach \& remove drum & 1.4 & & 3 & 4 & & & \\
\hline & $\begin{array}{l}\text { Sample waste from processes: } \\
\text { CWO,Desorb, Decon,APC }\end{array}$ & 4.0 & N/A & & & & & \\
\hline & Arrange for transfer & 20.7 & drum & 2 & 31 & & & \\
\hline Total Task 1 & & & & 33 & 81 & 0.17 & 33 & 5 \\
\hline \multirow[t]{9}{*}{$\begin{array}{l}\text { Preliminary } \\
\text { Treatment }\end{array}$} & Sample high TDS tank & 11.2 & drums & 15 & 17 & & & \\
\hline & Sample low TDS tank & 4.7 & drums & 15 & 7 & & & \\
\hline & Sample TOC waste & 6.1 & drums & 15 & 9 & & & \\
\hline & $\begin{array}{l}\text { Select treatment methods (10 } \\
\text { drum batch) }\end{array}$ & 10.8 & drums & 20 & 22 & & & \\
\hline & $\begin{array}{l}\text { Transfer organic waste to oil } \\
\text { water separator }\end{array}$ & 6.2 & drums & 3 & 20 & & & \\
\hline & $\begin{array}{l}\text { Filter high, low TDS and } \\
\text { organic waste (say } 10 \mathrm{gal} / \mathrm{min} \text { ) }\end{array}$ & 22.1 & drums & 6 & 122 & & & \\
\hline & Neutralize/ppt high TDS waste & 11.2 & drums & 11 & 124 & & & \\
\hline & $\begin{array}{l}\text { Settle precipitated aqueous } \\
\text { waste }\end{array}$ & 11.2 & drums & 6 & 62 & & & \\
\hline & Evaporate solids & 0.6 & drums & 6 & 3 & & & \\
\hline Total Task 2 & & & & 90 & 382 & 0.80 & 90 & 20 \\
\hline \multirow[t]{8}{*}{ UV oxidation } & CaS04 ppt (10 gpm) & 22.1 & drums & 11 & 243 & & & \\
\hline & Centrifuge (10 gpm) & 22.1 & drums & 11 & 243 & & & \\
\hline & sample waste & 2.2 & drums & 15 & 33 & & & \\
\hline & $\begin{array}{l}\text { Adjust UV oxidation ( } 30 \mathrm{~min} / 10 \\
\text { drums) }\end{array}$ & 22.1 & drums & 3 & 66 & & & \\
\hline & $\begin{array}{l}\text { Process through UV oxidation } \\
(50 \mathrm{gpm})\end{array}$ & 22.1 & drums - & 1 & 24 & & & \\
\hline & Carbon filtration $(10 \mathrm{gpm})$ & 22.1 & drums & 6 & 122 & & & \\
\hline & Ion exchange $(10 \mathrm{gpm})$ & 22.1 & drums & 6 & 122 & & & \\
\hline & Sample waste before discharge & 2.2 & & 30 & & & & 1 \\
\hline Total Task 3 & & & & 52 & 853 & 1.78 & 52 & \\
\hline Total per shift & & & & & & 2.74 & 175 & 26 \\
\hline Supervision & Ratio of $1: 10$ & & & & & 0.27 & & \\
\hline $\begin{array}{l}\text { Vac/sick/ } \\
\text { holiday relief }\end{array}$ & Assume 6 wks of absence & & & & & 0.35 & & \\
\hline $70 \%$ efficiency & & & & & & 4.81 & & \\
\hline Total per day & & & & & & 14.42 & & \\
\hline $\begin{array}{l}\text { Notes: } \\
\text { Assume high TI } \\
\text { debris treatm }\end{array}$ & $\begin{array}{l}\text { DS waste comes from RCPRP, o } \\
\text { nent and metal decon. }\end{array}$ & rg destructio & soil treat & nent, & 640.50 & $\mathrm{Ibs} / \mathrm{hr}$ & 11 & drums/shift \\
\hline $\begin{array}{l}\text { Assume waste } \\
\text { Assume waste } \\
\text { Total drums per }\end{array}$ & $\begin{array}{l}\text { from polymer, APC is low TDS } \\
\text { from process residue is organic li } \\
\text { hour }\end{array}$ & & & & $\begin{array}{l}267.70 \\
349.60 \\
22.1\end{array}$ & $\begin{array}{c}\mathrm{lbs} / \mathrm{hr} \\
\mathrm{lbs} / \mathrm{hr} \\
\mathrm{drums} / \mathrm{hr}\end{array}$ & $\begin{array}{l}5 \\
6\end{array}$ & $\begin{array}{l}\text { drums/shift } \\
\text { drums/shift }\end{array}$ \\
\hline
\end{tabular}

Assume tank batches are 550 gallons ( 10 drums)

Assume treatment selection time is required for 10 drum batches.

Assume residence time in oil water separator is 1 hour and tank is 1000 gallons (16 gpm)

Assume filtration, centrifuge and ppt rates are $10 \mathrm{gpm}$.

Assume solids to evaporator are $5 \%$ of incoming waste; assume drying rate is $10 \mathrm{gpm}$

Assume UV oxidation unit is $50 \mathrm{gpm}$ 
Table NT2-g Metal Decontamination Subsystem

\begin{tabular}{|c|c|c|c|c|c|c|c|c|}
\hline Task & Subtask & $\begin{array}{c}\text { Occurrence } \\
\text { Shift }\end{array}$ & Units & $\begin{array}{c}\text { Time } \\
\text { Required } \\
\text { (min) }\end{array}$ & $\left|\begin{array}{c}\text { Total Time I } \\
\text { Shift }\end{array}\right|$ & $\begin{array}{c}\text { FTEs } \\
\text { Needed }\end{array}$ & $\begin{array}{c}\text { Minutes/ } \\
\text { Drum }\end{array}$ & $\begin{array}{c}\text { Minutes' } \\
\text { Add'I } \\
\text { Drum }\end{array}$ \\
\hline \multirow{2}{*}{$\begin{array}{l}\text { Metals } \\
\text { Receiving/ } \\
\text { Feed Prep } \\
\text { Total Task }\end{array}$} & Transfer through air lock & 15.8 & drums & 5 & 79 & & & \\
\hline & & & & 5 & 79 & 0.17 & 5 & 0 \\
\hline \multirow[t]{8}{*}{ Waste Decon } & & & & & & & & \\
\hline & Stage containers & 15.8 & drum & 5 & 79 & & & \\
\hline & Decon waste & 15.8 & drum & 10 & 158 & & & \\
\hline & Sssay for recycle & 15.8 & drum & 30 & 475 & & & \\
\hline & Repack in drums & 15.8 & drum & 15 & 238 & & & \\
\hline & Close drum lid & 15.8 & drum & 15 & 238 & & & \\
\hline & Stage drums & 15.8 & drum & 5 & 79 & & & \\
\hline & $\begin{array}{l}\text { Monitor recirc filtration and } \\
\text { fugitive dust system }\end{array}$ & 24.0 & times & 6 & 144 & & & \\
\hline Total Task & & & & 86 & 1411 & 2.94 & 86 & \\
\hline Total FTEs/shift & & & & & & 3.11 & 91 & \\
\hline Supervision & Ratio of $1: 10$ & & & & & 0.31 & & \\
\hline $\begin{array}{l}\text { Vac/sick/ } \\
\text { holiday relief }\end{array}$ & Assume 6 wks of absence & & & & & 0.39 & & \\
\hline Total/shift & & & & & & 3.81 & & \\
\hline $70 \%$ efficiency & & & & & & 5.44 & & \\
\hline Total/day & & & & & & 16.33 & & \\
\hline
\end{tabular}

Notes:

Assume $50 \%$ of waste must be size reduced.

Assume $60 \mathrm{~min} / \mathrm{drum}$ for cutting 
Table NT2-h.

Lead Recovery

\begin{tabular}{|c|c|c|c|c|c|c|c|c|}
\hline Task & Subtask & $\begin{array}{c}\text { Occurrence } \\
\text { / Shift }\end{array} \mid$ & Units & $\begin{array}{c}\text { Time } \\
\text { Required } \\
\text { (min) }\end{array}$ & $\begin{array}{c}\text { Total Time } \\
\text { Shift }\end{array}$ & $\begin{array}{c}\text { FTEs } \\
\text { Needed }\end{array}$ & $\begin{array}{c}\text { Minutes/ } \\
\text { Drum }\end{array}$ & $\begin{array}{c}\text { Minutes/ } \\
\text { Add'l Drum }\end{array}$ \\
\hline \multirow[t]{3}{*}{$\begin{array}{l}\text { Lead Receiving/ } \\
\text { Feed Prep }\end{array}$} & Transfer through air lock & 0.48 & drums & 5 & 2 & & & \\
\hline & $\begin{array}{l}\text { Glove box separation of } \\
\text { sheet lead and gloves }\end{array}$ & 0.48 & drums & 60 & 29 & & & \\
\hline & Stage at decon & 0.48 & drums & 10 & 5 & & & \\
\hline Total Task & & & & 75 & 36 & 0.08 & 75 & \\
\hline \multirow{8}{*}{ Waste Decon } & & & & & & & & \\
\hline & Stage containers & 0.48 & drum & 5 & 2 & & & \\
\hline & Decon waste & 0.48 & drum & 10 & 5 & & & \\
\hline & Assay for recycle & 0.48 & drum & 30 & 14 & & & \\
\hline & Repack in drums & 0.48 & drum & 15 & 7 & & & \\
\hline & Close drum lid & 0.48 & drum & 15 & 7 & & & \\
\hline & Stage drums & 0.48 & drum & 5 & 2 & & & \\
\hline & $\begin{array}{l}\text { Monitor recirc filtration } \\
\text { and fugitive dust system }\end{array}$ & 24.00 & times & 6 & 144 & & & \\
\hline Total Task & & & & 86 & 182 & 0.38 & 86 & 30 \\
\hline Total FTEs/shift & & & & & & $\overline{0.46}$ & $\overline{161}$ & \\
\hline Supervision & Ratio of $1: 10$ & & & & & 0.05 & & \\
\hline $\begin{array}{l}\text { Vac/sick/holiday } \\
\text { refief }\end{array}$ & $\begin{array}{l}\text { Assume } 6 \text { wks of } \\
\text { absence }\end{array}$ & & & & & 0.06 & & \\
\hline Total/shift & & & & & & 0.56 & & \\
\hline $70 \%$ efficiency & & & & & & 0.80 & & \\
\hline Total/day & & & & & & 2.39 & & \\
\hline
\end{tabular}

Notes:

Assume assay for all drums @ $30 \mathrm{~min} / \mathrm{drum}$ 
Table NT2-i. Mercury Amalgamation

\begin{tabular}{|c|c|c|c|c|c|c|c|c|}
\hline Task & Subtask & $\begin{array}{c}\text { Occurrence } \\
\text { / Shift }\end{array}$ & Units & $\begin{array}{c}\text { Time } \\
\text { Required } \\
\text { (min) }\end{array}$ & $\begin{array}{c}\text { Total Time } \\
\text { / Shift }\end{array}$ & $\begin{array}{c}\text { FTEs } \\
\text { Needed }\end{array}$ & $\begin{array}{c}\text { Minutes/ } \\
\text { Drum }\end{array}$ & $\begin{array}{c}\text { Minutes/ } \\
\text { Add'l } \\
\text { Drum }\end{array}$ \\
\hline $\begin{array}{l}\text { Metals Receiving/ } \\
\text { Feed Prep }\end{array}$ & Transfer through air lock & 0.08 & drums & 5 & 0 & & & \\
\hline $\begin{array}{l}\text { Metals Receiving/ } \\
\text { Feed Prep }\end{array}$ & \begin{tabular}{|l} 
Transfer through air lock \\
Transfer liq mercury to tank
\end{tabular} & $\begin{array}{l}0.08 \\
0.06\end{array}$ & \begin{tabular}{|l} 
drums \\
drums
\end{tabular} & $\frac{5}{60}$ & $\frac{0}{4}$ & & & \\
\hline & $\begin{array}{l}\text { Transfer steel wool w/ Hg to } \\
\text { holding bin }\end{array}$ & 0.02 & drums & 10 & 0 & & & \\
\hline Total task & & & & 75 & 4 & 0.01 & 75 & 60 \\
\hline $\begin{array}{l}\text { Mercury } \\
\text { Amalgamation }\end{array}$ & Inspect equipment & 1.00 & time & 30 & & & & \\
\hline & $\begin{array}{l}\text { Transfer liq mercury to } \\
\text { amalgamater (1 gpm) }\end{array}$ & 0.06 & drum & 55 & 3 & & & \\
\hline & Measure additives & 0.08 & drum & 30 & 2 & & & \\
\hline & $\begin{array}{l}\text { Transfer steel wool to } \\
\text { amalgamater }\end{array}$ & 0.08 & drum & 20 & 2 & & & \\
\hline & Batch amalgamation & 0.08 & drum & 120 & 10 & & & 120 \\
\hline & Transfer out of amalgamater & 0.08 & drum & 55 & 4 & & & \\
\hline & Stage & 0.08 & drum & 5 & 0 & & & \\
\hline & Place at assay & 0.08 & drum & 5 & 0 & & & \\
\hline & Assay & 0.08 & drum & 20 & 2 & & & \\
\hline & Remove from assay & 0.08 & drum & 2 & 0 & & & \\
\hline Total Task & & & & 312 & 24 & 0.05 & 312 & 120 \\
\hline Total FTEs/shift & & & & & & 0.06 & 387 & \\
\hline Supervision & Ratio of 1:10 & & & & & 0.01 & & \\
\hline $\begin{array}{l}\text { Vac/sick/holiday } \\
\text { relief }\end{array}$ & Assume 6 wks of absence & & & & & 0.01 & & \\
\hline Total/shift & & & & & & 0.07 & & \\
\hline $70 \%$ efficiency & & & & & & 0.10 & & \\
\hline Total/day & & & & & & 0.31 & & \\
\hline
\end{tabular}

Notes:

Volume of steel wool: assume $3 \times$ vol of steel to mercury

Assume $5 \%$ of mercury is in residue (this should be conservative; $5 \%$ of mercury

is assumed to be in debris, not process residue)

Total volume of mercury in study is $82 \mathrm{lbs} / \mathrm{hr}$.

Therefore volume of steel wool $\mathrm{w} /$ mercury $=$

$0.50 \quad \mathrm{lbs} / \mathrm{hr}$

0.02 drums/shift

Batch size for amalgamater: Assume $1 \mathrm{drum} / \mathrm{batch}, 2 \mathrm{hrs} / \mathrm{batch}$ 


\begin{tabular}{|c|c|c|c|c|c|c|c|c|}
\hline Task & Subtask & $\begin{array}{c}\text { Occurrence/ } \\
\text { Shift }\end{array}$ & Units & $\begin{array}{c}\text { Time } \\
\text { Required } \\
\text { (min) }\end{array}$ & $\begin{array}{c}\text { Total } \\
\text { Time/ Shift }\end{array}$ & $\begin{array}{c}\text { FTEs } \\
\text { Needed }\end{array}$ & $\begin{array}{c}\text { Minutes/ } \\
\text { Drum }\end{array}$ & $\begin{array}{c}\text { Minutes } \\
\text { Add'l } \\
\text { Drum } \\
\end{array}$ \\
\hline \multirow[t]{3}{*}{$\begin{array}{l}\text { Special } \\
\text { Receiving/Feed } \\
\text { Prep }\end{array}$} & Transfer through air lock & 5.44 & drums & - & 27.2 & & & \\
\hline & $\begin{array}{l}\text { Glove box preparation of } \\
\text { wastes }\end{array}$ & 5.44 & drums & 60 & 326.4 & & & \\
\hline & Stage waste & 5.44 & drums & 3 & 16.32 & & & \\
\hline Total Task & & & & 68 & 369.9 & 0.77 & 68 & 60 \\
\hline \multirow[t]{7}{*}{ Waste Treatment } & Stage containers & 5.44 & drum & $\overline{3}$ & 16.32 & & & \\
\hline & $\begin{array}{l}\text { Treat waste as special } \\
\text { processes TBD }\end{array}$ & 5.44 & drum & 60 & 326.4 & & & \\
\hline & Sample treated waste & 5.44 & drum & 15 & 81.6 & & & \\
\hline & repack in drums & 5.44 & drum & 30 & 163.2 & & & \\
\hline & Close drum lid & 5.44 & drum & 3 & 16.32 & & & \\
\hline & Stage drums & 5.44 & drum & 3 & 16.32 & & & \\
\hline & & & & 114 & 620.16 & 1.29 & 114 & 60 \\
\hline Total FTEs/shift & & & & & & 2.06 & 182 & \\
\hline Supervision & Ratio of $1: 10$ & & & & & 0.21 & & \\
\hline $\begin{array}{l}\text { Vac/sick/holiday } \\
\text { relief }\end{array}$ & $\begin{array}{l}\text { Assume } 6 \text { wks of } \\
\text { absence }\end{array}$ & & & & & 0.26 & & \\
\hline Total/shift & & & & & & 2.53 & & \\
\hline $70 \%$ efficiency & & & & & & 3.62 & & \\
\hline Total/day & & & & & & 10.85 & & \\
\hline
\end{tabular}

Notes:

Assume all waste is prepared in glove box

Assume waste is treated in various batch processes that average 2 hours/drum

TBD $=$ To be determined 


\begin{tabular}{|c|c|c|c|c|c|c|c|c|}
\hline Task & Subtask & $\begin{array}{c}\text { Occurrence/ } \\
\text { Shift }\end{array}$ & Units & $\begin{array}{c}\text { Time } \\
\text { Required } \\
\text { (min) }\end{array}$ & $\begin{array}{c}\text { Total Time/ } \\
\text { Shift }\end{array}$ & $\begin{array}{c}\text { FTEs } \\
\text { Needed }\end{array}$ & $\begin{array}{c}\text { Minutes/ } \\
\text { Drum }\end{array}$ & $\begin{array}{l}\text { Minutes/ } \\
\text { Add'l Drum }\end{array}$ \\
\hline \multirow[t]{7}{*}{$\begin{array}{l}\text { Waste Receiving/ } \\
\text { Feed Prep }\end{array}$} & Transfer through air lock & 28.6 & drums & 5 & 143 & & & \\
\hline & Sample waste & 2.9 & drums & 15 & 43 & & & \\
\hline & Select process for waste & 28.6 & drums & 5 & 143 & & & \\
\hline & $\begin{array}{l}\text { Transfer to } \\
\text { macroencapsulation }\end{array}$ & 7.8 & drums & 2 & 16 & & & \\
\hline & $\begin{array}{l}\text { Transfer to } \\
\text { microencapsulation }\end{array}$ & 20.8 & drums & 2 & 42 & & & \\
\hline & Stage at process & 28.6 & drums & 2 & 57 & & & \\
\hline & & & & 31 & 443 & 0.92 & 31 & 5 \\
\hline \multirow[t]{8}{*}{ Waste Encapsulation } & Measure binder & 28.6 & drum & 5 & 143 & & & \\
\hline & Mix binder & 28.6 & drum & 5 & 143 & & & \\
\hline & Combine with waste & 28.6 & drum & 10 & 286 & & & \\
\hline & Repack in drums & 28.6 & drum & 5 & 143 & & & \\
\hline & Close drum lid & 28.6 & drum & 3 & 86 & & & \\
\hline & Stage pallets & 28.6 & drum & 2 & 57 & & & \\
\hline & $\begin{array}{l}\text { Monitor activated carbon } \\
\text { and fugitive dust system }\end{array}$ & 2.0 & times & 6 & 12 & & & \\
\hline & & & & 36 & 869 & 1.81 & 36 & 10 \\
\hline \multirow[t]{5}{*}{ Binder setup time } & $\begin{array}{l}\text { Move pallets to curing } \\
\text { area }\end{array}$ & 28.6 & drum & 2 & 57 & & & \\
\hline & Curing time & 28.6 & drum & & 0 & & & \\
\hline & Sample & 2.9 & drum & 15 & 43 & & & \\
\hline & Monitor curing process & 28.6 & drum & 10 & 286 & & & \\
\hline & $\begin{array}{l}\text { Move pallets from curing } \\
\text { area }\end{array}$ & 28.6 & times & 2 & 57 & & & \\
\hline Total Task & & & & 29 & 443 & 0.92 & 29 & 5 \\
\hline \multirow[t]{9}{*}{ Drum Decon } & Stage containers & 2.9 & drum & 5 & $\overline{14}$ & & & \\
\hline & Load conveyors & 2.9 & drum & 5 & 14 & & & \\
\hline & Decon drums & 2.9 & drum & 10 & 29 & & & \\
\hline & Assay drums & 2.9 & drum & 15 & 43 & & & \\
\hline & Unload conveyers & 2.9 & drum & 5 & 14 & & & \\
\hline & Palletize drums & 2.9 & drum & 2 & 6 & & & \\
\hline & Stage drums & 2.9 & drum & 5 & 14 & & & \\
\hline & & & & & & & & \\
\hline & & & & 47 & 134 & 0.28 & 47 & 15 \\
\hline Total FTEs/shift & & & & & & 3.93 & 143 & \\
\hline Supervision & Ratio of 1:10 & & & & & 0.39 & & \\
\hline Vac/sick/holiday relief & $\begin{array}{l}\text { Assume } 6 \text { wks of } \\
\text { absence }\end{array}$ & & & & & 0.50 & & \\
\hline Total/shift & & & & & & 4.83 & & \\
\hline $70 \%$ efficiency & & & & & & 6.90 & & \\
\hline Total/day & & & & & & 20.69 & & \\
\hline
\end{tabular}

Notes:

Assume all complex debris ( 8 drums) will be sent to macroencapsulation, rest to micro.

Assume $10 \%$ of drums are deconned.

Assume $10 \%$ of drums are assayed

Assume mixing requires $30 \mathrm{~min} / \mathrm{drum}$

Number of samples $=2.9$ 


\begin{tabular}{|c|c|c|c|c|c|c|c|c|}
\hline Task & Subtask & $\begin{array}{c}\text { Occurrence/ } \\
\text { shift }\end{array}$ & Units & $\begin{array}{c}\text { Time } \\
\text { Required } \\
\text { (min) }\end{array}$ & $\begin{array}{c}\text { Total Timel } \\
\text { Shift }\end{array}$ & $\begin{array}{c}\text { FTEs } \\
\text { Needed }\end{array}$ & $\begin{array}{c}\text { Minutes/ } \\
\text { Drum }\end{array}$ & $\begin{array}{l}\text { Minutes' } \\
\text { Add"l } \\
\text { Drum }\end{array}$ \\
\hline \multirow[t]{7}{*}{$\begin{array}{l}\text { Waste } \\
\text { Receiving/Feed } \\
\text { Prep }\end{array}$} & Transfer through air lock & 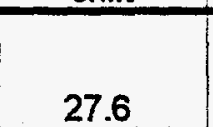 & drums & Lon & $-\pi$ & & & \\
\hline & Sample waste & 2.8 & drums & 15 & 41 & & & \\
\hline & Evaluate dryness & 2.8 & drums & 5 & 14 & & & \\
\hline & Dry waste & 10.9 & drums & 30 & N/A & & & \\
\hline & Monitor drying & 24.0 & times & 10 & 240 & & & \\
\hline & Stage at process & 27.6 & drums & 2 & 55 & & & \\
\hline & & & & 57 & 488 & 1.02 & 57 & 30 \\
\hline \multirow{9}{*}{ Encapsulation } & Measure polymer & 27.6 & drum & 5 & 138 & & & \\
\hline & Mix polymer & 27.6 & drum & 10 & 276 & & & \\
\hline & $\begin{array}{l}\text { Combine with waste in } \\
\text { extruder }\end{array}$ & 27.6 & drum & 10 & 276 & & & \\
\hline & Repack in drums & 24.0 & drum & 5 & 120 & & & \\
\hline & Close drum lid & 27.6 & drum & 3 & 83 & & & \\
\hline & Palletize drums & 27.6 & drum & 2 & 55 & & & \\
\hline & Stage drums & 24.0 & drum & 2 & 48 & & & \\
\hline & $\begin{array}{l}\text { Monitor activated carbon } \\
\text { and fugitive dust system }\end{array}$ & 8.0 & times & 6 & 48 & & & \\
\hline & & & & 43 & 1044 & 2.18 & 43 & 60 \\
\hline \multirow{6}{*}{ Binder setup time } & $\begin{array}{l}\text { Move pallets to curing } \\
\text { area }\end{array}$ & 24.0 & drum & 5 & 120 & & & \\
\hline & Curing time & 24.0 & drum & & 0 & & & \\
\hline & Sample & 2.4 & drum & 15 & 36 & & & \\
\hline & Monitor curing & 24.0 & drum & 10 & 240 & & & \\
\hline & $\begin{array}{l}\text { Move pallets from curing } \\
\text { area }\end{array}$ & 24.0 & times & 5 & 120 & & & \\
\hline & & & & 35 & 516 & 1.08 & 35 & 5 \\
\hline \multirow[t]{6}{*}{ Drum Decon } & Stage containers & 27.6 & drum & 5 & 138 & & & \\
\hline & Load conveyors & 27.6 & drumin & 5 & 138 & & & \\
\hline & Decon drums & 27.6 & drum & 10 & 276 & & & \\
\hline & Assay drums & 27.6 & drum & 15 & 414 & & & \\
\hline & Unload conveyers & 27.6 & drum & 5 & 138 & & & \\
\hline & Stage drums & 27.6 & drum & 5 & 138 & & & \\
\hline Total Task & & & & 45 & 1242 & 2.59 & 45 & 60 \\
\hline TotalFTEs/shift & & & & & & 6.86 & 180 & \\
\hline Supervision & Ratio of $1: 10$ & & & & & 0.69 & & \\
\hline $\begin{array}{l}\text { Vac/sick/holiday } \\
\text { relief }\end{array}$ & Assume 6 wks of absence & & & & & 0.87 & & \\
\hline Total/shift & & & & & & 8.41 & & \\
\hline $70 \%$ efficiency & & & & & & 12.02 & & \\
\hline Total/day & & & & & & 36.05 & & \\
\hline
\end{tabular}

Notes:

Assume $30 \%$ of process residue waste and $100 \%$ of other waste requires drying

Assume dryer can accept waste at the rate of 2 drums/hour

No. of samples $=2.4$ 
Table NT2-m. Air Pollution Control Subsystem

\begin{tabular}{|c|c|c|c|c|c|c|c|}
\hline Task & Subtask & $\begin{array}{c}\text { Occurrence/ } \\
\text { Shift }\end{array}$ & Units & $\begin{array}{c}\text { Time } \\
\text { Required } \\
\text { (min) }\end{array}$ & $\begin{array}{c}\text { Total Time } \\
\text { Shift }\end{array}$ & $\begin{array}{c}\text { FTEs } \\
\text { Needed }\end{array}$ & Minutes/lb \\
\hline $\begin{array}{l}\text { Monitor } \\
\text { Equipment }\end{array}$ & Dry filtration & 4 & times & 10 & 40 & & \\
\hline & HEPA filter & 4 & times & 5 & 20 & & \\
\hline & GPCR & 24 & times & 2 & 48 & & \\
\hline & Acid gas scrubber & 12 & times & 10 & 120 & & \\
\hline & Mist eliminator & 4 & times & 2 & 8 & & \\
\hline & GAC & 4 & times & 2 & 8 & & \\
\hline & Mersorb & 4 & times & 2 & 8 & & \\
\hline & Offgas monitor & 24 & times & 5 & 120 & & \\
\hline Total Task & & & & 38 & 372 & 0.78 & 0 \\
\hline Supervision & Ratio of $1: 10$ & & & & & 0.08 & \\
\hline $\begin{array}{l}\text { Vac/sick/holiday } \\
\text { relief }\end{array}$ & $\begin{array}{l}\text { Assume } 6 \text { wks of } \\
\text { absence }\end{array}$ & & & & & 0.10 & \\
\hline Total/shift & & & & & & 0.95 & \\
\hline $70 \%$ efficiency & & & & & & 1.36 & \\
\hline Total/day & & & & & & 4.08 & \\
\hline
\end{tabular}


Table NT2-n.

Certification and Shipping

\begin{tabular}{|c|c|c|c|c|c|c|c|c|}
\hline Task & Subtask & $\begin{array}{c}\text { Occurrencel } \\
\text { Shift }\end{array}$ & Units & $\begin{array}{c}\text { Time } \\
\text { Required } \\
\text { (min) }\end{array}$ & $\begin{array}{c}\text { Total Time/ } \\
\text { Shift }\end{array}$ & $\begin{array}{l}\text { FTEs } \\
\text { Needed }\end{array}$ & $\begin{array}{c}\text { Minutes/ } \\
\text { Drum }\end{array}$ & $\begin{array}{l}\text { Minute } \\
\text { Add'l } \\
\text { Drum }\end{array}$ \\
\hline \multirow[t]{5}{*}{ Waste Receiving } & Transfer through air lock & 49.8 & drums & 5 & 249 & & & \\
\hline & Sample waste & 5.0 & drums & 15 & 75 & & & \\
\hline & Resample waste & 0.5 & drums & 15 & 7 & & & \\
\hline & Stage waste & 49.8 & drums & 5 & 249 & & & \\
\hline & & & & 40 & 580 & 1.21 & 40 & 15 \\
\hline \multirow[t]{8}{*}{ Waste Assay } & Stage pallets & 49.8 & drum & 3 & 149 & & & \\
\hline & Load on conveyor & 49.8 & drum & 1 & 50 & & & \\
\hline & Assay RTR & 49.8 & drum & 15 & 746 & & & \\
\hline & Assay gamma & 49.8 & drum & 60 & 2986 & & & \\
\hline & Assay PAN & 49.8 & drum & 60 & 2986 & & & \\
\hline & Remove from conveyor & 49.8 & drum & 1 & 50 & & & \\
\hline & Repalletize & 49.8 & drum & 3 & 149 & & & \\
\hline & Stage pallets after assaying & 49.8 & drum & 15 & 746 & & & \\
\hline Total Task & & & & 158 & 7862 & 16.38 & 158 & 60 \\
\hline \multirow[t]{4}{*}{ Stage waste } & Stage uncertified waste & 49.8 & drum & 3 & 149 & & & \\
\hline & Transfer waste & 49.8 & drum & 3 & 149 & & & \\
\hline & Stage certified waste & 49.8 & drum & 3 & 149 & & & \\
\hline & Transfer waste & 49.8 & drum & 3 & 149 & & & \\
\hline Total Task & & & & 12 & 597 & 1.24 & 12 & \\
\hline \multirow[t]{4}{*}{ Ship Waste Truck } & Truck docking & 0.6 & truck & 30 & 17 & & & \\
\hline & Settle Paperwork & 0.6 & truck & 120 & 68 & & & \\
\hline & Load truck & 0.6 & truck & 60 & 34 & & & \\
\hline & Truck leaving & 0.6 & truck & 60 & 34 & & & \\
\hline Total Task & & & & 270 & 153 & 0.32 & 12 & \\
\hline Total FTEs/shift & & & & & & 19.15 & 222 & \\
\hline Supervision & Ratio of $1: 10$ & & & & & 1.91 & & \\
\hline $\begin{array}{l}\text { Vac/sick/holiday } \\
\text { relief }\end{array}$ & Assume 6 wks of absence & & & & & 2.43 & & \\
\hline Total/shift & & & $=$ & & & 23.49 & & \\
\hline $\begin{array}{l}\text { Adjustment for } 70 \% \\
\text { Efficiency }\end{array}$ & & & & & & 33.56 & & \\
\hline Total/day & & & & & & 100.69 & & \\
\hline
\end{tabular}

Notes:

Assume $10 \%$ of waste require sampling

Samples collected $=5.0$ 


\begin{tabular}{|c|c|c|c|c|c|c|}
\hline & Daily FTEs & $\begin{array}{l}\text { Time (min)/ } \\
\text { Single drum }\end{array}$ & Time (hrs) & $\begin{array}{c}\text { Add'l Time } \\
\text { for Next } \\
\text { Drum }\end{array}$ & \begin{tabular}{|c|}
$\begin{array}{c}\text { Time/ Drums } \\
\text { Received in a Shift } \\
\text { (minutes) }\end{array}$ \\
\end{tabular} & Time (hrs) \\
\hline Admininstration & 52.1 & N/A & & & & \\
\hline $\begin{array}{l}\text { Receiving / InspectionTasks } \\
\text { common for all waste }\end{array}$ & & 802 & 13.4 & 60 & 3727.6 & 62 \\
\hline Receiving and Prep-CWO & & 0 & 0.0 & & 0.0 & 0 \\
\hline Receiving and Prep-residue & & 229 & 3.8 & 45 & 1328.8 & 22 \\
\hline Receiving and Prep-soil & & 229 & 3.8 & 45 & 425.2 & 7 \\
\hline Receiving and Prep-debris & & 288.5 & 4.8 & 5 & 458.3 & 8 \\
\hline Receiving and Prep-lead & & 557 & 9.3 & 315 & 557.0 & 9 \\
\hline Receiving and Prep-mercury & & 516 & 8.6 & 315 & 516.0 & 9 \\
\hline Receiving and Prep-special & & 516 & 8.6 & 315 & 1914.6 & 32 \\
\hline Receiving and Prep-metal decon & & 229 & 3.8 & 35 & 554.4 & 9 \\
\hline Receiving and Prep & 197.7 & 676.2 & 11.3 & & & 0 \\
\hline Aqueous Waste & 14.4 & 175 & 2.9 & 36 & 934.3 & 16 \\
\hline Organic Destruction & 10.7 & 206 & 3.4 & 34 & 333.5 & 6 \\
\hline Vacuum Thermal Desorption & 23.0 & 425 & 7.1 & 26 & 1060.4 & 18 \\
\hline Metal Decon & 16.3 & 91 & 1.5 & 75 & 1204.0 & 20 \\
\hline Lead & 2.4 & 161 & 2.7 & N/A & 161.0 & 3 \\
\hline Mercury & 0.3 & 387.0 & 6.5 & N/A & 387.0 & 6 \\
\hline Special & 10.8 & 182.0 & 3.0 & 60.0 & 448.4 & 7 \\
\hline Grout & 20.7 & 143 & 2.4 & 10 & 418.6 & 7 \\
\hline Polymer & 36.0 & 180 & 3.0 & 60 & 1776.0 & 30 \\
\hline APC & 4.1 & 372 & 6.2 & & 372.0 & 6 \\
\hline Certification and Shipping & 100.7 & 222 & 3.7 & 60 & 3147.6 & 52 \\
\hline Total & 489.4 & & & & & \\
\hline
\end{tabular}

Notes:

Allocation of receiving and preparation time was done as follows:

Average time per drum was estimated, multiplied by the number of drums per shift. The time for each waste type was allocated according its percentage of total waste. 



\section{System NT-3 Time and Motion Study Tables}

NT3-a System NT-3: Time and Motion Analysis

NT3-b Administration Subsystem

NT3-c Receiving and Preparation Subsystem

NT3-d MEO Organic Destruction Subsystem

NT3-e Aqueous Waste Treatment Subsystem

NT3-f Aqueous Wash for Soil and Process Residue

NT3-g High Pressure Wash for Open Debris

NT3-h Metal Decontamination Subsystem

NT3-i Lead Recovery

NT3-j Mercury Amalgamation

NT3-k Special Waste

NT3-1 Grout Stabilization Subsystem

NT3-m Polymer Stabilization Subsystem

NT3-n Air Pollution Control Subsystem

NT3-o Certification and Shipping

NT3-p Summary of FTEs and time for a single drum to work through a system 


\begin{tabular}{|c|c|c|c|c|c|c|}
\hline Subsystem & $\begin{array}{l}\text { Mass Flow } \\
(\mathrm{lb} / \mathrm{hr})\end{array}$ & Waste Type & $\begin{array}{l}\text { No. of } \\
\text { Drums }\end{array}$ & $\begin{array}{c}\text { SCM } \\
\text { Unprocessed } \\
\text { Density } \\
\text { kg/m3 }\end{array}$ & $\begin{array}{l}\text { Density } \\
\mathrm{lb} / \mathrm{ft} 3\end{array}$ & $\begin{array}{l}\text { Density } \\
\mathrm{lb} / \text { drum }\end{array}$ \\
\hline Administration & 2,927 & & & & & \\
\hline Receiving and preparation & 2,927 & all & 6.2 & & 64.0 & 470.6 \\
\hline Aqueous waste treatment & 1,632 & $\mathrm{~L} 1100$ & 3.6 & & 62.0 & 455.9 \\
\hline Organic destruction & 326 & 22110 & 0.7 & & 62.0 & 455.9 \\
\hline $\begin{array}{l}\text { Process residue and inorganic } \\
\text { sludge treatment }\end{array}$ & 1,020 & S3120 & 3.2 & 700 & 43.7 & 321.2 \\
\hline Bulk soil treatment & 329 & $\mathbf{S 4 1 0 0}$ & 0.7 & & 67.0 & 492.6 \\
\hline Soft Debris treatment & 435 & 55300 & 3.0 & 320 & 20.0 & 146.8 \\
\hline Open Debris treatment & 80 & $\mathbf{5 5 1 1 0}$ & 0.4 & 400 & 25.0 & 183.5 \\
\hline Complex Debris treatment & 177 & $\mathbf{5 1 1 0}$ & 1.0 & 400 & 25.0 & 183.5 \\
\hline Metal decontamination & 462 & $\mathbf{S 5 1 1 0}$ & 2.0 & 509 & 31.8 & 233.5 \\
\hline Mercury amalgamation & 3 & X7100 & 0.003 & 2000 & 124.8 & 917.6 \\
\hline Lead recovery & 26 & $\times 7200$ & 0.0 & 2000 & 124.8 & 917.6 \\
\hline Polymer stabilization & 1,246 & $\$ 3120$ & 3.9 & 700 & 43.7 & 321.2 \\
\hline Air pollution control & 827 & & $\mathrm{~N} / \mathrm{A}$ & & & \\
\hline Grout stabilization & 958 & soil/debris & 2.8 & 750 & 46.8 & 344.1 \\
\hline Special treatment & 155 & $\times 6000, \times 7500$ & 0.7 & 500 & 31.2 & 229.4 \\
\hline Certification and shipping & 4,919 & 2000 & 6.2 & N/A & 107.9 & 793.4 \\
\hline vol reduction (out/in) & 0.60 & & 1.0 & & & \\
\hline
\end{tabular}

\section{Notes:}

This table provides the basis for the time and motion analysis.

Quantities of waste to a subsystem (Ibs/hr) are based on LMITCO mass balance.

Densities are the same as the LMITCO mass balance except where values are shown in the SCM column.

Where values are shown in the SCM column, densities are taken from SCM and converted to $\mathrm{Ib} / \mathrm{cu} \mathrm{ft}$

The waste quantities are converted from Ibs/hr to drums/hr.

Subsequent analysis is based on drums/shift of waste to a subsystem.

Waste to CSHIP includes recyclable metals and treated solid waste ready for disposal. 


\begin{tabular}{|c|c|c|c|c|c|}
\hline Task & Subtask & $\begin{array}{l}\text { FTEs } \\
\text { Needed }\end{array}$ & $\begin{array}{l}\text { Samples/ } \\
\text { Shift }\end{array}$ & $\begin{array}{c}\text { Time } \\
\text { Required } \\
\text { (min) }\end{array}$ & $\begin{array}{c}\text { Total Time } \\
\text { Shift }\end{array}$ \\
\hline Facility Management & $\begin{array}{l}\text { Facility Manager } \\
\text { Secretary } \\
\text { Receptionist/word processor }\end{array}$ & $\begin{array}{l}1 \\
1 \\
1\end{array}$ & & & \\
\hline Operations Management & $\begin{array}{l}\text { Department managers } \\
\text { Communications } \\
\text { Engineering Manager } \\
\text { Engineering staff } \\
\text { Maintenance Supervisor }\end{array}$ & $\begin{array}{l}2 \\
1 \\
1 \\
2 \\
1\end{array}$ & & & \\
\hline Personnel & $\begin{array}{l}\text { Personnel Manager } \\
\text { Nurse/medical/industrial safety } \\
\text { Security guards at facility } \\
\text { Security at guard bldg }\end{array}$ & $\begin{array}{l}1 \\
1 \\
4 \\
4\end{array}$ & & & \\
\hline Environmental & $\begin{array}{l}\text { Environmental manager } \\
\text { Environmental clerk }\end{array}$ & $\begin{array}{l}1 \\
1 \\
\end{array}$ & & & \\
\hline Shipping/receiving/Traffic & $\begin{array}{l}\text { Manager } \\
\text { Clerk }\end{array}$ & $\begin{array}{l}1 \\
1\end{array}$ & & & \\
\hline Purchasing & Buyer & 1 & & & \\
\hline Accounting & $\begin{array}{l}\text { Cost Accounting } \\
\text { Accounting Clerk } \\
\text { Payroll Clerks }\end{array}$ & $\begin{array}{l}2 \\
1 \\
2\end{array}$ & & & \\
\hline Laboratory & $\begin{array}{l}\text { Laboratory Manager } \\
\text { Lab Shift manager } \\
\text { Lab technicians for OSORT } \\
\text { Lab technicians for internal processes } \\
\text { Lab technicians for final waste form } \\
\text { Lab technicians for incoming supplies }\end{array}$ & $\begin{array}{c}1 \\
4 \\
4 \\
10 \\
3 \\
0.2\end{array}$ & $\begin{array}{c}11.1 \\
89.5 \\
10.3 \\
1.0\end{array}$ & $\begin{array}{l}30.0 \\
10.0 \\
30.0 \\
20.0\end{array}$ & $\begin{array}{l}334.0 \\
895.5 \\
308.6 \\
20.0 \\
\end{array}$ \\
\hline Health Physics & $\begin{array}{l}\text { Shift health physics staff } \\
\text { Health physics manager }\end{array}$ & $\begin{array}{l}4 \\
1\end{array}$ & & & \\
\hline & $\begin{array}{l}\text { Total except Lab } \\
\text { Total Lab } \\
\text { Total Admin }\end{array}$ & $\begin{array}{l}35 \\
22 \\
57\end{array}$ & & & \\
\hline
\end{tabular}


Table NT3-c. Receiving and Preparation Subsystem

\begin{tabular}{|c|c|c|c|c|c|c|c|c|}
\hline Task & Subtask & $\begin{array}{c}\text { Occurrence } \\
\text { I Shift }\end{array}$ & $\begin{array}{c}\text { Units for } \\
\text { Occurrence }\end{array}$ & $\begin{array}{l}\text { Time } \\
\text { Required } \\
\text { (min) }\end{array}$ & $\begin{array}{c}\text { Total Time } \\
\text { Shift }\end{array} \mid$ & $\begin{array}{l}\text { FTEs } \\
\text { Needed }\end{array}$ & $\begin{array}{l}\text { Add'l Time } \\
\text { for Next } \\
\text { Drum }\end{array}$ & \begin{tabular}{|c|} 
Average \\
Minutes/ Shitt \\
Drum
\end{tabular} \\
\hline \multirow{6}{*}{$\begin{array}{l}\text { Receive Waste } \\
\text { Truck }\end{array}$} & & & & & & \multirow[b]{7}{*}{0.32} & \multirow{7}{*}{-1.} & \multirow[b]{7}{*}{153} \\
\hline & Truck docking & 0.6 & truck & 30 & 17 & & & \\
\hline & Settle Paperwork & 0.6 & truck & 120 & 68 & & & \\
\hline & Unload truck & 0.6 & truck & 60 & 34 & & & \\
\hline & Stage pallets & 0.6 & truck & 60 & 34 & & & \\
\hline & No of pallets/shift & & & & & & & \\
\hline Total Task 1 & & & & 270 & 153 & & & \\
\hline \multirow[t]{4}{*}{$\begin{array}{l}\text { Receive Empty } \\
\text { container Truck }\end{array}$} & Truck docking & 0.3 & truck & 30 & 8 & \multirow[b]{5}{*}{0.08} & \multirow[b]{5}{*}{0} & \multirow[b]{5}{*}{40} \\
\hline & Settle Paperwork & 0.3 & truck & 30 & 8 & & & \\
\hline & Unload truck & 0.3 & truck & 60 & 17 & & & \\
\hline & Stage pallets & 0.3 & truck & 20 & 6 & & & \\
\hline Total Task 2 & & & & 140 & 40 & & & \\
\hline \multirow[t]{5}{*}{ Receive supplies } & Truck docking & 0.2 & truck & 30 & 6 & \multirow[b]{5}{*}{0.06} & \multirow[b]{5}{*}{0} & \multirow[b]{5}{*}{28} \\
\hline & Settle Paperwork & 0.2 & truck & 30 & 6 & & & \\
\hline & Unload truck & 0.2 & truck & 60 & 12 & & & \\
\hline & Stage pallets & 0.2 & truck & 20 & 4 & & & \\
\hline & & & & 140 & 28 & & & \\
\hline \multirow[t]{3}{*}{$\begin{array}{l}\text { Transfer to } \\
\text { Interim Storage }\end{array}$} & $\begin{array}{l}\text { Move pallets to } \\
\text { storage area }\end{array}$ & 6.2 & Pallet & 5 & 31 & \multirow[b]{4}{*}{0.26} & \multirow[b]{4}{*}{10} & \multirow[b]{4}{*}{10} \\
\hline & $\begin{array}{l}\text { Stack pallets/ } \\
\text { organize storage }\end{array}$ & 6.2 & Pallet & 10 & 62 & & & \\
\hline & Transfer to assay & 6.2 & Pallet & 5 & 31 & & & \\
\hline Total Task 4 & & & & 20 & 124 & & & \\
\hline \multirow{10}{*}{ Assay Drums } & Stage pallets & 12.4 & Pallet & 5 & 62 & \multirow[b]{10}{*}{14.77} & \multirow[b]{10}{*}{60} & \multirow[b]{10}{*}{150} \\
\hline & Load on conveyor & 49.8 & drum & 1 & 50 & & & \\
\hline & Assay RTR & 49.8 & drum & 15 & 746 & & & \\
\hline & Assay gamma & 49.8 & drum & 60 & 2986 & & & \\
\hline & Assay PAN & 49.8 & drum & 60 & 2986 & & & \\
\hline & $\begin{array}{l}\text { Remove from } \\
\text { conveyor }\end{array}$ & 49.8 & drum & 1 & 50 & & & \\
\hline & Repalletize & 49.8 & drum & 3 & 149 & & & \\
\hline & Stage pallets after & & & & & & & \\
\hline & assaying & 12.4 & Pallet & 5 & 62 & & & \\
\hline & & & & 150 & 7091 & & & \\
\hline Stage and move & Store solid waste & & & & & & & \\
\hline to OSORT & by category & 10.6 & Pallet & 10 & 106 & & & \\
\hline & Move to OSORT & 10.6 & Pallet & 5 & 53 & & & \\
\hline & Stage at OSORT & 10.6 & Pallet & 5 & 53 & & & \\
\hline Total Task 6 & & & Pallet & 20 & 213 & 0.44 & 5 & 17 \\
\hline Open Drums & Stage at drum & & & & & & & \\
\hline & opener & 10.6 & Pallet & 5 & 53 & & & \\
\hline & Load on conveyor & 42.6 & Drums & 5 & 213 & & & \\
\hline & Drum lid clamp & 42.6 & drum & 2 & 85 & & & \\
\hline & Drum lid opener & 42.6 & drum & 5 & 213 & & & \\
\hline & Lid staging & 42.6 & drum & 1 & 43 & & & \\
\hline & $\begin{array}{l}\text { Remove from } \\
\text { conveyor }\end{array}$ & 42.6 & drum & 1 & 43 & & & \\
\hline Total Task 7 & & & & 19 & 575 & 1.20 & 5 & 16 \\
\hline Dump Drums & $\begin{array}{l}\text { Assign drums to } \\
\text { dump stations }\end{array}$ & 42.6 & drum & 3 & 128 & & & \\
\hline & $\begin{array}{l}\text { Move drums to sort } \\
\text { table /bins }\end{array}$ & 42.6 & drum & 5 & 213 & & & \\
\hline & Dump drums & 42.6 & drum & 5 & 213 & & & \\
\hline Total Task 8 & & & & 13 & 554 & 1.15 & 5 & 11 \\
\hline
\end{tabular}


Table NT3-c. Receiving and Preparation Subsystem

\begin{tabular}{|c|c|c|c|c|c|c|c|c|}
\hline Task & Subtask & $\begin{array}{c}\text { Occurrence } \\
\text { / Shift }\end{array}$ & $\begin{array}{c}\text { Units for } \\
\text { Occurrence }\end{array}$ & $\begin{array}{l}\text { Time } \\
\text { Required } \\
\text { (min) }\end{array}$ & $\begin{array}{c}\text { Total Time } \\
\text { Shift }\end{array}$ & $\begin{array}{c}\text { FTEs } \\
\text { Needed }\end{array}$ & $\begin{array}{c}\text { Add'l Time } \\
\text { for Next } \\
\text { Drum }\end{array}$ & \begin{tabular}{|c|} 
Average \\
Minutes/ Shift/ \\
Drum
\end{tabular} \\
\hline \multirow[t]{5}{*}{ Sort Drums } & $\begin{array}{l}\text { Sort waste } \\
\text { robotically }\end{array}$ & 31.9 & drum & 30 & 958 & \multirow[b]{5}{*}{3.39} & \multirow[b]{5}{*}{45} & \multirow[b]{5}{*}{38} \\
\hline & $\begin{array}{l}\text { Transfer waste to } \\
\text { container }\end{array}$ & 31.9 & drum & 15 & 479 & & & \\
\hline & $\begin{array}{l}\text { select destination } \\
\text { for sorted waste }\end{array}$ & 31.9 & drum & 3 & 96 & & & \\
\hline & $\begin{array}{l}\text { Move container to } \\
\text { subsystem bin or } \\
\text { shredder }\end{array}$ & 31.9 & drum & 3 & 96 & & & \\
\hline & & & & 51 & 1629 & & & \\
\hline \multirow[t]{6}{*}{ Glove Box Sort } & $\begin{array}{l}\text { Transfer to glove } \\
\text { box (several trips) }\end{array}$ & 6.8 & drum & 30 & 205 & \multirow[b]{7}{*}{5.34} & \multirow[b]{7}{*}{315} & \multirow[b]{7}{*}{5} \\
\hline & $\begin{array}{l}\text { Sort waste by hand } \\
\text { in glove box }\end{array}$ & 6.8 & drum & 240 & 1639 & & & \\
\hline & Sampling (1/drum) & 6.8 & drum & 15 & 102 & & & \\
\hline & $\begin{array}{l}\text { Transfer waste to } \\
\text { containers }\end{array}$ & 6.8 & drum & 60 & 410 & & & \\
\hline & $\begin{array}{l}\text { Select destination } \\
\text { for sorted waste }\end{array}$ & 6.8 & drum & 15 & 102 & & & \\
\hline & $\begin{array}{l}\text { Move containers to } \\
\text { subsystem bin or } \\
\text { shredder }\end{array}$ & 6.8 & drum & 15 & 102 & & & \\
\hline Total Task 10 & & & & 375 & 2562 & & & \\
\hline \multirow[t]{4}{*}{$\begin{array}{l}\text { Assess Debris for } \\
\text { Debris Rule } \\
\text { Compliance }\end{array}$} & $\begin{array}{l}\text { Transfer open and } \\
\text { complex debris }\end{array}$ & 35.0 & drum & 3 & 105 & \multirow[b]{5}{*}{1.06} & \multirow[b]{5}{*}{5} & \multirow[b]{5}{*}{6} \\
\hline & Screen debris & 35.0 & drum & 4 & 140 & & & \\
\hline & \begin{tabular}{|l} 
Additional \\
sampling (25\%)
\end{tabular} & 8.7 & drum & 10 & 87 & & & \\
\hline & Inspection & 35.0 & drum & 5 & 175 & & & \\
\hline Total Task 11 & & & & 22 & 507 & & & \\
\hline \multirow[t]{4}{*}{$\begin{array}{l}\text { Gross Size } \\
\text { Reduction }\end{array}$} & $\begin{array}{l}\text { Transfer to cutting } \\
\text { table }\end{array}$ & 13.8 & drum & 3 & 41 & & & \\
\hline & Cut waste & 13.8 & drum & 30 & 413 & & & \\
\hline & Return to container & 13.8 & drum & 5 & 69 & & & \\
\hline & $\begin{array}{l}\text { Transfer to next } \\
\text { process }\end{array}$ & 13.8 & drum & 3 & 41 & & & \\
\hline \multirow{11}{*}{$\begin{array}{l}\text { Total Task } 12 \\
\text { Shredding }\end{array}$} & & & & 41 & 564 & 1.18 & 35 & 6 \\
\hline & $\begin{array}{l}\text { Transfer to } \\
\text { shredder }\end{array}$ & 37.3 & drum & 2 & 75 & \multirow[b]{11}{*}{1.73} & \multirow[b]{11}{*}{2} & \multirow[b]{11}{*}{30} \\
\hline & Stage waste & 37.3 & drum & 2 & 75 & & & \\
\hline & $\begin{array}{l}\text { Feed waste to } \\
\text { shredder }\end{array}$ & 37.3 & drum & 2 & 75 & & & \\
\hline & $\begin{array}{l}\text { Feed bad drums to } \\
\text { shredder }\end{array}$ & 21.3 & drum & 2 & 43 & & & \\
\hline & Shred stage 1 & 58.6 & drum & 2 & 117 & & & \\
\hline & Shred stage 2 & 58.6 & drum & 2 & 117 & & & \\
\hline & $\begin{array}{l}\text { Sample size of } \\
\text { waste }\end{array}$ & 5.9 & drum & 5 & 29 & & & \\
\hline & Rework 10\% & 0.6 & drum & 15 & 9 & & & \\
\hline & Return to container & 58.6 & drum & 3 & 176 & & & \\
\hline & $\begin{array}{l}\text { Transfer to next } \\
\text { process }\end{array}$ & 58.6 & drum & 2 & 117 & & & \\
\hline Total Task 13 & & & & 37 & 832 & & & \\
\hline
\end{tabular}


Table NT3-c. Receiving and Preparation Subsystem

\begin{tabular}{|c|c|c|c|c|c|c|c|c|}
\hline Task & Subtask & $\begin{array}{c}\text { Occurrence } \\
\text { IShift }\end{array}$ & $\begin{array}{c}\text { Units for } \\
\text { Occurrence }\end{array}$ & $\begin{array}{l}\text { Time } \\
\text { Required } \\
\text { (min) }\end{array}$ & $\begin{array}{c}\text { Total Time } \\
\text { Shift }\end{array}$ & $\begin{array}{c}\text { FTEs } \\
\text { Needed }\end{array}$ & $\begin{array}{l}\text { Add' Time } \\
\text { for Next } \\
\text { Drum }\end{array}$ & \begin{tabular}{|c|} 
Average \\
Minutes/ Shitt \\
Drum
\end{tabular} \\
\hline Sampling & $\begin{array}{l}\text { Sample opened } \\
\text { drums }\end{array}$ & 4.3 & drum & 5 & 21 & \multirow[b]{5}{*}{0.46} & \multirow[b]{5}{*}{10} & \multirow[b]{5}{*}{30} \\
\hline & $\begin{array}{l}\text { Sample sorted } \\
\text { waste }\end{array}$ & 5.9 & drum & 5 & 29 & & & \\
\hline & Resample (10\%) & 1.0 & drum & 5 & 5 & & & \\
\hline \multirow[b]{2}{*}{ Total Task 14} & Reportleval. results & 11.1 & drum & 10 & 111 & & & \\
\hline & & & & 25 & 167 & & & \\
\hline \multirow[t]{6}{*}{$\begin{array}{l}\text { Subsystem Bin } \\
\text { operation }\end{array}$} & Monitor bin height & 4.3 & drum & 3 & 13 & \multirow[b]{6}{*}{0.31} & \multirow[b]{6}{*}{0} & \multirow[b]{6}{*}{26} \\
\hline & Fill containers & 4.3 & drum & 3 & 13 & & & \\
\hline & Move containers & 4.3 & drum & 2 & 9 & & & \\
\hline & Stage containers & 4.3 & drum & 3 & 13 & & & \\
\hline & $\begin{array}{l}\text { Organize } \\
\text { campaigns }\end{array}$ & 4.3 & drum & 15 & 64 & & & \\
\hline & & & & 26 & 111 & & & \\
\hline \multirow[t]{9}{*}{ Internal Transfer } & $\begin{array}{l}\text { Move waste from } \\
\text { OSORT to other } \\
\text { subsystems }\end{array}$ & 4.3 & drum & 10 & 43 & \multirow[b]{9}{*}{5.42} & \multirow[b]{9}{*}{10} & \multirow[b]{9}{*}{57} \\
\hline & $\begin{array}{l}\text { Move waste from } \\
\text { subsystems to } \\
\text { CSHIP }\end{array}$ & 49.6 & drum & 10 & 496 & & & \\
\hline & $\begin{array}{l}\text { Move treated } \\
\text { waste to } \\
\text { stabilization } \\
\end{array}$ & 80.0 & drum & 10 & 800 & & & \\
\hline & $\begin{array}{l}\text { Move liquid waste } \\
\text { to AQWTR and } \\
\text { OrgDes }\end{array}$ & 7.2 & drum & 10 & 72 & & & \\
\hline & $\begin{array}{l}\text { Move waste to } \\
\text { secondary } \\
\text { treatment }\end{array}$ & 20.0 & drum & 10 & 200 & & & \\
\hline & $\begin{array}{l}\text { Move supplies } \\
\text { around }\end{array}$ & 20.0 & drum & 3 & 60 & & & \\
\hline & Move new drums & 24.9 & drum & 3 & 75 & & & \\
\hline & $\begin{array}{l}\text { Schedule } \\
\text { movement }\end{array}$ & 205.9 & drum & 1 & 206 & & & \\
\hline & & & & 57 & 1951 & & & \\
\hline \multirow[t]{4}{*}{ Box Breakdown } & Stage boxes & 10.0 & box & 2 & 20 & \multirow[b]{5}{*}{0.50} & \multirow[b]{5}{*}{10} & \multirow[b]{5}{*}{2} \\
\hline & $\begin{array}{l}\text { Move to opening } \\
\text { area }\end{array}$ & 10.0 & box & 3 & 30 & & & \\
\hline & Open boxes & 10.0 & box & 10 & 100 & & & \\
\hline & Transfer to dump & 10.0 & box & 3 & 30 & & & \\
\hline Total Task 17 & & & & 18 & 180 & & & \\
\hline \multirow[t]{6}{*}{ Container Decon } & Stage containers & 49.8 & drum & 5 & 249 & \multirow[b]{7}{*}{6.22} & \multirow[b]{7}{*}{15} & \multirow[b]{7}{*}{45} \\
\hline & Load conveyors & 49.8 & drum & 5 & 249 & & & \\
\hline & Decon drums & 49.8 & drum & 10 & 498 & & & \\
\hline & Assay drums & 49.8 & drum & 15 & 746 & & & \\
\hline & Unload conveyers & 49.8 & drum & 5 & 249 & & & \\
\hline & Stage drums & 49.8 & drum & 5 & 249 & & & \\
\hline Total Task 18 & & & & 45 & 2239 & & & \\
\hline
\end{tabular}


Table NT3-c. Receiving and Preparation Subsystem

\begin{tabular}{|c|c|c|c|c|c|c|c|c|}
\hline Task & Subtask & $\begin{array}{c}\text { Occurrence } \\
\text { I Shift }\end{array}$ & $\begin{array}{l}\text { Units for } \\
\text { Occurrence }\end{array}$ & $\begin{array}{c}\text { Time } \\
\text { Required } \\
\text { (min) }\end{array}$ & $\begin{array}{c}\text { Total Time } \\
\text { Shift }\end{array}$ & $\begin{array}{c}\text { FTEs } \\
\text { Needed } \\
\end{array}$ & $\begin{array}{l}\text { Add'l Time } \\
\text { for Next } \\
\text { Drum } \\
\end{array}$ & \begin{tabular}{|c|} 
Average \\
Minutes/ Shift \\
Drum
\end{tabular} \\
\hline FTEs/shift & & & & & 0 & \multirow{4}{*}{$\begin{array}{c}35.78 \\
3.58\end{array}$} & & \\
\hline Supervision & Ratio of $1: 10$ & & & & & & & \\
\hline $\begin{array}{l}\text { Vac/sick/holiday } \\
\text { relief }\end{array}$ & $\begin{array}{l}\text { Assume } 6 \text { wks of } \\
\text { absence }\end{array}$ & & & & & & & \\
\hline $\begin{array}{l}\text { Break relief } \\
\text { (included in } 6 \mathrm{hr} \\
\text { day) }\end{array}$ & $\begin{array}{l}\text { One person can } \\
\text { relieve } 3 \\
\text { (accounted for in } \\
\text { efficiency) }\end{array}$ & & & & & & & \\
\hline Total/shift & & & & & & 43.9 & & \\
\hline $\begin{array}{l}\text { Adj for } 70 \% \\
\text { Efficiency }\end{array}$ & & & & & & \multirow{2}{*}{$\begin{array}{c}62.7 \\
188.2\end{array}$} & & \\
\hline Total/day & & & & & & & & 669 \\
\hline
\end{tabular}

Notes:

Assume FTEs are available for $8 \mathrm{hrs} /$ day; because overall $70 \%$ efficiency is taken at the end.

Trucks have 22 pallets. Truckloads received based on total inventory to shipping at $300 \mathrm{lb} / \mathrm{drum}$ (see separate truck calc sheet)

Pallets are assumed to hold 455 gallon drums

As in inventory, assume $50 \%$ of drums are contaminated and can't be deconned.

Assume $50 \%$ of waste received requires interim storage; this will be dependent on assay system

Assume $10 \%$ of incoming waste is sampled

Assume sorted waste is $75 \%$ of total; all of debris, no liq, no lead/merc/spec, $70 \%$ of residue and soil

Assume $10 \%$ of sorted waste is sampled

Assume gross size reduction is necessary for wastes to metal decon \& lead

Assume gross size reduction is $1 \mathrm{hr}$ per drum.

Assume shredding is necessary for waste to proc res, soil, soft debris(sorted or not)

$0.75=$ fraction of feed to Receiving and Prep requiring shredding

Assume $10 \%$ of shredded waste is sampled.

Box breakdown includes time beyond that required if waste was packaged in drums

Assume glove box sorting required for $10 \%$ of open and complex debris, + all of special, mercury and lead

$0.14 \quad$ =fraction of feed to RCPRP requiring sorting

Assume glove box waste requires 1 sample/drum

Assume only complex and open debris require assessment, because open debris goes to CWO.

Assume liquids will arrive in drums and be transferred from receiving, and not go to the sorting cell

Assume transfer control for liquids takes the same time as for drums

Assume paperwork is accomplished within times shown

Average time per drum includes times for activities multiplied by the probability that the activity will occur.

Least time/drum/subsystem includes only the minimum requirements, no extra staging, sorting, or shredding

Max time/drum/subsystem includes all staging, shredding, glove box, etc 


\begin{tabular}{|c|c|c|c|c|c|c|c|c|}
\hline Task & Subtask & $\begin{array}{c}\text { Occurrencel } \\
\text { Shift }\end{array}$ & Units & $\begin{array}{l}\text { Time } \\
\text { Required } \\
\text { (min) }\end{array}$ & $\begin{array}{l}\text { Total Time / } \\
\text { Shift }\end{array}$ & $\begin{array}{c}\text { FTEs } \\
\text { Needed }\end{array}$ & $\begin{array}{l}\text { Minutes/ } \\
\text { First drum }\end{array}$ & $\begin{array}{l}\text { Minutes/ } \\
\text { Add"I Drum }\end{array}$ \\
\hline \multirow[t]{8}{*}{ Receive Waste } & Transfer through air lock & 3 & drum & 5 & 16 & & & \\
\hline & Feed waste from drum & 3 & drum & 3 & 10 & & & \\
\hline & Hook to transfer device & 3 & drum & 3 & 10 & & & \\
\hline & Transfer to tank $(10 \mathrm{gpm})$ & 3 & drum & 6 & 18 & & & \\
\hline & Empty drum bottoms & 3 & drum & 2 & 7 & & & \\
\hline & Detach \& remove drum & 3 & drum & 3 & 10 & & & \\
\hline & Sample feed vessel & 3 & drum & 5 & 16 & & & \\
\hline & $\begin{array}{l}\text { Arrange for transfer of } \\
\text { secondary waste from other } \\
\text { subsystems }\end{array}$ & 3 & drum & 2 & 4 & & & \\
\hline Total Task & & & & 28 & 90 & 0.19 & 28 & 17 \\
\hline \multirow[t]{5}{*}{ Feed Waste } & Sample waste in tank & 2 & times & 15 & 30 & & & \\
\hline & & & & & 0 & & & \\
\hline & $\begin{array}{l}\text { Screen and transfer waste (5 } \\
\text { gpm) to primary reactor }\end{array}$ & 6 & drums & 11 & 63 & & & \\
\hline & $\begin{array}{l}\text { Meter waste to reactor } \\
\text { (monitoring time) }\end{array}$ & 24 & & 3 & 72 & & & \\
\hline & $\begin{array}{l}\text { Meter waste to reactor }(300 \\
\text { lbs/hr) }\end{array}$ & 6 & drums & 6 & 32 & & & \\
\hline Total Task & & & & 17 & 135 & 0.28 & 17 & 6 \\
\hline \multirow[t]{10}{*}{$\begin{array}{l}\text { Operate MEO } \\
\text { Reactor }\end{array}$} & $\begin{array}{l}\text { Time to react organics } \\
\text { (min/drum) reaction rate: } \\
50 \mathrm{~kg} / \text { day/unit* } 42 \text { MEO units }\end{array}$ & 6 & drum & 142 & 818 & & & \\
\hline & Reaction rate $192 \mathrm{lbs} / \mathrm{hr}$ & 6 & drums & & & & & \\
\hline & Monitor pumps and manifold & 24 & times/shift & 5 & 120 & & & \\
\hline & Monitor MEO cells & 24 & times/shift & 5 & 120 & & & \\
\hline & $\begin{array}{l}\text { Monitor and adjust electrolyte } \\
\text { concentration }\end{array}$ & 24 & times/shift & 5 & 120 & & & \\
\hline & $\begin{array}{l}\text { Monitor and adjust } \\
\text { turbo-aerator for nitrous acid } \\
\text { conversion }\end{array}$ & 24 & times/shift & 5 & 120 & & & \\
\hline & $\begin{array}{l}\text { Monitor and adjust oxygen } \\
\text { input to aerator }\end{array}$ & 24 & times/shift & 5 & 120 & & & \\
\hline & Collect samples & 16 & times/shift & 15 & 240 & & & \\
\hline & $\begin{array}{l}\text { Monitor primary reactor and } \\
\text { catholyte reactor }\end{array}$ & 24 & times/shift & 5 & 120 & & & \\
\hline & & & & 142 & 960 & 2.00 & 142 & \\
\hline \multirow[t]{12}{*}{ Silver Recovery } & $\begin{array}{l}\text { Monitor and adjust blowdown } \\
\text { from anolyte stream }\end{array}$ & 24 & times & 5 & 120 & & & \\
\hline & $\begin{array}{l}\text { Nonitor and adjust blowdown } \\
\text { from catholyte stream } \\
\end{array}$ & 24 & times & 5 & 120 & & & \\
\hline & $\begin{array}{l}\text { Sample blowdown (anolyte and } \\
\text { catholyte }\end{array}$ & 4 & times & 15 & 60 & & & \\
\hline & $\begin{array}{l}\text { Monitor precipitation of silver } \\
\text { nitrate }\end{array}$ & 24 & times & 2 & 48 & & & \\
\hline & Monitor centrifuge & 24 & times & 5 & 120 & & & \\
\hline & Transfer silver chloride & 24 & times & 2 & 48 & & & \\
\hline & Precipitate silver & 24 & times & 5 & 120 & & & \\
\hline & Separate silver & 24 & times & 5 & 120 & & & \\
\hline & React silver to silver nitrate & 24 & times & 5 & 120 & & & \\
\hline & $\begin{array}{l}\text { Transfer AgNO3 to primary } \\
\text { reactor }\end{array}$ & 24 & times & 2 & 48 & & & \\
\hline & Transfer salts to Aq Waste & 24 & times & 2 & 48 & & & \\
\hline & Sample precipator reactor & 4 & times & 15 & 60 & & & \\
\hline Total Task & & & & 68 & 1032 & 2.15 & 68 & 6 \\
\hline
\end{tabular}


Table NT3-d.

MEO Organic Destruction Subsystem

\begin{tabular}{|c|c|c|c|c|c|c|c|c|}
\hline Task & Subtask & $\begin{array}{c}\text { Occurrencel } \\
\text { Shift }\end{array}$ & Units & $\begin{array}{c}\text { Time } \\
\text { Required } \\
\text { (min) }\end{array}$ & $\begin{array}{c}\text { Total Time / } \\
\text { Shift }\end{array}$ & $\begin{array}{l}\text { FTEs } \\
\text { Needed }\end{array}$ & $\begin{array}{l}\text { Minutes/ } \\
\text { First drum }\end{array}$ & $\begin{array}{l}\text { Minutes/ } \\
\text { Add'I Drum }\end{array}$ \\
\hline \multirow[t]{8}{*}{ Acid Recovery } & $\begin{array}{l}\text { Transfer blowdown to } \\
\text { evaporator }\end{array}$ & 24 & times & 2 & 48 & & & \\
\hline & Monitor evaporator & 24 & times & 5 & 120 & & & \\
\hline & $\begin{array}{l}\text { Transfer to filtration or } \\
\text { fractionater }\end{array}$ & 24 & times & 2 & 48 & & & \\
\hline & Monitor fractionater & 24 & times & 5 & 120 & & & \\
\hline & Monitor condenser & 8 & times & 2 & 16 & & & \\
\hline & Filter solution & 24 & times & 2 & 48 & & & \\
\hline & Sample filtrate & 2 & times & 15 & 30 & & & \\
\hline & Sample recycle acids & 8 & times & 15 & 120 & & & \\
\hline Total Task & & & & 32 & 198 & 0.41 & 32 & 6 \\
\hline \multirow[t]{4}{*}{ Offgas } & Monitor anolyte offgas transfer & 24 & times & 2 & 48 & & & \\
\hline & Monitor catholyte offgas & 24 & times & 2 & 48 & & & \\
\hline & $\begin{array}{l}\text { Monitor and adjust NOX } \\
\text { removal }\end{array}$ & 24 & times & 2 & 48 & & & \\
\hline & & & & 6 & 144 & 0.30 & 6 & 0 \\
\hline FTEs/shift & & & & & & 5.33 & 293 & 17 \\
\hline Supervision & Ratio of $1: 10$ & & & & & 0.53 & & \\
\hline Vac/sick/holiday relief & Assume 6 wks of absence & & & & & 0.68 & & \\
\hline & Adjust for $70 \%$ Efficiency & & & & & 1.96 & & \\
\hline Total/shift & & & & & & 8.50 & & \\
\hline Total/day & & & & & & 25.51 & & \\
\hline
\end{tabular}

Notes:

Assume sampling frequency $=10 \%$ of drums

From Blaines mass balance, the feed to subsystem is

Total feed $=$

1

241

Drum/hr

See overall table

Assume continuous CWO process

Assume solids removal once/day

Waste transferirecycle processes are continuous. Time is expected labor monitoring time

Assume drums of liquid transferred from Rec and Prep

Assume paperwork is accomplished within times shown

Total samples/shift = 33 


\begin{tabular}{|c|c|c|c|c|c|c|c|c|}
\hline Task & Subtask & $\begin{array}{c}\text { Occurrence/ } \\
\text { Shift }\end{array}$ & Unit & $\begin{array}{l}\text { Time } \\
\text { Required } \\
\text { (min) }\end{array}$ & $\left|\begin{array}{c}\text { Total Time / } \\
\text { Shift }\end{array}\right|$ & $\begin{array}{l}\text { FTEs } \\
\text { Needed }\end{array}$ & $\begin{array}{c}\text { Minutes/ } \\
\text { Drum }\end{array}$ & $\begin{array}{c}\text { Minutes/ } \\
\text { Add'I Drum }\end{array}$ \\
\hline \multirow[t]{10}{*}{ Receive Waste } & Transfer through air lock & 1 & drum & 5 & 7 & & & \\
\hline & Feed waste from drum & 1 & drum & 3 & 4 & & & \\
\hline & Hook to transfer device & 1 & drum & 3 & 4 & & & \\
\hline & Transfer to tank (10 gpm) & 1 & drum & 6 & 8 & & & \\
\hline & Empty drum bottoms & 1 & & 2 & 3 & & & \\
\hline & Sample feed vessel & 2 & & 10 & 20 & & & \\
\hline & Detach \& remove drum & 1 & & 3 & 4 & & & \\
\hline & $\begin{array}{l}\text { Sample waste from processes: } \\
\text { CWO,Desorb, Decon,APC }\end{array}$ & 4 & N/A & & & & & \\
\hline & Arrange for transfer & 27 & drum & 2 & 41 & & & \\
\hline & & & & 33 & 91 & 0.19 & 33 & 5 \\
\hline \multirow[t]{10}{*}{ Preliminary Treatment } & Sample high TDS tank & 1 & drums & 15 & 2 & & & \\
\hline & Sample low TDS tank & 7 & drums & 15 & 10 & & & \\
\hline & Sample TOC waste & & drums & 15 & & & & \\
\hline & $\begin{array}{l}\text { Select treatment methods (10 } \\
\text { drum batch) }\end{array}$ & 7 & drums & 20 & 13 & & & \\
\hline & $\begin{array}{l}\text { Transfer organic waste to oil } \\
\text { water separator }\end{array}$ & & drums & 3 & & & & \\
\hline & $\begin{array}{l}\text { Filter high, low TDS and organic } \\
\text { waste (say } 10 \mathrm{gall} / \mathrm{min} \text { ) }\end{array}$ & 8 & drums & 6 & 42 & & & \\
\hline & Neutralize/ppt high TDS waste & 1 & drums & 11 & 13 & & & \\
\hline & $\begin{array}{l}\text { Settle precipitated aqueous } \\
\text { waste }\end{array}$ & 1 & drums & 6 & 6 & & & \\
\hline & Evaporate solids & 0 & drums & 6 & 0 & & & \\
\hline & & & & 90 & 86 & 0.18 & 90 & 20 \\
\hline \multirow[t]{9}{*}{ UV oxidation } & CaSO4 ppt $(10 \mathrm{gpm})$ & $\overline{8}$ & drums & 11 & 84 & & & \\
\hline & Centrifuge (10 gpm) & 8 & drums & 11 & 84 & & & \\
\hline & Sample waste & 1 & drums & 15 & 12 & & & \\
\hline & $\begin{array}{l}\text { Adjust UV oxidation ( } 30 \mathrm{~min} / 10 \\
\text { drums) }\end{array}$ & 8 & drums & 3 & 23 & & & \\
\hline & $\begin{array}{l}\text { Process through UV oxidation } \\
(50 \mathrm{gpm})\end{array}$ & 8 & drums & 1 & 8 & & & \\
\hline & Carbon filtration (10 gpm) & 8 & drums & 6 & 42 & & & \\
\hline & Ion exchange $(10 \mathrm{gpm})$ & 8 & drums & 6 & 42 & & & \\
\hline & Sample waste before discharge & 1 & & 30 & & & & 1 \\
\hline & & & & 52 & 296 & 0.62 & 52 & \\
\hline Total per shift & & & & & & 0.99 & 175 & \\
\hline Supervision & Ratio of $1: 10$ & & & & & 0.10 & & \\
\hline Vac/sick/holiday relief & Assume 6 wks of absence & & & & & 0.13 & & \\
\hline $70 \%$ efficiency & & & & & & 1.73 & & \\
\hline Total per day & & & & & & 5.18 & & 1170 \\
\hline \multicolumn{9}{|c|}{ 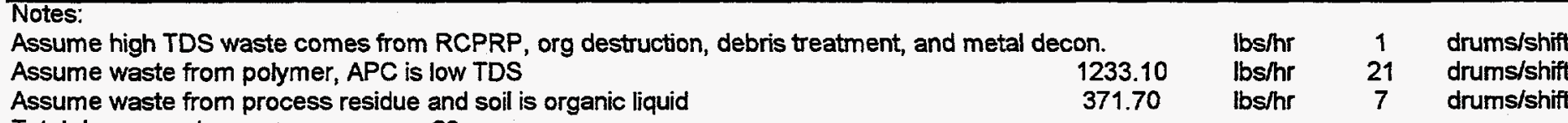 } \\
\hline
\end{tabular}

Total drums per hour= 29

Assume tank batches are 550 gallons (10 drums)

Assume treatment selection time is required for 10 drum batches.

Assume residence time in oil water separator is 1 hour and tank is 1000 gallons (16 gpm)

Assume filtration, centrifuge and ppt rates are $10 \mathrm{gpm}$.

Assume solids to evaporator are $5 \%$ of incoming waste; assume drying rate is $10 \mathrm{gpm}$

Assume UV oxidation unit is $50 \mathrm{gpm}$

Number of samples per shift $=$ 


\begin{tabular}{|c|c|c|c|c|c|c|c|c|}
\hline Task & Subtask & $\begin{array}{c}\text { Occurrencel } \\
\text { Shift }\end{array}$ & Units & $\begin{array}{c}\text { Time } \\
\text { Required } \\
\text { (min) }\end{array}$ & $\begin{array}{l}\text { Total } \\
\text { Time I } \\
\text { Shift }\end{array}$ & $\begin{array}{c}\text { FTEs } \\
\text { Needed }\end{array}$ & $\begin{array}{l}\text { Minutes/ } \\
\text { First drum }\end{array}$ & $\begin{array}{c}\text { Minutes/ } \\
\text { Add'l Drum }\end{array}$ \\
\hline Soil Receiving & Transfer through air lock & 31 & drums & 5 & 154 & & & \\
\hline Total Task & & & & 5 & 154 & 0.3 & 5 & 5 \\
\hline \multirow[t]{7}{*}{$\begin{array}{l}\text { Feed Waste from } \\
\text { drum }\end{array}$} & Stage at feed bin (drums) & 31 & drums & 3 & 92 & & & \\
\hline & Hook to transfer device & 31 & drums & 3 & 92 & & & \\
\hline & $\begin{array}{l}\text { Transfer into feed bin } \\
\text { (metering screw) }\end{array}$ & 31 & drums & 5 & 154 & & & \\
\hline & $\begin{array}{l}\text { Feed screw monitoring } \\
\text { time }\end{array}$ & & drums & & & & & \\
\hline & Empty drum bottoms & 31 & drums & 2 & 62 & & & \\
\hline & Sample feed vessel & 2 & drums & 5 & 10 & & & \\
\hline & Detach \& remove drum & 31 & drums & 3 & 92 & & & \\
\hline Total Task & & & & 16 & 503 & 1.0 & 16 & 16 \\
\hline \multirow[t]{3}{*}{ Wash Water Prep } & Sample wash water & 3 & drums & $\overline{5}$ & 15 & & & \\
\hline & Adjust Water Volume & 3 & drums & 10 & 31 & & & \\
\hline & Adjust surfactant & 3 & drums & 10 & 31 & & & \\
\hline Total Task & & & & 25 & 77 & 0.2 & 25 & \\
\hline \multirow[t]{5}{*}{ Washing Process } & $\begin{array}{l}\text { Add waste to tank (5000 } \\
\text { lbs/hr) }\end{array}$ & 92 & drums & 4 & 356 & & & \\
\hline & Wash waste $(4000 \mathrm{lbs} / \mathrm{hr})$ & 92 & drums & 5 & N/A & & & \\
\hline & $\begin{array}{l}\text { Transfer waste and water } \\
\text { from tank ( } 35 \mathrm{gpm})\end{array}$ & 462 & drums & 2 & 726 & & & \\
\hline & Monitor tank & 24 & times & 5 & 120 & & & \\
\hline & & & & 6 & 120 & 0.3 & 6 & 5 \\
\hline \multirow[t]{9}{*}{ Pre-rinse and Rinse } & $\begin{array}{l}\text { Screening ( } 35 \mathrm{gpm}) \\
\text { (most of water leaves } \\
\text { process here) }\end{array}$ & 462 & drums & 2 & 726 & & & \\
\hline & $\begin{array}{l}\text { Hydrocyclone (2@35 } \\
\text { gpm) }\end{array}$ & 185 & drums & 1 & 145 & & & \\
\hline & transfer to rinse contactor & 185 & drums & 1 & 145 & & & \\
\hline & $\begin{array}{l}\text { Rinse contactor ( } 5000 \\
\text { gal); } 6: 1 \text { water to } \\
\text { soil/residue; } 9000 \mathrm{lbs} / \mathrm{hr}\end{array}$ & 185 & drums & 2 & 396 & & & \\
\hline & $\begin{array}{l}\text { Transfer to dryer ( } 2 \times \text { vol } \\
\text { of soil) }\end{array}$ & 185 & drums & 1 & 145 & & & \\
\hline & Drying@35 gpm & 185 & drums & 2 & 290 & & & \\
\hline & Monitor operations & 24 & times & 5 & 120 & & & \\
\hline & Collect samples & 16 & times & 5 & 80 & & & \\
\hline & & & & 6 & 200 & 0.4 & 6 & 2 \\
\hline
\end{tabular}




\begin{tabular}{|c|c|c|c|c|c|c|c|c|}
\hline Task & Subtask & $\begin{array}{c}\text { Occurrencel } \\
\text { Shift }\end{array}$ & Units & $\begin{array}{c}\text { Time } \\
\text { Required } \\
\text { (min) } \\
\end{array}$ & $\begin{array}{l}\text { Total } \\
\text { Time I } \\
\text { Shift } \\
\end{array}$ & $\begin{array}{c}\text { FTEs } \\
\text { Needed }\end{array}$ & $\begin{array}{l}\text { Minutes/ } \\
\text { First drum }\end{array}$ & $\begin{array}{l}\text { Minutes/ } \\
\text { Add'I Drum }\end{array}$ \\
\hline \multirow[t]{14}{*}{ Recycle Processes } & $\begin{array}{l}\text { These are all monitoring } \\
\text { times }\end{array}$ & & & & 0 & & & \\
\hline & Solubility Reduction & 8.0 & times & 5 & 40 & & & \\
\hline & Additive Adjustment & 8.0 & times & 5 & 40 & & & \\
\hline & Transfer to Wash Tank & 16.0 & times & 2 & 32 & & & \\
\hline & Transfer to Ultrafiltration & 8.0 & times & 2 & 16 & & & \\
\hline & Ultrafiltration & 24.0 & times & 5 & 120 & & & \\
\hline & Dissolved Air Flotation & 8.0 & times & 5 & 40 & & & \\
\hline & Surfactant Separation & 24.0 & times & 5 & 120 & & & \\
\hline & Additive Adjustment & 8.0 & times & 5 & 40 & & & \\
\hline & Steam stripping & 8.0 & times & 5 & 40 & & & \\
\hline & $\begin{array}{l}\text { Transfer recycled } \\
\text { surfactant }\end{array}$ & 8.0 & times & 5 & 40 & & & \\
\hline & $\begin{array}{l}\text { Transfer waste to organic } \\
\text { destruction }\end{array}$ & 8.0 & times & 5 & 40 & & & \\
\hline & $\begin{array}{l}\text { Transfer metals to } \\
\text { polymer }\end{array}$ & 8.0 & times & 5 & 40 & & & \\
\hline & Collect samples & 24.0 & times & 5 & 120 & & & \\
\hline Total Task & & & & 59 & 728 & 1.5 & 59 & \\
\hline \multicolumn{2}{|c|}{ TotalFTEs/day= FTEs per shift } & & & & & 3.7 & & \\
\hline Supervision & Ratio of 1:10 & & & & & 0.4 & 117 & 2 \\
\hline $\begin{array}{l}\text { Vac/sick/holiday } \\
\text { relief }\end{array}$ & $\begin{array}{l}\text { Assume } 6 \text { wks of } \\
\text { absence }\end{array}$ & & & & & 0.5 & & \\
\hline Total/shift & & & & & & 4.6 & & \\
\hline $70 \%$ efficiency & & & & & & 6.5 & & \\
\hline Total/day & & & & & & 6.5 & & \\
\hline
\end{tabular}

Notes:

Sample wash water every 10 drums

Assume drum transfer of $15 \mathrm{~min} / \mathrm{drum}$ or $.5 \mathrm{cu} \mathrm{ft} / \mathrm{min}$

System designed for 1 shift not 3

Residence time in wash tank based on $4 x$ wt of water to feed

Wash tank is $3000 \mathrm{gal}$.

Assume transfer rates are $10 \mathrm{gpm}$; this includes both waste and rinse or wash water

Waste to screening includes water in tank ( $4 x$ input volume)

Waste to rinse contactor and hydrocyclone assumes 1:1 soil to water ( $2 x$ input volume)

Rinse tank has 5000 gallons of water and soil (size is 6000 gal)

Drying: assume $1 \mathrm{hr}$ drying time,2000 lbs/hr ( $6 \mathrm{drums} / \mathrm{hr}$ )

For purposes of processing time, recycle is not included, as these are not soil treatment

Samples collected per shift=

45 
Table NT3-g. High Pressure Wash for Open Debris

\begin{tabular}{|c|c|c|c|c|c|c|c|c|}
\hline Task & Subtask & $\begin{array}{c}\begin{array}{c}\text { Occurrencel } \\
\text { Shift }\end{array} \\
\end{array}$ & Units & $\begin{array}{c}\text { Time } \\
\text { Required } \\
\text { (min) }\end{array}$ & $\begin{array}{c}\text { Total Time } / \\
\text { Shift }\end{array}$ & $\begin{array}{c}\text { FTEs } \\
\text { Needed } \\
\end{array}$ & $\begin{array}{c}\text { Minutes/ } \\
\text { Drum }\end{array}$ & $\begin{array}{c}\text { Minutes/ } \\
\text { Add'l } \\
\text { Drum } \\
\end{array}$ \\
\hline \multirow[t]{3}{*}{ Debris Receiving } & Transfer through air lock & 35 & drums & 5 & 175 & & & \\
\hline & Stage drums for campaigns & 35 & drums & 15 & 524 & & & \\
\hline & & & & 20 & 699 & 1.5 & 20 & 15 \\
\hline \multirow[t]{6}{*}{$\begin{array}{l}\text { Feed Waste from } \\
\text { bin }\end{array}$} & Stage at feed bin (drums) & 35 & drums & 3 & 105 & & & \\
\hline & Hook to transfer device & 35 & drums & 3 & 105 & & & \\
\hline & $\begin{array}{l}\text { Transfer into feed bin } \\
\text { (metering screw) }\end{array}$ & 35 & drums & 15 & 524 & & & \\
\hline & Empty drum bottoms & 35 & drums & 2 & 70 & & & \\
\hline & Sample feed vessel & 3 & drums & 10 & 35 & & & \\
\hline & Detach \& remove drum & 35 & drums & 3 & 105 & & & \\
\hline Total Task & & & & 36 & 944 & 2.0 & 36 & 23 \\
\hline \multirow[t]{3}{*}{ Wash Water Prep } & Sample wash water & $\overline{3}$ & drums & $\overline{55}$ & 17 & & & \\
\hline & Adjust Water Volume & 3 & drums & 10 & 35 & & & \\
\hline & Adjust surfactant & 3 & drums & 10 & 35 & & & \\
\hline Total Task & & & & 25 & 87 & 0.2 & 25 & \\
\hline \multirow[t]{2}{*}{ Washing Process } & Check out Equipment & $\overline{1}$ & times & $\overline{30}$ & 30 & & & \\
\hline & Add waste to tank & 35 & drums & 15 & 524 & & & 15 \\
\hline \multirow[t]{4}{*}{$\begin{array}{l}\text { See notes; based } \\
\text { on } 16 \text { drum batch }\end{array}$} & Wash/ rinse waste & 35 & drums & 17 & N/A & & & \\
\hline & Transfer water from tank & 35 & drums & 28 & 961 & & & \\
\hline & Monitor tank & 24 & times & 5 & 120 & & & \\
\hline & Collect Samples & 3 & times & 5 & 15 & & & \\
\hline Total Task & & & & 94 & 1636 & 3.4 & 94 & \\
\hline Total per shift & & & & & & $\overline{7.0}$ & $\overline{175}$ & \\
\hline Supervision & Ratio of 1:10 & & & & & 0.7 & & \\
\hline $\begin{array}{l}\text { Vac/sick/holiday } \\
\text { relief }\end{array}$ & Assume 6 wks of absence & & & & & 0.9 & & \\
\hline Total/shift & & & & & & 8.6 & & \\
\hline $70 \%$ efficiency & & & & & & 12.3 & & \\
\hline Total/day & & & & & & 36.9 & & \\
\hline Total FTEs & & & & & & 36.9 & & \\
\hline
\end{tabular}

Notes:

Sample wash water every 10 drums

Assume drum transfer of $15 \mathrm{~min} / \mathrm{drum}$ or $.5 \mathrm{cu} \mathrm{ft} / \mathrm{min}$

Batch size is 1 to 2 tons; say $3000 \mathrm{lbs}$ or 16 drums

Residence time in wash tank based on 3 stages, 90 minutes each

Assume transfer rates are $10 \mathrm{gpm}$; this includes both waste and rinse or wash water

Assume water volume is roughly $5 x$ waste volume 
Table NT3-h. Metal Decontamination Subsystem

\begin{tabular}{|c|c|c|c|c|c|c|c|c|}
\hline Task & Subtask & $\begin{array}{c}\text { Occurrencel } \\
\text { Shift }\end{array}$ & Units & $\begin{array}{c}\text { Time } \\
\text { Required } \\
\text { (min) }\end{array}$ & $\begin{array}{c}\text { Total Time } \\
\text { Shift }\end{array}$ & $\begin{array}{l}\text { FTEs } \\
\text { Needed }\end{array}$ & $\begin{array}{l}\text { Minutes/ } \\
\text { Drum }\end{array}$ & $\begin{array}{l}\text { Minutesl } \\
\text { Addel } \\
\text { Drum }\end{array}$ \\
\hline \multirow{2}{*}{$\begin{array}{l}\text { Metals Receiving/ } \\
\text { Feed Prep } \\
\text { Total Task }\end{array}$} & Transfer through air lock & 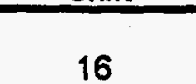 & drums & (1.0.0 & $\pi$ & & & \\
\hline & & & & 5 & 79 & 0 & 5 & 0 \\
\hline \multirow[t]{7}{*}{ Waste Decon } & Stage containers & 16 & drum & 5 & $\overline{79}$ & & & \\
\hline & Decon waste & 16 & drum & 10 & 158 & & & \\
\hline & Assay for recycle & 16 & drum & 30 & 475 & & & \\
\hline & Repack in drums & 16 & drum & 15 & 238 & & & \\
\hline & Close drum lid & 16 & drum & 15 & 238 & & & \\
\hline & Stage drums & 16 & drum & 5 & 79 & & & \\
\hline & $\begin{array}{l}\text { Monitor recirc filtration and } \\
\text { fugitive dust system }\end{array}$ & 24 & times & 6 & 144 & & & \\
\hline Total Task & & & & 86 & 1411 & 3 & 86 & \\
\hline Total FTEs/shift & & & & & & $\overline{3}$ & 91 & \\
\hline Supervision & Ratio of $1: 10$ & & & & & $\mathbf{0}$ & & \\
\hline $\begin{array}{l}\text { Vac/sick/holiday } \\
\text { relief }\end{array}$ & Assume 6 wks of absence & & & & & 0 & & \\
\hline Total/shift & & & & & & 4 & & \\
\hline $70 \%$ efficiency & & & & & & 5 & & \\
\hline Total/day & & & & & & 16 & & \\
\hline
\end{tabular}

Notes: $\quad$ Assume $50 \%$ of waste must be size reduced. (need basis for this)

Assume $60 \mathrm{~min} / \mathrm{drum}$ for cutting 
Table NT3-i

Lead Recovery

\begin{tabular}{|c|c|c|c|c|c|c|c|c|}
\hline Task & Subtask & $\begin{array}{c}\text { Occurrencel } \\
\text { Shift }\end{array}$ & Units & $\begin{array}{l}\text { Time } \\
\text { Required } \\
\text { (min) }\end{array}$ & $\begin{array}{c}\text { Total Time/ } \\
\text { Shift }\end{array}$ & $\begin{array}{c}\text { FTEs } \\
\text { Needed }\end{array}$ & $\begin{array}{c}\text { Minutes/ } \\
\text { Drum }\end{array}$ & $\begin{array}{c}\text { Minutes/ } \\
\text { Add'I Drum }\end{array}$ \\
\hline \multirow[t]{3}{*}{$\begin{array}{l}\text { Lead } \\
\text { Receiving/Feed } \\
\text { Prep }\end{array}$} & Transfer through air lock & 0.24 & drums & 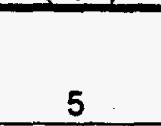 & 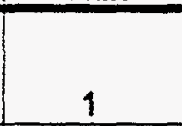 & & & \\
\hline & $\begin{array}{l}\text { Glove box separation of } \\
\text { sheet lead and gloves }\end{array}$ & 0.24 & drums & 60 & 14 & & & \\
\hline & Stage at decon & 0.24 & drums & 10 & 2 & & & \\
\hline \multirow{8}{*}{$\frac{\text { Total Task }}{\text { Waste Decon }}$} & & & & 75 & 18 & 0 & 75 & \\
\hline & Stage containers & 0.24 & drum & 5 & $\overline{1}$ & & & \\
\hline & Decon waste & 0.24 & drum & 10 & 2 & & & \\
\hline & Assay for recycle & 0.24 & drum & 30 & 7 & & & \\
\hline & Repack in drums & 0.24 & drum & 15 & 4 & & & \\
\hline & Close drum lid & 0.24 & drum & 15 & 4 & & & \\
\hline & Stage drums & 0.24 & drum & 5 & 1 & & & \\
\hline & $\begin{array}{l}\text { Monitor recirc filtration } \\
\text { and fugitive dust system }\end{array}$ & 24.00 & times & 6 & 144 & & & \\
\hline Total Task & & & & 86 & 163 & 0 & 86 & 30 \\
\hline Total FTEs/shift & & & & & & 0 & 161 & \\
\hline Supervision & Ratio of $1: 10$ & & & & & 0 & & \\
\hline $\begin{array}{l}\text { Vac/sick/holiday } \\
\text { relief }\end{array}$ & $\begin{array}{l}\text { Assume } 6 \text { wks of } \\
\text { absence }\end{array}$ & & & & & 0 & & \\
\hline Total/shift & & & & & & 0 & & \\
\hline $70 \%$ efficiency & & & & & & 1 & & \\
\hline Total/day & & & & & & 2 & & \\
\hline
\end{tabular}

Notes:

Assume assay for all drums @ $30 \mathrm{~min} / \mathrm{drum}$ 
Table NT3-j. : Mercury Amalgamation

\begin{tabular}{|c|c|c|c|c|c|c|c|c|}
\hline Task & Subtask & $\begin{array}{c}\text { Occurrencel } \\
\text { Shift }\end{array}$ & Units & $\begin{array}{c}\text { Time } \\
\text { Required } \\
\text { (min) }\end{array}$ & $\begin{array}{c}\text { Total } \\
\text { Timel Shift }\end{array}$ & $\begin{array}{c}\text { FTEs } \\
\text { Needed }\end{array}$ & $\begin{array}{c}\text { Minutes/ } \\
\text { Drum }\end{array}$ & $\begin{array}{c}\text { Minutes/ } \\
\text { Add"l } \\
\text { Drum } \\
\end{array}$ \\
\hline $\begin{array}{l}\text { Metals Receiving/ } \\
\text { Feed Prep }\end{array}$ & Transfer through air lock & 0.02 & drums & 5.0 & $\frac{0.1}{12}$ & & & \\
\hline |Total Task & Transfer liq mercury to tank & 0.02 & drums & $\frac{60.0}{65.0}$ & $\frac{1.3}{1.4}$ & 0.0 & 65.0 & 600 \\
\hline $\begin{array}{l}\text { Mercury } \\
\text { Amalgamation }\end{array}$ & Inspect equipment & 1.00 & time & 30.0 & & & & \\
\hline & $\begin{array}{l}\text { Transfer liq mercury to } \\
\text { amalgamater (1 gpm) }\end{array}$ & 0.02 & drum & 55.0 & 1.2 & & & \\
\hline & Measure additives & 0.02 & drum & 30.0 & 0.7 & & & \\
\hline & Batch amalgamation & 0.02 & drum & 120.0 & 2.6 & & & 120.0 \\
\hline & Transfer out of amalgamater & 0.02 & drum & 55.0 & 1.2 & & & \\
\hline & Stage & 0.02 & drum & 5.0 & 0.1 & & & \\
\hline & Place at assay & 0.02 & drum & 5.0 & 0.1 & & & \\
\hline & Assay & 0.02 & drum & 20.0 & 0.4 & & & \\
\hline & Remove from assay & 0.02 & drum & 2.0 & 0.0 & & & \\
\hline Total Task & & & & 292.0 & 6.4 & 0.0 & 292.0 & 120.0 \\
\hline Total FTEs/shift & & & & & & 0.0 & 357.0 & \\
\hline Supervision & Ratio of $1: 10$ & & & & & 0.0 & & \\
\hline $\begin{array}{l}\text { Vac/sick/holiday } \\
\text { relief }\end{array}$ & Assume 6 wks of absence & & & & & 0.0 & & \\
\hline Total/shift & & & & & & 0.0 & & \\
\hline $70 \%$ efficiency & & & & & & 0.0 & & \\
\hline Totallday & & & & & & 0.1 & & \\
\hline
\end{tabular}

Notes:

Batch size for amalgamater: Assume $1 \mathrm{drum} / \mathrm{batch}, 2 \mathrm{hrs} / \mathrm{batch}$ 
Table NT3-k. Special Waste

\begin{tabular}{|c|c|c|c|c|c|c|c|c|}
\hline Task & Subtask & $\begin{array}{c}\text { Occurrence } \\
\text { / Shift }\end{array}$ & Units & $\begin{array}{c}\text { Time } \\
\text { Required } \\
\text { (min) }\end{array}$ & Total Time & $\begin{array}{l}\text { FTEs } \\
\text { Needed }\end{array}$ & $\begin{array}{l}\text { Minutes/ } \\
\text { Drum }\end{array}$ & $\begin{array}{l}\text { Minutes/ } \\
\text { Add"l } \\
\text { Drum }\end{array}$ \\
\hline \multirow[t]{4}{*}{$\begin{array}{l}\text { Special } \\
\text { Receiving/Feed } \\
\text { Prep }\end{array}$} & Transfer through air lock & 5.4 & drums & 5.0 & 27.2 & & & \\
\hline & $\begin{array}{l}\text { Glove box preparation of } \\
\text { wastes }\end{array}$ & 5.4 & drums & 60.0 & 326.4 & & & \\
\hline & Stage waste & 5.4 & drums & 3.0 & 16.3 & & & \\
\hline & & & & 68.0 & 369.9 & 0.8 & 68.0 & 60.0 \\
\hline \multirow[t]{7}{*}{ Waste Treatment } & Stage containers & 5.4 & drum & 3 & 16.3 & & & \\
\hline & $\begin{array}{l}\text { Treat waste as special } \\
\text { processes TBD }\end{array}$ & 5.4 & drum & 60 & 326.4 & & & \\
\hline & Sample treated waste & 5.4 & drum & 15 & 81.6 & & & \\
\hline & Repack in drums & 5.4 & drum & 30 & 163.2 & & & \\
\hline & Close drum lid & 5.4 & drum & 3 & 16.3 & & & \\
\hline & Stage drums & 5.4 & drum & 3 & 16.3 & & & \\
\hline & & & & 114.0 & 620.2 & 1.3 & 114.0 & 60.0 \\
\hline TotalFTEs/shift & & & & & & 2.1 & 182.0 & \\
\hline Supervision & Ratio of $1: 10$ & & & & & 0.2 & & \\
\hline $\begin{array}{l}\text { Vac/sick/holiday } \\
\text { relief }\end{array}$ & $\begin{array}{l}\text { Assume } 6 \text { wks of } \\
\text { absence }\end{array}$ & & & & & 0.3 & & \\
\hline Total/shift & & & & & & 2.5 & & \\
\hline $70 \%$ efficiency & & & & & & 3.6 & & \\
\hline Total/day & & & & & & 10.8 & & \\
\hline
\end{tabular}

Notes:

Assume all waste is prepared in glove box

Assume waste is treated in various batch processes that average 2 hours/drum

TBD $=$ To be determined 
Table NT3-I. Grout Stabilization Subsystem

\begin{tabular}{|c|c|c|c|c|c|c|c|c|}
\hline Task & Subtask & $\begin{array}{c}\text { Occurrence/ } \\
\text { Shift }\end{array}$ & Units & $\begin{array}{c}\text { Time } \\
\text { Required } \\
\text { (min) }\end{array}$ & $\begin{array}{c}\text { Total Time / } \\
\text { Shift }\end{array}$ & $\begin{array}{c}\text { FTEs } \\
\text { Needed }\end{array}$ & $\begin{array}{c}\text { Minutes/ } \\
\text { Drum }\end{array}$ & $\begin{array}{l}\text { Minutes/ } \\
\text { Add'l } \\
\text { Drum }\end{array}$ \\
\hline \multirow[t]{6}{*}{$\begin{array}{l}\text { Waste } \\
\text { Receiving/ Feed } \\
\text { Prep }\end{array}$} & Transfer through air lock & 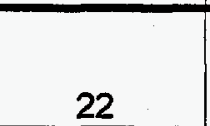 & drums & Len. & 111 & & & \\
\hline & Sample waste & 2 & drums & 15 & 33 & & & \\
\hline & Select process for waste & 22 & drums & 5 & 111 & & & \\
\hline & $\begin{array}{l}\text { Transfer to } \\
\text { macroencapsulation }\end{array}$ & 8 & drums & 2 & 16 & & & \\
\hline & $\begin{array}{l}\text { Transfer to } \\
\text { microencapsulation }\end{array}$ & 14 & drums & 2 & 29 & & & \\
\hline & Stage at process & 22 & drums & 2 & 44 & & & \\
\hline Total Task & & & & 31 & 345 & 0.7 & 31 & 5 \\
\hline \multirow[t]{7}{*}{$\begin{array}{l}\text { Waste } \\
\text { Encapsulation }\end{array}$} & Measure binder & 22 & drum & 5 & 111 & & & \\
\hline & Mix binder & 22 & drum & 5 & 111 & & & \\
\hline & Combine with waste & 22 & drum & 10 & 222 & & & \\
\hline & Repack in drums & 22 & drum & 5 & 111 & & & \\
\hline & Close drum lid & 22 & drum & 3 & 67 & & & \\
\hline & Stage pallets & 22 & drum & 2 & 44 & & & \\
\hline & $\begin{array}{l}\text { Monitor activated carbon } \\
\text { and fugitive dust system }\end{array}$ & 2 & times & 6 & 12 & & & \\
\hline \multirow{6}{*}{$\begin{array}{l}\text { Total Task } \\
\text { Binder setup } \\
\text { time }\end{array}$} & & & & 36 & 679 & 1.4 & 36 & 10 \\
\hline & $\begin{array}{l}\text { Move pallets to curing } \\
\text { area }\end{array}$ & 22 & drum & 2 & 44 & & & \\
\hline & Curing time & 22 & drum & & 0 & & & \\
\hline & Samples & 2 & times & 15 & 33 & & & \\
\hline & Monitor curing process & 22 & drum & 10 & 222 & & & \\
\hline & $\begin{array}{l}\text { Move pallets from curing } \\
\text { area }\end{array}$ & 22 & times & 2 & 44 & & & \\
\hline Total Task & & & & 29 & 345 & 0.7 & 29 & 5 \\
\hline \multirow[t]{7}{*}{ Drum Decon } & Stage containers & 2 & drum & 5 & 11 & & & \\
\hline & Load conveyors & 2 & drum & 5 & 11 & & & \\
\hline & Decon drums & 2 & drum & 10 & 22 & & & \\
\hline & Assay drums & 2 & drum & 15 & 33 & & & \\
\hline & Unload conveyers & 2 & drum & 5 & 11 & & & \\
\hline & Palletize drums & 2 & drum & 2 & 4 & & & \\
\hline & Stage drums & 2 & drum & 5 & 11 & & & \\
\hline Total Task & & & & 47 & 105 & 0.2 & 47 & 15 \\
\hline Total FTEs/shift & & & & & & 3 & 143 & \\
\hline Supervision & Ratio of $1: 10$ & & & & & 0 & & \\
\hline $\begin{array}{l}\text { Vac/sick/holiday } \\
\text { relief }\end{array}$ & $\begin{array}{l}\text { Assume } 6 \text { wks of } \\
\text { absence }\end{array}$ & & & & & 0 & & \\
\hline Total/shift & & & & & & 4 & & \\
\hline $70 \%$ efficiency & & & & & & 5 & & \\
\hline Total/day & & & & & & 16 & & \\
\hline
\end{tabular}

Notes:

Assume all complex debris ( 8 drums) will be sent to macroencapsulation, rest to micro.

Assume $10 \%$ of drums are deconned.

Assume $10 \%$ of drums are assayed

Assume mixing requires $30 \mathrm{~min} / \mathrm{drum}$

No. of samples $=2$ 
Table NT3-m. Polymer Stabilization Subsystem

\begin{tabular}{|c|c|c|c|c|c|c|c|c|}
\hline Task & Subtask & $\begin{array}{c}\text { Occurrence/ } \\
\text { Shift }\end{array}$ & Units & $\begin{array}{l}\text { Time } \\
\text { Required } \\
\text { (min) }\end{array}$ & $\begin{array}{c}\text { Total Time / } \\
\text { Shift }\end{array}$ & $\begin{array}{c}\text { FTEs } \\
\text { Needed }\end{array}$ & $\begin{array}{l}\text { Minutes/ } \\
\text { Drum }\end{array}$ & $\begin{array}{l}\text { Minutes/ } \\
\text { Add'I } \\
\text { Drum }\end{array}$ \\
\hline $\begin{array}{l}\text { Waste } \\
\text { Receiving/Feed } \\
\text { Prep }\end{array}$ & $\begin{array}{l}\text { Transfer through air } \\
\text { lock }\end{array}$ & 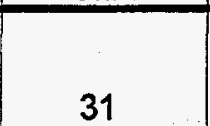 & drums & 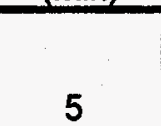 & - & & & \\
\hline & Sample waste & 3 & drums & 15 & 47 & & & \\
\hline & Evaluate dryness & 3 & drums & 5 & 16 & & & \\
\hline & Dry waste & 31 & drums & 30 & N/A & & & \\
\hline & \begin{tabular}{|l|} 
Monitor drying \\
\end{tabular} & 24 & times & 10 & 240 & & & \\
\hline & $\begin{array}{l}\text { Stage dried waste at } \\
\text { process }\end{array}$ & 31 & drums & 2 & 62 & & & \\
\hline Total Task & & & & 57 & 519 & 1 & 57 & 30 \\
\hline Encapsulation & Measure polymer & 31 & drum & 5 & 155 & & & \\
\hline & Mix polymer & 31 & drum & 10 & 310 & & & \\
\hline & $\begin{array}{l}\text { Combine with waste in } \\
\text { extruder }\end{array}$ & 31 & drum & 10 & 310 & & & \\
\hline & Repack in drums & 31 & drum & 5 & 155 & & & \\
\hline & Close drum lid & 31 & drum & 3 & 93 & & & \\
\hline & Palletize drums & 31 & drum & 2 & 62 & & & \\
\hline & Stage drums & 31 & drum & 2 & 62 & & & \\
\hline & $\begin{array}{l}\text { Monitor activated } \\
\text { carbon and fugitive dust } \\
\text { system }\end{array}$ & 8 & times & 6 & 48 & & & \\
\hline Total Task & & 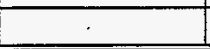 & & 43 & 1196 & 2 & 43 & 60 \\
\hline Binder setup time & $\begin{array}{l}\text { Move pallets to curing } \\
\text { area }\end{array}$ & 31 & drum & 5 & 155 & & & \\
\hline & Curing time & 31 & drum & & 0 & & & \\
\hline & Samples & 3 & times & 15 & 47 & & & \\
\hline & Monitor curing & 31 & drum & 10 & 310 & & & \\
\hline & $\begin{array}{l}\text { Move pallets from } \\
\text { curing area }\end{array}$ & 31 & times & 5 & 155 & & & \\
\hline Total Task & & & & 35 & 667 & 1 & 35 & 5 \\
\hline Drum Decon & Stage containers & 31 & drum & 5 & 155 & & & \\
\hline & Load conveyors & 31 & drum & 5 & 155 & & & \\
\hline & Decon drums & 31 & drum & 10 & 310 & & & \\
\hline & Assay drums & 31 & drum & 15 & 466 & & & \\
\hline & Unload conveyers & 31 & drum & 5 & 155 & & & \\
\hline & Stage drums & 31 & drum & 5 & 155 & & & \\
\hline Total Task & & & & 45 & 1397 & 3 & 45 & 60 \\
\hline Total FTEs/shift & & & & & & 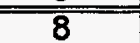 & 180 & \\
\hline Supervision & Ratio of $1: 10$ & & & & & 1 & & \\
\hline $\begin{array}{l}\text { Vac/sick/holiday } \\
\text { relief }\end{array}$ & $\begin{array}{l}\text { Assume } 6 \text { wks of } \\
\text { absence }\end{array}$ & & & & & 1 & & \\
\hline Total/shift & & & & & & 10 & & \\
\hline $70 \%$ efficiency & & & & & & 14 & & \\
\hline Total/day & & & & & & 41 & & \\
\hline
\end{tabular}

Notes:

Assume $30 \%$ of process residue waste and $100 \%$ of other waste requires drying

Assume $1 \mathrm{hr}$ drying time, $2000 \mathrm{lbs} / \mathrm{hr}$

No. of samples $=3$ 
Table NT3-n.

Air Pollution Control Subsystem

\begin{tabular}{|c|c|c|c|c|c|c|c|}
\hline Task & Subtask & $\begin{array}{c}\text { Occurrencel } \\
\text { Shift }\end{array}$ & Units & $\begin{array}{c}\text { Time } \\
\text { Required } \\
\text { (min) }\end{array}$ & $\begin{array}{c}\text { Total Time } \\
\text { Shift }\end{array}$ & $\begin{array}{c}\text { FTEs } \\
\text { Needed }\end{array}$ & Minutes/lb \\
\hline \multirow[t]{8}{*}{ Monitor Equipment } & dry filtration & 4 & times & 10 & 40 & & \\
\hline & hepa filter & 4 & times & 5 & 20 & & \\
\hline & GPCR & 24 & times & 2 & 48 & & \\
\hline & Acid gas scrubber & 12 & times & 10 & 120 & & \\
\hline & mist eliminator & 4 & times & 2 & 8 & & \\
\hline & GAC & 4 & times & 2 & 8 & & \\
\hline & mersorb & 4 & times & 2 & 8 & & \\
\hline & offgas monitor & 24 & times & 5 & 120 & & \\
\hline Total Task & & & & 38 & 372 & 1 & 0 \\
\hline Supervision & Ratio of $1: 10$ & & & & & 0 & \\
\hline $\begin{array}{l}\text { Vac/sick/holiday } \\
\text { relief }\end{array}$ & $\begin{array}{l}\text { Assume } 6 \text { wks of } \\
\text { absence }\end{array}$ & & & & & 0 & \\
\hline Total/shift & & & & & & 1 & \\
\hline $70 \%$ efficiency & & & & & & 1 & \\
\hline Total/day & & & & & & 4 & \\
\hline
\end{tabular}


Table NT3-O.

Certification and Shipping

\begin{tabular}{|c|c|c|c|c|c|c|c|c|}
\hline Task & Subtask & $\begin{array}{c}\text { Occurrencel } \\
\text { Shift }\end{array}$ & Units & $\begin{array}{c}\text { Time } \\
\text { Required } \\
\text { (min) }\end{array}$ & $\begin{array}{c}\text { Total Time / } \\
\text { Shift }\end{array}$ & $\begin{array}{c}\text { FTEs } \\
\text { Needed }\end{array}$ & $\begin{array}{c}\text { Minutes/ } \\
\text { Drum }\end{array}$ & $\begin{array}{l}\text { Minutes' } \\
\text { Add"l } \\
\text { Drum }\end{array}$ \\
\hline \multirow[t]{5}{*}{ Waste Receiving } & Transfer through air lock & 50 & drums & 5 & 248 & & & \\
\hline & Sample waste & 5 & drums & 15 & 74 & & & \\
\hline & Resample waste & 0 & drums & 15 & 7 & & & \\
\hline & Stage waste & 50 & drums & 5 & 248 & & & \\
\hline & & & & 40 & 578 & 1 & 40 & 15 \\
\hline \multirow[t]{8}{*}{ Waste Assay } & Stage pallets & 50 & drum & 3 & 149 & & & \\
\hline & Load on conveyor & 50 & drum & 1 & 50 & & & \\
\hline & Assay RTR & 50 & drum & 15 & 744 & & & \\
\hline & Assay gamma & 50 & drum & 60 & 2976 & & & \\
\hline & Assay PAN & 50 & drum & 60 & 2976 & & & \\
\hline & Remove from conveyor & 50 & drum & 1 & 50 & & & \\
\hline & Repalletize & 50 & drum & 3 & 149 & & & \\
\hline & $\begin{array}{l}\text { Stage pallets after } \\
\text { assaying }\end{array}$ & 50 & drum & 15 & 744 & & & \\
\hline Total Task & & & & 158 & 7837 & 16 & 158 & 60 \\
\hline \multirow[t]{5}{*}{ Stage waste } & Stage uncertified waste & 50 & drum & 3 & 149 & & & \\
\hline & Transfer waste & 50 & drum & 3 & 149 & & & \\
\hline & Stage certified waste & 50 & drum & 3 & 149 & & & \\
\hline & Transfer waste & 50 & drum & $\overline{3}$ & 149 & & & \\
\hline & & & & 12 & 595 & 1 & 12 & \\
\hline \multirow{4}{*}{ Ship Waste Truck } & Truck docking & 1 & truck & 30 & 17 & & & \\
\hline & Settle Paperwork & 1 & truck & 120 & 68 & & & \\
\hline & Load truck & 1 & truck & 60 & 34 & & & \\
\hline & Truck leaving & 1 & truck & 60 & 34 & & & \\
\hline Total Task & & & & 270 & 152 & 0 & 12 & \\
\hline Total FTEs/shift & & & & & & 19 & 222 & \\
\hline Supervision & Ratio of $1: 10$ & & & & & 2 & & \\
\hline $\begin{array}{l}\text { Vac/sick/holiday } \\
\text { relief }\end{array}$ & $\begin{array}{l}\text { Assume } 6 \text { wks of } \\
\text { absence }\end{array}$ & & & & & 2 & & \\
\hline Total/shift & & & & & & 23 & & \\
\hline $\begin{array}{l}\text { Adjustment for } 70 \% \\
\text { Efficiency }\end{array}$ & & & & & & 33 & & \\
\hline Total/day & & & & & & 100 & & \\
\hline
\end{tabular}

Notes:

Samples collected $=5$

Assume $10 \%$ of waste require sampling 


\begin{tabular}{|c|c|c|c|c|c|c|}
\hline & Daily FTES & $\begin{array}{l}\text { Time (min)/ } \\
\text { Single drum }\end{array}$ & Time (hrs) & $\begin{array}{l}\text { Add'l Time } \\
\text { for Next } \\
\text { Drum } \\
\end{array}$ & $\begin{array}{l}\text { Time/Drums } \\
\text { Received in a } \\
\text { Shift (minutes) } \\
\end{array}$ & Time (hrs) \\
\hline Admin & 57.3 & N/A & & & & \\
\hline $\begin{array}{l}\text { Receiving /Inspection Tasks } \\
\text { common for all waste }\end{array}$ & & 802.0 & 13.4 & 60.0 & 3727.6 & 62.1 \\
\hline $\begin{array}{l}\text { Receiving and Prep-liquids } \\
\text { Receiving and Prep-residue } \\
\text { Receiving and Prep-soil } \\
\text { Receiving and Prep-debris } \\
\end{array}$ & & $\begin{array}{c}\frac{0.0}{229.0} \\
229.0 \\
288.5 \\
\end{array}$ & $\begin{array}{l}\frac{0.0}{3.8} \\
3.8 \\
4.8 \\
\end{array}$ & $\begin{array}{l}45.0 \\
45.0 \\
5.0 \\
\end{array}$ & $\begin{array}{c}\frac{0.0}{1328.8} \\
425.2 \\
458.3 \\
\end{array}$ & $\begin{array}{l}\frac{0.0}{22.1} \\
7.1 \\
7.6 \\
\end{array}$ \\
\hline Receiving and Prep-lead & & 557.0 & 9.3 & 315.0 & 557.0 & 9.3 \\
\hline Receiving and Prep-mercury & & 516.0 & 8.6 & 315.0 & 516.0 & 8.6 \\
\hline Receiving and Prep-special & & 516.0 & 8.6 & 315.0 & 1914.6 & 31.9 \\
\hline $\begin{array}{l}\text { Receiving and Prep-metal decon } \\
\text { Receiving and Prep }\end{array}$ & 195.5 & $\begin{array}{l}229.0 \\
668.7 \\
\end{array}$ & $\frac{3.8}{11.1}$ & 35.0 & 554.4 & $\frac{9.2}{0.0}$ \\
\hline Aqueous Waste & 5.2 & 175 & 2.9 & 36 & 1170.4 & 19.5 \\
\hline $\begin{array}{l}\text { Organic Destruction } \\
\text { Residue/Soil Treatment } \\
\end{array}$ & 25.5 & $\frac{293}{117}$ & $\begin{array}{l}4.9 \\
2.0 \\
\end{array}$ & $\frac{17}{16}$ & $\frac{371.1}{594.3}$ & $\frac{6.2}{9.9}$ \\
\hline Open Debris & 36.9 & 175 & 2.9 & 23 & 233.0 & 3.9 \\
\hline Metal Decon & 16.3 & 91 & 1.5 & 75 & 1204.0 & 20.1 \\
\hline $\begin{array}{l}\text { Lead } \\
\text { Mercury }\end{array}$ & $\frac{2}{0.1}$ & $\frac{161}{357.0}$ & $\begin{array}{l}2.7 \\
6.0 \\
\end{array}$ & $\frac{N / A}{N / A}$ & $\begin{array}{l}161.0 \\
357.0 \\
\end{array}$ & $\begin{array}{l}2.7 \\
6.0 \\
\end{array}$ \\
\hline Special & 10.8 & 182.0 & 3.0 & 60.0 & 448.4 & 7.5 \\
\hline Grout & 16.1 & 143 & 2.4 & 10 & 355.4 & 5.9 \\
\hline Polymer & 41.4 & 180 & 3.0 & 60 & 1982.4 & 33.0 \\
\hline APC & 4.1 & 372 & 6.2 & & 372.0 & 6.2 \\
\hline Certification and Shipping & 100.4 & 222 & 3.7 & 60 & 3138.0 & 52.3 \\
\hline Total & 518.1 & & & & & \\
\hline
\end{tabular}

Notes:

Allocation of receiving and preparation time was done as follows: Average time per drum was estimated, multiplied by the number of drums per shift. The time for each waste type was allocated according its percentage of total waste. 




\section{System NT-5 Time and Motion Study Tables}

NT5-a System NT-5: Time and Motion Analysis

NT5-b Administration Subsystem

NT5-c Receiving and Preparation Subsystem

NT5-d CWO Organic Destruction Subsystem

NT5-e CWO Organic Destruction Subsystem for Soft Debris

NT5-f Vacuum Thermal Desorption for Process Residue

NT5-g Aqueous Waste Treatment Subsystem

NT5-h Aqueous Wash for Soil

NT5-i High Pressure Wash for Open Debris

NT5-j Metal Decontamination Subsystem

NT5-k Lead Recovery

NT5-1 Mercury Amalgamation

NT5-m Special Waste

NT5-n Grout Stabilization Subsystem

NT5-o Polymer Stabilization Subsystem

NT5-p Air Pollution Control Subsystem

NT5-q Certification and Shipping

NT5-r Summary of FTEs and time for a single drum to work through a system 


\begin{tabular}{|c|c|c|c|c|c|c|}
\hline Subsystem & $\begin{array}{c}\text { Mass Flow } \\
(\mathrm{lb} / \mathrm{hr})\end{array}$ & Waste Type & $\begin{array}{l}\text { No. of } \\
\text { Drums }\end{array}$ & $\begin{array}{c}\mathrm{SCM} \\
\text { Unprocessed } \\
\text { Density } \\
\mathrm{kg} / \mathrm{m} 3 \\
\end{array}$ & $\begin{array}{l}\text { Density } \\
\text { lb/ft3 }\end{array}$ & $\begin{array}{l}\text { Density } \\
\mathrm{lb} \text { /drum }\end{array}$ \\
\hline Administration & 2,927 & & & & & \\
\hline Receiving and preparation & 2,927 & all & 6.22 & & 64 & 471 \\
\hline Aqueous waste treatment & 1,956 & L1100 & 4.29 & & 62 & 456 \\
\hline Organic destruction & 256 & $L 2110$ & 0.56 & & 62 & 456 \\
\hline $\begin{array}{l}\text { Process residue and inorganic } \\
\text { sludge treatment }\end{array}$ & 1,020 & $\$ 3120$ & 3.18 & 700 & 44 & 321 \\
\hline Bulk soil treatment & 329 & $\$ 4100$ & 0.67 & & 67 & 493 \\
\hline Soft Debris treatment & 435 & $\$ 5300$ & 2.96 & 320 & 20 & 147 \\
\hline Open Debris treatment & 80 & $\$ 5110$ & 0.44 & 400 & 25 & 184 \\
\hline Complex Debris treatment & 177 & $\$ 5110$ & 0.97 & 400 & 25 & 184 \\
\hline Metal decontamination & 462 & $\$ 5110$ & 1.98 & 509 & 32 & 234 \\
\hline Mercury amalgamation & 3 & $\times 7100$ & 0.00 & 2000 & 125 & 918 \\
\hline Lead recovery & 26 & $\times 7200$ & 0.03 & 2000 & 125 & 918 \\
\hline Polymer stabilization & 1,127 & $\$ 3120$ & 3.51 & 700 & 44 & 321 \\
\hline Pre-polymer drying & 459 & $\$ 3120$ & 1.43 & 700 & 44 & 321 \\
\hline Air pollution control & 1,433 & & N/A & & & \\
\hline Grout stabilization & 651 & soil/debris & 1.89 & 750 & 47 & 344 \\
\hline Special treatment & 155 & $X 6000, \times 7500$ & 0.68 & 500 & 31 & 229 \\
\hline Certification and shipping & 4,270 & 2000 & 5.49 & N/A & 106 & 777 \\
\hline vol reduction (out/in) & 0.69 & & 0.88 & & & \\
\hline
\end{tabular}

Notes:

This table provides the basis for the time and motion analysis.

Quantities of waste to a subsystem (lbs/hr) are based on LMITCO mass balance of 5/30/96 except for grout and polymer, and certification and shipping ( $9 / 10 / 96$ balance).

Densities are the same as the LMITCO mass balance except where values are shown in the SCM column. Where values are shown in the SCM column, densities are taken from SCM and converted to $\mathrm{lb} / \mathrm{ft} 3$..

The waste quantities are converted from lbs/hr to drums/hr.

Subsequent analysis is based on drums/shift of waste to a subsystem. 


\begin{tabular}{|c|c|c|c|c|c|}
\hline Task & Subtask & $\begin{array}{c}\text { FTEs } \\
\text { Needed } \\
\end{array}$ & $\begin{array}{c}\text { Samples! } \\
\text { Shift }\end{array}$ & $\begin{array}{c}\text { Time } \\
\text { Required } \\
\text { (min) }\end{array}$ & $\begin{array}{c}\text { Total Time/ } \\
\text { Shift }\end{array}$ \\
\hline Facility Management & $\begin{array}{l}\text { Facility Manager } \\
\text { Secretary } \\
\text { Receptionist/word processor }\end{array}$ & $\begin{array}{l}1 \\
1 \\
1\end{array}$ & & & \\
\hline Operations Management & $\begin{array}{l}\text { Department managers } \\
\text { Communications } \\
\text { Engineering Manager } \\
\text { Engineering staff } \\
\text { Maintenance Supervisor }\end{array}$ & $\begin{array}{l}2 \\
1 \\
1 \\
2 \\
1\end{array}$ & & & \\
\hline Personnel & $\begin{array}{l}\text { Personnel Manager } \\
\text { Nurse/medical/industrial safety } \\
\text { Security guards at facility } \\
\text { Security at guard bldg }\end{array}$ & $\begin{array}{l}1 \\
1 \\
4 \\
4\end{array}$ & & & \\
\hline Environmental & $\begin{array}{l}\text { Environmental manager } \\
\text { Environmental clerk }\end{array}$ & $\begin{array}{l}1 \\
1\end{array}$ & & & \\
\hline Shipping/Receiving $/$ raffic & $\begin{array}{l}\text { Manager } \\
\text { Clerk }\end{array}$ & $\begin{array}{l}1 \\
1\end{array}$ & & & \\
\hline Purchasing & Buyer & 1 & & & \\
\hline Accounting & $\begin{array}{l}\text { Cost Accounting } \\
\text { Accounting Clerk } \\
\text { Payroll Clerks }\end{array}$ & $\begin{array}{l}2 \\
1 \\
2\end{array}$ & & & \\
\hline Laboratory & $\begin{array}{l}\text { Laboratory Manager } \\
\text { Lab Shift manager } \\
\text { Lab technicians for OSORT } \\
\text { Lab technicians for internal processe } \\
\text { Lab technicians for final waste form } \\
\text { Lab technicians for incoming supplie }\end{array}$ & $\begin{array}{c}1 \\
4 \\
4 \\
11 \\
3 \\
0.2 \\
\end{array}$ & $\begin{array}{c}11.3 \\
100.2 \\
8.3 \\
1.0 \\
\end{array}$ & $\begin{array}{l}30.0 \\
10.0 \\
30.0 \\
20.0 \\
\end{array}$ & $\begin{array}{c}340.3 \\
1002.1 \\
249.1 \\
20.0 \\
\end{array}$ \\
\hline Health Physics & $\begin{array}{l}\text { Shift health physics staff } \\
\text { Health physics manager }\end{array}$ & $\begin{array}{l}4 \\
1 \\
\end{array}$ & & & \\
\hline & $\begin{array}{l}\text { Total except Lab } \\
\text { Total Lab } \\
\text { Total Admin }\end{array}$ & $\begin{array}{l}35 \\
23 \\
58\end{array}$ & & & \\
\hline
\end{tabular}

Note:

Laboratory time is estimated by calculating the samples per shift. To fill all shifts for a 7 day week, 4 FTEs @ 6 hours per day of analysis time are assumed. 


\begin{tabular}{|c|c|c|c|c|c|c|c|c|}
\hline Task & Subtask & $\begin{array}{c}\text { Occurrencel } \\
\text { Shift }\end{array}$ & $\begin{array}{c}\text { Units for } \\
\text { Occurrence }\end{array}$ & $\begin{array}{l}\text { Time } \\
\text { Required } \\
\text { (min) }\end{array}$ & $\begin{array}{c}\text { Total Time } \\
\text { Shift }\end{array}$ & $\begin{array}{l}\text { FTEs } \\
\text { Needed }\end{array}$ & \begin{tabular}{|c|} 
Add'VTime \\
for Next \\
Drum
\end{tabular} & $\begin{array}{c}\text { Ave. } \\
\text { Minutes/Shifto } \\
\text { rum }\end{array}$ \\
\hline \multirow[t]{5}{*}{ Receive Waste Truck } & Truck docking & 0.6 & truck & 30 & 17 & \multirow[b]{6}{*}{0.3} & \multirow[t]{6}{*}{ 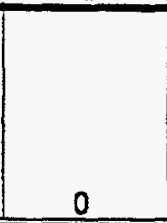 } & \multirow[b]{6}{*}{153} \\
\hline & Settle Paperwork & 0.6 & truck & 120 & 68 & & & \\
\hline & Unload truck & 0.6 & truck & 60 & 34 & & & \\
\hline & stage pallets & 0.6 & truck & 60 & 34 & & & \\
\hline & No of pallets/shift & & & & & & & \\
\hline Total Task 1 & & & & 270 & 153 & & & \\
\hline \multirow[t]{4}{*}{$\begin{array}{l}\text { Receive Empty } \\
\text { container Truck }\end{array}$} & Truck docking & 0.3 & truck & 30 & 8 & \multirow[b]{5}{*}{0.1} & \multirow[b]{5}{*}{0} & \multirow[b]{5}{*}{40} \\
\hline & Settle Paperwork & 0.3 & truck & 30 & 8 & & & \\
\hline & Unioad truck & 0.3 & truck & 60 & 17 & & & \\
\hline & Stage pallets & 0.3 & truck & 20 & 6 & & & \\
\hline Total Task 2 & & & & 140 & 40 & & & \\
\hline \multirow[t]{5}{*}{ Receive supplies } & Truck docking & $\overline{0.2}$ & truck & 30 & 6 & \multirow[b]{5}{*}{0.1} & \multirow[b]{5}{*}{0} & \multirow[b]{5}{*}{28} \\
\hline & Settle Paperwork & 0.2 & truck & 30 & 6 & & & \\
\hline & Unioad truck & 0.2 & truck & 60 & 12 & & & \\
\hline & Stage pallets & 0.2 & truck & 20 & 4 & & & \\
\hline & & & & 140 & 28 & & & \\
\hline \multirow[t]{3}{*}{$\begin{array}{l}\text { Transfer to interim } \\
\text { Storage }\end{array}$} & $\begin{array}{l}\text { Move pallets to storage } \\
\text { area }\end{array}$ & 6.2 & Pallet & 5 & 31 & \multirow[b]{4}{*}{0.3} & \multirow[b]{4}{*}{10} & \multirow[b]{4}{*}{10} \\
\hline & $\begin{array}{l}\text { Stack pallets/ organize } \\
\text { storage }\end{array}$ & 6.2 & Pallet & 10 & 62 & & & \\
\hline & Transfer to assay & 6.2 & Pallet & 5 & 31 & & & \\
\hline Total Task 4 & & & & 20 & 124 & & & \\
\hline \multirow[t]{9}{*}{ Assay Drums } & Stage pallets & 12.4 & Pallet & 5 & 62 & & & \\
\hline & Load on conveyor & 49.8 & drum & 1 & 50 & & & \\
\hline & Assay RTR & 49.8 & drum & 15 & 746 & & & \\
\hline & Assay gamma & 49.8 & drum & 60 & 2986 & & & \\
\hline & Assay PAN & 49.8 & drum & 60 & 2986 & & & \\
\hline & Remove from conveyor & 49.8 & drum & 1 & 50 & & & \\
\hline & Repalletize & 49.8 & drum & 3 & 149 & & & \\
\hline & $\begin{array}{l}\text { Stage pallets after } \\
\text { assaying }\end{array}$ & 12.4 & Pallet & 5 & 62 & & & \\
\hline & & & & 150 & 7091 & 14.8 & 60 & 150 \\
\hline $\begin{array}{l}\text { Stage and move to } \\
\text { OSORT }\end{array}$ & $\begin{array}{l}\text { Store solid waste by } \\
\text { category }\end{array}$ & 11.0 & Pallet & 10 & 110 & & & \\
\hline & Move to OSORT & 11.0 & Pallet & 5 & 55 & & & \\
\hline & Stage at OSORT & 11.0 & Pallet & 5 & 55 & & & \\
\hline Total Task 6 & & & Pallet & 20 & 219 & 0.5 & 5 & 20 \\
\hline Open Drums & Stage at drum opener & 11.0 & Pallet & 5 & 55 & & & \\
\hline & Load on conveyor & 43.9 & Drums & 5 & 219 & & & \\
\hline & Drum lid clamp & 43.9 & drum & 2 & 88 & & & \\
\hline & Drum lid opener & 43.9 & drum & 5 & 219 & & & \\
\hline & Lid staging & 43.9 & drum & 1 & 44 & & & \\
\hline & Remove from conveyor & 43.9 & drum & 1 & 44 & & & \\
\hline Total Task 7 & & & & 19 & 592 & 1.2 & 5 & 19 \\
\hline Dump Drums & $\begin{array}{l}\text { Assign drums to dump } \\
\text { stations }\end{array}$ & 43.9 & drum & 3 & 132 & & & \\
\hline & $\begin{array}{l}\text { Move drums to sort } \\
\text { table /bins }\end{array}$ & 43.9 & drum & 5 & 219 & & & \\
\hline & Dump drums & 43.9 & drum & $\frac{5}{5}$ & $\frac{210}{219}$ & & & \\
\hline Total Task 8 & & & & 13 & 570 & 1.2 & 5 & 13 \\
\hline Sort Drums & Sort waste robotically & 32.9 & drum & 30 & 987 & & & \\
\hline & $\begin{array}{l}\text { Transfer waste to } \\
\text { container }\end{array}$ & 32.9 & drum & 15 & 494 & & & \\
\hline & $\begin{array}{l}\text { Select destination for } \\
\text { sorted waste }\end{array}$ & 32.9 & drum & 3 & 99 & & & \\
\hline & $\begin{array}{l}\text { Move container to } \\
\text { subsystem bin or } \\
\text { shredder }\end{array}$ & 32.9 & drum & 3 & 99 & & & \\
\hline Total Task 9 & & & & 51 & 1678 & 3.5 & 45 & 38 \\
\hline
\end{tabular}




\begin{tabular}{|c|c|c|c|c|c|c|c|c|}
\hline Task & Subtask & $\begin{array}{c}\text { Occurrencel } \\
\text { Shift }\end{array}$ & $\begin{array}{c}\text { Units for } \\
\text { Occurrence }\end{array}$ & $\begin{array}{l}\text { Time } \\
\text { Required } \\
\text { (min) }\end{array}$ & $\left|\begin{array}{c}\text { Total Time } 1 \\
\text { Shift }\end{array}\right|$ & $\begin{array}{l}\text { FTEs } \\
\text { Needed }\end{array}$ & \begin{tabular}{|c|} 
Add'VTime \\
for Next \\
Drum
\end{tabular} & $\begin{array}{c}\text { Ave. } \\
\text { Minutes/Shitud } \\
\text { rum }\end{array}$ \\
\hline \multirow[t]{6}{*}{ Glove Box Sort } & $\begin{array}{l}\text { Transfer to glove box } \\
\text { (several trips) }\end{array}$ & 6.8 & drum & 30 & 205 & \multirow[b]{6}{*}{5.3} & \multirow[b]{6}{*}{315} & \multirow[b]{6}{*}{5} \\
\hline & $\begin{array}{l}\text { Sort waste by hand in } \\
\text { glove box }\end{array}$ & $\frac{6.8}{6.8}$ & drum & $\frac{240}{15}$ & $\frac{1639}{102}$ & & & \\
\hline & $\begin{array}{l}\text { Sampling (1/drum) } \\
\text { Transfer waste to } \\
\text { containers }\end{array}$ & 6.8 & drum & 60 & 410 & & & \\
\hline & $\begin{array}{l}\text { Select destination for } \\
\text { sorted waste }\end{array}$ & 6.8 & drum & 15 & 102 & & & \\
\hline & $\begin{array}{l}\text { Move containers to } \\
\text { subsystem bin or } \\
\text { shredder }\end{array}$ & 6.8 & drum & 15 & 102 & & & \\
\hline & & & & 375 & 2562 & & & \\
\hline \multirow[t]{4}{*}{$\begin{array}{l}\text { Assess Debris for } \\
\text { Debris Rule } \\
\text { Compliance }\end{array}$} & $\begin{array}{l}\text { Transfer open and } \\
\text { complex debris }\end{array}$ & 11.3 & drum & 3 & 34 & \multirow[b]{5}{*}{0.3} & \multirow[b]{5}{*}{5} & \multirow[b]{5}{*}{6} \\
\hline & Screen debris & 11.3 & drum & 4 & 45 & & & \\
\hline & $\begin{array}{l}\text { Additional sampling } \\
(25 \%)\end{array}$ & 2.8 & drum & 10 & 28 & & & \\
\hline & Inspection & 11.3 & drum & 5 & 56 & & & \\
\hline Total Task 11 & & & & 22 & 164 & & & \\
\hline \multirow[t]{4}{*}{ Gross Size Reduction } & Transfer to cutting table & 14.2 & drum & 3 & 43 & \multirow[b]{5}{*}{1.2} & \multirow[b]{5}{*}{35} & \multirow[b]{5}{*}{6} \\
\hline & Cut waste & 14.2 & drum & 30 & 425 & & & \\
\hline & Retum to container & 14.2 & drum & 5 & 71 & & & \\
\hline & $\begin{array}{l}\text { Transfer to next } \\
\text { process }\end{array}$ & 14.2 & drum & 3 & 43 & & & \\
\hline Total Task 12 & & & & 41 & 581 & & & \\
\hline \multirow[t]{11}{*}{ Shredding } & Transfer to shredder & 37.3 & drum & 2 & 75 & \multirow[b]{11}{*}{1.7} & \multirow[b]{11}{*}{2} & \multirow[b]{11}{*}{30} \\
\hline & Stage waste & 37.3 & drum & 2 & 75 & & & \\
\hline & Feed waste to shredder & 37.3 & drum & 2 & 75 & & & \\
\hline & $\begin{array}{l}\text { Feed damaged drums } \\
\text { to shredder }\end{array}$ & 21.9 & drum & 2 & 44 & & & \\
\hline & Shred stage 1 & 59.3 & drum & 2 & 119 & & & \\
\hline & Shred stage 2 & 59.3 & drum & $\overline{2}$ & 119 & & & \\
\hline & Sample size of waste & 5.9 & drum & 5 & 30 & & & \\
\hline & Rework $10 \%$ & 0.6 & drum & 15 & 9 & & & \\
\hline & Return to container & 59.3 & drum & 3 & 178 & & & \\
\hline & $\begin{array}{l}\text { Transfer to next } \\
\text { process }\end{array}$ & 59.3 & drum & 2 & 119 & & & \\
\hline & & & & 37 & 840 & & & \\
\hline \multirow[t]{6}{*}{ Sampling } & & & & & 0 & \multirow[b]{6}{*}{0.5} & \multirow[b]{6}{*}{10} & \multirow[b]{6}{*}{30} \\
\hline & Sample opened drums & 4.4 & drum & 5 & 22 & & & \\
\hline & Sample sorted waste & 5.9 & drum & 5 & 30 & & & \\
\hline & Resample (10\%) & 1.0 & drum & 5 & 5 & & & \\
\hline & Reportieval. results & 11.3 & drum & 10 & 113 & & & \\
\hline & & & & 25 & 170 & & & \\
\hline \multirow[t]{6}{*}{$\begin{array}{l}\text { Subsystem Bin } \\
\text { operation }\end{array}$} & Monitor bin height & 4.4 & drum & 3 & 13 & \multirow[b]{6}{*}{0.3} & \multirow[b]{6}{*}{0} & \multirow[b]{6}{*}{26} \\
\hline & Fill containers & 4.4 & drum & 3 & 13 & & & \\
\hline & Move containers & 4.4 & drum & 2 & 9 & & & \\
\hline & Stage containers & 4.4 & drum & 3 & 13 & & & \\
\hline & Organize campaigns & 4.4 & drum & 15 & 66 & & & \\
\hline & & & & 26 & 114 & & & \\
\hline
\end{tabular}




\begin{tabular}{|c|c|c|c|c|c|c|c|c|}
\hline Task & Subtask & $\begin{array}{c}\text { Occurrencel } \\
\text { Shift }\end{array}$ & $\begin{array}{c}\text { Units for } \\
\text { Occurrence }\end{array}$ & $\begin{array}{c}\text { Time } \\
\text { Required } \\
\text { (min) }\end{array}$ & $\left|\begin{array}{c}\text { Total Time I } \\
\text { Shift }\end{array}\right|$ & $\begin{array}{l}\text { FTEs } \\
\text { Needed }\end{array}$ & $\begin{array}{c}\text { Add'litime } \\
\text { for Next } \\
\text { Drum }\end{array}$ & $\begin{array}{c}\text { Ave. } \\
\begin{array}{c}\text { Minutes/Shift/D } \\
\text { rum }\end{array}\end{array}$ \\
\hline \multirow[t]{9}{*}{ Internal Transfer } & $\begin{array}{l}\text { Move waste from } \\
\text { OSORT to other } \\
\text { subsystems }\end{array}$ & 4.4 & drum & 10 & -10 & \multirow[b]{9}{*}{5.2} & \multirow[b]{9}{*}{10} & \multirow[t]{9}{*}{ - } \\
\hline & $\begin{array}{l}\text { Move waste from } \\
\text { subsystems to CSHIP }\end{array}$ & 43.9 & drum & 10 & 439 & & & \\
\hline & $\begin{array}{l}\text { Move treated waste to } \\
\text { stabilization }\end{array}$ & 80.0 & drum & 10 & 800 & & & \\
\hline & $\begin{array}{l}\text { Move liquid waste to } \\
\text { AQWTR and OrgDes }\end{array}$ & 5.9 & drum & 10 & 59 & & & \\
\hline & $\begin{array}{l}\text { Move waste to } \\
\text { secondary treatment }\end{array}$ & 20.0 & drum & 10 & 200 & & & \\
\hline & Move supplies around & 20.0 & drum & 3 & 60 & & & \\
\hline & Move new drums & 24.9 & drum & 3 & 75 & & & \\
\hline & Schedule movement & 199.1 & drum & 1 & 199 & & & \\
\hline & & & & 57 & 1876 & & & \\
\hline \multirow[t]{4}{*}{ Box Breakdown } & Stage boxes & 10.0 & box & 2 & 20 & \multirow[b]{5}{*}{0.5} & \multirow[b]{5}{*}{10} & \multirow[b]{5}{*}{2} \\
\hline & Move to opening area & 10.0 & box & 3 & 30 & & & \\
\hline & Open boxes & 10.0 & box & 10 & 100 & & & \\
\hline & Transfer to dump & 10.0 & box & 3 & 30 & & & \\
\hline Total Task 17 & & & & 18 & 180 & & & \\
\hline \multirow[t]{6}{*}{ Container Decon } & Stage containers & 49.8 & drum & 5 & 249 & \multirow[b]{7}{*}{6.2} & \multirow[b]{7}{*}{15} & \multirow[b]{7}{*}{45} \\
\hline & Load conveyors & 49.8 & drum & 5 & 249 & & & \\
\hline & Decon drums & 49.8 & drum & 10 & 498 & & & \\
\hline & Assay drums & 49.8 & drum & 15 & 746 & & & \\
\hline & Unload conveyers & 49.8 & drum & 5 & 249 & & & \\
\hline & Stage drums & 49.8 & drum & 5 & 249 & & & \\
\hline Total Task 18 & & & & 45 & 2239 & & & \\
\hline \multirow{2}{*}{$\begin{array}{l}\text { FTEs/shitit } \\
\text { Supervision }\end{array}$} & & & & & & \multirow{2}{*}{$\begin{array}{l}36.5 \\
3.7\end{array}$} & & \multirow{7}{*}{676} \\
\hline & Ratio of $1: 10$ & & & & & & & \\
\hline Vac/sick/holiday relief & $\begin{array}{l}\text { Assume } 6 \text { wks of } \\
\text { absence }\end{array}$ & & & & & \multirow[t]{2}{*}{4.6} & & \\
\hline $\begin{array}{l}\text { Break relief (included } \\
\text { in } 6 \mathrm{hr} \text { day) }\end{array}$ & $\begin{array}{l}\text { One person can relieve } \\
3 \text { (accounted for in } \\
\text { efficiency) }\end{array}$ & & & - & & & & \\
\hline Total/shift & & & & & & \multirow{3}{*}{$\begin{array}{c}44.8 \\
64.0 \\
191.9\end{array}$} & & \\
\hline Adj for $70 \%$ Efficiency & & & & & & & & \\
\hline Total/day & & & & & & & & \\
\hline
\end{tabular}

Notes:

Assume FTEs are available for 8 hrs/day; because overall $70 \%$ efficiency is taken at the end.

Trucks have 22 pallets. Truckloads received based on total inventory to shipping at $300 \mathrm{lb} / \mathrm{drum}$ (see separate truck calc sheet)

Pallets are assumed to hold 455 gallon drums

As in inventory, assume $50 \%$ of drums are contaminated and can't be deconned.

Assume $50 \%$ of waste received requires interim storage; this will be dependent on assay system

Assume $10 \%$ of incoming waste is sampled

Assume sorted waste is $75 \%$ of total; all of debris, no liq, no lead/merc/spec, $70 \%$ of residue and soil

Assume $10 \%$ of sorted waste is sampled

Assume gross size reduction is necessary for wastes to metal decon \& lead

Assume gross size reduction is $1 \mathrm{hr}$ per drum.

Assume shredding is necessary for waste to proc res, soil, soft debris(sorted or not)

$$
0.75 \text { =fraction of feed to RCPRP requiring shredding }
$$

Assume $10 \%$ of shredded waste is sampled.

Box breakdown includes time beyond that required if waste was packaged in drums

Assume glove box sorting required for $10 \%$ of open and complex debris, + all of special, mercury and lead

$$
0.14 \text { =fraction of feed to RCPRP requiring glove box sorting }
$$

Assume glove box waste requires 1 sample/drum

Assume only complex and open debris require assessment, because open debris goes to CWO.

Assume liquids will arrive in drums and be transferred from receiving, and not go to the sorting cell

Assume transfer control for liquids takes the same time as for drums

Assume paperwork is accomplished within times shown

Average time per drum includes times for activities multiplied by the probability that the activity will occur. 


\begin{tabular}{|c|c|c|c|c|c|c|c|c|}
\hline Task & Subtask & $\begin{array}{c}\text { Occurrencel } \\
\text { Shift }\end{array}$ & $\begin{array}{c}\text { Units for } \\
\text { Occurrence }\end{array}$ & $\begin{array}{l}\text { Time } \\
\text { Required } \\
\text { (min) }\end{array}$ & $\left|\begin{array}{c}\text { Total Time } \\
\text { Shift }\end{array}\right|$ & $\begin{array}{c}\text { FTEs } \\
\text { Needed }\end{array}$ & $\begin{array}{l}\text { Add'lTime } \\
\text { for Next } \\
\text { Drum }\end{array}$ & $\begin{array}{c}\text { Ave. } \\
\text { Minutes/Shift/D } \\
\text { rum }\end{array}$ \\
\hline
\end{tabular}

Notes (cont.)

Least time/drum/subsystem includes only the minimum requirements, no extra staging, sorting, or shredding

Max time/drum/subsystem includes all staging, shredding, glove box, etc 


\begin{tabular}{|c|c|c|c|c|c|c|c|c|}
\hline Task & Subtask & $\begin{array}{c}\text { Occurrencel } \\
\text { Shift }\end{array}$ & $\begin{array}{c}\text { Units for } \\
\text { Occurrence }\end{array}$ & $\begin{array}{c}\text { Time } \\
\text { Required } \\
\text { (min) }\end{array}$ & $\begin{array}{c}\text { Total Time / } \\
\text { Shift }\end{array}$ & $\begin{array}{l}\text { FTEs } \\
\text { Needed }\end{array}$ & $\begin{array}{l}\text { Addilitime } \\
\text { for Next } \\
\text { Drum }\end{array}$ & $\begin{array}{c}\text { Average } \\
\text { Minutes/Shift } \\
\text { Drum }\end{array}$ \\
\hline \multirow[t]{8}{*}{ Receive Waste } & Transfer through air lock & 3.3 & drum & 5 & 16 & & & \\
\hline & Feed waste from drum & 3.3 & drum & 3 & 10 & & & \\
\hline & Hook to transfer device & 3.3 & drum & 3 & 10 & & & \\
\hline & Transfer to tank (10 gpm) & 3.3 & drum & 6 & 18 & & & \\
\hline & Empty drum bottoms & 3.3 & drum & 2 & 7 & & & \\
\hline & Detach \& remove drum & 3.3 & drum & 3 & 10 & & & \\
\hline & Sample feed vessel & 3.3 & drum & 5 & 16 & & & \\
\hline & $\begin{array}{l}\text { Arrange for transfer of } \\
\text { secondary waste from other } \\
\text { subsystems }\end{array}$ & 1.2 & drum & 2 & 2 & & & \\
\hline Total Task & & & & 28 & 88 & 0.18 & 28 & 17 \\
\hline \multirow[t]{4}{*}{ Feed waste to reactor } & $\begin{array}{l}\text { Startup Instrumentation and } \\
\text { valve check }\end{array}$ & 1.0 & & 30 & 30 & & & \\
\hline & $\begin{array}{l}\text { Meter waste to reactor } \\
\text { (monitoring time) }\end{array}$ & 24.0 & & 10 & 240 & & & \\
\hline & $\begin{array}{l}\text { Meter waste to reactor ( } 300 \\
\text { lbs/hr) }\end{array}$ & 4.5 & drums & 6 & 25 & & & \\
\hline & & & & 36 & 270 & 0.56 & 36 & 6 \\
\hline \multirow[t]{5}{*}{ Operate Reactor } & Instrumentation/Equip check & 1.0 & time & 30 & $30^{-1}$ & & & \\
\hline & $\begin{array}{l}\text { Time to react organics } \\
\text { (min/drum) reaction rate: } 797 \\
\text { lbs/hr }\end{array}$ & 4.5 & drum & 34 & 154 & & & \\
\hline & $\begin{array}{l}\text { Flow velocity (gpm)= } \\
\text { drums/shift" } 55 \text { gal/drum } /(480 \\
\text { min/shift) }\end{array}$ & 0.5 & & & & & & \\
\hline & $\begin{array}{l}\text { Residence time (min)= Reactor } \\
\text { volumefflow velocity: Reactor } \\
\text { volume is } 5 \% \text { of } 500 \mathrm{gal}\end{array}$ & 48.7 & minutes & & & & & \\
\hline & & & & 64 & 184 & 0.38 & 64 & 34 \\
\hline \multirow[t]{10}{*}{ Waste Transfer/ Recycle } & $\begin{array}{l}\text { Waste removed from tank } \\
\text { (pump } 500 \text { gal @ } 10 \mathrm{gpm} \text { ) }\end{array}$ & 9.1 & drum & 6 & 50 & & & \\
\hline & Filter solution & 24.0 & times & 2 & 48 & & & \\
\hline & Sample filtrate & 2.0 & times & 15 & 30 & & & \\
\hline & Recycle acids & 24.0 & times & 2 & 48 & & & \\
\hline & Operate condenser & 1.0 & times & 16 & 16 & & & \\
\hline & Wash solution & 24.0 & times & 2 & 48 & & & \\
\hline & Sample & 2.0 & times & 15 & 30 & & & \\
\hline & Transfer@10 gpm to filter & 44.8 & drums & 6 & 246 & & & \\
\hline & Transfer @10 gpm from filter & 44.8 & drums & 6 & 246 & & & \\
\hline & & & & 63 & 270 & 0.56 & $\overline{63}$ & 6 \\
\hline \multirow[t]{6}{*}{ Treat inorganics } & Transfer to neutralizer & 24.0 & & 2 & 48 & & & \\
\hline & Precipitate filtered solids & 24.0 & & 2 & 48 & & & \\
\hline & Filter precipitate & 24.0 & & 2 & 48 & & & \\
\hline & Transfer fittrate to Aq. Waste & 24.0 & & 2 & 48 & & & \\
\hline & $\begin{array}{l}\text { Transfer precipitated solids to } \\
\text { polymer }\end{array}$ & 24.0 & & 2 & 48 & & & \\
\hline & Collect sample & 2.0 & & 5 & 10 & & & \\
\hline Total Task & & & & 15 & 250 & 0.52 & 15 & 34 \\
\hline FTEs/shift & & & & & & 2.21 & 206 & \\
\hline Supervision & Ratio of 1:10 & & & & & 0.22 & & \\
\hline Vacisick/holiday relief & Assume 6 wks of absence & & & & & 0.28 & & \\
\hline Adjust for $70 \%$ Efficiency & & & & & & 0.81 & & \\
\hline Total/shift & & & & & & 3.53 & & \\
\hline Total/day & & & & & & 10.58 & & \\
\hline
\end{tabular}

Notes:

Total Samples/Shift $=\quad 4.3$

Assume sampling frequency $=10 \%$ of drums

From Blaines mass balance, the feed to subsystem $=241.40 \quad \mathrm{lbs} / \mathrm{hr}$

Total feed is (drums $/ \mathrm{hr}$ ) $=0.6$

Assume continuous CWO process

Assume solids removal once/day

Waste transferfrecycle processes are continuous. Time is expected labor monitoring time

Assume drums of liquid transferred from Rec and Prep

Assume paperwork is accomplished within times shown 


\begin{tabular}{|c|c|c|c|c|c|c|c|c|}
\hline Task & Subtask & $\begin{array}{c}\text { Occurrencel } \\
\text { Shift }\end{array}$ & $\begin{array}{c}\text { Units for } \\
\text { Occurrence }\end{array}$ & $\begin{array}{c}\text { Time } \\
\text { Required } \\
\text { (min) }\end{array}$ & $\begin{array}{l}\text { Total } \\
\text { Time I } \\
\text { Shift }\end{array}$ & $\begin{array}{l}\text { FTEs } \\
\text { Needed }\end{array}$ & $\begin{array}{l}\text { Add'VTime } \\
\text { for Next } \\
\text { Drum }\end{array}$ & $\begin{array}{c}\text { Average } \\
\text { Minutes/Shift } \\
\text { Drum }\end{array}$ \\
\hline \multirow[t]{3}{*}{ Receive Waste } & Transfer through air lock & 24 & drum & 5 & 118 & & & \\
\hline & Stage drums for campaigns & 24 & drum & 5 & 118 & & & \\
\hline & & & & 10 & 237 & 0 & 10 & 15 \\
\hline \multirow[t]{8}{*}{ Feed Waste from drum } & Stage at feed bin (drums) & 24 & drum & $=\frac{2}{3}$ & 71 & & & \\
\hline & Hook to transfer device & 24 & drum & 3 & 71 & & & \\
\hline & $\begin{array}{l}\text { Transfer into feed bin ( } 2-300 \\
\text { lb/hr metering screws) }\end{array}$ & 24 & drum & 15 & 348 & & & \\
\hline & Feed screw monitoring time & 24 & & 10 & 240 & & & \\
\hline & Empty drum bottoms & 24 & & 2 & 47 & & & \\
\hline & Sample feed vessel & 2 & & 10 & 20 & & & \\
\hline & Detach \& remove drum & 24 & & 3 & 71 & & & \\
\hline & & & & 36 & 520 & 1 & 36 & 33 \\
\hline \multirow[t]{4}{*}{ Feed waste to reactor } & $\begin{array}{l}\text { Startup instrumentation and } \\
\text { valve check }\end{array}$ & 1 & & 30 & 30 & & & \\
\hline & $\begin{array}{l}\text { Meter waste to reactor (600 } \\
\text { lbs/hr) }\end{array}$ & 24 & & 15 & 348 & & & \\
\hline & Feed screw monitoring time & 24 & & 10 & 240 & & & \\
\hline & & & & 45 & 270 & 1 & 45 & 15 \\
\hline \multirow[t]{3}{*}{ Operate reactor } & Instrumentation/Equip check & 1 & & 30 & 30 & & & \\
\hline & $\begin{array}{l}\text { Reaction rate (see rxn calcs } \\
\text { table): } 1069 \mathrm{lb} / \mathrm{hr} \text { in a } 2500 \\
\text { gal vessel }\end{array}$ & 24 & drum & 21 & 488 & & & \\
\hline & & & & 51 & 518 & 1 & 51 & 21 \\
\hline \multirow[t]{10}{*}{ Waste Transfer/ Recycle } & $\begin{array}{l}\text { Waste removed from tank } \\
\text { (pump } 5 \text { gpm) }\end{array}$ & 24 & times & 2 & 48 & & & \\
\hline & Filter solution & 24 & times & 2 & 48 & & & \\
\hline & Sample filtrate & 2 & times & 15 & 30 & & & \\
\hline & Recycle acids & 24 & times & 2 & 48 & & & \\
\hline & Operate condenser & 1 & times & 16 & 16 & & & \\
\hline & Wash solution & 24 & times & 2 & 48 & & & \\
\hline & Sample & 2 & times & 15 & 30 & & & \\
\hline & Transfer @ $10 \mathrm{gpm}$ to filter & 237 & drums & 6 & 1302 & & & \\
\hline & $\begin{array}{l}\text { Transfer @ } 10 \mathrm{gpm} \text { from } \\
\text { filter }\end{array}$ & 237 & -drums & 6 & 1302 & & & \\
\hline & & & & 65 & 268 & 1 & 65 & \\
\hline \multirow[t]{7}{*}{ Treat inorganics } & Transfer to neutralizer & 24 & & $\overline{2}$ & 48 & & & \\
\hline & Precipitate filtered solids & 24 & & 2 & 48 & & & \\
\hline & Filter precipitate & 24 & & 2 & 48 & & & \\
\hline & Transfer filtrate to Aq. Waste & 24 & & 2 & 48 & & & \\
\hline & $\begin{array}{l}\text { Transfer precipitated solids to } \\
\text { polymer }\end{array}$ & 24 & & 2 & 48 & & & \\
\hline & Collect sample & 2 & & 5 & 10 & & & \\
\hline & & & & 15 & 250 & 1 & 15 & \\
\hline FTEs/shift & & & & & & 4 & & \\
\hline Supervision & Ratio of $1: 10$ & & & & & 0 & & \\
\hline Vac/sick/holiday relief & Assume 6 wks of absence & & & & & 1 & & \\
\hline Adjustmnet for $70 \%$ Efficiency & & & & & & 2 & & \\
\hline Total/shift & & & & & & 7 & 221 & 15 \\
\hline Total/day & & & & & & 21 & & \\
\hline
\end{tabular}

Notes:

From Blaines mass balance, the feed to subsystem is

$\mathrm{lbs} / \mathrm{hr}$

Total feed is (drums/hr) =

Assume continuous process for CWO

Assume solids removal once/day

Waste transfer/recycle processes are continuous. Time is expected labor monitoring time

Number of process samples $=8$ 


\begin{tabular}{|c|c|c|c|c|c|c|c|c|}
\hline Task & Subtask & $\begin{array}{c}\text { Occurrence/ } \\
\text { Shift }\end{array}$ & Units & $\begin{array}{c}\text { Time } \\
\text { Required } \\
\text { (min) }\end{array}$ & $\begin{array}{l}\text { Total Time/ } \\
\text { Shift }\end{array}$ & $\begin{array}{l}\text { FTEs } \\
\text { Needed }\end{array}$ & $\begin{array}{l}\text { Minutes/ } \\
\text { Drum }\end{array}$ & $\begin{array}{l}\text { Timel } \\
\text { Add'l } \\
\text { Drum }\end{array}$ \\
\hline \multirow[t]{3}{*}{ Receive Waste } & Transfer through air lock & 25.4 & & 5 & 127 & & & \\
\hline & Stage drums for campaigns & 25.4 & & 2 & 51 & & & \\
\hline & & & & 7 & 178 & 0.37 & 7 & 2 \\
\hline \multirow[t]{6}{*}{$\begin{array}{l}\text { Feed Waste from } \\
\text { drum }\end{array}$} & Stage at feed bin (drums) & 25.4 & & 3 & 76 & & & \\
\hline & Hook to transfer device & 25.4 & & 3 & 76 & & & \\
\hline & Transfer into feed bin & 25.4 & & 5 & 127 & & & \\
\hline & Empty drum bottoms & 25.4 & & 2 & 51 & & & \\
\hline & Sample feed vessel & 2.0 & & 5 & 10 & & & \\
\hline & Detach \& remove drum & 25.4 & & 3 & 76 & & & \\
\hline Total Task & & & & 16 & 290 & 0.60 & 16 & 5 \\
\hline \multirow[t]{8}{*}{$\begin{array}{l}\text { Vacuum Thermal } \\
\text { Desorption }\end{array}$} & $\begin{array}{l}\text { Unit is number of batches: } \\
\text { batch is } 15000 \text { lbs or }\end{array}$ & 46.7 & & $\begin{array}{l}\text { drums/ } \\
\text { batch }\end{array}$ & & & & \\
\hline & $\begin{array}{l}\text { Check equipment, instruments } \\
\text { before startup }\end{array}$ & 0.5 & & 30 & 16 & & & \\
\hline & $\begin{array}{l}\begin{array}{l}\text { Charge desorber (15000 } \\
\text { lbs/hr) }\end{array} \\
\end{array}$ & 0.5 & & 60 & 33 & & & \\
\hline & Heat desorber & 0.5 & & 60 & 33 & & & \\
\hline & Desorber batch & 0.5 & & 60 & 33 & & & \\
\hline & Cool desorber & 0.5 & & 30 & 16 & & & \\
\hline & Discharge desorbed waste & 0.5 & & 15 & 8 & & & \\
\hline & & & & 225 & 122 & 0.26 & 225 & 0 \\
\hline \multirow[t]{5}{*}{ Monitor Offgas } & Monitor cooler 1 & 24.0 & & 1 & 24 & & & \\
\hline & Monitor condenser 1 & 24.0 & & 1 & 24 & & & \\
\hline & Monitor condenser 2 & 24.0 & & 1 & 24 & & & \\
\hline & Monitor transfer lines to APC & 24.0 & & 1 & 24 & & & \\
\hline & & & & 4 & 96 & 0.20 & 0 & 0 \\
\hline \multirow[t]{5}{*}{ Condensate handling } & $\begin{array}{l}\text { Sample holding vessel from } \\
\text { cond. } 1\end{array}$ & 1.0 & & 15 & 15 & & & \\
\hline & $\begin{array}{l}\text { Sample holding vessel from } \\
\text { condenser } 2\end{array}$ & 1.0 & & 15 & 15 & & & \\
\hline & $\begin{array}{l}\text { Transfer to aqueous waste } \\
\text { treatment }\end{array}$ & 0.5 & & 20 & 10 & & & \\
\hline & $\begin{array}{l}\text { Transfer to mercury } \\
\text { amalgamation }\end{array}$ & 0.5 & & 20 & 10 & & & \\
\hline & & & & 70 & 50 & 0.10 & & \\
\hline \multirow[t]{5}{*}{$\begin{array}{l}\text { Separate desorbed } \\
\text { waste }\end{array}$} & Sample waste & 0.5 & batch & 5 & 3 & & & \\
\hline & Select destination (see note) & 16.2 & drums & 1 & 16 & & & \\
\hline & Transfer waste to $\mathrm{Hg}$ leaching & 4.8 & drums & 2 & 10 & & & \\
\hline & Transfer waste to polymer stabi & 11.3 & drums & 2 & 23 & & & \\
\hline & & & & 10 & 51 & 0.11 & 10 & 8 \\
\hline \multirow[t]{15}{*}{$\begin{array}{l}\text { Mercury cont. solids } \\
\text { leaching }\end{array}$} & Process is sized for $1000 \mathrm{lbs} / \mathrm{hr} / \mathrm{c}$ & of waste or 2 & 5 drums & E/shift & & & & \\
\hline & Measure leaching agent & 0.2 & drums & 20 & 4 & & & \\
\hline & Leach waste & 0.2 & & 90 & 18 & & & \\
\hline & Transfer to wash 1 & 0.2 & & 20 & 4 & & & \\
\hline & Wash & 0.2 & & 60 & 12 & & & \\
\hline & Sample & 0.2 & & 15 & 3 & & & \\
\hline & Transfer to wash 2 & 0.2 & & 20 & 4 & & & \\
\hline & Wash & 0.2 & & 60 & 12 & & & \\
\hline & Sample & 0.2 & & 15 & 3 & & & \\
\hline & Transfer to filter & 0.2 & & 20 & 4 & & & \\
\hline & Filter solids & 0.2 & & 30 & 6 & & & \\
\hline & Sample/evaluate & 0.2 & & 30 & 6 & & & \\
\hline & Transfer liquid to aqueous wast & 0.2 & & 10 & 2 & & & \\
\hline & Transfer solid to polymer & 0.2 & & 10 & $\frac{2}{2}$ & & & \\
\hline & & & & 400 & 78 & 0.16 & 84 & 0 \\
\hline
\end{tabular}




\begin{tabular}{|c|c|c|c|c|c|c|c|c|}
\hline Task & Subtask & $\begin{array}{c}\text { Occurrencer } \\
\text { Shift }\end{array}$ & Units & $\begin{array}{c}\text { Time } \\
\text { Required } \\
\text { (min) }\end{array}$ & $\begin{array}{l}\text { Total Time/ } \\
\text { Shift }\end{array}$ & $\begin{array}{c}\text { FTEs } \\
\text { Needed }\end{array}$ & $\begin{array}{l}\text { Minutes/ } \\
\text { Drum }\end{array}$ & $\begin{array}{l}\text { Time/ } \\
\text { Add"l } \\
\text { Drum }\end{array}$ \\
\hline \multirow[t]{16}{*}{$\begin{array}{l}\text { Leachate/ filtrate } \\
\text { Ttreatment }\end{array}$} & Transfer leachate to mercury re & 0.2 & & 20 & -10 & & & \\
\hline & Transfer rinse waste water to $\mathrm{m}$ & 0.2 & & 20 & 4 & & & \\
\hline & Mercury reduction over steel $w$ & 0.2 & & 60 & 12 & & & \\
\hline & Sample & 0.2 & & 15 & 3 & & & \\
\hline & Transfer to mercury ppt & 0.2 & & 20 & 4 & & & \\
\hline & Sample & 0.2 & & 15 & 3 & & & \\
\hline & Add precipitation agents & 0.2 & & 15 & 3 & & & \\
\hline & Settle tank & 0.2 & & 60 & 12 & & & \\
\hline & Sample solids & 0.2 & & 15 & 3 & & & \\
\hline & Transfer solids to polymer & 0.2 & & 10 & 2 & & & \\
\hline & Transfer liquid to iodine recover & 0.2 & & 10 & 2 & & & \\
\hline & Add chemicals ( $\mathrm{H} 2 \mathrm{SO} 4, \mathrm{H} 2 \mathrm{O} 2$ & 0.2 & & 15 & 3 & & & \\
\hline & Reaction & 0.2 & & 30 & $\overline{6}$ & & & \\
\hline & Recover iodine & 0.2 & & 60 & 12 & & & \\
\hline & Transfer solids & 0.2 & & 20 & 4 & & & \\
\hline & Transfer liquid to wash 2 & 0.2 & & 10 & 2 & & & \\
\hline Total Task & & & & 395 & 77 & 0.16 & 83 & 0 \\
\hline FTEs/shift & & & & & 0 & $1 . \overline{96}$ & 425 & 15 \\
\hline Supervision & Ratio of $1: 10$ & & & & & 0.20 & & \\
\hline Vac/sick/holiday relief & Assume 6 wks of absence & & & & & 0.25 & & \\
\hline Total/shift & & & & & & 2.41 & 425 & 15 \\
\hline $\begin{array}{l}\text { Adjustment for } 70 \% \\
\text { efficiency }\end{array}$ & & & & & & 3.44 & & \\
\hline Total/day & & & & & & 10.32 & & \\
\hline
\end{tabular}

Notes:

Thermal Desorption Batch size of 15,000 lbs

Assume drum transfer of $15 \mathrm{~min} / \mathrm{drum}$ or $0.5 \mathrm{ft3} / \mathrm{min}$

Only 0.6 batches required per shift based on feed to subsystem

The condenser/aqueous transfer monitoring functions will occur when the desorber is running

Number of drums following treatment is based on the $5 / 30$ mass balance: $1020 \mathrm{lbs} / \mathrm{hr}$ in and $648 \mathrm{lbs} / \mathrm{hr}$ out

Assume $30 \%$ of the waste goes to mercury leaching process

Mercury leaching process was sized for $1000 \mathrm{lbs} / \mathrm{hr}$ of waste (@ $321 \mathrm{lbs} / \mathrm{drum}$ thisconverts to 25 drums/shift)

Number of process samples $=$ 


\begin{tabular}{|c|c|c|c|c|c|c|c|c|}
\hline Task & Subtask & $\begin{array}{c}\text { Occurrencel } \\
\text { Shift }\end{array}$ & Units & $\begin{array}{c}\text { Time } \\
\text { Required } \\
\text { (min) }\end{array}$ & $\begin{array}{c}\text { Total Timer } \\
\text { Shift }\end{array}$ & $\begin{array}{l}\text { FTEs } \\
\text { Needed } \\
\end{array}$ & $\begin{array}{c}\text { Minutes/ } \\
\text { Drum }\end{array}$ & $\begin{array}{l}\text { Time } \\
\text { Addy } \\
\text { Drum }\end{array}$ \\
\hline \multirow[t]{9}{*}{ Receive Waste } & Transfer through air lock & 1 & drum & 5 & 7 & & & \\
\hline & Feed waste from drum & 1 & drum & 3 & 4 & & & \\
\hline & Hook to transfer device & 1 & drum & 3 & 4 & & & \\
\hline & Transfer to tank (10 gpm) & 1 & drum & 6 & 8 & & & \\
\hline & Empty drum bottoms & 1 & & 2 & 3 & & & \\
\hline & Sample feed vessel & 2 & & 10 & 20 & & & \\
\hline & Detach \& remove drum & 1 & & 3 & 4 & & & \\
\hline & $\begin{array}{l}\text { Sample waste from processes: } \\
\text { CWO,Desorb, Decon,APC }\end{array}$ & 4 & N/A & & & & & \\
\hline & Arrange for transfer & 33 & drum & 2 & 49 & & & \\
\hline Total Task & & & & 33 & 100 & 0.21 & 33 & 5 \\
\hline \multirow[t]{10}{*}{ Preliminary Treatment } & Sample high TDS tank & 28 & drums & 15 & 42 & & & \\
\hline & Sample low TDS tank & 6 & drums & 15 & 9 & & & \\
\hline & Sample TOC waste & 0 & drums & 15 & 0 & & & \\
\hline & $\begin{array}{l}\text { Select treatment methods (10 } \\
\text { drum batch) }\end{array}$ & 6 & drums & 20 & 12 & & & \\
\hline & $\begin{array}{l}\text { Transfer organic waste to oil } \\
\text { water separator }\end{array}$ & $\underline{0}$ & drums & 3 & 0 & & & \\
\hline & $\begin{array}{l}\text { Filter high, low TDS and organic } \\
\text { waste (say } 10 \text { gal/min) }\end{array}$ & 34 & drums & 6 & 188 & & & \\
\hline & Neutralize/ppt high TDS waste & 28 & drums & 11 & 309 & & & \\
\hline & $\begin{array}{l}\text { Settle precipitated aqueous } \\
\text { waste }\end{array}$ & 28 & drums & 6 & 154 & & & \\
\hline & Evaporate solids & 1 & drums & 6 & 8 & & & \\
\hline & & & & 90 & 715 & 1.49 & 90 & 20 \\
\hline \multirow[t]{8}{*}{ UV Oxidation } & Cas04 ppt (10 gpm) & 34 & drums & 11 & 376 & & & \\
\hline & Centrifuge (10 gpm) & 34 & drums & 11 & 376 & & & \\
\hline & sample waste & 3 & drums & 15 & 51 & & & \\
\hline & $\begin{array}{l}\text { Adjust UV oxidation ( } 30 \text { min/10 } \\
\text { drums) }\end{array}$ & 34 & drums & 3 & 103 & & & \\
\hline & $\begin{array}{l}\text { Process through UV oxidation } \\
\text { (50 gpm) }\end{array}$ & 34 & drums & 1 & 38 & & & \\
\hline & Carbon filtration (10 gpm) & 34 & drums & 6 & 188 & & & \\
\hline & lon exchange (10 gpm) & 34 & drums & 6 & 188 & & & \\
\hline & Sample waste before discharge & 3 & & 30 & & & & 1 \\
\hline Total Task 3 & & & & 52 & 1321 & 2.75 & 52 & \\
\hline Total per shift & & & & & 0 & 4.45 & 175 & 26 \\
\hline Supervision & Ratio of $1: 10$ & & & & & 0.44 & & \\
\hline Vac/sick/holiday relief & Assume 6 wks of absence & & & & & 0.56 & & \\
\hline $\begin{array}{l}\text { Adjustment for } 70 \% \\
\text { efficiency }\end{array}$ & & & & & & 7.80 & & \\
\hline Total per day & & & & & & 23.39 & & 1170 \\
\hline
\end{tabular}

Notes:

Assume high TDS waste comes from RCPRP, org destruction, soil treatment, debris treatment, and metal decon.

Assume waste from polymer, APC is low TDS

Assume waste from process residue is organic lia

Assume waste from RCPRP is organic liq

Total drums per hour=

34.32

Assume tank batches are 550 gallons (10 drums)

Assume treatment selection time is required for 10 drum batches.

Assume residence time in oil water separator is 1 hour and tank is 1000 gallons (16 gpm)

Assume fittration, centrifuge and ppt rates are $10 \mathrm{gpm}$.

Assume solids to evaporator are $5 \%$ of incoming waste; assume drying rate is $10 \mathrm{gpm}$

Assume UV oxidation unit is $50 \mathrm{gpm}$

Number of process sample

41.6
28.08 drums/shift

$\begin{array}{clll}6.40 & \mathrm{lbs} / \mathrm{hr} & 0.11 & \text { drums/shift } \\ 349.60 & \mathrm{lbs} / \mathrm{hr} & 6.13 & \text { drums/shift }\end{array}$




\begin{tabular}{|c|c|c|c|c|c|c|c|c|}
\hline Task & Subtask & $\begin{array}{c}\text { Occurrencel } \\
\text { Shift }\end{array}$ & Units & $\begin{array}{c}\text { Time } \\
\text { Required } \\
\text { (min) }\end{array}$ & $\begin{array}{l}\text { Total } \\
\text { Time/ } \\
\text { Shift }\end{array}$ & $\begin{array}{l}\text { FTEs } \\
\text { Needed }\end{array}$ & $\begin{array}{l}\text { Minutes/ } \\
\text { Drum }\end{array}$ & $\begin{array}{c}\text { Time/ Add'l } \\
\text { Drum }\end{array}$ \\
\hline Soil Receiving & Transfer through air lock & 5.4 & Idrums & 5 & 27 & & & \\
\hline Total Task & & & & 5 & 27 & 0.06 & 5 & 5 \\
\hline \multirow[t]{7}{*}{$\begin{array}{l}\text { Feed Waste from } \\
\text { drum }\end{array}$} & Stage at feed bin (drums) & 5.4 & drums & 3 & 16 & & & \\
\hline & Hook to transfer device & 5.4 & drums & 3 & 16 & & & \\
\hline & $\begin{array}{l}\text { Transfer into feed bin } \\
\text { (metering screw) }\end{array}$ & 5.4 & drums & 5 & 27 & & & \\
\hline & Feed screw monitoring time & & drums & & & & & \\
\hline & Empty drum bottoms & 5.4 & drums & 2 & 11 & & & \\
\hline & Sample feed vessel & 2.0 & drums & 5 & 10 & & & \\
\hline & Detach \& remove drum & 5.4 & drums & 3 & 16 & & & \\
\hline Total Task & & & & 16 & 96 & 0.20 & 16 & 13 \\
\hline \multirow[t]{3}{*}{ Wash Water Prep } & Sample wash water & 0.5 & drums & 5 & 3 & & & \\
\hline & Adjust Water Volume & 0.5 & drums & 10 & 5 & & & \\
\hline & Adjust surfactant & 0.5 & drums & 10 & 5 & & & \\
\hline Total Task & & & & 25 & 13 & 0.03 & 25 & \\
\hline \multirow[t]{5}{*}{ Washing Process } & Add waste to tank & 16.1 & drums & 5 & 80 & & & \\
\hline & Wash waste (1200 lbs/hr) & 16.1 & drums & 25 & N/A & & & \\
\hline & $\begin{array}{l}\text { Transfer waste and water from } \\
\text { tank }\end{array}$ & 80.4 & drums & 6 & 442 & & & \\
\hline & Monitor tank & 24.0 & times & 5 & 120 & & & \\
\hline & & & & 30 & 120 & 0.25 & 30 & 25 \\
\hline \multirow[t]{9}{*}{$\begin{array}{l}\text { Rinse } \\
\text { Re aslu }\end{array}$} & $\begin{array}{l}\text { Screening ( } 10 \mathrm{gpm}) \text { (most of } \\
\text { water leaves process here) }\end{array}$ & 80.4 & drums & 2 & 126 & & & \\
\hline & Hydrocyclone (10 gpm) & 32.2 & drums & 6 & 177 & & & \\
\hline & Transfer to rinse contactor & 32.2 & drums & 6 & 177 & & & \\
\hline & Rinse contactor (2000 lbs/hr) & 32.2 & drums & 15 & 475 & & & \\
\hline & Transfer to dryer ( $2 x$ vol of soil) & 32.2 & drums & 2 & 51 & & & \\
\hline & Drying @4 drums/hr & 32.2 & drums & 15 & 482 & & & \\
\hline & Monitor operations & 24.0 & times & 5 & 120 & & & \\
\hline & Collect samples & 16.0 & times & 5 & 80 & & & \\
\hline & & & & 42 & 200 & 0.42 & 42 & 15 \\
\hline \multirow[t]{15}{*}{ Recycle Processes } & These are all monitoring times & & & & 0 & & & \\
\hline & Solubility Reduction & 8.0 & times & 5 & 40 & & & \\
\hline & Additive Adjustment & 8.0 & times & 5 & 40 & & & \\
\hline & Transfer to Wash Tank & 16.0 & times & 2 & 32 & & & \\
\hline & Transfer to Ultrafiltration & 8.0 & times & 2 & 16 & & & \\
\hline & Ultrafiltration & 24.0 & times & 5 & 120 & & & \\
\hline & Dissolved Air Flotation & 8.0 & times & 5 & 40 & & & \\
\hline & Surfactant Separation & 24.0 & times & 5 & 120 & & & \\
\hline & Additive Adjustment & 8.0 & times & 5 & 40 & & & \\
\hline & Steam stripping & 8.0 & times & 5 & 40 & & & \\
\hline & Transfer recycled surfactant & 8.0 & times & 5 & 40 & & & \\
\hline & $\begin{array}{l}\text { Transfer waste to organic } \\
\text { destruction }\end{array}$ & 8.0 & times & 5 & 40 & & & \\
\hline & Transfer metals to polymer & 8.0 & times & 5 & 40 & & & \\
\hline & Collect samples & 24.0 & times & 5 & 120 & & & \\
\hline & & & & 59 & 728 & 1.52 & & \\
\hline
\end{tabular}


Jable NT5-h

Aqueous Wash for Soil

\begin{tabular}{|c|c|c|c|c|c|c|c|c|}
\hline Task & Subtask & $\begin{array}{c}\text { Occurrence/ } \\
\text { Shift }\end{array}$ & Units & $\begin{array}{c}\text { Time } \\
\text { Required } \\
\text { (min) }\end{array}$ & $\begin{array}{l}\text { Total } \\
\text { Time/ } \\
\text { Shift }\end{array}$ & $\begin{array}{c}\text { FTEs } \\
\text { Needed }\end{array}$ & $\begin{array}{l}\text { Minutes' } \\
\text { Drum }\end{array}$ & $\begin{array}{c}\text { Time/ Add'l } \\
\text { Drum }\end{array}$ \\
\hline \multicolumn{2}{|c|}{ Total FTEs/day = FTEs per shift } & & & & & 2.47 & & \\
\hline Supervision & Ratio of $1: 10$ & & & & & 0.25 & 118 & 15 \\
\hline $\begin{array}{l}\text { Vac/sick/holiday } \\
\text { relief }\end{array}$ & Assume 6 wks of absence & & & & & 0.31 & & \\
\hline Total/shift & & & & & & 3.03 & & \\
\hline $\begin{array}{l}\text { Adjustment for } \\
70 \% \text { Efficiency }\end{array}$ & & & & & & 4.32 & & \\
\hline Total/day & & & & & & 4.32 & & \\
\hline
\end{tabular}

Notes:

Sample wash water every 10 drums

Assume drum transfer of $15 \mathrm{~min} / \mathrm{drum}$ or $.5 \mathrm{ft} 3 / \mathrm{min}$

System designed for 1 shift not 3

Residence time in wash tank based on $4 x$ wt of water to feed

Wash tank is $700 \mathrm{gal}$ ( 12 drums); residence time per drum =

$358.21 \mathrm{~min}$

Assume transfer rates are $10 \mathrm{gpm}$; this includes both waste and rinse or wash water

Waste to screening includes water in tank ( $4 x$ input volume)

Waste to rinse contactor and hydrocyclone assumes 1:1 soil to water ( $2 x$ input volume)

Rinse tank has 1300 gallons of water and soil. Residence time $=705.56$

Drying: assume $1 \mathrm{hr}$ drying time,2000 lbs/hr (4 drums/hr)

For purposes of processing time, recycle is not included, as these are not soil treatment

No. of samples $=40.5$ 


\begin{tabular}{|c|c|c|c|c|c|c|c|c|}
\hline Task & Subtask & $\begin{array}{c}\text { Occurrencel } \\
\text { Shift }\end{array}$ & Units & $\begin{array}{c}\text { Time } \\
\text { Required } \\
\text { (min) }\end{array}$ & $\begin{array}{c}\text { Total Timel } \\
\text { Shift }\end{array}$ & $\begin{array}{c}\text { FTEs } \\
\text { Needed }\end{array}$ & $\begin{array}{l}\text { Minutes/ } \\
\text { Drum }\end{array}$ & $\begin{array}{l}\text { Time/ } \\
\text { Add"I } \\
\text { Drum }\end{array}$ \\
\hline Debris Receiving & Transfer through air lock & 3.5 & drums & 5 & 18 & & & \\
\hline Debris Receiving & Transfer through air lock & 3.5 & drums & 5 & 18 & & & \\
\hline & Stage drums for campaigns & 3.5 & drums & 15 & 53 & & & \\
\hline Total Task & & & & 20 & 70 & 0.15 & 20 & 15 \\
\hline $\begin{array}{l}\text { Feed Waste from } \\
\text { drum }\end{array}$ & Stage at feed bin (drums) & 3.5 & drums & 3 & 11 & & & \\
\hline & Hook to transfer device & 3.5 & drums & 3 & 11 & & & \\
\hline & $\begin{array}{l}\text { Transfer into feed bin (metering } \\
\text { screw) }\end{array}$ & 3.5 & drums & 15 & 53 & & & \\
\hline & Empty drum bottoms & 3.5 & drums & 2 & 7 & & & \\
\hline & Sample feed vessel & 0.4 & drums & 10 & 4 & & & \\
\hline & Detach \& remove drum & 3.5 & drums & 3 & 11 & & & \\
\hline Total Task & & & & 36 & 95 & 0.20 & 36 & 23 \\
\hline Wash Water Prep & Sample wash water & 0.4 & drums & 5 & 2 & & & \\
\hline & Adjust Water Volume & 0.4 & drums & 10 & 4 & & & \\
\hline & Adjust surfactant & 0.4 & drums & 10 & 4 & & & \\
\hline Total Task & & & & 25 & 9 & 0.02 & 25 & \\
\hline Washing Process & Check out Equipment & 1.0 & times & 30 & 30 & & & \\
\hline $\begin{array}{l}\text { See notes; based } \\
\text { on } 16 \text { drum batch }\end{array}$ & Wash/ rinse waste & 3.5 & drums & 17 & N/A & & & \\
\hline & Transfer water from tank & 3.5 & drums & 28 & 97 & & & \\
\hline & Monitor tank & 24.0 & times & 5 & 120 & & & \\
\hline & Collect Samples & 3.0 & times & 5 & 15 & & & \\
\hline & Remove waste from tank & 3.5 & drums & 15 & 53 & & & 15 \\
\hline Total Task & & & & 84 & 262 & 0.55 & 84 & \\
\hline Total per shift & & & & & & 0.91 & 165 & \\
\hline Supervision & Ratio of $1: 10$ & & & & & 0.09 & & \\
\hline $\begin{array}{l}\text { Vac/sick/holiday } \\
\text { relief }\end{array}$ & Assume 6 wks of absence & & & & & 0.12 & & \\
\hline Total/shift & & & & & & 1.11 & & \\
\hline $\begin{array}{l}\text { Adjustment for } 70 \% \\
\text { efficiency }\end{array}$ & & & & & & 1.59 & & \\
\hline Total/day & & & & & & 4.78 & & \\
\hline Total FTEs & & & & & & 4.78 & & \\
\hline
\end{tabular}

Notes:

Sample wash water every 10 drums

Assume drum transfer of $15 \mathrm{~min} / \mathrm{drum}$ or $.5 \mathrm{cu} \mathrm{ft} / \mathrm{min}$

Batch size is 1 to 2 tons; say 3000 lbs or

Residence time in wash tank based on 3 stages, 90 minutes each

Assume transfer rates are $10 \mathrm{gpm}$; this includes both waste and rinse or wash water

Assume water volume is roughly $5 x$ waste volume 


\begin{tabular}{|c|c|c|c|c|c|c|c|c|}
\hline Table NT5-j & Metal Decontamination S & bsystem & & & & & & \\
\hline Task & Subtask & $\begin{array}{c}\text { Occurrence/ } \\
\text { Shift }\end{array}$ & Units & $\begin{array}{c}\text { Time } \\
\text { Required } \\
\text { (min) }\end{array}$ & $\begin{array}{c}\text { Total Time/ } \\
\text { Shift }\end{array}$ & $\begin{array}{c}\text { FTEs } \\
\text { Needed }\end{array}$ & $\begin{array}{c}\text { Minutes/ } \\
\text { Drum }\end{array}$ & $\begin{array}{c}\text { Time/ Add'I } \\
\text { Drum }\end{array}$ \\
\hline \multirow{2}{*}{$\begin{array}{l}\text { Metals Receiving/ } \\
\text { Feed Prep } \\
\text { Total Task } \\
\end{array}$} & Transfer through air lock & 15.8 & drums & 5 & 79 & & & \\
\hline & & & & 5 & 79 & 0.2 & 5 & 0 \\
\hline \multirow[t]{8}{*}{ Waste Decon } & Stage containers & 15.8 & drum & $\overline{5}$ & 79 & & & \\
\hline & Decon waste & 15.8 & drum & 10 & 158 & & & \\
\hline & Assay for recycle & 15.8 & drum & 30 & 475 & & & \\
\hline & Repack in drums & 15.8 & drum & 15 & 238 & & & \\
\hline & Close drum lid & 15.8 & drum & 15 & 238 & & & \\
\hline & Stage drums & 15.8 & drum & 5 & 79 & & & \\
\hline & $\begin{array}{l}\text { Monitor recirc filtration and } \\
\text { fugitive dust system }\end{array}$ & 24.0 & times & 6 & 144 & & & \\
\hline & & & & 86 & 1411 & 2.9 & 86 & \\
\hline Total FTEs/shift & & & & & & $\overline{3.1}$ & 91 & \\
\hline Supervision & Ratio of $1: 10$ & & & & & 0.3 & & \\
\hline $\begin{array}{l}\text { Vac/sick/holiday } \\
\text { relief }\end{array}$ & Assume 6 wks of absence & & & & & 0.4 & & \\
\hline Total/shift & & & & & & 3.8 & & \\
\hline $\begin{array}{l}\text { Adjustment for } \\
70 \% \text { efficiency }\end{array}$ & & & & & & 5.4 & & \\
\hline Total/day & & & & & & 16.3 & & \\
\hline
\end{tabular}

Notes:

Assume $50 \%$ of waste must be size reduced.

Assume $60 \mathrm{~min} / \mathrm{drum}$ for cutting 
Table NT5-k Lead Recovery

\begin{tabular}{|c|c|c|c|c|c|c|c|c|}
\hline Task & Subtask & $\begin{array}{c}\text { Occurrence/ } \\
\text { Shift }\end{array}$ & Units & $\begin{array}{c}\text { Time } \\
\text { Required } \\
\text { (min) }\end{array}$ & $\begin{array}{c}\text { Total Time/ } \\
\text { Shift }\end{array}$ & $\begin{array}{c}\text { FTEs } \\
\text { Needed }\end{array}$ & $\begin{array}{c}\text { Minutes/ } \\
\text { Drum }\end{array}$ & $\begin{array}{c}\text { Time/ Add'I } \\
\text { Drum }\end{array}$ \\
\hline \multirow[t]{3}{*}{$\begin{array}{l}\text { Lead } \\
\text { Receiving/Feed } \\
\text { Prep }\end{array}$} & Transfer through air lock & 0.24 & drums & -1 & 1 & & & \\
\hline & $\begin{array}{l}\text { Glove box separation of } \\
\text { sheet lead and gloves }\end{array}$ & 0.24 & drums & 60 & 14 & & & \\
\hline & Stage at decon & 0.24 & drums & 10 & 2 & & & \\
\hline \multirow{8}{*}{$\frac{\text { Total Task }}{\text { Waste Decon }}$} & & & & 75 & 18 & 0.04 & 75 & \\
\hline & Stage containers & 0.24 & drum & 5 & 1 & & & \\
\hline & Decon waste & 0.24 & drum & 10 & 2 & & & \\
\hline & Assay for recycle & 0.24 & drum & 30 & 7 & & & \\
\hline & Repack in drums & 0.24 & drum & 15 & 4 & & & \\
\hline & Close drum lid & 0.24 & drum & 15 & 4 & & & \\
\hline & Stage drums & 0.24 & drum & 5 & 1 & & & \\
\hline & $\begin{array}{l}\text { Monitor recirc filtration } \\
\text { and fugitive dust system }\end{array}$ & 24.00 & times & 6 & 144 & & & \\
\hline Total Task & & & & 86 & 163 & 0.34 & 86 & 30 \\
\hline Total FTEs/shift & & & & & & 0.38 & 161 & \\
\hline Supervision & Ratio of $1: 10$ & & & & & 0.04 & & \\
\hline $\begin{array}{l}\text { Vac/sick/holiday } \\
\text { relief }\end{array}$ & $\begin{array}{l}\text { Assume } 6 \text { wks of } \\
\text { absence }\end{array}$ & & & & & 0.05 & & \\
\hline Total/shift & & & & & & 0.46 & & \\
\hline $\begin{array}{l}\text { Adjustment for } \\
70 \% \text { efficiency }\end{array}$ & & & & & & 0.66 & & \\
\hline Total/day & & & & & & 1.98 & & \\
\hline
\end{tabular}

Notes:

Assume assay for all drums @ $30 \mathrm{~min} / \mathrm{drum}$ 


\begin{tabular}{|c|c|c|c|c|c|c|c|c|}
\hline Table NT5-I & Mercury Amalgamation & & & & & & & \\
\hline Task & Subtask & $\begin{array}{c}\text { Occurrence/ } \\
\text { Shift }\end{array}$ & Units & $\begin{array}{c}\text { Time } \\
\text { Required } \\
\text { (min) }\end{array}$ & \begin{tabular}{|c|} 
Total \\
Time/ Shift \\
\end{tabular} & $\begin{array}{c}\text { FTEs } \\
\text { Needed } \\
\end{array}$ & $\begin{array}{c}\text { Minutes/ } \\
\text { Drum }\end{array}$ & $\begin{array}{l}\text { Timel } \\
\text { Add'I } \\
\text { Drum }\end{array}$ \\
\hline \multicolumn{9}{|l|}{$\begin{array}{l}\text { Metals Receiving/ } \\
\text { Feed Prep }\end{array}$} \\
\hline & Transfer through air lock & 0.02 & drums & 5 & 0 & & & \\
\hline & Transfer liq mercury to tank & 0.02 & drums & 60 & 1 & & & \\
\hline & $\begin{array}{l}\text { Transfer steel wool w/ Hg to } \\
\text { holding bin }\end{array}$ & 0.001 & drums & 10 & 0 & & & \\
\hline Total Task & & & & 75 & 1 & 0.00 & 75 & 60 \\
\hline \multicolumn{9}{|l|}{$\begin{array}{l}\text { Mercury } \\
\text { Amalgamation }\end{array}$} \\
\hline & Inspect equipment & 1.00 & time & 30 & & & & \\
\hline & $\begin{array}{l}\text { Transfer liq mercury to } \\
\text { amalgamater (1 gpm) }\end{array}$ & 0.02 & drum & 55 & 1 & & & \\
\hline & Measure additives & 0.02 & drum & 30 & 1 & & & \\
\hline & $\begin{array}{l}\text { Transfer steel wool to } \\
\text { amalgamater }\end{array}$ & 0.02 & drum & 20 & 0 & & & \\
\hline & Batch amalgamation & 0.02 & drum & 120 & 3 & & & 120 \\
\hline & Transfer out of amalgamater & 0.02 & drum & 55 & 1 & & & \\
\hline & Stage & 0.02 & drum & 5 & 0 & & & \\
\hline & Place at assay & 0.02 & drum & 5 & 0 & & & \\
\hline & Assay & 0.02 & drum & 20 & 0 & & & \\
\hline & Remove from assay & 0.02 & drum & 2 & 0 & & & \\
\hline Total Task & & & & 312 & 7 & 0.01 & 312 & 120 \\
\hline Total FTEs/shift & & & & & & 0.02 & $3 \overline{387}$ & \\
\hline Supervision & Ratio of $1: 10$ & & . & & & 0.00 & & \\
\hline $\begin{array}{l}\text { Vac/sick/holiday } \\
\text { relief }\end{array}$ & Assume 6 wks of absence & & & & & 0.00 & & \\
\hline Total/shift & & & & & & 0.02 & & \\
\hline $\begin{array}{l}\text { Adjustment for } \\
70 \% \text { efficiency }\end{array}$ & & & - & & & 0.03 & & \\
\hline Total/day & & & & & & 0.09 & & \\
\hline
\end{tabular}

Notes:

Volume of steel wool: assume $3 \times$ vol of steel to mercury

Assume $5 \%$ of mercury is in residue (this should be conservative; $5 \%$ of mercury is assumed to be in debris, not process residue)

Total volume of mercury in study is $2.5+0.1 \mathrm{lbs} / \mathrm{hr}$.

Therefore volume of steel wool w/mercury $=\quad 0.020 \mathrm{lbs} / \mathrm{hr}$

Batch size for amalgamater: Assume 1 drum/batch, 2 hrs /batch

$0.001 \mathrm{drums} / \mathrm{shift}$ 
$-$

\begin{tabular}{|c|c|c|c|c|c|c|c|c|}
\hline Task & Subtask & $\begin{array}{c}\text { Occurrence/ } \\
\text { Shift }\end{array}$ & Units & $\begin{array}{c}\text { Time } \\
\begin{array}{c}\text { Required } \\
\text { (min) }\end{array}\end{array}$ & $\begin{array}{c}\text { Total } \\
\text { Time/ Shift }\end{array}$ & $\begin{array}{l}\text { FTEs } \\
\text { Needed }\end{array}$ & $\begin{array}{l}\text { Minutes/ } \\
\text { Drum }\end{array}$ & $\begin{array}{c}\text { Timel Add'l } \\
\text { Drum }\end{array}$ \\
\hline \multirow[t]{4}{*}{$\begin{array}{l}\text { Special } \\
\text { Receiving/Feed Prep }\end{array}$} & Transfer through air lock & 5.4 & drums & 5 & 27 & & & \\
\hline & $\begin{array}{l}\text { Glove box preparation of } \\
\text { wastes }\end{array}$ & 5.4 & drums & 60 & 326 & & & \\
\hline & Stage waste & 5.4 & drums & 3 & 16 & & & \\
\hline & & & & 68 & 370 & 0.77 & 68 & 60 \\
\hline \multirow[t]{7}{*}{ Waste Treatment } & Stage containers & 5.4 & drum & $\overline{3}$ & 16 & & & \\
\hline & $\begin{array}{l}\text { Treat waste as special } \\
\text { processes TBD }\end{array}$ & 5.4 & drum & 60 & 326 & & & \\
\hline & Sample treated waste & 5.4 & drum & 15 & 82 & & & \\
\hline & Repack in drums & 5.4 & drum & 30 & 163 & & & \\
\hline & Close drum lid & 5.4 & drum & 3 & 16 & & & \\
\hline & Stage drums & 5.4 & drum & 3 & 16 & & & \\
\hline & & & & 114 & 620 & 1.29 & 114 & 60 \\
\hline Total FTEsishift & & & & & & 2.06 & 182 & \\
\hline Supervision & Ratio of $1: 10$ & & & & & 0.21 & & \\
\hline $\begin{array}{l}\text { Vac/sick/holiday } \\
\text { relief }\end{array}$ & $\begin{array}{l}\text { Assume } 6 \text { wks of } \\
\text { absence }\end{array}$ & & & & & 0.26 & & \\
\hline Total/shift & & & & & & 2.53 & & \\
\hline $\begin{array}{l}\text { Adjustment for } 70 \% \\
\text { efficiency }\end{array}$ & & & & & & 3.62 & & \\
\hline Total/day & & & & & & 10.85 & & \\
\hline
\end{tabular}

Notes:

Assume all waste is prepared in glove box

Assume waste is treated in various batch processes that average 2 hours/drum

TBD $=$ To be determined 


\begin{tabular}{|c|c|c|c|c|c|c|c|c|}
\hline Task & Subtask & $\begin{array}{c}\text { Occurrencel } \\
\text { Shift }\end{array}$ & Units & $\begin{array}{c}\text { Time } \\
\text { Required } \\
\text { (min) }\end{array}$ & $\begin{array}{c}\text { Total Time/ } \\
\text { Shift }\end{array}$ & $\begin{array}{c}\text { FTEs } \\
\text { Needed }\end{array}$ & $\begin{array}{c}\text { Minutes/ } \\
\text { Drum }\end{array}$ & $\begin{array}{c}\text { Time/ Add"I } \\
\text { Drum }\end{array}$ \\
\hline \multirow[t]{7}{*}{$\begin{array}{l}\text { Waste Receiving/ } \\
\text { Feed Prep }\end{array}$} & Transfer through air lock & 15.1 & drums & 5 & 76 & & & \\
\hline & Sample waste & 1.5 & drums & 15 & 23 & & & \\
\hline & Select process for waste & 15.1 & drums & 5 & 76 & & & \\
\hline & $\begin{array}{l}\text { Transfer to } \\
\text { macroencapsulation }\end{array}$ & 7.8 & drums & 2 & 16 & & & \\
\hline & $\begin{array}{l}\text { Transfer to } \\
\text { microencapsulation }\end{array}$ & 7.4 & drums & 2 & 15 & & & \\
\hline & Stage at process & 15.1 & drums & 2 & 30 & & & \\
\hline & & & & 31 & 234 & 0.49 & 31 & 5 \\
\hline \multirow[t]{8}{*}{ Waste Encapsulation } & Measure binder & 15.1 & drum & 5 & 76 & & & \\
\hline & Mix binder & 15.1 & drum & 5 & 76 & & & \\
\hline & Combine with waste & 15.1 & drum & 10 & 151 & & & \\
\hline & Repack in drums & 15.1 & drum & 5 & 76 & & & \\
\hline & Close drum lid & 15.1 & drum & 3 & 45 & & & \\
\hline & Stage pallets & 15.1 & drum & 2 & 30 & & & \\
\hline & $\begin{array}{l}\text { Monitor activated carbon } \\
\text { and fugitive dust system }\end{array}$ & 2.0 & times & 6 & 12 & & & \\
\hline & & & & 36 & 466 & 0.97 & 36 & 10 \\
\hline \multirow[t]{5}{*}{ Binder setup time } & $\begin{array}{l}\text { Move pallets to curing } \\
\text { area }\end{array}$ & 15.1 & drum & 2 & 30 & & & \\
\hline & Curing time & 15.1 & drum & & 0 & & & \\
\hline & Sample & 1.5 & drum & 15 & 23 & & & \\
\hline & Monitor curing process & 15.1 & drum & 10 & 151 & & & \\
\hline & $\begin{array}{l}\text { Move pallets from curing } \\
\text { area }\end{array}$ & 15.1 & times & 2 & 30 & & & \\
\hline Total Task & & & - & 29 & 234 & 0.49 & 29 & 5 \\
\hline \multirow[t]{8}{*}{ Drum Decon } & Stage containers & 1.5 & drum & 5 & 8 & & & \\
\hline & Load conveyors & 1.5 & drum & 5 & 8 & & & \\
\hline & Decon drums & 1.5 & drum & 10 & 15 & & & \\
\hline & Assay drums & 1.5 & drum & 15 & 23 & & & \\
\hline & Unload conveyers & 1.5 & drum & 5 & 8 & & & \\
\hline & Palletize drums & 1.5 & drum & 2 & 3 & & & \\
\hline & Stage drums & 1.5 & drum & 5 & 8 & & & \\
\hline & & & & 47 & 71 & 0.15 & 47 & 15 \\
\hline Total FTEs/shift & & & & & & 2.09 & 143 & \\
\hline Supervision & Ratio of $1: 10$ & & & & & 0.21 & & \\
\hline $\begin{array}{l}\text { Vac/sick/holiday } \\
\text { relief }\end{array}$ & $\begin{array}{l}\text { Assume } 6 \text { wks of } \\
\text { absence }\end{array}$ & & & & & 0.27 & & \\
\hline Total/shift & & & & & & 2.57 & & \\
\hline $\begin{array}{l}\text { Adjustment for } 70 \% \\
\text { Efficiency }\end{array}$ & & & & & & 3.67 & & \\
\hline Total/day & & & & & & 11.01 & & \\
\hline
\end{tabular}

\section{Notes:}

Assume all complex debris ( 8 drums) will be sent to macroencapsulation, rest to micro.

Assume $10 \%$ of drums are deconned.

Assume $10 \%$ of drums are assayed

Assume mixing requires $30 \mathrm{~min} / \mathrm{drum}$

No. of samples 


\begin{tabular}{|c|c|c|c|c|c|c|c|c|}
\hline Task & Subtask & $\begin{array}{c}\text { Occurrencel } \\
\text { Shift }\end{array}$ & Units & $\begin{array}{c}\text { Time } \\
\text { Required } \\
\text { (min) }\end{array}$ & $\begin{array}{c}\text { Total Timel } \\
\text { Shift }\end{array}$ & $\begin{array}{c}\text { FTEs } \\
\text { Needed }\end{array}$ & $\begin{array}{c}\text { Minutes/ } \\
\text { Drum }\end{array}$ & $\begin{array}{l}\text { Timel } \\
\text { Add'l } \\
\text { Drum } \\
\end{array}$ \\
\hline \multirow[t]{7}{*}{$\begin{array}{l}\text { Waste } \\
\text { Receiving/Feed Prep }\end{array}$} & $\begin{array}{l}\text { Transfer through air } \\
\text { lock }\end{array}$ & 28.1 & drums & 5 & 140 & & & \\
\hline & Sample waste & 2.8 & drums & 15 & 42 & & & \\
\hline & Evaluate dryness & 2.8 & drums & 5 & 14 & & & \\
\hline & Dry waste & 11.4 & drums & 30 & N/A & & & \\
\hline & Monitor drying & 24.0 & times & 10 & 240 & & & \\
\hline & Stage at process & 28.1 & drums & 2 & 56 & & & \\
\hline & & & & 57 & 493 & 1.03 & 57 & 30 \\
\hline \multirow[t]{9}{*}{ Encapsulation } & Measure polymer & 28.1 & drum & 5 & 140 & & & \\
\hline & Mix polymer & 28.1 & drum & 10 & 281 & & & \\
\hline & $\begin{array}{l}\text { Combine with waste in } \\
\text { extruder }\end{array}$ & 28.1 & drum & 10 & 281 & & & \\
\hline & Repack in drums & 24.0 & drum & 5 & 120 & & & \\
\hline & Close drum lid & 28.1 & drum & 3 & 84 & & & \\
\hline & Palletize drums & 28.1 & drum & 2 & 56 & & & \\
\hline & Stage drums & 24.0 & drum & 2 & 48 & & & \\
\hline & $\begin{array}{l}\text { Monitor activated } \\
\text { carbon and fugitive dust } \\
\text { system }\end{array}$ & 8.0 & times & 6 & 48 & & & \\
\hline & & & & 43 & 1058 & 2.21 & 43 & 60 \\
\hline \multirow[t]{6}{*}{ Binder setup time } & $\begin{array}{l}\text { Move pallets to curing } \\
\text { area }\end{array}$ & 24.0 & drum & 5 & 120 & & & \\
\hline & Curing time & 24.0 & drum & & 0 & & & \\
\hline & Sample & 2.4 & & 15 & 36 & & & \\
\hline & Monitor curing & 24.0 & drum & 10 & 240 & & & \\
\hline & $\begin{array}{l}\text { Move pallets from } \\
\text { curing area }\end{array}$ & 24.0 & timēs & 5 & 120 & & & \\
\hline & & & & 35 & 516 & 1.08 & 35 & 5 \\
\hline \multirow[t]{6}{*}{ Drum Decon } & Stage containers & 28.1 & drum & 5 & 140 & & & \\
\hline & Load conveyors & 28.1 & drum & 5 & 140 & & & \\
\hline & Decon drums & 28.1 & drum & 10 & 281 & & & \\
\hline & Assay drums & 28.1 & drum & 15 & 421 & & & \\
\hline & Unload conveyers & 28.1 & drum & 5 & 140 & & & \\
\hline & Stage drums & 28.1 & drum & 5 & 140 & & & \\
\hline Total Task & & & & 45 & 1264 & 2.63 & 45 & 60 \\
\hline Total FTEs/shift & & & & & & 6.94 & 180 & \\
\hline Supervision & Ratio of $1: 10$ & & & & & 0.69 & & \\
\hline $\begin{array}{l}\text { Vac/sick/holiday } \\
\text { relief }\end{array}$ & $\begin{array}{l}\text { Assume } 6 \text { wks of } \\
\text { absence }\end{array}$ & & & & & 0.88 & & \\
\hline Total/shift & & & & & & 8.51 & & \\
\hline $\begin{array}{l}\text { Adjustment for } 70 \% \\
\text { Efficiency }\end{array}$ & & & & & & 12.16 & & \\
\hline Total/day & & & & & & 36.49 & & \\
\hline
\end{tabular}

\section{Notes:}

Assume $30 \%$ of process residue waste and $100 \%$ of other waste requires drying Assume dryer can accept waste at the rate of 2 drums/hour

No. of samples $=2.4$ 
Air Pollution Control Subsystem

\begin{tabular}{|c|c|c|c|c|c|c|c|}
\hline Task & Subtask & $\begin{array}{c}\text { Occurrence } \\
\text { Shift }\end{array}$ & Units & $\begin{array}{c}\text { Time } \\
\text { Required } \\
\text { (min) }\end{array}$ & $\begin{array}{c}\text { Total Timel } \\
\text { Shift }\end{array}$ & $\begin{array}{l}\text { FTEs } \\
\text { Needed }\end{array}$ & Minutes/ Ib \\
\hline \multirow[t]{8}{*}{ Monitor Equipment } & Dry filtration & 4 & times & 10 & 40 & & \\
\hline & HEPA filter & 4 & times & 5 & 20 & & \\
\hline & GPCR & 24 & times & 2 & 48 & & \\
\hline & Acid gas scrubber & 12 & times & 10 & 120 & & \\
\hline & Mist eliminator & 4 & times & 2 & 8 & & \\
\hline & GAC & 4 & times & 2 & 8 & & \\
\hline & Mersorb & 4 & times & 2 & 8 & & \\
\hline & Offgas monitor & 24 & times & 5 & 120 & & \\
\hline Total Task & & & & 38 & 372 & 0.8 & 0 \\
\hline Supervision & Ratio of $1: 10$ & & & & & 0.1 & \\
\hline Vac/sick/holiday relief & $\begin{array}{l}\text { Assume } 6 \text { wks of } \\
\text { absence }\end{array}$ & & & & & 0.1 & \\
\hline Total/shift & & & & & & 1.0 & \\
\hline $\begin{array}{l}\text { Adjustment for } 70 \% \\
\text { Efficiency }\end{array}$ & & & & & & 1.4 & \\
\hline Total/day & & & & & & 4.1 & \\
\hline
\end{tabular}


_Table NT5-q

Certification and Shipping

\begin{tabular}{|c|c|c|c|c|c|c|c|c|}
\hline Task & Subtask & $\begin{array}{c}\text { Occurrencel } \\
\text { Shift }\end{array}$ & Units & $\begin{array}{c}\text { Time } \\
\text { Required } \\
\text { (min) }\end{array}$ & $\begin{array}{c}\text { Total Timel } \\
\text { Shift }\end{array}$ & $\begin{array}{c}\text { FTEs } \\
\text { Needed }\end{array}$ & $\begin{array}{c}\text { Minutes/ } \\
\text { Drum }\end{array}$ & $\begin{array}{c}\text { Timel Add"l } \\
\text { Drum }\end{array}$ \\
\hline \multirow[t]{5}{*}{ Waste Receiving } & Transfer through air lock & 43.9 & drums & 5 & 220 & & & \\
\hline & Sample waste & 4.4 & drums & 15 & 66 & & & \\
\hline & Resample waste & 0.4 & drums & 15 & 7 & & & \\
\hline & Stage waste & 43.9 & drums & 5 & 220 & & & \\
\hline & & & & 40 & 512 & 1.07 & 40 & 15 \\
\hline \multirow[t]{9}{*}{ Waste Assay } & Stage pallets & 43.9 & drum & 3 & 132 & & & \\
\hline & Load on conveyor & 43.9 & drum & 1 & 44 & & & \\
\hline & Assay RTR & 43.9 & drum & 15 & 659 & & & \\
\hline & Assay gamma & 43.9 & drum & 60 & 2635 & & & \\
\hline & Assay PAN & 43.9 & drum & 60 & 2635 & & & \\
\hline & Remove from conveyor & 43.9 & drum & 1 & 44 & & & \\
\hline & Repalletize & 43.9 & drum & $\overline{3}$ & 132 & & & \\
\hline & $\begin{array}{l}\text { Stage pallets after } \\
\text { assaying }\end{array}$ & 43.9 & drum & 15 & 659 & & & \\
\hline & & & & 158 & 6939 & 14.46 & 158 & 60 \\
\hline \multirow[t]{4}{*}{ Stage waste } & Stage uncertified waste & 43.9 & drum & 3 & 132 & & & \\
\hline & Transfer waste & 43.9 & drum & 3 & 132 & & & \\
\hline & Stage certified waste & 43.9 & drum & 3 & 132 & & & \\
\hline & Transfer waste & 43.9 & drum & 3 & 132 & & & \\
\hline Total Task & & & & 12 & 527 & 1.10 & 12 & \\
\hline \multirow[t]{4}{*}{ Ship Waste Truck } & Truck docking & 0.5 & truck & 30 & $\overline{15}$ & & & \\
\hline & Settle Paperwork & 0.5 & truck & 120 & 60 & & & \\
\hline & Load truck & 0.5 & truck & 60 & 30 & & & \\
\hline & Truck leaving & 0.5 & truck & 60 & 30 & & & \\
\hline Total Task & & & & 270 & 135 & 0.28 & 12 & \\
\hline Total FTEs/shift & & & & & & 16.90 & 222 & \\
\hline Supervision & Ratio of $1: 10$ & & & & & 1.69 & & \\
\hline Vac/sick/holiday relief & $\begin{array}{l}\text { Assume } 6 \text { wks of } \\
\text { absence. }\end{array}$ & & & & & 2.15 & & \\
\hline Total/shift & & & & & & 20.74 & & \\
\hline $\begin{array}{l}\text { Adjustment for } 70 \% \\
\text { Efficiency }\end{array}$ & & & & & & 29.62 & & \\
\hline Total/day & & & & & & 88.87 & & \\
\hline
\end{tabular}

Notes:

Assume $10 \%$ of waste require sampling

Samples collected $=4.4$ 


\begin{tabular}{|c|c|c|c|c|c|c|}
\hline & Daily FTES & $\begin{array}{l}\text { Time (min)/ } \\
\text { Single Drum }\end{array}$ & Time (hrs) & $\begin{array}{l}\text { Add'I Time } \\
\text { for Next } \\
\text { Drum }\end{array}$ & $\begin{array}{l}\text { Time/Drums } \\
\text { Received in a } \\
\text { Shift (min) }\end{array}$ & Time (hrs) \\
\hline Administration & 57.9 & N/A & & & & \\
\hline $\begin{array}{l}\text { Receiving /Inspection Tasks } \\
\text { common for all waste }\end{array}$ & & 802 & 13 & 60 & 3728 & 62 \\
\hline Receiving and Prep-CWO & & 0 & 0 & & 0 & 0 \\
\hline Receiving and Prep-soft & & 229 & 4 & 45 & 1250 & 21 \\
\hline Receiving and Prep-residue & & 229 & 4 & 45 & 1329 & 22 \\
\hline Receiving and Prep-soil & & 229 & 4 & 45 & 425 & 7 \\
\hline Receiving and Prep-debris & & 289 & 5 & 5 & 340 & 6 \\
\hline Receiving and Prep-lead & & 557 & 9 & 315 & 557 & 9 \\
\hline Receiving and Prep-mercury & & 516 & 9 & 315 & 516 & 9 \\
\hline Receiving and Prep-special & & 516 & 9 & 315 & 1915 & 32 \\
\hline Receiving and Prep-metal decon & & 229 & 4 & 35 & 554 & 9 \\
\hline Receiving and Prep & 191.9 & 676.2 & 11 & & & 0 \\
\hline Aqueous Waste & 23.4 & 175 & 3 & 36 & 1375 & 23 \\
\hline Organic Destruction & 10.6 & 206 & 3 & 34 & 325 & 5 \\
\hline Vacuum Thermal Desorption & 10.3 & 425 & 7 & 26 & 1060 & 18 \\
\hline Soil Treatment & 4.3 & 118 & 2 & 15 & 183 & 3 \\
\hline Soft Debris & 20.6 & 221 & 4 & 33 & 962 & 16 \\
\hline Open Debris & 4.8 & 165 & 3 & 23 & 223 & 4 \\
\hline Metal Decon & 16.3 & 91 & 2 & 75 & 1204 & 20 \\
\hline Lead & 2.0 & 161 & & N/A & 161 & 3 \\
\hline Mercury & 0.1 & 387.0 & 6.45 & N/A & 387 & 6 \\
\hline Special & 10.8 & 182.0 & 3 & 60.0 & 448 & 7 \\
\hline Grout & 11.0 & 143 & 2 & 10 & 284 & 5 \\
\hline Polymer & 36.5 & 180 & 3 & 60 & 1805 & 30 \\
\hline APC & 4.1 & 372 & 6 & & 372 & 6 \\
\hline Certification and Shipping & 88.9 & 222 & 4 & 60 & 2797 & 47 \\
\hline Total & 493.5 & & & & & \\
\hline
\end{tabular}

Notes:

Allocation of receiving and preparation time was done as follows:

Average time per drum was estimated, multiplied by the number

of drums per shift. The time for each waste type was allocated

according its percentage of total waste. 


\section{APPENDIX B}

SureTrak Modeling Assumptions 


\section{SureTrak Modeling Assumptions}

The Gant charts (Figures 1 through 5) were developed with SureTrak software and are based on the summary tables A1-p, C1-m, NT2-o, NT3-p and NT5-r. Figures A1, C1, NT2, NT3 and NT5 use the following bases:

1) Receiving and Preparation is divided into multiple steps.

2) All waste is processed through Receive and Assay.

3) Following Receive and Assay, sorting or other feed preparation is performed. Since this is different based on waste type, a preparation stage is included for all nonliquid feed.

4) Successors to Receive and Assay are on a finish-to-finish basis. Feed preparation cannot end before all waste is assayed; a lag time required to process a drum though feed preparation is inserted.

5) Successors to Receive and Assay are also on a start-to-start basis. Some waste can be treated at feed preparation before all waste is received. However, no waste can be treated before at least one drum has been processed through Receive and Assay. A start-to-start lag is required to process one drum though Receive and Assay.

6) Successors to processing systems are all modeled as both finish-to-finish and start-to-start.

7) Lead recovery and mercury amalgamation are modeled on a finish-to-finish basis only. This allows waste to be received at Certification and Shipping before these processes have treated a single drum. These small volume processes would otherwise delay the start of certification and shipping which is not representative of anticipated operations. 